Universidade de São Paulo

Instituto de Física

\title{
Caracterização estrutural de dispersões aquosas de lipídios aniônicos
}

\author{
Daniela Akiko Nomura
}

Orientadora: Profa. Dra. Maria Teresa de Moura Lamy

Tese de doutorado apresentada ao Instituto de Física para a obtenção do título de Doutor em Ciências.

Banca Examinadora:

Profa. Dra. Maria Teresa Moura Lamy (IFUSP)

Prof. Dr. Adriano Mesquita Alencar (IFUSP)

Prof. Dr. Cristiano Luis P. de Oliveira (IFUSP)

Prof. Dr. Julio Henrique K. Rozenfeld (UNIFESP)

Profa. Dra. Sônia Renaux W. Louro (PUC/RJ)

São Paulo

2018 
FICHA CATALOGRÁFICA

Preparada pelo Serviço de Biblioteca e Informação do Instituto de Física da Universidade de São Paulo

Nomura, Daniela Akiko

Caracterização estrutural de dispersões aquosas de lipídios aniônicos. São Paulo, 2018.

Tese (Doutorado) - Universidade de São Paulo. Instituto de Física. Depto. de Física Geral.

Orientador: Profa. Dra. Maria Teresa Moura Lamy

Área de Concentração: Física da Matéria Condensada; Biofísica Molecular.

Unitermos: 1. Biofísica; 2. Lipídio; 3. Lipossomos.

USP/IF/SBI-037/2018 
Dedico esta tese aos meus pais, Eliza e Cecílio e aos meus avós, Fussae, Tomie, Seinosuke e Iwao, pelo amor, incentivo e exemplo de vida. 



\section{Agradecimentos}

Ao apoio financeiro da FAPESP, desde a bolsa de iniciação científica (Processo 2010/19784-3), a bolsa de mestrado (Processo 2011/14507-4), que se transformou na bolsa de doutorado direto (Processo 2013/14296-9) e pela bolsa BEPE (Processo 2015/14695-6), que possibilitou o estágio de 6 meses na University of Graz, Graz, Áustria.

À professora Maria Teresa Lamy, pela orientação desde a Iniciação científica, pelo apoio, confiança e ensinamentos! Pelas discussões, conversas, monitorias, compreensão, incentivo, paciência, amizade, passeios, preocupação, conselhos e consideração de sempre.

Ao professor Georg Pabst, por ter aceitado colaborar com este trabalho na área de SAXS e WAXS. Por ter me recebido em seu grupo de pesquisa e ter me orientado durante o estágio BEPE que foi realizado. Pelos ensinamentos, paciência, discussões, por toda a ajuda e amizade.

À professora Carla Goldman, pelas discussões teóricas, parceria, conselhos, amizade e incentivo.

Ao professor Leandro Barbosa, pelas discussões, conselhos, amizade e pela disponibilidade em sempre ajudar.

À professora Vera pelas aulas, discussões e importantes contribuições para o trabalho, principalmente em espalhamento de luz estático e física estatística.

Ao Dr. Evandro Duarte, por toda ajuda no laboratório, pelas importantes contribuições a este trabalho, principalmente na parte de ressonância paramagnética eletrônica, pela amizade, conversas, caronas e confiança. Por estar sempre disposto a ajudar e pelo auxílio nas medidas realizadas no LNLS.

À Dra Thais Enoki, pela co-orientação durante a iniciação cientifica, pelas inúmeras discussões cientificas, pelos valiosos conselhos, dedicação, ensinamentos e amizade. Agradeço por todo o apoio, confiança e incentivo.

A todo o grupo de Biofísica, pela boa convivência no ambiente de trabalho e no laboratório. Aos colegas com quem tive o prazer de trabalhar, pelas conversas, desabafos, conselhos, compreensão, discussões científicas, ensinamentos e por serem 
sempre muito solícitos em ajudar. Agradeço especialmente ao Tiago, Rafael, Cíntia, Júlio, Antônio, Juliana, Marcos, Fernanda e Vinicius.

A todo o grupo de Biofísica do "Institute of Molecular Biosciences", da University of Graz, Áustria. Pelas interessantes discussões cientificas, pela ajuda com os experimentos de SAXS e WAXS e pela troca de experiências e conhecimento. Por terem me recebido muito bem, pelos bolos, vinhos, conversas e passeios incríveis. Pelas amizades que tenho certeza que perdurarão por muito tempo. Agradeço em especial o Charlie, Georg, Anna, Barbara, Michi, Drew, Michal, Santosh, Christina, Lisa e o Alexander. Agradeço à família Weitzer, Ursula e Ludwig por terem me recebido em sua casa durante minha permanência de 1 mês em Graz em 2017, por todo o carinho e dedicação.

A todos os professores que fizeram parte de minha formação, por toda a dedicação, incentivo e ensinamentos. Agradeço à professora Nuricel Aguilera pela oportunidade do meu primeiro emprego e ao Luiz Fernando Malvestiti, pelo estágio realizado na UDDO.

Aos meus colegas de graduação e de escola, que foram essenciais nesta longa caminhada. Agradeço aos amigos do colégio Objetivo, das olimpíadas científicas e do Instituto de Física.

Ao meu namorado Diego, pelo companheirismo, compreensão, paciência, apoio e incentivo. Agradeço a toda a minha família, meus pais, meus avós, meus irmãos, minhas tias e tios, primas e primos, por sempre me apoiarem, incentivarem, pelo amor incondicional, pela preocupação e pela ajuda e suporte sempre que necessário. É muito bom poder contar sempre com vocês, nas horas boas e ruins.

À tia Sadae pelas caronas, conversas e conselhos. À minha queria amiga Aline. Aos amigos Caio, Mari e Carlos e ao meu querido afilhado Enzo.

Muito obrigada a todos que me apoiaram! 
"A tarefa não é tanto ver aquilo que ninguém viu, mas pensar o que ninguém ainda pensou sobre aquilo que todo mundo vê."

(Arthur Schopenhaver) 



\section{Resumo}

É conhecido que a força iônica do meio desempenha um papel fundamental na estrutura de vesículas aniônicas de DMPG (dimiristoil fosfatidilglicerol) em dispersões aquosas. A baixa força iônica ( $6 \mathrm{mM}$ ), as dispersões de DMPG exibem várias características anômalas, que foram interpretadas como a abertura de poros na bicamada ao longo da larga "região de transição de fase" gel-fluida (de $\sim 18^{\circ} \mathrm{C}$ a $30^{\circ} \mathrm{C}$ ). Aqui, revisitamos o sistema de DMPG em tampão a baixa força iônica, mas com dispersões obtidas após a extrusão por filtros de $100 \mathrm{~nm}$, portanto menos polidispersas. Para enfatizar as interações eletrostáticas entre as cabeças polares dos lipídios, que não estarão blindadas pela presença de sais na solução, estudamos dispersões de DMPG em água pura, de modo a monitorar os agregados presentes na dispersão, e suas interações. As dispersões em água foram caracterizadas antes e depois da extrusão. Para tal, utilizamos diversas técnicas experimentais, em diferentes temperaturas: espalhamento de luz estático (SLS) e dinâmico (DLS), calorimetria diferencial de varredura (DSC), Ressonância Paramagnética Eletrônica (RPE) de marcadores de spin incorporados aos agregados, espalhamento de raios-X a altos e baixos ângulos (WAXS e SAXS), e medidas de viscosidade, turbidez, mobilidade eletroforética e condutividade elétrica.

Resultados das várias técnicas com dispersões extrusadas de DMPG em tampão mostraram que o comportamento anômalo é observado de forma similar ao de dispersões não extrusadas. Entretanto, o pico de SAXS em muito baixo ângulo é visto de 5 a $45^{\circ} \mathrm{C}$, e não apenas na região de transição de fase, portanto não deve ser modelado como a distância entre poros na bicamada lipídica que se abririam nesta região. A distância de repetição relacionada a este pico diminui na região de transição de fase, e com o aumento da concentração lipídica.

Medidas de DSC indicaram que, em água, a "região de transição de fase" da vesícula de DMPG é ainda mais ampla, começando em torno de $10^{\circ} \mathrm{C}$, mas ainda terminando em $\sim 30^{\circ} \mathrm{C}$. No entanto, a alta condutividade elétrica, viscosidade, mobilidade eletroforética, raio efetivo, e a baixa turbidez, vistas apenas na região de transição de fase do DMPG em tampão, são encontradas até altas temperaturas em água, quando a bicamada lipídica já se encontra na fase fluida. Medidas de RPE e WAXS mostraram a transição da membrana de uma fase mais rígida/imóvel/organizada para uma fase mais frouxa/móvel. Dados de espalhamento de luz, RPE e SAXS mostram que, similar ao DMPG em tampão, em água, o DMPG organiza-se como vesículas esféricas, unilamelares, mas possivelmente menores e mais carregadas, exibindo fortes interações vesícula-vesícula. Nas medidas de SAXS, o pico de Bragg na região de muito baixo ângulo foi visto em todas as temperaturas (de 5 a $60^{\circ} \mathrm{C}$ ), sendo que a distância de repetição diminui para temperaturas maiores do que $10^{\circ} \mathrm{C}$. Os resultados obtidos para dispersões em água, reforçam o comportamento anômalo observado anteriormente para dispersões em tampão em baixa força iônica. De acordo com eles, propomos a existência de vesículas altamente deformadas e ionizadas a partir de uma certa temperatura, $\mathrm{T}_{1}$ para o DMPG em água e $T_{m}{ }^{\text {on }}$ em tampão baixa força iônica, sendo que em água a forte repulsão eletrostática PG-PGlevaria a fortes deformações e interações vesícula-vesícula, em uma ampla extensão de temperaturas.

Palavras-chave: Biofísica Molecular, dispersões lipídicas, membranas modelo, lipídio aniônico, DMPG 



\section{Abstract}

It is known that the ionic strength plays a fundamental role in the structure of DMPG (dimyristoyl phosphatidylglycerol) anionic vesicles in water medium. At low ionic strength ( 6 $\mathrm{mM}$ ), DMPG dispersions display several anomalous characteristics, which were interpreted as the opening of bilayer pores along the wide bilayer gel-fluid "transition region" (from $\sim 18^{\circ} \mathrm{C}$ to $30^{\circ} \mathrm{C}$ ). Here, we revisit DMPG in buffer at low ionic strength, but with dispersions obtained after the extrusion by $100 \mathrm{~nm}$ filters, thus less polydisperse. To emphasize electrostatic interactions between the polar head-groups, which will not be shielded by ions in solution, we studied DMPG dispersions in pure water to monitor the aggregates in the dispersion and their interactions. Water dispersions were characterized before and after extrusion. For such, we used several experimental techniques, at different temperatures: light scattering, both static (SLS) and dynamic (DLS); differential scanning calorimetry (DSC); electron spin resonance (ESR) of spin labels incorporated into the aggregates, Small and Wide Angle X-Ray Scattering (SAXS and WAXS); and viscosity, turbidity, electrophoretic mobility and electrical conductivity measurements.

Several techniques with extruded dispersions of DMPG in buffer showed that the anomalous behavior is also observed. However, the SAXS peak at very low angles is seen from 5 to $45^{\circ} \mathrm{C}$, and not only in the "phase transition region", therefore it should not be modeled as the distance of correlated pores in the lipid bilayer that would open in this region. The repeating distance related to this peak decreases in the "phase transition region", and with increasing lipid concentration.

DSC indicates that, in water, the bilayer gel-fluid transition is even wider, starting around $10^{\circ} \mathrm{C}$ but still ending $\sim 30^{\circ} \mathrm{C}$. However, high electric conductivity, viscosity, electrophoretic mobility, effective radius and low turbidity found only in the gel-fluid "transition region" for DMPG in buffer, are found at higher temperatures in water, when lipid bilayers are already in the fluid state. ESR and WAXS measurements evidenced the transition of the membrane from a more rigid/immobile/organized phase to a more soft/mobile phase. Light scattering, ESR and SAXS data showed that, similar to DMPG in buffer, in water, DMPG is organized as spherical unillamelar vesicles, but possibly smaller, highly charged, displaying strong vesicle-vesicle interactions. With SAXS the Bragg peak at very low angles was seen at all temperatures (from 5 to $60^{\circ} \mathrm{C}$ ) with the repetition distance decreasing at temperatures higher than $10^{\circ} \mathrm{C}$. The results obtained for water dispersions reinforce the anomalous behavior previously observed for buffer at low ionic strength dispersions. According to them, we propose the existence of highly deformed and ionized vesicles from a certain temperature, $T_{1}$ for DMPG in water and $T_{m}{ }^{\text {on }}$ in buffer at low ionic strength. In water the strong PG- - PG- electrostatic repulsion would lead to strong deformations and vesicle-vesicle interactions, over a wide range of temperatures.

Keywords: Molecular Biophysics, lipid dispersions, model membranes, anionic lipids, DMPG 



\section{Lista de abreviaturas}

16-PCSL 1-palmitoil-2-estearoil (16- doxil)-sn-glícero-3- fosfatidilcolina

5-PCSL 1-palmitoil-2-estearoil (5-doxil)-sn-glícero-3-fosfatidilcolina

DLS Espalhamento de luz dinâmico

DMPC Dimiristoil fosfatidilcolina

DMPG Dimiristoil fosfatidilglicerol

DSC Calorimentria diferencial de varredura

EDTA Ácido etilenodiamido tetra-acético

HEPES Ácido de N-(2-Hidroxietil)-Piperazina-N-2-etano sulfônico

LNLS Laboratório Nacional de Luz Síncrotron

$\mathrm{NaCl} \quad$ Cloreto de sódio

POPE Palmitoil oleoil fosfatidiletanolamina

RPE Ressonância paramagnética eletrônica

SAXS Espalhamento de raios- $X$ a baixo ângulo

SLS Espalhamento de luz estático

WAXS Espalhamento de raios- $X$ a alto ângulo 



\section{Lista de figuras}

Figura 1.2.1: Representação da membrana plasmática baseada no modelo de "mosaico fluido". [Fonte: figura 9-25 de Voet \& Voet, 2014].

Figura 1.2.2: Proposta atualizada do modelo mosaico fluido, com maior quantidade de proteínas e espessura da bicamada lipídica variável. [Fonte: Engelman, 2005].

Figura 1.3.1: Os lipídios apresentam uma cabeça polar hidrofílica e uma ou mais cadeias hidrocarbônicas hidrofóbicas.

Figura 1.3.2: Exemplos de estruturas típicas formadas por lipídios em meio aquoso de acordo com sua geometria. [Figura adaptada de Barroso, 2010 e Tresset, 2009].

Figura 1.3.3: Estrutura molecular do DMPG.

Figura 1.4.1: Configurações da bicamada lipídica na transição gel-fluida. [Figura adaptada de Voet, D.; Voet, J.G. (2008)]

Figura 2.2.1: Feixe de luz monocromático incidindo em uma amostra que absorve neste comprimento de onda. O caminho óptico percorrido pela luz neste caso é dado por L.

Figura 2.3.1: Esquema do aparato experimental utilizado em medidas de espalhamento de luz e definição do vetor de espalhamento $\mathrm{q}$, sendo que $/ \mathrm{Ki} /=/ \mathrm{Ke} /$.

Figura 2.3.2: Flutuações da intensidade da luz espalhada devido à variação na densidade de partículas no volume de observação. [Figura adaptada de Berne e Pecora, 2000]

Figura 2.3.3: Exemplo de gráfico de Zimm para nanoesferas de poliestireno de $92 \mathrm{~nm}$ de diâmetro, obtido com 4 diferentes concentrações de nanoesferas e diferentes ângulos entre 40 e $140^{\circ}$.

Figura 2.4.1: Representação esquemática do espalhamento de raio-X pela amostra.....

Figura 2.4.2: Representação de uma curva de SAXS + WAXS mostrando a informação que podemos obter em cada região de ângulos de espalhamento de Raios-X. Quanto maior o ângulo de espalhamento, pela Lei de Bragg, menor é a estrutura observada. [Figura adaptada de Hirai et al., 2015].

Figura 2.4.3: Perfil de densidade eletrônica de acordo com a equação 3.10 [Figura adaptada de Pabst et al., 2000]..

Figura 2.4.4: Representação da difração de Raios-X de acordo com a Lei de Bragg. [Fonte: http://wiki.stoa.usp.br]

Figura 2.5.1: Ilustração de como as medias de RPE são realizadas, variando-se o campo magnético e fixando-se a frequência da microonda.

Figura 2.5.2: Espectros de RPE do radical nitróxido sob diferentes condições: (a) campo magnético paralelo ao eixo $x$, (b) ao eixo y e (c) ao eixo z; em solução congelada (d) e em solução de baixa viscosidade (e). [Figura adaptada de Marsh, 1981].

Figura 2.5.3: Espectros de RPE de Tempol em soluções de viscosidade crescentes de cima para baixo. Os valores de $\tau_{c}$ foram calculados pela equação 2.5.2. [Figura adaptada de Smith, 1972].......

Figura 2.5.4: Marcador de spin inserido na bicamada lipídica, fazendo um ângulo a com a direção normal à bicamada. [Figura adaptada de Knowles et al., 1976]. 
Figura 3.1.1: Estrutura molecular dos lipídios (DMPG e DOPE), dos marcadores de spin (5 e 16-PCSL) e do alceno tricoseno utilizados. [Fonte: avantilipids.com e chemicalbook.com (tricoseno)].

Figura 3.2.1: Dispositivo acoplado ao mini-extrusor da Avanti para a realização da extrusão de forma automatizada. O dispositivo empurra a amostra de uma seringa para a outra, forçando-a a passar pelo filtro com poros do tamanho escolhido. Neste dispositivo é possível selecionar o número de vezes que a amostra passa pelo filtro, a temperatura da placa de apoio do extrusor e a potência do motor que realiza o movimento

Figura 3.2.2: Exemplo de amostras utilizadas no experimento de curvatura espontânea do DMPG. 43

Figura 3.2.3: a) Variação da capacidade térmica em função da temperatura de uma dispersão de $10 \mathrm{mM}$ de DMPG em água, já subtraída da referência (água). b) variação do calor específico obtido após a divisão da capacidade térmica pelo número de mols na amostra e linha de base cúbica criada pelo software da Microcal, sendo esta linha de base subtraída da curva experimental.

Figura 3.2.4: Os valores de entalpia das transições foram obtidos pelo cálculo das áreas sob a curva de capacidade térmica, hachuradas na figura.

Figura 3.2.5: aparato experimental utilizado nas medidas de viscosidade (Fonte: Barroso, R.P., tese de doutorado, 2010).

Figura 3.2.6: Ilustração do capilar da Malvern utilizado para as medidas de mobilidade eletroforética. . 49

Figura 3.2.7: Aparelho de espalhamento de luz da Brookhaven Instruments Corporation. .51

Figura 3.2.8: Aparelho Zetasizer Nano ZS9O, da Malvern, que foi utilizado para medidas de DLS e de mobilidade eletroforética.

Figura 3.2.9: Aparato experimental para medidas de DLS do Institute of Inorganic Chemistry da Graz University of Technology, Áustria.....

Figura 3.2.10: Exemplos de ajustes da função de autocorrelação da luz espalhada a $90^{\circ}$ obtidos pela Dra. Angela Chemelli no programa ORTLight. No gráfico da esquerda para a dispersão de $1 \mathrm{mM}$ de DMPG em água e no gráfico da direita para a dispersão de $10 \mathrm{mM}$ de DMPG em água, ambos em $T=20^{\circ} \mathrm{C}$...........54

Figura 3.2.11: Aparato experimental utilizado nas medidas de RPE.

Figura 3.2.12: Espectros de RPE de uma dispersão de $10 \mathrm{mM}$ de DMPG + 0,8 mol\% do marcador 5-PCSL em água, mostrando os desdobramentos hiperfinos máximo $\left(A_{\max }\right)$ e mínimo $\left(A_{\min }\right)$..

Figura 3.2.13: Espectro de RPE de uma dispersão de $10 \mathrm{mM}$ de DMPG + 0,3 mol\% do marcador 16-PCSL em água a $60^{\circ} \mathrm{C}$, mostrando como os parâmetros $h_{+1}$, ho, h-1 e aoforam medidos a partir dos espectros experimentais.

Figura 3.2.14: a) " $\mu$-Cell" e b) "Paste Cell", ambas da Anton Paar.

Figura 3.2.15: Exemplo de curvas de SWAXS obtidas para dispersões de DMPG $50 \mathrm{mM}$ em água, na fase gel $\left(5^{\circ} \mathrm{C}\right)$, na transição de fase $\left(23^{\circ} \mathrm{C}\right)$ e na fase fluida $\left(60^{\circ} \mathrm{C}\right)$

Figura 4.1.1: Curvas da variação do calor específico em função da temperatura para três amostras distintas de DMPG 10mM em água, após a extrusão. (a) As curvas foram medidas com a temperatura aumentando a uma taxa de $20^{\circ} \mathrm{C} / \mathrm{h}$ (b) As curvas foram medidas com a temperatura diminuindo a uma taxa de $20^{\circ} \mathrm{C} / \mathrm{h}$.

Figura 4.1.2: Varreduras sucessivas da amostra 3 (figura 4.1.1) aumentando (gráfico a) e diminuindo (gráfico b) a temperatura a uma taxa de $20^{\circ} \mathrm{C} / \mathrm{h}$. 
Figura 4.1.3: Típicos perfis de DSC de dispersões de $10 \mathrm{mM}$ de DMPG antes da extrusão (curva preta), após extrusão por filtros de $100 \mathrm{~nm}$ (curvas vermelhas) e após extrusão por filtros de $30 \mathrm{~nm}$ (curva azul) em água.

Figura 4.1.4: a)Típicas curvas de DSC para uma dispersão de $50 \mathrm{mM}$ de DMPG em água, extrusada por filtro de $100 \mathrm{~nm}$ a uma taxa de $10^{\circ} \mathrm{C} / \mathrm{h}$, sendo o intervalo de tempo entre a $1^{a}$ e a $2^{a}$ varredura e entre a $2^{a}$ e a 3ㅁ varredura de 11 horas. b) Comparação dos resultados obtidos para as dispersões de 10 e 50 $m M$ de DMPG, depois da extrusão.

Figura 4.1.5: Curvas de DSC de dispersões de $10 \mathrm{mM}$ de DMPG em água (curvas pretas) e em água com o acréscimo de 0,1 $\mathrm{mM}$ (curvas vermelhas) e 0,5 $\mathrm{mM}$ (curvas azuis) de $\mathrm{NaCl}$, antes (gráfico a) e depois (gráfico b) da extrusão, sendo esquentadas a uma taxa de $20^{\circ} \mathrm{C} / \mathrm{h}$. As curvas foram deslocadas verticalmente para uma melhor visualização.

Figura 4.2.1: Viscosidade cinemática em função da temperatura para dispersões extrusadas de $10 \mathrm{mM}$ de DMPG em água e de água pura. Cada curva é a média entre medidas de duas amostras distintas e a incerteza é dada pelo desvio padrão das medidas.

Figura 4.2.2: Medidas do incremento da viscosidade relativa para dispersões de $10 \mathrm{mM}$ de DMPG em água, antes (pontos azuis) e depois (pontos vermelhos) da extrusão. Cada curva é a média entre medidas de duas amostras distintas e a incerteza é dada pelo desvio padrão das medidas.

Figura 4.2.3: Viscosidade cinemática de uma dispersão extrusada de $10 \mathrm{mM}$ de DMPG em água, com a temperatura aumentando (pontos rosas) e depois diminuindo (pontos verdes).

Figura 4.3.1: Medida de condutividade elétrica em função da temperatura para duas dispersões extrusadas de $10 \mathrm{mM}$ de DMPG em água e para água pura.

Figura 4.3.2: Medidas de condutividade reduzida para dispersões de $10 \mathrm{mM}$ de DMPG em água antes (pontos azuis) e depois (pontos vermelhos) da extrusão.

Figura 4.3.3: Condutividade reduzida de uma dispersão de $10 \mathrm{mM}$ de DMPG em água, extrusada, com a temperatura aumentando (pontos rosas) e depois diminuindo (pontos verdes).

Figura 4.4.1: Medidas de mobilidade eletroforética $(\mu)$ para duas amostras distintas de 10 mM de DMPG em água depois da extrusão e $\mu$ dos contraíons $\mathrm{Na}^{+}$calculados usando a equação 3.2.5.

Figura 4.4.2: Mobilidade eletroforética corrigida de uma dispersão extrusada de $10 \mathrm{mM}$ de DMPG em água.

Figura 4.5.1: Medidas de absorbância a $350 \mathrm{~nm}$, em função da temperatura, de dispersões de $10 \mathrm{mM}$ de DMPG em água, antes (pontos azuis) e depois (pontos vermelhos) da extrusão, sendo o caminho óptico de $2 \mathrm{~mm}$.

Figura 4.6.1: Funções de autocorrelação da luz espalhada normalizadas para dispersões extrusadas de DMPG em água com diferentes concentrações lipídicas: a) $1 \mathrm{mM}$ e em b) $10 \mathrm{mM}$, sendo mostrado em destaque a região de maiores $\tau$, onde o ajuste não é satisfatório. As linhas sólidas representam os ajustes obtidos via software Ortlight e os círculos representam os dados experimentais em diferentes temperaturas: $5,15,20,30$ e $45^{\circ} \mathrm{C}$.

Figura 4.6.2: Distribuição de tamanhos dos agregados de DMPG obtidos pela transformada inversa de Laplace, para uma dispersão de $1 \mathrm{mM}$ (gráfico da esquerda) e $10 \mathrm{mM}$ (gráfico da direita) nas temperaturas $5,15,20,30$ e $45^{\circ} \mathrm{C}$.

Figura 4.6.3: Resultados de DLS obtidos para uma dispersão de $1 \mathrm{mM}$ de DMPG em água, mostrados na tabela 4.1 
Figura 4.6.4: Gráfico de Zimm para dispersões de DMPG em água nas concentrações: 4,82; 12,4; 13,8 e $16,5 \mathrm{mg} / \mathrm{mL}$, variando o ângulo de 40 a $140^{\circ}$ e em diferentes temperaturas $\left(20,30,45\right.$ e $\left.60^{\circ} \mathrm{C}\right)$.

Figura 4.6.5: Gráfico de Zimm para dispersões de DMPG em água nas concentrações: 0,34; 0,69; 1,03; 1,38; 1,72 e 2,07 mg/mL, variando o ângulo de 40 a $140^{\circ}$ e em diferentes temperaturas $\left(20,30\right.$ e $\left.45^{\circ} \mathrm{C}\right)$.

Figura 4.6.6: Gráfico de Zimm obtido para diferentes concentrações lipídicas: 0,05; 0,5; 1,0 e 1,5 mM de $D M P G$ a $20^{\circ} \mathrm{C}$.

Figura 4.6.7: Gráficos de espalhamento de luz estático para dispersão extrusada $10 \mathrm{mM}$ ) de DMPG em água em diferentes temperaturas $\left(20,30\right.$ e $\left.45^{\circ} \mathrm{C}\right)$.

Figura 4.6.8: a)Comparação entre as razões IvH/Ivv para dispersões de DMPG em água (pontos em vermelho), de DMPG em HEPES (pontos azuis), de nanoesferas de poliestireno, de DMPC e de micelas de SDS em diferentes concentrações. Em (b) temos uma ampliação da região com razão de despolarização próxima a 0,005. [figura modificada de Enoki et al., 2012].

Figura 4.6.9: Razão de despolarização (IVH/lvv) de dispersões de 1 e $10 \mathrm{mM}$ de DMPG em água, medidas no "Institute of Inorganic Chemistry" da Graz University of Technology, Graz, Áustria.

Figura 4.7.1: Sobreposição dos resultados de DSC, incremento da viscosidade relativa $\left(\eta_{i}\right)$, condutividade reduzida ( $\left.\sigma_{\text {red }}\right)$, absorbância a $350 \mathrm{~nm}$, mobilidade corrigida $\left(\mu_{\text {corr }}\right)$ e raio efetivo $\left(R_{\text {eff }}\right)$ calculado por $D L S$ de dispersões extrusadas de $10 \mathrm{mM}$ (1 mM para a medida de $R_{\text {eff }}$ ) de DMPG em água.

Figura 5.1.1: a) Comparação de curvas de DSC de dispersões de DMPG $10 \mathrm{mM}$ em tampão a baixa força iônica antes e depois da extrusão, sendo que a curva não extrusada foi deslocada verticalmente para melhor visualização. b) Resultados obtidos com diferentes amostras extrusadas de DMPG 10 mM. Todas as curvas foram obtidas aquecendo-se as amostras a uma taxa de $20^{\circ} \mathrm{C} / \mathrm{h}$.

Figura 5.1.2: DSC de dispersões de $10 \mathrm{mM}$ de DMPG antes da extrusão (curva preta), após extrusão por filtros de $100 \mathrm{~nm}$ (curvas vermelhas) e após extrusão por filtros de $30 \mathrm{~nm}$ (curvas azuis) em tampão a baixa força iônica, com os respectivos valores de entalpia da transição de fase.

Figura 5.1.3: Comparação de curvas típicas de DSC de dispersões extrusadas de 10 mM de DMPG em água (curva vermelha) e em tampão a baixa força iônica (curva azul). O resultado em tampão foi deslocado verticalmente para melhor visualização.

Figura 5.2.1: Viscosidade cinemática em função da temperatura para dispersões extrusadas de $10 \mathrm{mM}$ de DMPG em tampão (curva vermelha) e do tampão (curva preta). Cada curva é a média entre medidas de duas amostras distintas e a incerteza é dada pelo desvio padrão das medidas.

Figura 5.2.2: Incremento da viscosidade relativa com a temperatura para dispersões de 10 mM de DMPG antes (curva azul, extraídas de Barroso, 2010) e depois (curva vermelha) da extrusão. As temperaturas indicadas para $T_{m}{ }^{\text {on }}$ e $T_{m}{ }^{\text {off }}$ são as mesmas dos gráficos de DSC (figura 5.1.3).

Figura 5.2.3: Comparação do incremento da viscosidade relativa de dispersões extrusadas de $10 \mathrm{mM}$ de DMPG em água e em tampão a baixa força iônica. As setas indicam as temperaturas de início e final da transição de fase, vistas por DSC.

Figura 5.3.1: Medidas de condutividade elétrica do tampão HEPES e de duas amostras distintas de 10 $m M$ de DMPG em tampão extrusadas.

Figura 5.3.2: Condutividade reduzida de dispersões de $10 \mathrm{mM}$ de DMPG em tampão HEPES.

Figura 5.3.3: Comparação dos resultados de condutividade reduzida para dispersões extrusadas de 10 mM de DMPG em água (curva vermelha) e em tampão (curva azul), sendo indicadas as temperaturas de 
início e final da transição de fase vista por DSC. O resultado em água foi multiplicado por 0,03 de modo a facilitar a comparação com o resultado em tampão.

Figura 5.4.1: a) Comparação dos resultados de mobilidade eletroforética e b) mobilidade corrigida para dispersões de 10 mM de DMPG extrusadas e não extrusadas (Barroso, 2010) em tampão HEPES.

Figura 5.4.2: Comparação das mobilidades corrigidas das dispersões extrusadas de $10 \mathrm{mM}$ de DMPG em água e em tampão HEPES baixa força iônica.

Figura 5.5.1: Medidas de absorbância a $350 \mathrm{~nm}$ em função da temperatura de dispersões de $10 \mathrm{mM}$ de DMPG em tampão, antes (pontos azuis, dados de Barroso et al., 2010) e depois (pontos vermelhos) da extrusão. Cada curva é a média de 2 medidas de amostras distintas.

Figura 5.5.2: Comparação das medidas de absorbância à $350 \mathrm{~nm}$ para dispersões extrusadas de $10 \mathrm{mM}$ de DMPG em tampão (curva azul) e em água (curva vermelha).

Figura 5.6.1: Funções normalizadas da autocorrelação da luz espalhada para dispersões extrusadas de 1 mM de DMPG em diferentes temperaturas e diferentes solventes: $\boldsymbol{a}$ ) em tampão a baixa força iônica e b) em tampão a alta força iônica. As linhas sólidas representam os ajustes obtidos via software Ortlight e os círculos representam as medidas experimentais.

Figura 5.6.2: Distribuição de tamanhos dos agregados de DMPG obtidos pela transformada inversa de Laplace para dispersões extrusadas de $1 \mathrm{mM}$ de DMPG em diferentes temperaturas $\left(5,15,20,30\right.$ e $\left.45^{\circ} \mathrm{C}\right)$ e em diferentes meios: em a) em tampão HEPES a baixa força iônica e em b) em tampão HEPES a alta força iônica.

Figura 5.6.3: Raio efetivo (Reff) em função da temperatura de agregados de DMPG em meios de diferente força iônica, conforme valores da tabela 5.1 .

Figura 5.6.4: Medidas de DLS de dispersões de $1 \mathrm{mM}$ de DMPG em tampão extrusadas por filtros de 30 e $100 \mathrm{~nm}$.

Figura 5.6.5: Curvas de espalhamento de luz estático de dispersão de DMPC em tampão, com concentração de $1,5 \mathrm{mM}$, nas temperaturas 20,23 e $43^{\circ} \mathrm{C}$.

Figura 5.6.6: Curvas de espalhamento de luz estático de dispersão de $1 \mathrm{mM}$ de DMPG em tampão, nas temperaturas $16,20,28$ e $43^{\circ} \mathrm{C}$......

Figura 5.6.7: Destaque das medidas da figura 5.6.6 nas temperaturas de transição de fase: 20 e $28^{\circ} \mathrm{C}$ ajustadas por equações de $2^{\circ}$ grau.

Figura 5.6.8: Razão de despolarização da luz espalhada (IVH/lvv) para vesículas de DMPG em água pura, em tampão a baixa força iônica e em tampão a alta força iônica em diferentes temperaturas $(5,15,20$, 30 e $45^{\circ} \mathrm{C}$ ). As medidas foram realizadas com as amostras recém preparadas (símbolos fechados) e após deixar as amostras durante 1 semana em temperatura ambiente (símbolos abertos).

Figura 5.7.1: Sobreposição dos resultados de DSC, incremento da viscosidade relativa $\left(\eta_{i}\right)$, condutividade reduzida ( $\left.\sigma_{\text {red }}\right)$, absorbância a $350 \mathrm{~nm}$, mobilidade elefrorética ( $\left.\mu_{\text {corr }}\right)$ e raio efetivo (Reff) calculado por DLS de dispersões extrusadas de $10 \mathrm{mM}$ (1 mM para a medida de $\left.R_{\text {eff }}\right)$ de DMPG a) em água e b) em tampão a baixa força iônica.

Figura 5.8.1: Curvas da variação de calor específico em função da temperatura para duas amostras distintas de DMPG com concentração lipídica de 50mM em tampão (HEPES $10 \mathrm{mM}+\mathrm{NaCl} 2 \mathrm{mM}$ ) após a extrusão. A curva vermelha foi medida aumentando-se a temperatura a uma taxa de $10^{\circ} \mathrm{C} / \mathrm{h}$ e a curva azul a $20^{\circ} \mathrm{C} / \mathrm{h}$ 
Figura 5.8.2: Comparação das curvas de DSC de dispersões extrusadas e não extrusadas (Barroso, 2010) de $50 \mathrm{mM}$ de DMPG em tampão a baixa força iônica, sendo a taxa de aquecimento de $10^{\circ} \mathrm{C} / \mathrm{h}$.

Figura 5.8.3: a) Curvas de DSC para a dispersão de 50 mM de DMPG em tampão baixa força iônica extrusada, esquentando e esfriando. b) comparação dos resultados obtidos para as dispersões de 10 e $50 \mathrm{mM}$ de DMPG, depois da extrusão. Taxa de variação da temperatura de $20^{\circ} \mathrm{C} / \mathrm{h}$.

Figura 5.8.4: Comparação de curvas típicas de DSC de dispersões extrusadas de $50 \mathrm{mM}$ de DMPG em água (curva vermelha) e em tampão a baixa força iônica (curva azul). O resultado em tampão foi deslocado verticalmente para melhor visualização.

Figura 5.8.5: Viscosidade cinemática em função da temperatura para dispersões extrusadas de $50 \mathrm{mM}$ de DMPG em tampão (curva vermelha) e do tampão (curva preta). Cada curva é a média entre medidas de duas amostras distintas e a incerteza é dada pelo desvio padrão das medidas.

Figura 5.8.6: Incremento da viscosidade relativa com a temperatura para dispersões de 50 mM de DMPG antes (curva azul, extraídas de Barroso, 2010) e depois (curva vermelha) da extrusão. As linhas tracejadas vermelhas indicam $T_{m}{ }^{\text {on }}$ e $T_{m}{ }^{\text {off }}$ das dispersões extrusadas e as azuis das não extrusadas, de acordo com os gráficos de DSC da figura 5.7.2.

Figura 5.8.7: Medidas de condutividade elétrica aumentando e diminuindo a temperatura do tampão HEPES e de uma dispersão extrusada de 50 mM de DMPG em tampão.

Figura 5.8.8: Condutividade reduzida de dispersões de $50 \mathrm{mM}$ de DMPG em tampão HEPES antes e depois da extrusão (Barroso, 2010). As linhas tracejadas vermelhas indicam $T_{m}^{\text {on }}$ e $T_{m}{ }^{\text {off }}$ das dispersões extrusadas e as azuis das não extrusadas, de acordo com os gráficos de DSC da figura 5.7.2. Cada curva é a média entre medidas de duas amostras distintas e a incerteza é dada pelo desvio padrão das medidas.

Figura 5.8.9: Medidas de absorbância a $350 \mathrm{~nm}$ em função da temperatura de dispersões de $50 \mathrm{mM}$ de DMPG em tampão, antes (pontos azuis, dados de Barroso et al., 2010) e depois (pontos vermelhos) da extrusão. Cada curva é a média de 2 medidas de amostras distintas.

Figura 5.8.10: Sobreposição dos resultados de DSC, incremento da viscosidade relativa $\left(\eta_{i}\right)$, condutividade reduzida ( $\sigma_{\text {red }}$ ) e absorbância a $350 \mathrm{~nm}$ para dispersões de $50 \mathrm{mM}$ de DMPG $50 \mathrm{mM}$ em tampão à baixa força iônica, após a extrusão.

Figura 6.1.1: Típicos espectros de RPE para dispersões de $10 \mathrm{mM}$ de DMPG em água + 0,8 mol\% do marcador 5-PCSL, antes (curvas da esquerda) e depois (curvas da direita) da extrusão em diferentes temperaturas.

Figura 6.1.2: Ilustração que representa o marcador de spin 5-PCSL incorporado à bicamada lipídica. .. 133

Figura 6.1.3: Desdobramento hiperfino máximo em função da temperatura para duas amostras distintas de dispersões extrusadas (símbolos fechados) e não extrusadas (símbolos abertos) de $10 \mathrm{mM}$ de DMPG em água + 0,8 mol\% do marcador 5-PCSL.

Figura 6.1.4: Desdobramento hiperfino mínimo em função da temperatura para duas amostras distintas de dispersões extrusadas (símbolos fechados) e não extrusadas (símbolos abertos) de $10 \mathrm{mM}$ de DMPG em água + 0,8 mol\% do marcador 5-PCSL.

Figura 6.1.5: Média e desvio padrão dos valores calculados para os parâmetros $a_{o}$ e $S_{\text {ef }}$ para duas amostras distintas de 10 mM de DMPG antes e depois da extrusão em água, na fase fluida da bicamada. 
Figura 6.1.6: Espectros de RPE de dispersões não extrusadas de $10 \mathrm{mM}$ de DMPG com o marcador 5PCSL em água (curvas vermelhas) e em tampão (curvas azuis) (Duarte et al., 2008) em diferentes temperaturas: na fase gel $\left(5^{\circ} \mathrm{C}\right)$, na região de transição de fase $\left(20^{\circ} \mathrm{C}\right)$ e na fase fluida $\left(45^{\circ} \mathrm{C}\right)$.

Figura 6.1.7: Comparação dos parâmetros $2 A_{\max }$ e $2 A_{\min }$ de medidas de RPE de dispersões de $10 \mathrm{mM}$ de $D M P G$ em água (pontos vermelhos) e em tampão (pontos azuis).

Figura 6.1.8: Comparação dos parâmetros ao e $S_{\text {ef }}$ para dispersões de $10 \mathrm{mM}$ de DMPG em água e em tampão baixa força iônica.

Figura 6.2.1: Típicos espectros de RPE para dispersões de $10 \mathrm{mM}$ de DMPG em água + 0,3 mol\% do marcador de spin 16-PCSL, não extrusadas (curvas da esquerda) e extrusadas (curvas da direita) em diferentes temperaturas.

Figura 6.2.2: Ilustração que representa o marcador de spin 16-PCSL incorporado à bicamada lipídica. 140

Figura 6.2.3: Espectros de RPE de dispersões de $10 \mathrm{mM}$ de DMPG em água com o marcador 16-PCSL extrusadas (curvas vermelhas) e não extrusadas (curvas azuis) em diferentes temperaturas: na fase gel $\left(5^{\circ} \mathrm{C}\right)$, na região de transição de fase $\left(20^{\circ} \mathrm{C}\right)$ e na fase fluida $\left(45^{\circ} \mathrm{C}\right)$.

Figura 6.2.4: Medidas de RPE de uma dispersão extrusada de $10 \mathrm{mM}$ de DMPG em água + 0,3 mol\% de 16-PCSL quando aumentamos a temperatura de 5 a $60^{\circ} \mathrm{C}$ (curvas em vermelho) e quando diminuímos a temperatura de 60 a $5^{\circ} \mathrm{C}$ (curvas em azul).

Figura 6.2.5: Razão entre as alturas do pico de campo baixo e central $\left(h_{+1} / h_{0}\right)$ de dispersões extrusadas $e$ não extrusadas de $10 \mathrm{mM}$ de DMPG em água. Cada curva é a média entre as medidas de duas amostras distintas, sendo a incerteza dada pelo desvio padrão dos resultados.

Figura 6.2.6: Razão entre as alturas do pico de campo alto e central (h-1/ho) e ao de dispersões extrusadas e não extrusadas de $10 \mathrm{mM}$ de DMPG em água para temperaturas a partir de $45^{\circ} \mathrm{C}$. Cada curva é a média entre as medidas de duas amostras distintas, sendo a incerteza dada pelo desvio padrão dos resultados.

Figura 6.2.7: Espectros de RPE de dispersões extrusadas de $10 \mathrm{mM}$ de DMPG com o marcador 16-PCSL em água (curvas vermelhas) e em tampão (curvas azuis) em diferentes temperaturas: na fase gel $\left(5^{\circ} \mathrm{C}\right)$, na região de transição de fase $\left(20^{\circ} \mathrm{C}\right)$ e na fase fluida $\left(45^{\circ} \mathrm{C}\right)$.

Figura 6.2.8: Razão entre as alturas do pico de campo baixo e central $\left(h_{+1} / h_{0}\right)$ de dispersões extrusadas de $10 \mathrm{mM}$ de DMPG com o marcador 16 - PCSL em água (pontos vermelhos) e em tampão (pontos azuis). Cada curva é a média entre as medidas de duas amostras distintas, sendo a incerteza dada pelo desvio padrão dos resultados.

Figura 6.2.9: Razão $h_{-1} / h_{0}$ e ao de dispersões extrusadas de $10 \mathrm{mM}$ de DMPG em água (temperaturas de 45 a $60^{\circ} \mathrm{C}$ ) e em tampão (temperaturas de 35 a $50^{\circ} \mathrm{C}$ ). Cada curva é a média entre as medidas de duas amostras distintas, sendo a incerteza dada pelo desvio padrão dos resultados.

Figura 6.3.1: Dado experimental e simulação da curva de RPE da dispersão extrusada de $10 \mathrm{mM}$ de $D M P G$ em água a $5^{\circ} \mathrm{C}$, considerando-se um único sinal de RPE.

Figura 6.3.2: Dado experimental e simulação dada pela soma dos sinais da população 1 e 2 da curva de $R P E$ da dispersão extrusada de $10 \mathrm{mM}$ de DMPG em água a $5^{\circ} \mathrm{C}$, considerando-se dois sinais de RPE, sendo a população 1 mais frouxa e a população 2 mais rígida.

Figura 6.3.3: Dados experimentais e ajustes obtidos pelas simulações teóricas de espectros de RPE de dispersões extrusadas de $10 \mathrm{mM}$ de DMPG + 0,3 mol\% de 16-PCSL em algumas temperaturas. 
Figura 6.3.4: Parâmetros obtidos das simulações dos espectros de RPE, sendo apresentados os resultados de 5 a $24^{\circ} \mathrm{C}$ e de 50 a $60^{\circ} \mathrm{C}$. A população 1 (प) representa o sinal mais frouxo e a população 2 (O) o sinal mais rígido. Em a) tempo de correlação rotacional, $\tau$, em b) porcentagem de cada população e em c) parâmetro de ordem, So.

Figura 7.1.1: Picos de WAXS em $q \sim 1,5 \AA^{-1}$ e ajustes por gaussianas de dispersões extrusadas de $50 \mathrm{mM}$ de DMPG em a) água e em b) tampão a baixa força iônica. As curvas a diferentes temperaturas foram deslocadas verticalmente para uma melhor visualização dos picos.

Figura 7.1.2: a) Posição e b) largura dos picos de WAXS para dispersões extrusadas de 50 mM de DMPG em água em tampão a baixa força iônica.

Figura 7.1.3: Picos de WAXS ajustados por gaussianas para uma dispersão extrusada de 50 mM de DMPG em tampão a baixa força iônica. As curvas a diferentes temperaturas foram deslocadas verticalmente para uma melhor visualização dos picos.

Figura 7.1.4: a) Posição e b) largura dos picos de WAXS para uma dispersão extrusada de $50 \mathrm{mM}$ de DMPG em tampão a baixa força iônica.

Figura 7.2.1: Curvas de SAXS normalizadas pela concentração lipídica para dispersões de DMPG em água nas concentrações de 1, 10 e $50 \mathrm{mM}$, antes (curvas continuas) e depois (curvas tracejadas) da extrusão (apenas a dispersão de $10 \mathrm{mM}$ foi extrusada). Os gráficos em destaque representam a região de muito baixo $q$, em escala linear e logarítmica.

Figura 7.2.2: Curvas de SAXS normalizadas pela concentração lipídica para dispersões de DMPG em tampão HEPES, nas concentrações de 1, 10, 20 e 50 mM, antes (curvas continuas) e depois (curvas tracejadas) da extrusão. Os gráficos em destaque representam a região de muito baixo q, em escala linear e logarítmica.

Figura 7.2.3: Exemplos de ajustes obtidos com o programa GAP na região de baixo ângulo de uma curva de SAXS (gráfico da esquerda) de uma dispersão de $10 \mathrm{mM}$ de DMPG em água, medida no LNLS, e de uma curva de SWAXS (gráfico da direita) de uma dispersão de $50 \mathrm{mM}$ de DMPG em tampão a baixa força iônica, medida no aparelho SAXSpace, ambas a $23^{\circ} \mathrm{C}$.

Figura 7.2.4: Perfil de densidade eletrônica de uma dispersão extrusada de 10 mM de DMPG em água em diferentes temperaturas.

Figura 7.2.5: Variação da espessura das bicamadas $\left(d_{B}\right)$ com a temperatura para dispersões extrusadas e não extrusadas de $10 \mathrm{mM}$ de DMPG em água.

Figura 7.2.6: Perfil de densidade eletrônica de uma dispersão extrusada de 10 mM de DMPG em tampão a baixa força iônica em diferentes temperaturas.

Figura 7.2.7: Espessura das bicamadas $\left(d_{B}\right)$ de dispersões extrusadas de $10 \mathrm{mM}$ de DMPG em água e em tampão a baixa força iônica.

Figura 7.2.8: Espessura das bicamadas $\left(d_{B}\right)$ de dispersões extrusadas de $50 \mathrm{mM}$ de DMPG em água e em tampão a baixa força iônica.

Figura 7.2.9: Curvas de SAXS de dispersões extrusadas de DMPG em água em diferentes concentrações lipídicas: a) $10 \mathrm{mM}$ e b) $50 \mathrm{mM}$. A região de muito baixo q é apresentada em destaque, para a melhor visualização dos picos, em escala linear e logarítmica.

Figura 7.2.10: Picos de Bragg de dispersões extrusadas (linhas sólidas) e não extrusadas (linhas tracejadas) de dispersões de $10 \mathrm{mM}$ de DMPG em água. 
Figura 7.2.11: Medidas de SAXS de dispersões extrusadas de $30 \mathrm{mM}$ de DMPG em água medidas com a máxima distância amostra-detector possível no LNLS. A região de muito baixo q é apresentada em destaque, para a melhor visualização dos picos, em escala linear e logarítmica.

Figura 7.2.12: Posição dos picos de Bragg $\left(q_{P}\right)$ e distâncias de repetição (d) calculadas para dispersões extrusadas de 10, 30 e 50 mM de DMPG em água.

Figura 7.2.13: Curvas de SAXS de dispersões de $50 \mathrm{mM}$ de DMPG em tampão a) depois da extrusão e b) sem extrusar. A região de muito baixo qé apresentada em destaque, para a melhor visualização dos picos, em escala linear e logarítmica......

Figura 7.2.14: Posição dos picos de Bragg $\left(q_{P}\right)$ e distâncias de repetição $(d)$ calculadas para dispersões extrusadas e não extrusadas de 50 mM de DMPG em tampão.

Figura 7.2.15: Diferentes medidas de SAXS do tampão HEPES, usando-se as mesmas configurações e a $23^{\circ} \mathrm{C}$, realizadas no SAXSpace. Em destaque é apresentada a região de muito baixo q em escala linear e logarítmica.

Figura 7.2.16: Medidas de SAXS para dispersões extrusada de 10, 20, 30, 40, 50 e 60 mM de DMPG em tampão a baixa força iônica a $23^{\circ} \mathrm{C}$, com tempo de exposição para cada curva de 30 minutos. 173

Figura 7.2.17: Posição dos picos e distância de repetição calculadas a partir dos picos a baixo q da figura 7.2.16.

Figura 7.2.18: Esquematização do modelo em que cada vesícula ocupa um mesmo volume $\left(D^{3}\right)$, sendo $D$ a distância entre os centros de vesículas vizinhas e $\mathrm{x}$ a distância entre suas bicamadas. $R$ é o raio da vesícula e d é a espessura da bicamada.

Figura 7.2.19: Cálculos das distâncias entre bicamadas de vesículas vizinhas (distância x da figura 7.2.18) para diferentes concentrações lipídicas. Os pontos coloridos indicam as distâncias de correlação da figura 7.2.17.

Figura 7.2.20: Cálculos das distâncias entre os centros de vesículas vizinhas (distância D da figura 7.2.18) para diferentes concentrações lipídicas. Os pontos coloridos indicam as distâncias de correlação da figura 7.2.17.

Figura 8.1: Resultados de DSC, incremento da viscosidade relativa $\left(\eta_{i}\right)$, condutividade reduzida $\left(\sigma_{\text {red }}\right)$ e turbidez de dispersões não extrusadas de 10 mM de DMPG em tampão HEPES a alta força iônica (250 mM de NaCl). (Resultados obtidos em Barroso, 2010).

Figura 8.2: Sobreposição dos resultados de DSC, incremento da viscosidade relativa $\left(\eta_{i}\right)$, condutividade reduzida $\left(\sigma_{\text {red }}\right)$, turbidez, mobilidade elefrorética corrigida $\left(\mu_{\text {corr }}\right)$ e raio efetivo $\left(R_{\text {ef }}\right)$ calculado por $D L S$, espessura da bicamada $\left(d_{B}\right)$, posição do pico de WAXS $\left(q_{c}\right)$, distância de repetição dos picos de SAXS na região de muito baixo $q(d)$ e $h_{+1} / h_{0}$ de dispersões extrusadas de $10 \mathrm{mM}$ (1 mM para a medida de $R_{e f ;} e$ $50 \mathrm{mM}$ para $q_{c}$ e d) de DMPG em tampão a baixa força iônica.

Figura 8.3: Modelo de vesículas com deformações na bicamada. [fonte: Enoki, 2010].

Figura 8.4: Sobreposição dos resultados de DSC, incremento da viscosidade relativa $\left(\eta_{i}\right)$, condutividade reduzida $\left(\sigma_{\text {red }}\right)$, turbidez, mobilidade elefrorética corrigida $\left(\mu_{\text {corr }}\right)$ e raio efetivo $\left(R_{e f}\right)$ calculado por $D L S$, espessura da bicamada $\left(d_{B}\right)$, posição do pico de WAXS $\left(q_{c}\right)$, distância de repetição dos picos de SAXS na região de muito baixo $q(d)$ e $h_{+1} / h_{0}$ de dispersões extrusadas de 10 mM (1 mM para a medida de $R_{e f} e$ $50 \mathrm{mM}$ para $q_{c}$ e d) de DMPG em água.

Figura 8.5: a) Deformações observadas por microscopia de fluorescência de vesículas de DPPC em água marcadas com 0,09 mol\% de NBD-PE [Figura 1 de Selinger et al., 2013]. b) Representação de uma bicamada na fase ripple [fonte: Barroso, 2010]. 



\section{Sumário}

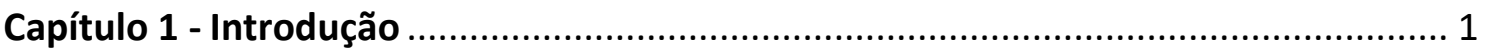

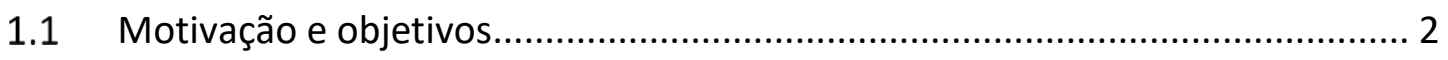

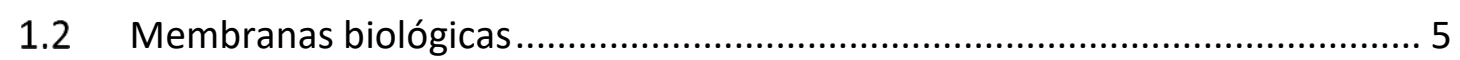

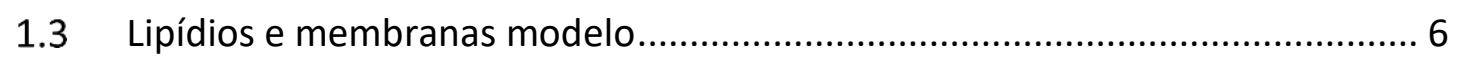

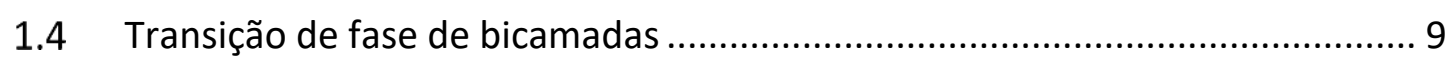

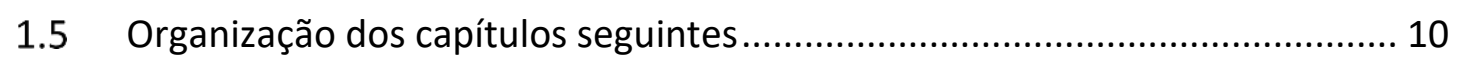

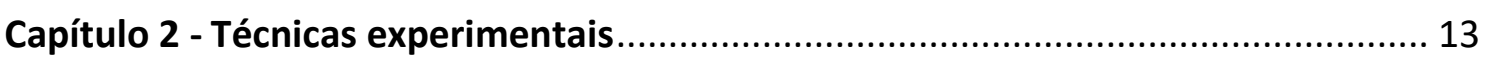

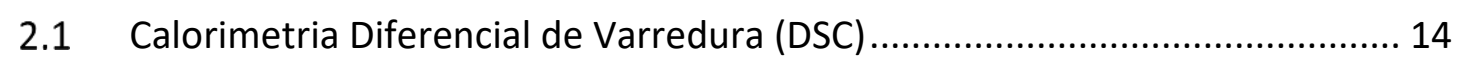

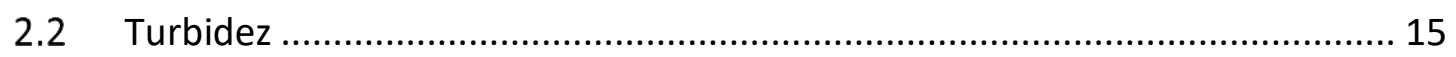

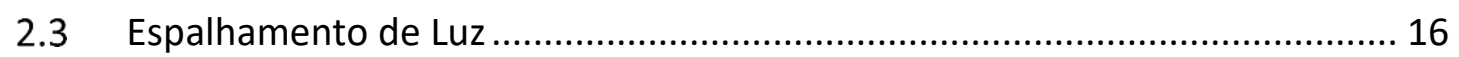

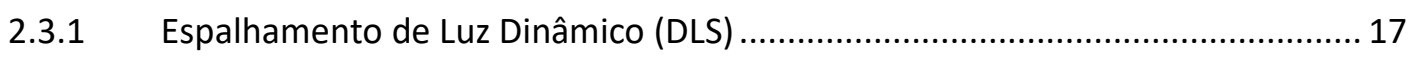

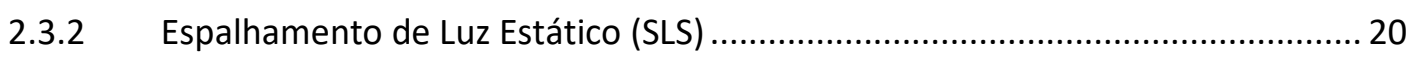

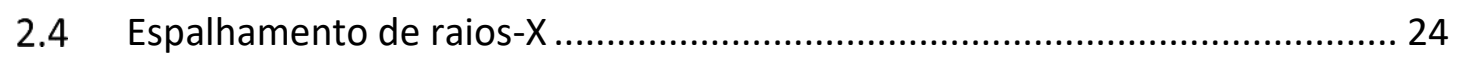

2.5 Ressonância paramagnética eletrônica (RPE) ............................................... 28

2.6 Condutividade elétrica e mobilidade eletroforética ....................................... 34

2.7 Cálculos das distâncias entre vesículas e fração volume................................. 36

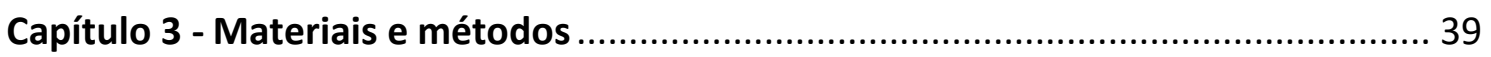

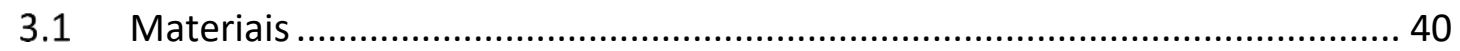

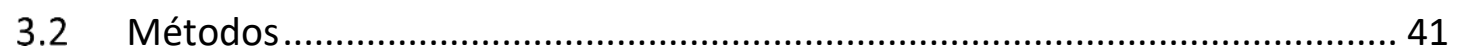

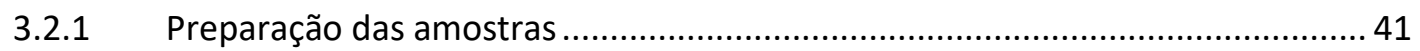

3.2.2 Medidas de Calorimetria Diferencial de Varredura (DSC) ................................ 44

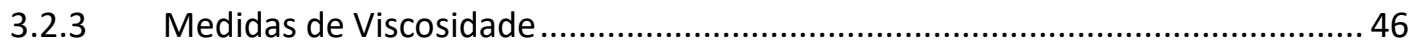

3.2.4 Medidas de Condutividade Elétrica ................................................................. 47

3.2.5 Medidas de Absorbância (Turbidez) ................................................................ 48

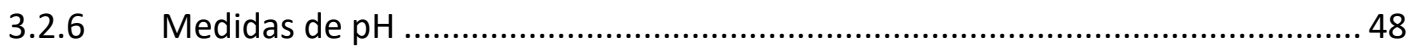

3.2.7 Medidas de Mobilidade eletroforética ............................................................ 49

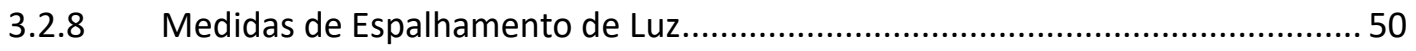

3.2.9 Medidas de Ressonância Paramagnética Eletrônica (RPE) de marcadores de spin 54

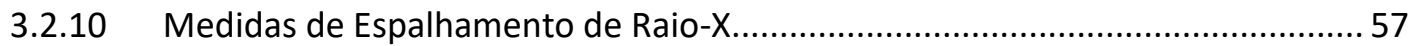

Capítulo 4 - Resultados e discussões: algumas técnicas utilizadas em dispersões de DMPG em água ....

4.1 Calorimetria Diferencial de Varredura (DSC) .............................................. 62

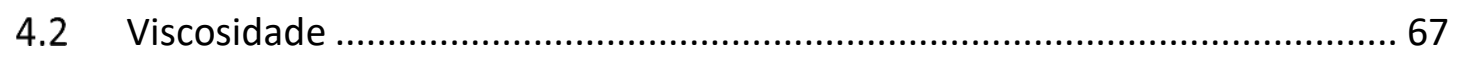




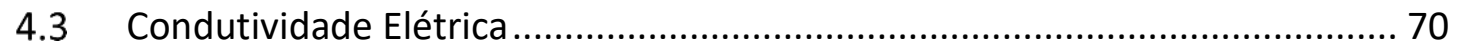

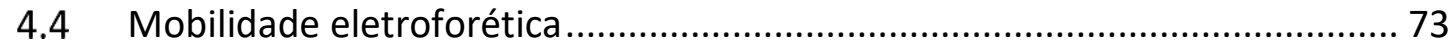

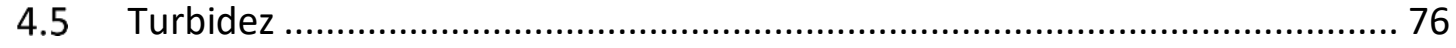

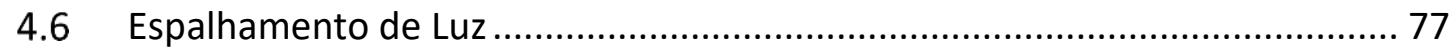

4.6.1 Espalhamento de Luz Dinâmico (DLS) …………................................................ 77

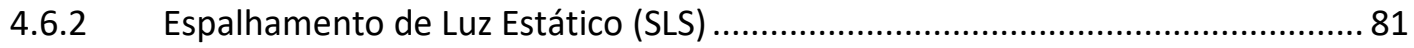

4.6.3 Medidas da razão de despolarização da luz espalhada $\left(\mathrm{l}_{\mathrm{vH}} / \mathrm{llv}_{\mathrm{vv}}\right)$........................... 85

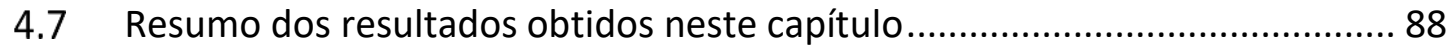

Capítulo 5 - Resultados e discussões: dispersões de DMPG em tampão comparadas

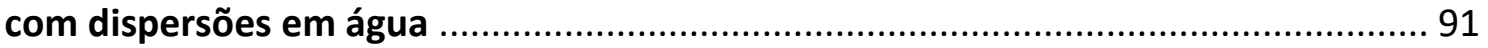

5.1 Calorimetria Diferencial de Varredura (DSC) ............................................... 92

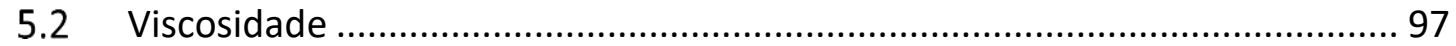

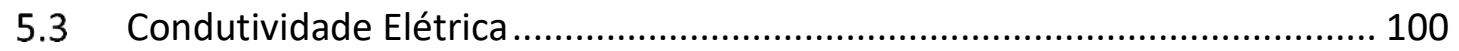

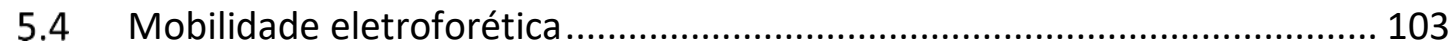

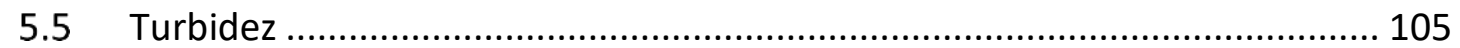

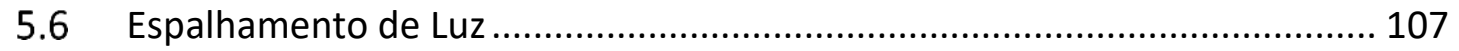

5.6.1 Espalhamento de Luz Dinâmico (DLS) …….................................................... 107

5.6.2 Espalhamento de Luz Estático (SLS) .......................................................... 111

5.6.3 Medidas da razão de despolarização da luz espalhada $\left(I_{\mathrm{vH}} / \mathrm{I}_{\mathrm{vv}}\right)$......................... 113

5.7 Resumo dos resultados obtidos com dispersões de $10 \mathrm{mM}$ de DMPG em

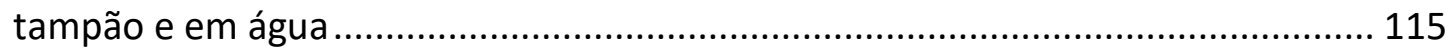

5.8 Resultados de dispersões extrusadas de $50 \mathrm{mM}$ de DMPG em tampão HEPES 118

5.8.1 Calorimetria Diferencial de Varredura (DSC) ............................................... 118

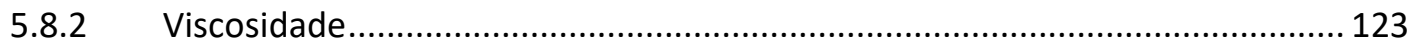

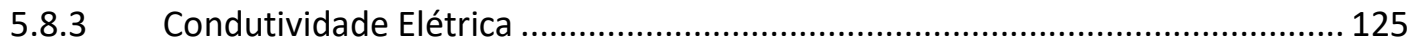

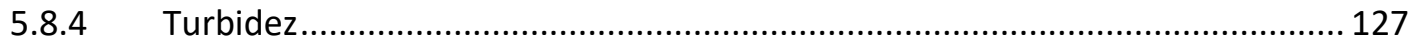

5.8.5 Resumo dos resultados obtidos para dispersões de $50 \mathrm{mM}$ de DMPG ............. 128

Capítulo 6 - Resultados e discussões: Ressonância Paramagnética Eletrônica (RPE) de

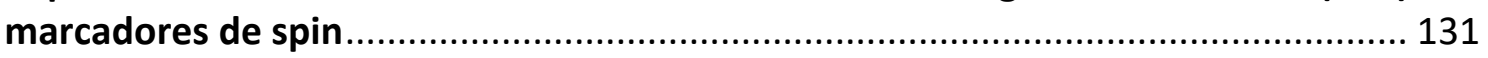

6.1 Dispersões de DMPG com o marcador de spin 5-PCSL ............................... 132

6.2 Dispersões de DMPG com o marcador de spin 16-PCSL .............................. 139

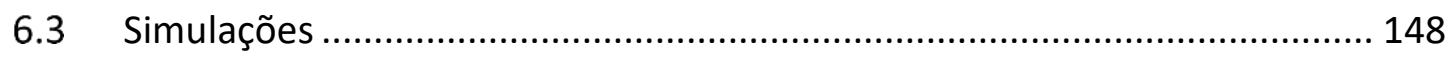

Capítulo 7 - Resultados e discussões: Espalhamento de raios-X a alto (WAXS) e a

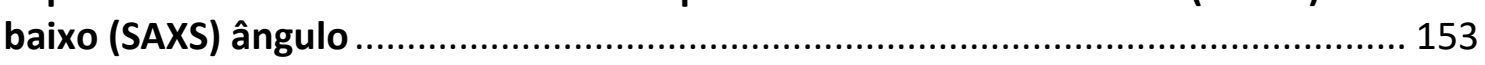

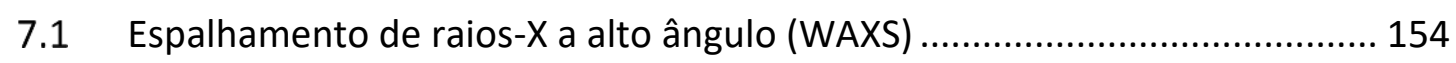

7.2 Espalhamento de raios-X a baixo ângulo (SAXS) ...................................... 157 
7.2.1 Espalhamento na região de baixo q ....................................................... 161

7.2.2 Espalhamento na região de muito baixo q............................................. 165

7.3 Medidas de curvatura espontânea do DMPG .................................. 177

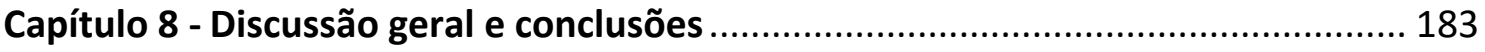

Apêndice A - Medidas de espalhamento de luz de nanoesferas de poliestireno ..... 199

A.1 DLS de dispersões de nanoesferas de poliestireno.................................. 200

A.2 SLS de dispersões de nanoesferas de poliestireno .................................... 205

Apêndice B - Medidas de DLS com diferentes concentrações lipídicas ................... 209

Apêndice C - Simulações de SAXS na região de muito baixo q ............................ 217

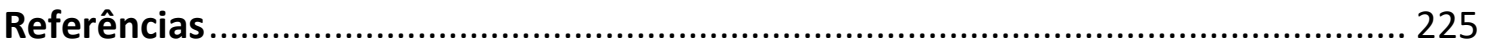





\section{Capítulo 1 - Introdução}

Neste capítulo de introdução descrevemos as motivações e objetivos do trabalho, situando o problema abordado e sua relevância dentro da área de Biofísica Molecular. 


\subsection{Motivação e objetivos}

Sob condições fisiológicas, muitas membranas celulares são negativamente carregadas, devido à presença de lipídios com cabeças polares aniônicas. O fosfatidil glicerol (PG) é o mais abundante fosfolipídio aniônico encontrado nas membranas celulares procarióticas, e tem sido muito estudado e utilizado como modelo para membranas biológicas, ou regiões de membranas, negativamente carregadas.

Em condições fisiológicas (força iônica 150 mM e pH 7,4), o DMPG apresenta uma transição de fase gel-fluido altamente cooperativa, em torno de $23{ }^{\circ} \mathrm{C}$. Nestas condições, seu comportamento é análogo ao de dimiristoil fosfatidilcolina (DMPC), cuja cabeça polar é zwiteriônica (apresenta cargas positiva e negativa). No entanto, a baixa força iônica ( $6 \mathrm{mM}$ ), o DMPG exibe um comportamento termo-estrutural distinto e muito interessante (Alakoskela e Kinnunen, 2007; Heimburg e Biltonen, 1994; LamyFreund e Riske, 2003; Riske et al., 1997,1999, 2001, 2004; Salonen et al., 1989; Schneider et al., 1999; Barroso et al., 2010, Enoki et al., 2012), apresentando uma "região de transição de fase", entre as fases gel e fluida, aproximadamente entre $18\left(\mathrm{Tm}^{\mathrm{on}}\right)$ e $35^{\circ} \mathrm{C}$ $\left(T_{m}{ }^{\text {off }}\right)$. No perfil de Calorimetria Diferencial de Varredura (DSC) aparece um pico estreito de absorção de calor em $\mathrm{T}_{\mathrm{m}}{ }^{\text {nn }}$, seguido por outros mais largos, sendo o último em $\mathrm{T}_{\mathrm{m}}{ }^{\text {off }}$ (Salonen et al., 1989; Heimburg e Biltonen, 1994; Riske et al., 1997; 1999). Marcadores de spin e fluorescentes, incorporados à bicamada lipídica, mostraram uma mudança contínua no empacotamento da membrana nesta região de transição (Riske et al., 2001; Lamy-Freund e Riske, 2003), sendo que com alguns marcadores de spin, é possível observar, nitidamente, a existência de uma queda mais acentuada no empacotamento da bicamada no início da transição, em $\mathrm{T}_{\mathrm{m}}{ }^{\text {on }}$. A região de transição é também caracterizada por baixa turbidez, sendo que a dispersão de DMPG é visualmente transparente nesta região (Heimburg e Biltonen, 1994; Riske et al., 1997) e por alta viscosidade e alta condutividade (Heimburg e Biltonen, 1994; Riske et al., 1997; Barroso et al., 2010). Além do baixo espalhamento de luz, apresenta um baixo espalhamento de raios-X a baixo ângulo (SAXS) (Riske et al., 2004), técnica que também permitiu detectar a presença de um pico (não muito estreito) de interferência a muito baixo ângulo, correspondendo a uma distância de repetição da ordem de $400 \AA$ (Riske et al., 2009a). 
Medidas de RPE mostraram que não há fusão dos agregados de DMPG ao longo da transição de fase (Lamy-Freund e Riske, 2003).

Algumas outras características importantes são também observadas na "região de transição". Espectros de ressonância paramagnética eletrônica (RPE) de marcadores de spin, com o marcador 16-PCSL que monitora a região do centro da bicamada, indicaram a presença de dois sinais de RPE, sugerindo a coexistência de dois domínios com microviscosidades diferentes: um deles típico de bicamada, e outro altamente fluido e hidratado, semelhante a anfifílicos em micelas, possivelmente em sítios de alta curvatura (Riske et al., 2003). Para temperaturas acima de $T_{m}{ }^{\text {fff }}$, a bicamada reorganizase em uma fase fluida convencional. A observação de vesículas gigantes de DMPG, em baixa força iônica, indica seu "desaparecimento" quando a amostra é esfriada, saindo da fase fluida e entrando na região de transição. Entretanto, a vesícula não se desfaz, pois ela reaparece na mesma posição, quando a temperatura da amostra é aumentada, acima de $T_{m}{ }^{\text {off }}$, voltando à fase fluida (Riske et al., 2004). Essa observação levou à sugestão de que a baixa turbidez poderia estar relacionada à perda de contraste óptico da bicamada com o meio.

As propriedades da região de transição discutidas acima levaram a propostas de diferentes modelos para os agregados de DMPG em baixa força iônica. Em um deles, qualitativo, foi sugerida a possibilidade de "membranas perfuradas" para a região de transição do DMPG em baixa força iônica (Riske et al., 2009a), capazes de explicar as propriedades ópticas, resultados de RPE de marcadores de spin, e o pico de SAXS na região de muito baixo ângulo. Neste modelo, foi proposto que os picos de SAXS estariam relacionados à distância entre poros da bicamada, sendo realizadas simulações das curvas de SAXS e propostos modelos teóricos para esta proposta (Spinozzi et al., 2010; Amaral e Spinozzi, 2016).

Em outra proposta (Riske et al., 1997), considerando os dados de espalhamento de luz e viscosidade, foi proposto a existência de pequenas vesículas de DMPG agregadas nas fases gel e fluida, que desagregariam na região de transição, ideia que foi desenvolvida posteriormente em um modelo estatístico (Goldman, 2001; Goldman et al., 1999). As propriedades elétricas dos sistemas também foram abordadas em Nunes 
et al., 2009. No entanto, nenhum dos modelos é capaz de explicar o conjunto de resultados experimentais existente.

Todo o estudo experimental discutido acima foi feito para DMPG a baixa força iônica, mas em tampão, portanto para valores de forção iônica entre 4 e 10 mM. Entretanto, existem trabalhos na literatura feitos com DMPG em água pura, onde dados de microscopia eletrônica indicaram a presença de fragmentos de bicamada, bicelas (Epand, Hui, 1986), ou de fases bidimensionais tipo esponja (Gershfeld et al., 1986; Koshinuma et al, 1999). Estudos preliminares, feitos pelo nosso Grupo de Biofísica, mostraram que, de fato, DMPG em água apresenta um comportamento diferente de DMPG em tampão a baixa força iônica (Riske, K.A., 2001). Portanto, neste trabalho iremos focar em dispersões de DMPG em muito baixa força iônica, isto é, em água pura. Com isso, pretende-se enfatizar as interações eletrostáticas entre as cabeças polares dos lipídios, que não estarão blindadas pela presença de sais, e monitorar, por diversas técnicas, os agregados presentes na dispersão, e suas interações.

Realizamos experimentos com as técnicas de espalhamento de luz, tanto estático (SLS) como dinâmico (DLS), para monitorar o tamanho dos agregados e suas interações, de calorimetria diferencial de varredura (DSC) para observar as possíveis transições de fase das membranas lipídicas, de Ressonância Paramagnética Eletrônica (RPE) de marcadores de spin incorporados aos agregados, que possibilita o estudo da estrutura dos agregados em escala molecular e de espalhamento de raios- $X$ a altos e baixos ângulos (WAXS e SAXS), para obter informações quanto à forma e possíveis interações entre os agregados. Também realizamos medidas de viscosidade, condutividade elétrica e mobilidade eletroforética para monitorar o comportamento térmico destas grandezas.

O estudo com as dispersões de DMPG em água foi realizado para dispersões extrusadas e não extrusadas, portanto mais e menos polidispersas. Nos trabalhos anteriores, a extrusão das dispersões de DMPG em tampão a baixa força iônica só foi realizada em Enoki et al., 2012, para medidas de espalhamento de luz. Como o processo de extrusão diminui a polidispersidade das dispersões, resultando em agregados de tamanhos mais homogêneos, realizamos medidas com as diversas técnicas experimentais de dispersões extrusadas de DMPG em tampão a baixa força iônica e 
comparamos estes resultados com os de dispersões em tampão não extrusadas (Barroso, 2010) e também com os resultados obtidos para as dispersões em água.

\subsection{Membranas biológicas}

As membranas biológicas funcionam como uma barreira semipermeável entre os meios intra e extra-celular, sendo essenciais para a organização das células e, consequentemente, para a manutenção da vida. Um modelo para a estrutura das membranas biológicas muito conhecido é o modelo de "mosaico fluido", que foi proposto por Singer e Nicholson, em 1972. Neste modelo as membranas são constituídas basicamente por lipídios e proteínas, sendo que os lipídios se organizam na forma de uma bicamada fluida onde as proteínas inserem-se total ou parcialmente, sendo que estas podem se difundir lateralmente na matriz lipídica (ver figura 1.2.1).

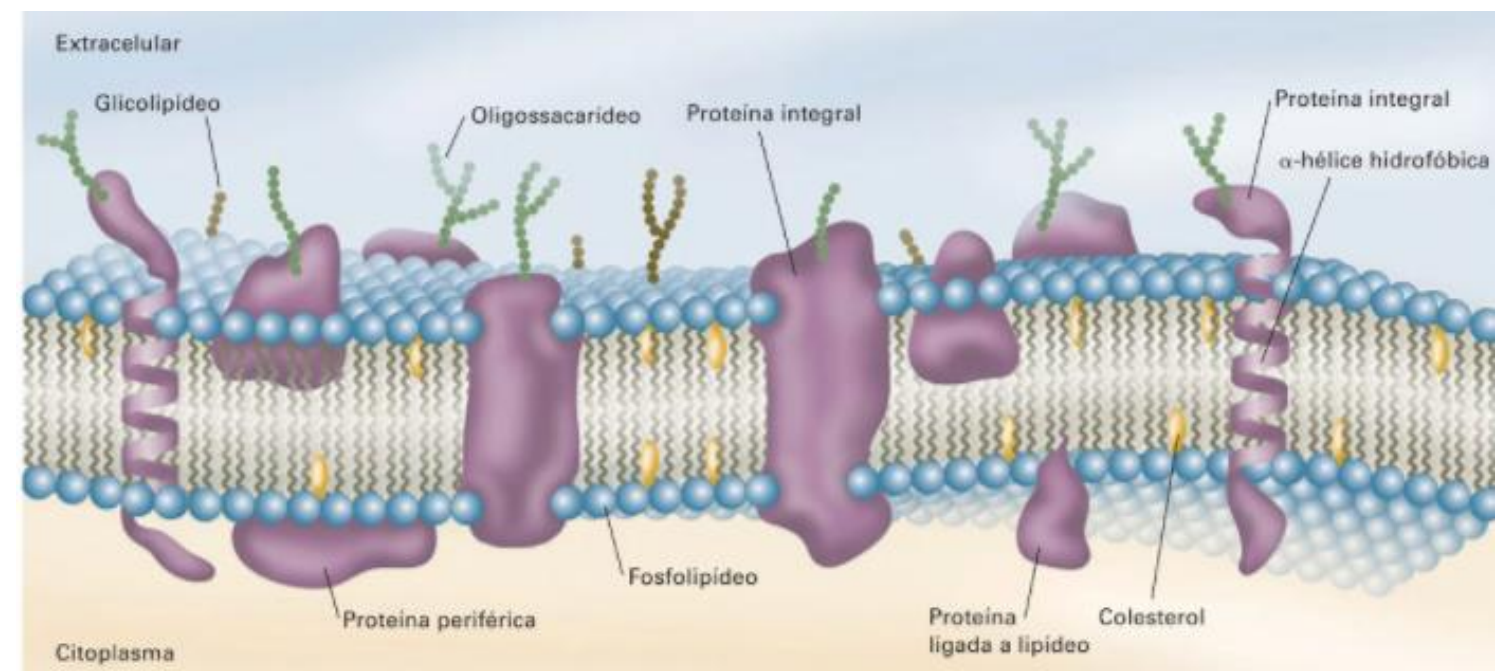

Figura 1.2.1: Representação da membrana plasmática baseada no modelo de "mosaico fluido". [Fonte: figura 9-25 de Voet \& Voet, 2014]

Alguns ajustes e correções para este modelo foram propostos, como por exemplo em Engelman, 2005 é proposto que a membrana é formada por um grande número de proteínas, que causam perturbações na bicamada lipídica de modo que sua espessura varie consideravelmente (figura 1.2.2) 


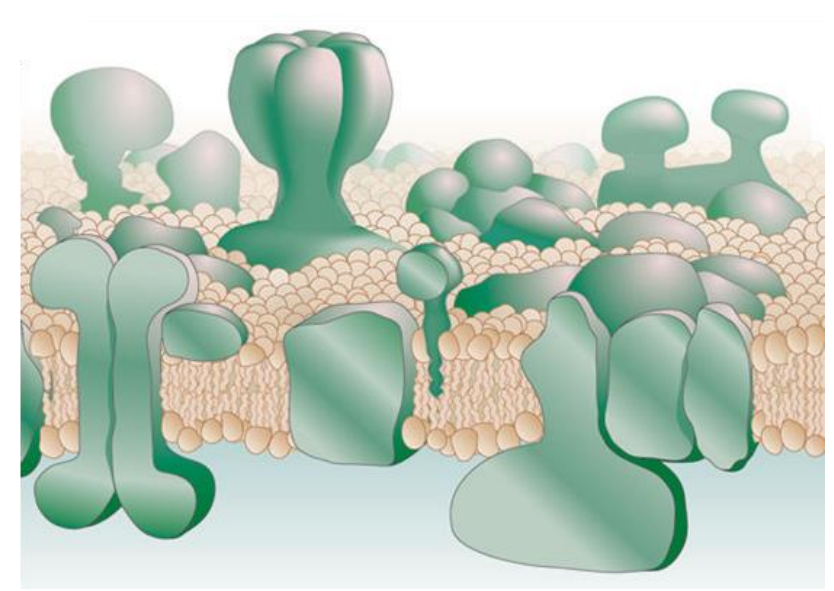

Figura 1.2.2: Proposta atualizada do modelo mosaico fluido, com maior quantidade de proteínas e espessura da bicamada lipídica variável. [Fonte: Engelman, 2005]

Dada a grande complexidade e especificidade das membranas celulares, que apresentam diferentes composições lipídicas e proteicas, é comum que se realize estudos com sistemas miméticos de membrana, sendo que o modelo mais simples de uma membrana biológica é uma bicamada lipídica que forma vesícula (lipossomo).

\subsection{Lipídios e membranas modelo}

Lipídios são biomoléculas que se caracterizam por desempenharem diversas funções no organismo e por serem insolúveis em água, porém solúveis em compostos orgânicos, como álcool, clorofórmio, acetona, entre outros (Voet-Voet, 2008). Aqui estamos interessados nos lipídios que compõem as membranas celulares. Esses lipídios possuem uma cabeça polar hidrofílica e uma ou mais cadeias hidrocarbônicas hidrofóbicas. O fato de apresentarem uma região hidrofóbica e outra hidrofílica confere a essas moléculas o caráter anfifílico.

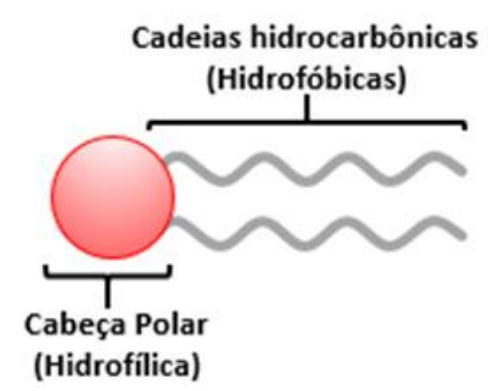

Figura 1.3.1: Os lipídios apresentam uma cabeça polar hidrofílica e uma ou mais cadeias hidrocarbônicas hidrofóbicas. 
Em geral, as cabeças polares dos lipídios apresentam cargas elétricas, que, em pH neutro, podem classificar os lipídios em catiônicos, quando apresentam carga positiva, aniônico, quando apresentam carga negativa ou zwitteriônicos, quando apresentam carga positiva e negativa, que os tornam neutros.

Ao se dispersarem em solução aquosa, os lipídios formam estruturas que minimizam o contato de sua parte hidrofóbica com as moléculas de água, fenômeno conhecido como efeito hidrofóbico. Diferentes estruturas podem ser formadas, dependendo principalmente da forma geométrica do lipídio, isto é, da relação entre a seção transversal da cabeça polar e das cadeias laterais. Enquanto lipídios com duas cadeias hidrocarbônicas, de geometria cilíndrica, apresentam a tendência em formar bicamadas lipídicas, que podem se fechar formando vesículas, detergentes, com apenas uma cauda hidrocarbônica, formam estruturas com grande curvatura, como as micelas. No caso de lipídios com as cabeças polares pequenas quando comparadas às áreas das caudas, como o DOPE que foi utilizado neste trabalho, tendem a formam fases hexagonais inversas. 

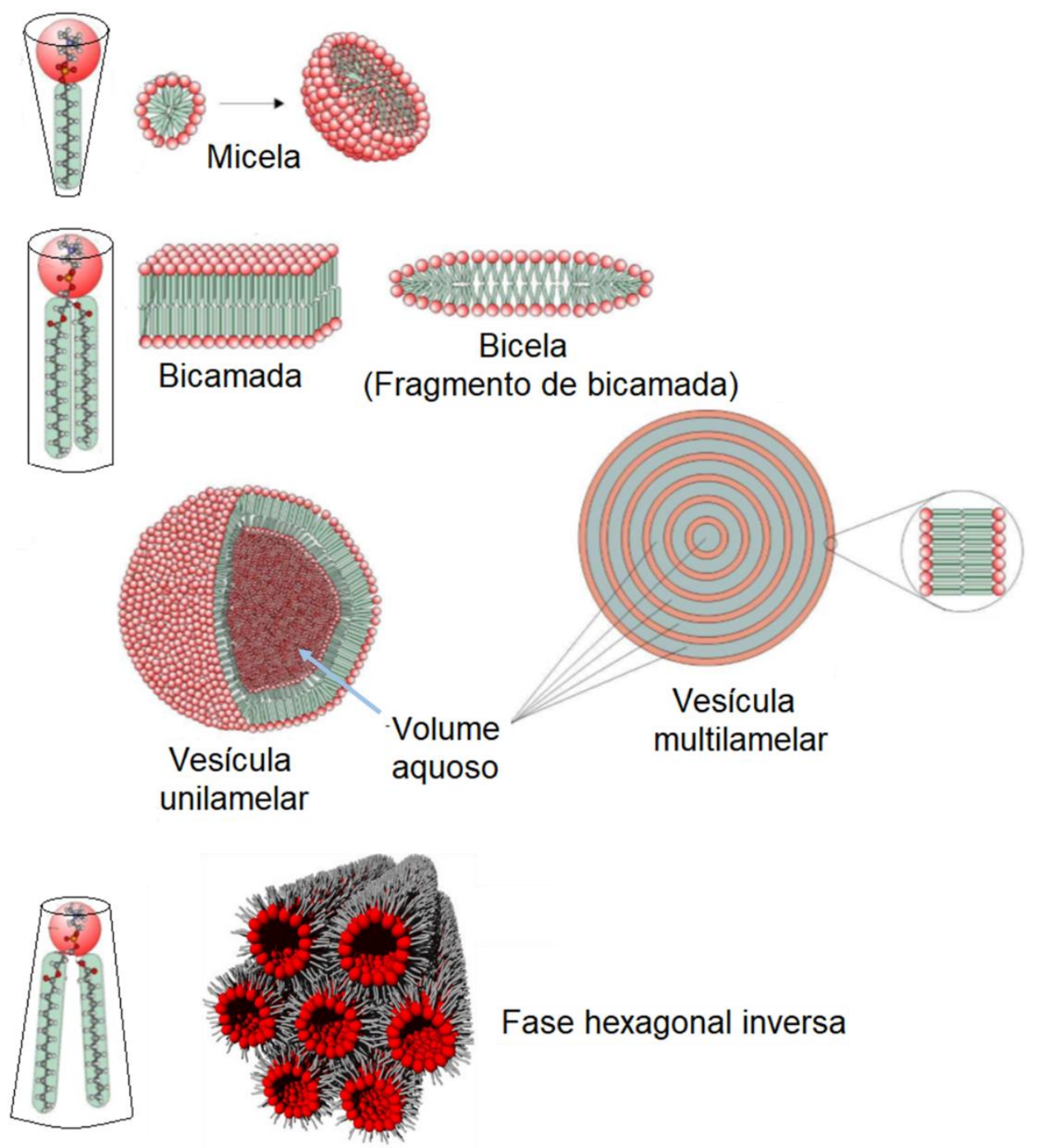

Fase hexagonal inversa

Figura 1.3.2: Exemplos de estruturas típicas formadas por lipídios em meio aquoso de acordo com sua geometria. [Figura adaptada de Barroso, 2010 e Tresset, 2009].

Nesta tese iremos trabalhar com membranas modelo formadas pelo lipídio DMPG. O DMPG é um fosfolipídio aniônico, saturado, com 14 carbonos em cada uma das duas cadeias hidrocarbônicas e com um grupo fosfato ligado a um grupo glicerol em sua cabeça polar (figura 1.3.3).
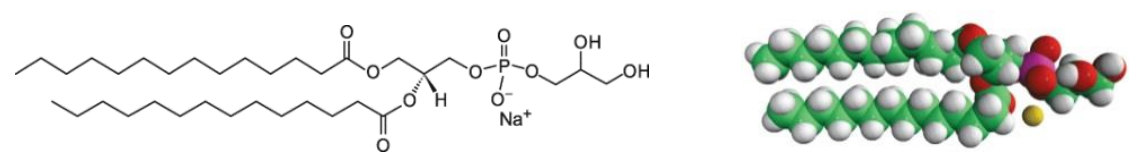

Figura 1.3.3: Estrutura molecular do DMPG. 
A molécula de DMPG, por sua forma geométrica cilíndrica, tende a formar bicamadas lipídicas, que se fecham em vesículas unilamelares, onde as cabeças polares ficam voltadas para meios aquosos enquanto as caudas hidrofóbicas estão voltadas umas para outras, no centro das duas superfícies.

Membranas modelo de DMPG são muito utilizadas nos estudos de interações de peptídeos com bicamadas lipídicas negativamente carregadas. Além disto, dispersões lipídicas de DMPG em baixa força iônica apresentam propriedades termo-estruturais bastante peculiares durante a chamada "região de transição de fase", conforme descrito na seção 1.1 desta tese, tratando-se de um sistema extremamente interessante e intrigante do ponto de vista físico-químico. Recentemente, em Shahine et al., 2017 foi mostrada atividade biológica do grupo PG, que é reconhecido por receptores de célula T e desempenhando um importante papel na resposta imunológica, sendo mais um exemplo da importância e relevância do estudo e caracterização deste fosfolipídio.

\subsection{Transição de fase de bicamadas}

Bicamadas lipídicas puras, saturadas, apresentam uma transição de fase característica, onde as cadeias hidrocarbônicas transicionam de uma fase com alto grau de empacotamento (fase gel) para uma fase fluida, onde as cadeias hidrocarbônicas têm mais liberdade (ver, por ex., Heimburg, 2007).
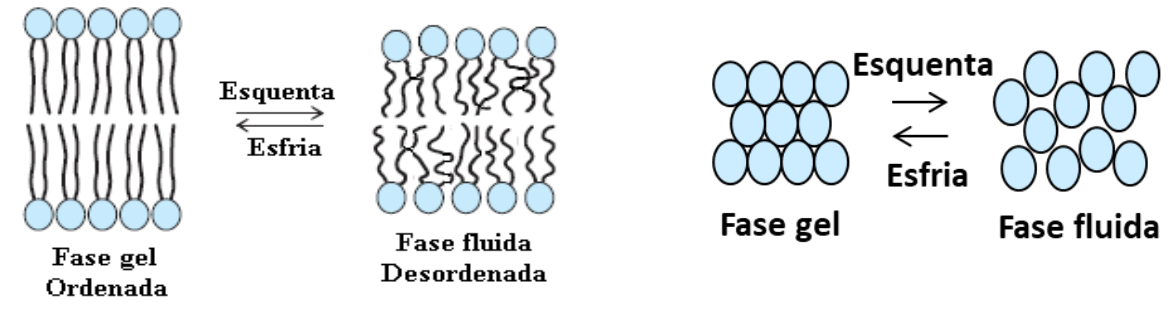

Figura 1.4.1: Configurações da bicamada lipídica na transição gel-fluida. [Figura adaptada de Voet, D.; Voet, J.G. (2008)]

$\mathrm{Na}$ fase gel quase todas as cadeias hidrocarbônicas se encontram na configuração all-trans, sendo esta a configuração de menor energia, onde as interações de van der Waals fazem com que as cadeias fiquem mais próximas e muito mais organizadas, ocupando uma área pequena. Como as cadeias estão estendidas ao máximo, a espessura da bicamada é maior na fase gel do que na fase fluida. Já na fase 
fluida, as cadeias hidrocarbônicas apresentam dobras gauche, diminuindo a espessura da bicamada e aumentando a área ocupada pelos lipídios. Nesta configuração, diminuise drasticamente o empacotamento da bicamada, conferindo maior liberdade de movimento e desordem às cadeias.

A temperatura em que ocorre a transição de fase $\left(T_{m}\right)$ depende das interações entre as cadeias hidrocarbônicas e entre as cabeças polares. Quanto maior o comprimento das cadeias, maior é a temperatura de transição. A presença de duplas ligações nas cadeias também altera $\mathrm{T}_{\mathrm{m}}$. No caso de lipídios carregados, condições externas que influenciam as interações eletrostáticas entre cabeças polares vizinhas também alteram a transição de fase da bicamada.

Um pico estreito e intenso nas curvas de calorimetria caracteriza a temperatura de transição de fase, sendo que um pico de calor específico intenso e estreito indica uma transição de fase altamente cooperativa. No caso de bicamadas formadas por uma mistura de lipídios, perde-se a cooperatividade da transição devida à diferença na temperatura de transição dos diferentes lipídios, sendo difícil determinar $T_{m}$ neste caso. A cooperatividade também diminui quando se aumenta a curvatura da bicamada, pois as interações entre os lipídios são diferentes nas monocamadas interna e externa da membrana, já que podem ter curvaturas significativamente diferentes, diminuindo a cooperatividade da transição. No caso de vesículas grandes, as membranas são praticamente planas e a probabilidade de se encontrar lipídios na fase fluida é a mesma nas monocamadas externa e interna, sendo alta a cooperatividade da transição (Heimburg, 2007).

\subsection{Organização dos capítulos seguintes}

Dado o grande número de técnicas experimentais utilizadas e de resultados obtidos, esta tese foi dividida em 8 capítulos. No capítulo 2 são apresentadas, de forma breve e resumida, as principais técnicas experimentais utilizadas nesta tese. O capítulo 3 é composto pela lista de materiais utilizados, o modo de preparação das amostras e a descrição dos equipamentos e dos métodos experimentais utilizados.

Os resultados e discussões são apresentados nos capítulos de 4 a 7, sendo que no capítulo 4 são apresentados os resultados e discussões obtidos com algumas das 
técnicas experimentais (DSC, medidas de viscosidade, condutividade elétrica, mobilidade eletroforética e turbidez), antes e depois da extrusão, e medidas de SLS e DLS (seção 4.6) para dispersões extrusadas de DMPG em água pura.

No capítulo 5 apresentamos os resultados e discussões de dispersões extrusadas de DMPG em tampão a baixa força iônica, utilizando-se as mesmas técnicas experimentais do capítulo 4. Comparou-se os resultados obtidos com os resultados de dispersões não extrusadas (obtidos em Barroso, 2010) e com os resultados obtidos no capítulo 4 para as dispersões de DMPG em água.

O capítulo 6 apresenta os resultados e discussões obtidos por RPE para dispersões extrusadas e não extrusadas de $10 \mathrm{mM}$ de DMPG em água com os marcadores 5-PCSL (seção 6.1), que monitora a região próxima às cabeças polares, e 16PCSL (seção 6.2), que monitora o centro da bicamada. Os resultados foram comparados com resultados obtidos para dispersões de DMPG em tampão a baixa força iônica. Para as dispersões extrusadas de DMPG em água com o marcador 16-PCSL, foram realizadas simulações teóricas em algumas temperaturas (seção 6.3).

O capítulo 7 é dedicado aos resultados e discussões de medidas de SAXS e WAXS de dispersões de DMPG em água e em tampão a baixa força iônica. Os resultados de SAXS foram divididos em 2 seções: espalhamento na região de baixo q (seção 7.2.1), de onde obteve-se informações da bicamada lipídica e espalhamento na região de muito baixo q (seção 7.2.2), onde o pico de Bragg foi observado. Na seção 7.3 apresentamos medidas da curvatura espontânea do DMPG em meios de diferente força iônica: água e tampão HEPES a alta e baixa força iônica.

No capítulo 8 são apresentadas as discussões finais e conclusões desta tese.

No apêndice A é apresentado um estudo realizado com medidas de espalhamento de luz de dispersões de nanoesferas de poliestireno de tamanhos conhecidos, de modo a verificar os limites das técnicas de DLS e SLS e a confiabilidade dos métodos de análise e dos aparelhos utilizados. No apêndice B mostramos resultados de DLS obtidos com diferentes concentrações lipídicas de DMPG em água.

No apêndice $C$ são mostradas algumas das tentativas de simular os picos de SAXS na região de muito baixo ângulo, utilizando-se diferentes fatores de estrutura e diferentes programas de simulação. 


\section{Capítulo 2 - Técnicas experimentais}

Neste capítulo apresentamos as principais técnicas experimentais utilizadas nesta tese. Dado o grande número de técnicas utilizadas, a apresentação é feita de forma resumida e objetiva, indicando-se as principais referências onde é possível obter informações mais detalhadas. 


\subsection{Calorimetria Diferencial de Varredura (DSC)}

(ver, por exemplo, Heimburg, 2007)

A técnica de DSC nos fornece informações termodinâmicas acerca de possíveis transições de fase, ou fenômenos que envolvam variações de calor absorvido ou emitido pela amostra, com relação ao solvente puro. Em um calorímetro, a capacidade térmica $\left(C_{p}\right)$ é medida, sendo que ela é definida, em pressão constante, pela quantidade de calor $(d Q)$ que precisa ser fornecida ao sistema para que seja observada uma variação de temperatura $(d T)$ :

$$
C_{p}=\left(\frac{d Q}{d T}\right)_{p} .
$$

A variação de entalpia $(d H)$, que corresponde ao calor envolvido em um dado processo termodinâmico, pode ser escrito como:

$$
d H=d Q+V d p
$$

onde $V$ é o volume ocupado e $d p$ é a variação de pressão. Em medidas sob pressão constante, podemos escrever:

$$
C_{p}=\left(\frac{d H}{d T}\right)_{p}
$$

Desta forma, podemos escrever a variação de entalpia como:

$$
\Delta H=\int_{T_{0}}^{T} C_{p} d T
$$

O calor específico é definido como a capacidade térmica por partícula da solução. Sendo $N$ o número de mols na solução, o calor específico à pressão constante $\left(c_{p}\right)$ é dado pela razão:

$$
c_{p}=\frac{1}{N}\left(\frac{d H}{d T}\right)_{p}
$$


Desta forma, podemos escrever a variação de entalpia em função do calor específico como:

$$
\frac{\Delta H}{N}=\int_{T_{0}}^{T_{1}} c_{p} d T .
$$

\subsection{Turbidez}

(ver, por exemplo, Hiemenz, 1985; Valeur, 2001; Skoog et al., 2006)

Quando incidimos luz sobre um sistema, esta luz pode ser transmitida, refratada, espalhada ou absorvida. Fótons são absorvidos quando sua energia corresponde à diferença entre dois níveis energéticos das moléculas que atravessam, transferindo energia para o material e atenuando o feixe incidente naquele comprimento de onda.

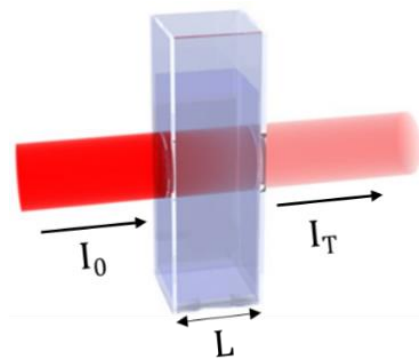

Figura 2.2.1: Feixe de luz monocromático incidindo em uma amostra que absorve neste comprimento de onda. O caminho óptico percorrido pela luz neste caso é dado por $\mathrm{L}$.

A Absorbância $(A)$ é a grandeza que quantifica a intensidade de luz absorvida pela amostra. A lei empírica de Lambert-Beer relaciona a Absorbância com o coeficiente de extinção molar $(\varepsilon)$, que depende da molécula absorvedora, com a concentração $(C)$ das espécies absorvedoras e com o caminho óptico $(L)$, que é a espessura da amostra percorrida pela luz incidente:

$$
A=\varepsilon . C . L .
$$

Tanto $A$ como $\varepsilon$ dependem do comprimento de onda da luz incidente. 
A Absorbância é definida como o logaritmo da razão entre a intensidade de luz incidente $\left(I_{0}\right)$ e transmitida $\left(I_{T}\right)$ :

$$
A \equiv \log \left(\frac{I_{0}}{I_{T}}\right)=-\log \left(\frac{I_{T}}{I_{0}}\right)
$$

Se o sistema não absorve luz, porém espalha luz, podemos escrever $I_{T}$ em função de $I o$ e da intensidade de luz espalhada $(I S)$ :

$$
I_{T}=I_{0}-I_{S}
$$

Substituindo 2.2 .3 em 2.2.2:

$$
A=-\log \left(\frac{I_{0}-I_{S}}{I_{0}}\right)=-\log \left(1-\frac{I_{S}}{I_{0}}\right)
$$

onde identificamos a turbidez $(\tau)$, que é definida pela razão $I S / I o$ e está relacionada à absorbância por:

$$
\tau=1-10^{-A}
$$

\subsection{Espalhamento de Luz}

(ver, por exemplo, Hiemenz,1985; Brown, 1993; Berne e Pecora, 2000; Enoki, 2010)

As técnicas de espalhamento de luz dinâmico e estático são técnicas nãoinvasivas que resultam da interação da radiação eletromagnética com a matéria. São técnicas largamente utilizadas no estudo de partículas em solução, como polímeros, proteínas, vesículas lipídicas e várias outras moléculas de interesse biológico.

Estas técnicas utilizam luz visível como fonte de energia e um detector para a luz espalhada a ângulos $\theta$. A partir das características da radiação espalhada, obtêm-se informações acerca da forma e estrutura dos centros espalhadores, além de informações sobre os processos difusivos. Na figura 2.3.1 apresentamos o esquema do aparato experimental utilizado em medidas de espalhamento de luz. 


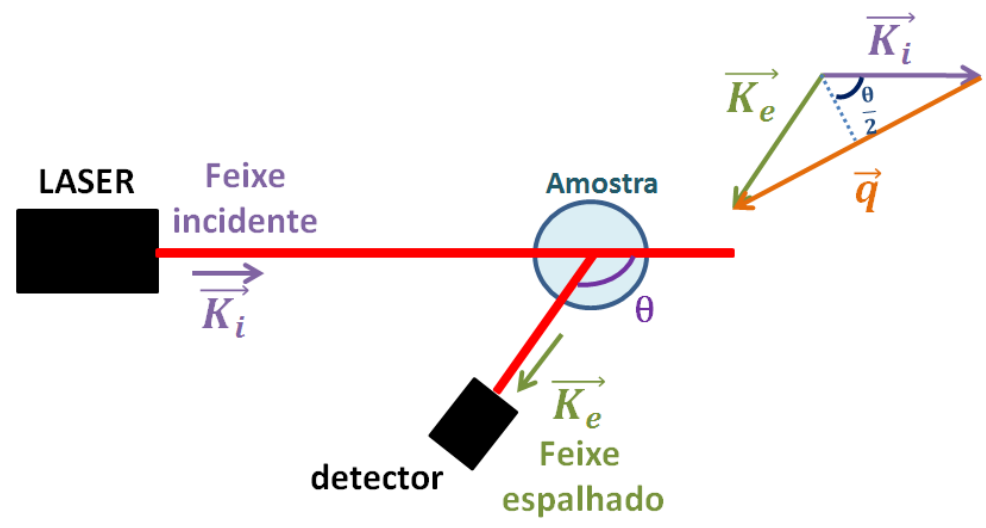

Figura 2.3.1: Esquema do aparato experimental utilizado em medidas de espalhamento de luz e definição do vetor de espalhamento $\vec{q}$, sendo que $\overrightarrow{\mid K_{l}}|=| \overrightarrow{K_{e}} \mid$.

A diferença vetorial entre $\mathrm{K}_{\mathrm{i}}$ e $\mathrm{K}_{\mathrm{e}}$ nos dá o vetor de espalhamento $\mathbf{q}$ (ver figura 2.3.1), cujo módulo é dado por:

$$
|\mathrm{q}|=\frac{4 \pi \mathrm{n}_{0}}{\lambda_{0}} \operatorname{sen}\left(\frac{\theta}{2}\right)
$$

onde $n_{0}$ é o índice de refração do solvente, $\lambda o$ é o comprimento de onda da luz incidente e $\theta$ corresponde ao ângulo de espalhamento.

\subsubsection{Espalhamento de Luz Dinâmico (DLS)}

O DLS surgiu na década de 60 , quando se observou que as flutuações da intensidade de luz espalhada no tempo podiam ser usadas para obter informações sobre o movimento browniano de partículas dispersas ou macromoléculas em solução. A figura 2.3.2 ilustra um padrão de flutuações da intensidade da luz espalhada, em um determinado ângulo, em um volume fixo, iluminado, onde entram e saem partículas. 


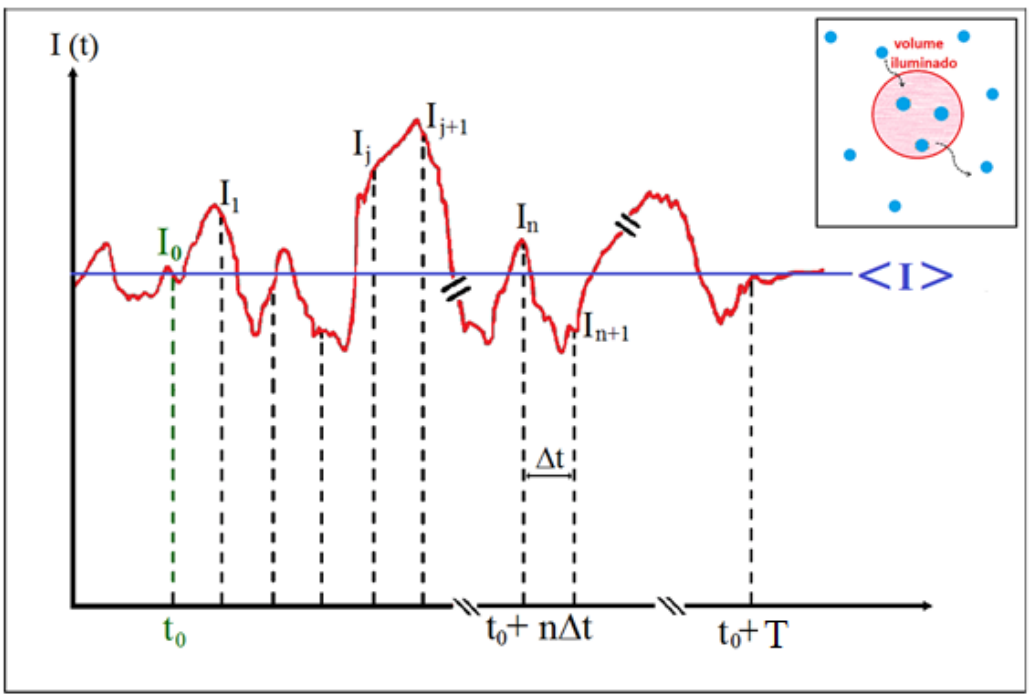

Figura 2.3.2: Flutuações da intensidade da luz espalhada devido à variação na densidade de partículas no volume de observação. [Figura adaptada de Berne e Pecora, 2000]

O detector capta a intensidade da luz espalhada e o correlator registra os pulsos em intervalos discretos $\Delta t$, tomando-se valores para a intensidade $I(t)$ da luz espalhada em um instante de tempo t e a correspondente intensidade $I(t+\tau)$ em um instante posterior $(t+\tau)$, para todo $t$ dentro do intervalo $T$ em que o sinal é observado. 0 correlator calcula a função de correlação da intensidade de luz espalhada, $G^{(2)}(\tau)$, através da média do produto:

$$
G^{(2)}(\tau)=\langle I(t) I(t+\tau)\rangle_{t}=\lim _{N \rightarrow \infty} \frac{1}{N} \sum_{j}^{N} I_{j} I_{j+n}
$$

onde $I_{j}$ é a medida da intensidade da luz no instante $t_{j}=j . \Delta t$ e $I_{j+n}$ a medida de intensidade no instante $t_{j+n}$, sendo $t_{j+n}-t_{j}=n \Delta t=\tau$. Essa função é também chamada de função de autocorrelação, pois correlaciona as intensidades de luz espalhadas em instantes $t$ e $t+\tau$.

A quantidade $\Delta t$ é um intervalo que define uma unidade usada para discretizar o tempo. O aparelho fixa uma "janela" de tempo $\tau$ e calcula o produto (equação 2.3.2) para cada $j$. No final toma a média dividindo por $N$, sendo que $(\Delta t) \cdot N=T$ e no limite para o qual $N \rightarrow \infty, \Delta t \rightarrow 0$.

Os valores mínimo e máximo para $\tau$, respectivamente $\tau_{\min }$ e $\tau_{\max }$, são escolhidos de forma adequada, e dependem de uma estimativa prévia do coeficiente de difusão 
das partículas a serem detectadas e, portanto, de seus tamanhos. Quanto menor $\tau_{\min }$, maior será a sensibilidade da medida a partículas menores.

A partir das medidas de $G^{(2)}(\tau)$, para sistemas diluídos, é possível o cálculo da função de autocorrelação temporal do campo elétrico $(\vec{E}), g^{(1)}(\tau)$, através da relação de Siegert (Brown, 1993):

$$
\frac{G^{(2)}(\tau)}{\langle I\rangle^{2}}=g^{(2)}(\tau)=1+\beta\left|g^{(1)}(\tau)\right|^{2}
$$

onde $\beta$ refere-se a parâmetros experimentais e

$$
\frac{G^{(1)}(\tau)}{\langle I\rangle^{2}}=g^{(1)}(\tau)=\frac{\langle\vec{E}(t) \vec{E}(t+\tau)\rangle_{t}}{\langle I\rangle},
$$

onde $\langle I\rangle$ é a intensidade média da luz espalhada.

Para sistemas monodispersos, e diluídos, é possível mostrar que $g^{(1)}(\tau)$ decai exponencialmente $\operatorname{com} \tau$.

$$
g^{(1)}(\tau) \approx e^{-q^{2 D} T \tau}=e^{-\Gamma \tau}
$$

onde $D_{T}$ é o coeficiente de difusão translacional da partícula e $\Gamma$ é a taxa de decaimento, tal que:

$$
\Gamma \equiv q^{2} D_{T}
$$

A partir de $D_{T}$ podemos obter o diâmetro hidrodinâmico $\left(D_{e f}\right)$, assumindo que as partículas espalhadoras são esferas, utilizando a equação de Stokes-Einstein:

$$
D_{e f}=\frac{k_{B} T}{3 \pi \eta D_{T}}
$$

sendo $k_{B}$ a constante de Boltzmann, $T$ a temperatura e $\eta$ a viscosidade do solvente.

É importante saber que o diâmetro hidrodinâmico calculado pela equação 2.3.7, para esferas densas, coincide com a média z-average do diâmetro $\left(\bar{D}_{z}\right)$, onde a massa é proporcional ao volume da esfera, isto é, à terceira potência do raio da esfera:

$$
\bar{D}_{z}=\frac{\sum_{i} N_{i} M_{i}^{2} D_{i}}{\sum_{i} N_{i} M_{i}^{2}}
$$


sendo $N_{i}, M_{i}$, e $D_{i}$, respectivamente, o número, a massa e o diâmetro hidrodinâmico de uma partícula $i$ presente na amostra.

Ao lidar com sistemas polidispersos, os diferentes tamanhos presentes na dispersão representam decaimentos variados, sendo necessário um método adequado para separar os decaimentos.

Considerando que a dinâmica dos agregados presentes nas dispersões possa ser descrita por processos difusivos, a função de autocorrelação temporal pode ser tratada pelo método da expansão em Cumulantes (Koppel, 1972) representado pelo polinômio:

$$
g^{(1)}(\tau)=A \exp \left\{(-\Gamma \tau)\left[1+\frac{1}{2 !} \mu_{2} \tau^{2}-\frac{1}{3 !} \mu_{3} \tau^{3}+\cdots\right]\right\}
$$

onde $A$ é a amplitude da distribuição e $\mu_{2}$ é o segundo momento ou cumulante quadrático da expansão e $\mu_{3}$ é o terceiro momento ou cumulante cúbico. Este método descreve uma variância relativa da média, a qual se relaciona ao índice polidispersão, $\mu_{2} / \Gamma^{2}$, do sistema.

Outros métodos muito utilizados na análise dos dados de DSL são os métodos do CONTIN e de Multi-exponenciais.

Método do CONTIN: Utiliza a transformada inversa de Laplace da função de autocorrelação para estimar a distribuição de populações na dispersão. Várias metodologias têm sido desenvolvidas para se estimar a transformada inversa numericamente, dado a complexidade do problema.

Ajuste por multi-exponenciais: É o ajuste da função de autocorrelação por uma soma de exponenciais, assumindo a presença de partículas de dois, três ou quatro tamanhos diferentes, bem definidos. A diferença com o método dos cumulantes é que para o caso do ajuste com um número limitado de exponenciais, assume-se que alguns poucos tamanhos sejam predominantes na amostra.

\subsubsection{Espalhamento de Luz Estático (SLS)}

Para o espalhamento estático de luz, usa-se a teoria de espalhamento de luz de Rayleigh, que é válida para partículas pequenas (em relação ao comprimento de onda da luz incidente), com as correções de Debye para flutuações de densidade em líquidos. 
A teoria de Debye leva em conta a interferência entre os feixes espalhados por diferentes regiões do objeto e, desta forma, sendo válida para partículas maiores.

No caso de espalhamento por macromoléculas em solução, que não possuem posições e nem orientações de equilíbrio definidas, devemos levar em conta as interferências intrapartícula, explicitada no fator de forma e interpartícula, que aparece no fator de estrutura. Neste caso, obtém-se para a razão entre a intensidade de luz espalhada $\left(I_{s}(\theta)\right)$ e incidente $\left(I_{0}\right)$ (Enoki, 2010):

$$
\frac{I_{s}(\theta)}{I_{0}}=\frac{\pi^{2} \Pi^{2}(\theta)}{\lambda_{0}^{4} R^{2}}\left\{\left(2 n_{0} \frac{d n}{d c} \frac{M_{w}}{N_{A}}\right)^{2}\left(1-\frac{R_{g}^{2} q^{2}}{3}\right) \frac{c N_{A} V}{M_{w}^{2}}\left(\frac{1}{M_{w}}+2 A_{2} c\right)^{-1}\right\},
$$

onde $R$ é a posição do detector, $\Pi(\theta)$ está relacionado com a polarização da onda incidente, $c$ é a concentração da amostra, dada em $\mathrm{mg} / \mathrm{mL}$, $V$ é o volume da amostra, $d n / d c$ é o incremento do índice de refração da solução pela concentração de amostra, $A_{2}$ é o segundo coeficiente do virial, $M_{W}$ é a massa molecular médio e $R_{g}$ é o raio de giração médio das partículas.

Podemos agrupar as constantes da seguinte forma:

$$
K=\frac{4 \pi^{2} n_{0}^{2}\left(\frac{d n}{d c}\right)^{2}}{N_{A} \lambda_{0}^{4}}
$$

De modo que K está associado às propriedades ópticas dos centros espalhadores.

$$
\Delta R_{\theta}=\frac{I_{s} V / R^{2}}{I_{0} \Pi^{2}(\theta)}
$$

$\Delta R_{\theta}$ é a razão Rayleigh, que em geral é definida por unidade de volume.

Desta forma, podemos reescrever a equação 3.2.10 da seguinte forma:

$$
\frac{\Delta R_{\theta}}{K c}=\underbrace{\left\{1-\frac{R_{g}^{2} q^{2}}{3}\right\}}_{\mathrm{P}(\mathrm{q})} \underbrace{\left\{\frac{1}{M_{w}}+2 A_{2} c\right\}^{-1}}_{\mathrm{S}(\mathrm{q})}
$$

onde o primeiro termo à direita está relacionado com o fator de forma $(P(q))$ e o segundo termo com o fator de estrutura $(S(q))$.

No método desenvolvido por Zimm (1948), válido para sistemas diluídos, o espalhamento de luz é medido para vários ângulos, e em uma faixa de concentrações 
de soluto. A metodologia de Zimm Plot é um método gráfico regido pelo inverso da equação 2.3 .13 , isto é, pela seguinte equação:

$$
\frac{K c}{\Delta R_{\theta}}=\left\{1+\frac{R_{g}^{2} q^{2}}{3}\right\}\left\{\frac{1}{M_{w}}+2 A_{2} c\right\}
$$

Estabelecendo-se dois limites podemos obter os parâmetros de interesse. No limite de $q \rightarrow 0$, a equação 2.3.14 pode ser escrita por:

$$
\left(\frac{K c}{\Delta R_{\theta}}\right)_{q \rightarrow 0}=\left\{\frac{1}{M_{w}}+2 A_{2} c\right\} .
$$

Isto é, obtemos uma reta limite de $\left(K c / \Delta R_{\theta}\right)_{q \rightarrow 0}$ em função de $c$, cujo coeficiente angular está relacionado a $A_{2}$. O segundo coeficiente do virial está relacionado às interações entre partículas.

Já no limite em que c $\rightarrow 0$, a equação 2.3.14 é dada por:

$$
\left(\frac{K c}{\Delta R_{\theta}}\right)_{c \rightarrow 0}=\left\{1+\frac{R_{g}^{2} q^{2}}{3}\right\}\left\{\frac{1}{M_{w}}\right\} .
$$

Neste caso, temos uma reta limite de $\left(K c / \Delta R_{\theta}\right)_{c \rightarrow 0}$ em função de $\theta$, com coeficiente angular relacionado ao $R_{g}$ da partícula.

A intercepção das duas retas limites apresentadas nas equações 2.3 .15 e 2.3.16 se dá em:

$$
\left(\frac{K c}{\Delta R_{\theta}}\right)_{c=q=0}=\left\{\frac{1}{M_{w}}\right\}
$$

Sendo possível obter a $M_{W}$ média das partículas em solução. 


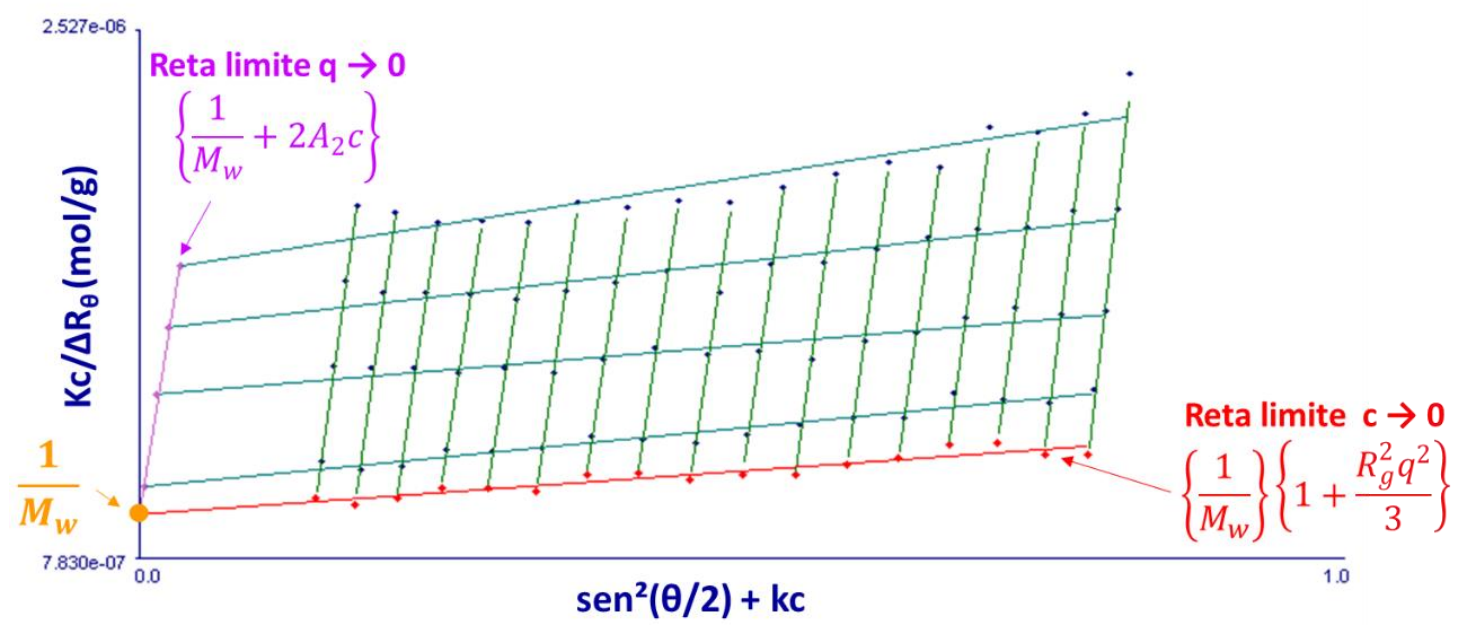

Figura 2.3.3: Exemplo de gráfico de Zimm para nanoesferas de poliestireno de $92 \mathrm{~nm}$ de diâmetro, obtido com 4 diferentes concentrações de nanoesferas e diferentes ângulos entre 40 e $140^{\circ}$.

Para soluções polidispersas, os parâmetros obtidos para $M_{W}$ e $R_{g}$ correspondem a um Z-average, isto é, uma média ponderada pelas massas dos agregados ao quadrado, como mostrado na equação 2.3 .8 , isto é:

$$
\bar{M}_{w}=\frac{\sum_{i} N_{i} M_{i}^{2}\left(M_{w}\right)_{i}}{\sum_{i} N_{i} M_{i}^{2}}
$$

e

$$
\bar{R}_{g}=\frac{\sum_{i} N_{i} M_{i}^{2}\left(R_{g}\right)_{i}}{\sum_{i} N_{i} M_{i}^{2}}
$$

A intensidade da luz espalhada, em função do ângulo de espalhamento, para partículas de dimensões compatíveis ao comprimento de onda da radiação incidente, depende do fator de forma e do fator de estrutura da dispersão em estudo. O segundo coeficiente do virial, $A 2$, que está relacionado às interações entre partículas, a massa molecular média, $M_{W}$, e raio de giração da partícula, $R_{g}$, podem ser obtidos através desse método. 


\subsection{Espalhamento de raios-X}

(ver, por exemplo, Glatter \& Kratky, 1982; Pabst et al.,2000, 2003)

Espalhamento de raios-X a baixo ângulo (Small angle X-ray scattering, SAXS) é uma técnica não-destrutiva muito utilizada no estudo de sistemas de interesse biológico, uma vez que permite a obtenção de informações importantes como o tamanho, forma e possíveis interações entre as partículas espalhadoras. Nesta técnica, o feixe de raios-X incidente $\left(\overrightarrow{k_{l}}\right)$, de comprimento de onda da ordem de $\sim 1 \AA$, é espalhado $\left(\overrightarrow{k_{e}}\right)$ pelos elétrons presentes na amostra, sendo coletado a ângulos muito baixos (tipicamente de $0,1^{\circ}$ a $10^{\circ}$ ). As grandezas de interesse podem ser calculadas a partir das curvas de intensidade de espalhamento em função do vetor de espalhamento.

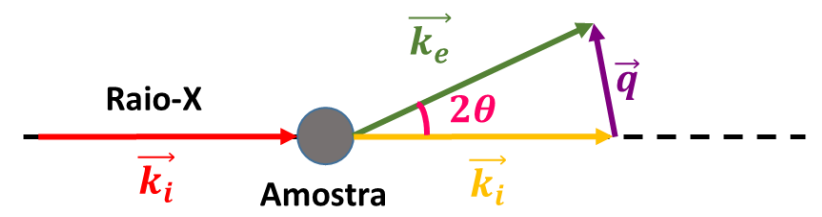

Figura 2.4.1: Representação esquemática do espalhamento de raio-X pela amostra.

Também é possível coletar o feixe espalhado a ângulos maiores (Wide angle XRay Scattering, WAXS), obtendo informações quanto ao empacotamento das cadeias hidrocarbônicas dentro da bicamada lipídica. 


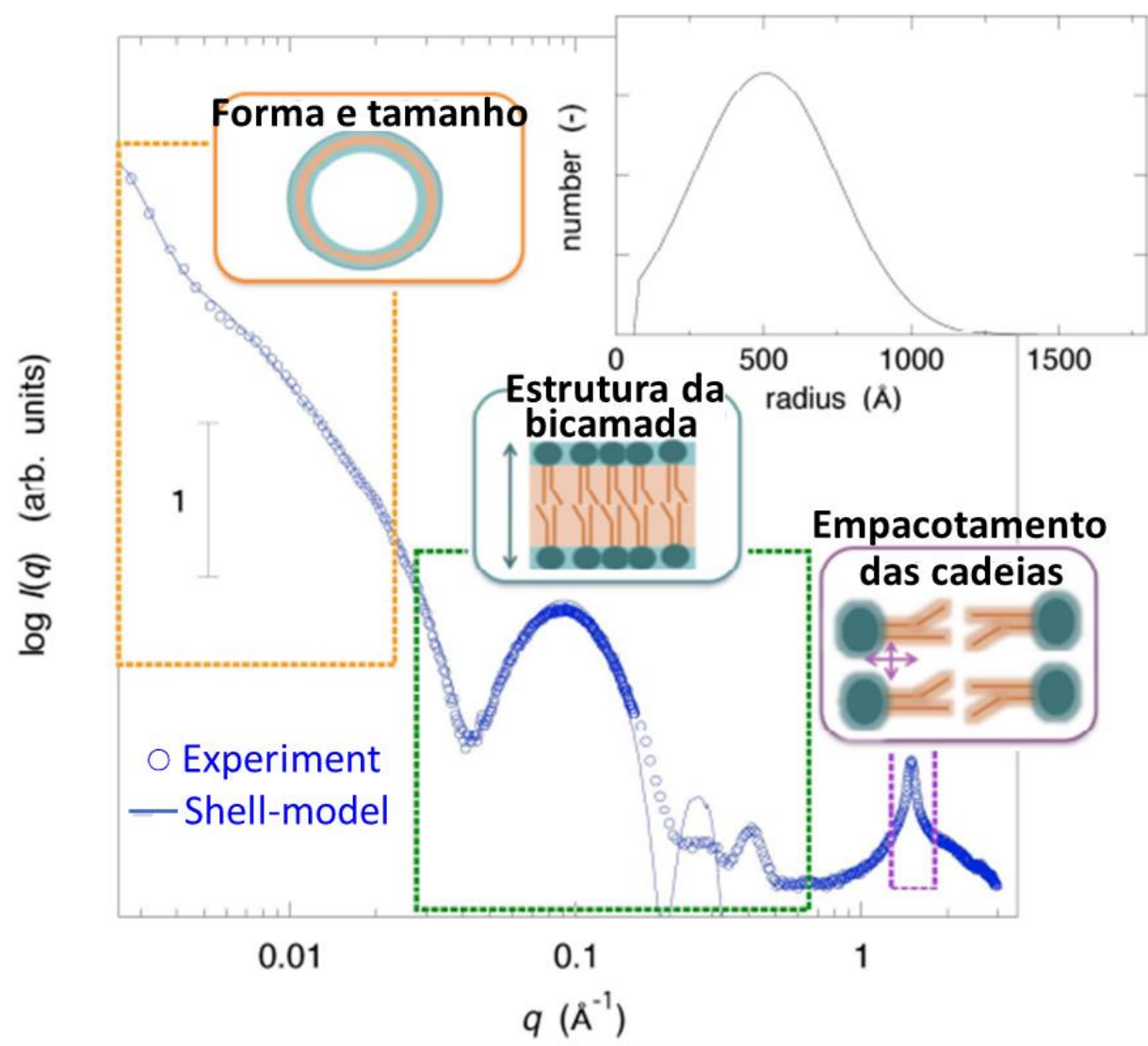

Figura 2.4.2: Representação de uma curva de SAXS + WAXS mostrando a informação que podemos obter em cada região de ângulos de espalhamento de Raios-X. Quanto maior o ângulo de espalhamento, pela Lei de Bragg, menor é a estrutura observada. [Figura adaptada de Hirai et al., 2015].

Na figura 2.2 vemos que o ângulo de espalhamento é definido por $2 \theta$ e como trata-se de um espalhamento elástico, isto é, $\left|\overrightarrow{k_{l}}\right|=\left|\overrightarrow{k_{e}}\right|$, o vetor de espalhamento $\vec{q}$ é dado por:

$$
|q|=\frac{4 \pi \operatorname{sen} \theta}{\lambda}
$$

onde $\lambda$ é o comprimento de onda da radiação incidente.

A intensidade de espalhamento da radiação pode ser escrita por:

$$
I(q)=N\langle P(q)\rangle \cdot\langle S(q)\rangle,
$$

onde $\mathrm{N}$ é o número de centros espalhadores, $\mathrm{S}(\mathrm{q})$ é o fator de estrutura, que está relacionado à organização e interações das partículas em solução e $P(q)$ é o fator de 
forma, que está relacionado com a forma, dimensão e contraste de densidade eletrônica das partículas espalhadoras.

Como estamos interessados no espalhamento causado pela membrana de uma vesícula, $P(q)$ é dado pela transformada de Fourier da densidade eletrônica ( $\rho$ ) de uma bicamada única, ao longo do eixo z, que é a direção perpendicular à espessura da bicamada.

$$
P(q)=\int d z \rho(z) \exp (i q z)
$$

$\rho(z)$ varia na direção perpendicular ao plano da bicamada devido às diferenças entre a densidade eletrônica da região da cabeça polar, da região hidrocarbônica e do centro das bicamadas, onde se encontram os terminais metileno. Neste trabalho, utilizamos o modelo em que o perfil de densidade eletrônica é dado pela soma de 3 gaussianas, duas representando a região da cabeça polar e uma, de amplitude negativa, que representa a região central da bicamada (Pabst et al., 2000):

$$
\rho(z)=\rho_{C H_{2}}+\overline{\rho_{H}}\left[\exp \left(-\frac{\left(z-z_{H}\right)^{2}}{2 \sigma_{H}^{2}}\right)+\exp \left(-\frac{\left(z+z_{H}\right)^{2}}{2 \sigma_{H}^{2}}\right)\right]+\overline{\rho_{C}} \exp \left(-\frac{z^{2}}{2 \sigma_{C}^{2}}\right)
$$

onde $\rho_{\mathrm{CH}_{2}}$ é a densidade eletrônica do metileno, $\overline{\rho_{H}} \equiv \rho_{H}-\rho_{C H_{2}}$ é a densidade eletrônica da cabaça polar e $\overline{\rho_{C}} \equiv \rho_{C}-\rho_{C H_{2}}$ é a densidade eletrônica das caudas hidrocarbônicas. $z_{H}$ é a posição do pico Gaussiano da cabeça polar $z_{C}=0$ é a posição do pico Gaussiano que representa as cadeias hidrocarbônicas. $\sigma_{H}$ e $\sigma_{C}$ são as larguras dos picos.

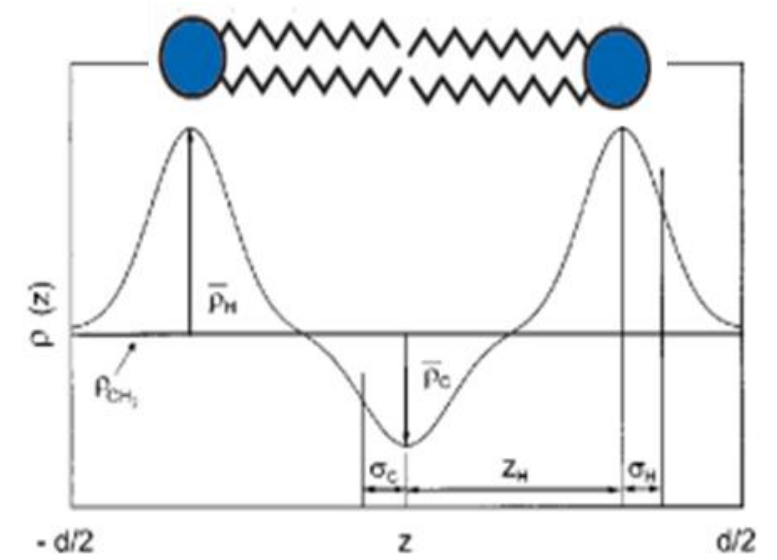

Figura 2.4.3: Perfil de densidade eletrônica de acordo com a equação 3.10 [Figura adaptada de Pabst et al., 2000]. 
A partir dos parâmetros da figura 2.4.3, é possível obter a espessura da bicamada (dB) a partir da relação (Pabst et al., 2003):

$$
d_{B}=2\left(z_{H}+2 \sigma_{H}\right)
$$

Para sistemas não interagentes, $S(q)=1$, de modo que a intensidade de espalhamento é composta apenas pelo fator de forma. Quando a intensidade de raios$X$ é espalhada por estruturas que se repetem, aparecem picos de interferência construtivas quando a diferença de caminho percorrido é igual a um número inteiro do comprimento de onda da radiação, que é conhecida como a lei de Bragg:

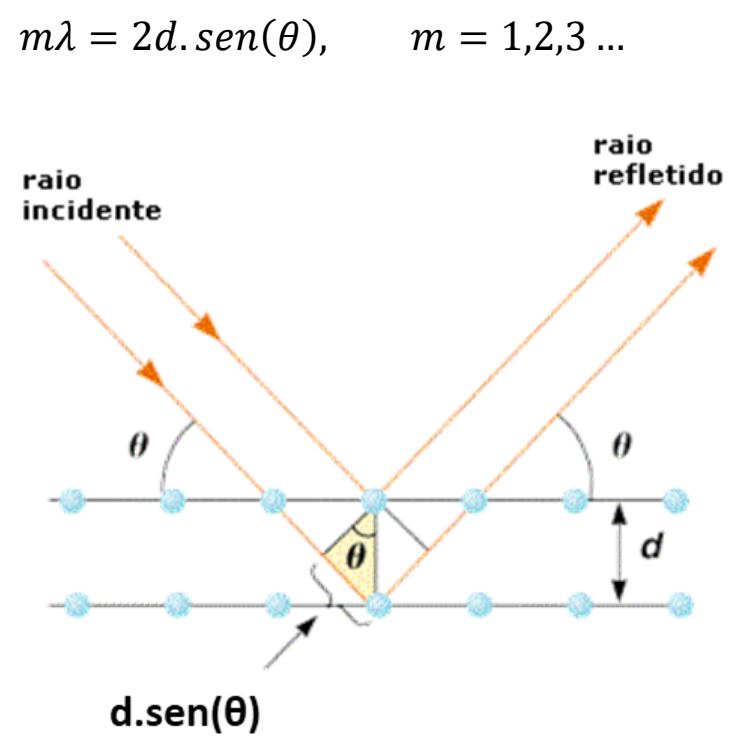

Figura 2.4.4: Representação da difração de Raios-X de acordo com a Lei de Bragg. [Fonte: http://wiki.stoa.usp.br]

Relacionando as equações 2.4 .5 e 2.4.1, podemos calcular a distância de repetição d, pela relação:

$$
d=\frac{2 \pi}{q}
$$

Para a análise dos dados de SAXS, é desejável o uso de um modelo que leve em conta além dos picos de Bragg, o espalhamento difuso e possíveis influências instrumentais na intensidade de raios $X$ espalhados, o que é chamado de análise global da curva de SAXS. O programa GAP (Global Analysis Program) faz o ajuste da curva de SAXS levando em conta a fase lamelar, através da equação (Pabst et al., 2000): 


$$
I(q)=\left(1-N_{\text {diff }}\right) \frac{S(q)|F(q)|^{2}}{q^{2}}+N_{\text {diff }} \frac{|F(q)|^{2}}{q^{2}}
$$

onde $\mathrm{N}_{\text {diff }}$ é uma constante de escala que leva em conta a fração de bicamadas correlacionadas.

Os fatores de estrutura disponíveis neste programa são para sistemas multilamelares, considerando-se flutuações térmicas (pequenas flutuações nas posições das bicamadas em torno de posições de equilíbrio bem definidas e igualmente espaçadas), teoria paracristalina (desordem de bicamadas perfeitamente planas que se deslocam de suas posições principais) e teoria de Caillé modificada (leva em conta flutuações de ondulação da membrana) (Pabst et al., 2003).

\subsection{Ressonância paramagnética eletrônica (RPE)}

(ver, por exemplo, Knowles et al., 1976; Marsh, 1981;Bales, 1989; Wertz et al., 1994)

A técnica de RPE baseia-se nas propriedades paramagnéticas de elétrons desemparelhados, que resultam em um momento de dipolo magnético total não nulo. Dado que a maioria dos sistemas biológicos não apresentam elétrons desemparelhados, não produzindo sinal de RPE, faz-se necessário o uso de sondas paramagnéticas (marcadores de spin). Neste trabalho fizemos uso de marcadores que contém o radical nitróxido, que é bastante estável e inerte e pode ser ligado à cadeia hidrocarbônica de moléculas anfifílicas, em diferentes posições, e inserem-se no interior da bicamada lipídica.

Na presença de um campo magnético externo, estático, os elétrons desemparelhados com número quântico de spin $S=1 / 2$, movimentam-se em torno de um eixo de quantização na direção do campo elétrico aplicado, com componente do momento angular de spin paralelo $\left(m_{s}=+1 / 2\right)$ ou antiparalelo $\left(m_{s}=-1 / 2\right)$. Um campo magnético oscilante perpendicular ao campo magnético estático, induz transições entre os níveis quantizados de energia quando a energia da radiação eletromagnética corresponde à diferença de energia entre eles. A partir das transições observadas do spin eletrônico e de interações hiperfinas entre os spins do elétron e do núcleo, que leva 
a um desdobramento espectral em novos níveis de energia, obtém-se informações do micro-ambiente em que o marcador se encontra.

Nos experimentos de RPE, fixa-se a frequência de radiação eletromagnética e varia-se o campo magnético externo, para que a condição de ressonância seja satisfeita. A frequência de ressonância de um elétron desemparelhado é da ordem de $10^{3}$ vezes maior que a frequência do núcleo, desta forma, os experimentos de $R P E$ requerem frequências em torno do $\mathrm{GHz}$ (Grell, 1981), sendo que a frequência mais utilizada é da ordem de $9 \mathrm{GHz}$ (Banda-X).

A Hamiltoniana de spin do elétron desemparelhado, considerando-se a interação Zeeman $\left(1^{\circ}\right.$ termo) e a interação hiperfina $\left(2^{\circ}\right.$ termo $)$ pode ser escrita por :

$$
\mathcal{H}=\beta . \boldsymbol{H} \cdot \boldsymbol{g} . \boldsymbol{S}+\boldsymbol{I} \cdot \boldsymbol{A} . \boldsymbol{S}
$$

onde $\beta$ é o magnéton de Bohr, $H$ é o campo magnético estático aplicado, $\boldsymbol{g}$ e $\boldsymbol{A}$ são tensores de $2^{a}$ ordem, relacionados à interação Zeeman com o campo magnético externo, e à interação hiperfina com o campo magnético local devido à presença do núcleo, respectivamente, e $S$ e $I$ são os operadores momento angular de spin do elétron desemparelhado e do núcleo, respectivamente.

O grupo nitróxido, que possui $S=1 / 2$, é um sistema de dois níveis $\left(m_{S}=+1 / 2\right.$, $1 / 2$ ). Sendo o momento angular do spin nuclear do nitrogênio $I=1$, cada nível se desdobra em outros 3 níveis, com números quânticos $m_{I}=-1,0$ e +1 , de modo que sua interação hiperfina possui três linhas, sendo observadas, pelas regras de seleção, as transições que correspondem a $\Delta m_{S}= \pm 1$ e $\Delta m_{I}=0$, que são caracterizadas pela mesma frequência de microonda $\left(h v=g \beta H+A m_{I}\right)$, mas por valores distintos de campo magnético externo (figura 2.5.1). 


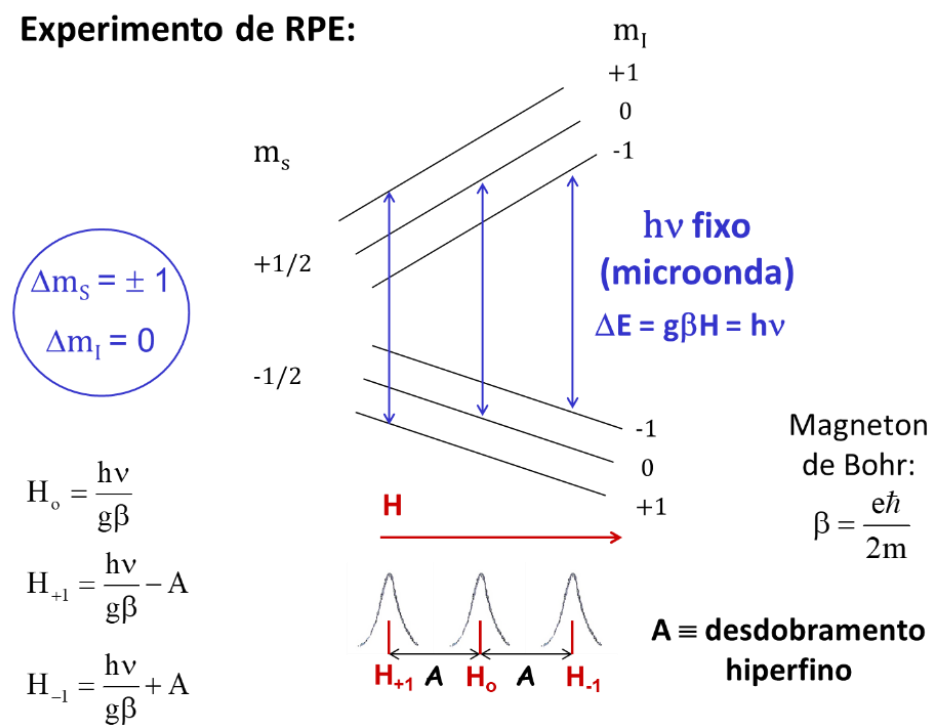

Figura 2.5.1: Ilustração de como as medias de RPE são realizadas, variando-se o campo magnético e fixando-se a frequência da microonda.

Em geral, os eixos moleculares do nitróxido coincidem com os eixos principais dos tensores $\mathbf{g}$ e $\mathbf{A}$, de modo que a anisotropia da molécula está contida nesses tensores (figura 2.5.2). 


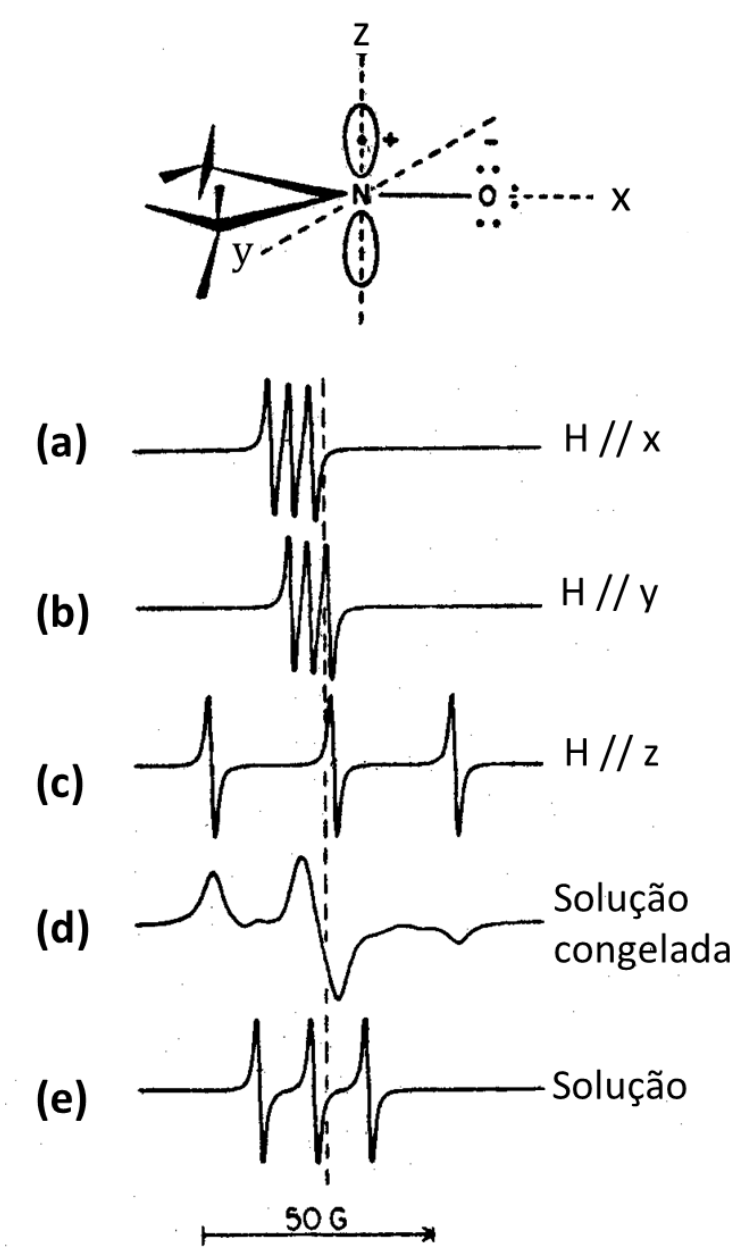

Figura 2.5.2: Espectros de RPE do radical nitróxido sob diferentes condições: (a) campo magnético paralelo ao eixo x, (b) ao eixo y e (c) ao eixo z; em solução congelada (d) e em solução de baixa viscosidade (e). [Figura adaptada de Marsh, 1981].

O desdobramento hiperfino, A, do nitróxido varia com a orientação do campo magnético em relação ao eixo do nitróxido (figura 2.5.2), sendo que essa anisotropia espectral faz com que o RPE seja sensível à movimentos moleculares em meios condensados.

Uma vez que o elétron desemparelhado se encontra preferencialmente no eixo $z$, a simetria pode ser descrita, aproximadamente, por uma simetria axial, conforme pode ser visto na figura 2.5.2 a grande assimetria entre os eixos z (paralelo) e os eixo $\mathrm{x}$ e y (perpendiculares). Os principais valores dos tensores $\boldsymbol{g}$ e $\boldsymbol{A}$ são apresentados na tabela 2.1 (Hubbell \& McConnell, 1971), para o marcador doxil, que apresenta simetria quase axial do radical nitróxido: 
Tabela 2.1: Valores principais dos tensores $g$ e $A$

\begin{tabular}{ccc|ccc}
\hline \multicolumn{3}{c|}{ Tensor $\mathbf{g}$} & \multicolumn{3}{c}{ Tensor $\mathbf{A}$} \\
\hline $\mathbf{g}_{\mathbf{x x}}$ & $\mathrm{g}_{\mathrm{yy}}$ & $\mathrm{g}_{\mathrm{zz}}$ & $\mathrm{A}_{\mathrm{xx}}$ & $\mathrm{A}_{\mathrm{yy}}$ & $\mathrm{A}_{\mathrm{zz}}$ \\
\hline $\mathbf{2 , 0 0 8 8}$ & 2,0058 & 2,0022 & $5,9 \mathrm{G}$ & $5,4 \mathrm{G}$ & $32,9 \mathrm{G}$ \\
\hline
\end{tabular}

Desta forma, podemos considerar $\left(A_{x x} \approx A_{y y}\right)=A_{\perp} e\left(g_{x x} \approx g_{y y}\right)=g_{\perp}$ e $A_{z z}=A_{\|}$ e $g_{z z}=g_{\|}$. Na figura 2.5.2 (d) temos um espectro de movimento muito lento, também chamado de espectro de pó, de modo que o espectro é a soma de contribuições do radical nitróxido alinhado em todas as direções possíveis. No caso apresentado na figura 2.5.2 (e) o movimento é muito rápido, e o espectro resultante é a média das orientações, de modo que obtemos um fator-g: $g_{0}=\left(g_{x x}+g_{y y}+g_{z z}\right) / 3$ e um desdobramento hiperfino isotrópico dado por: $a_{0}=\left(A_{x x}+A_{y y}+A_{z z}\right) / 3$.

Na figura 2.5.3 são mostrados exemplos de espectros de RPE obtidos com o marcador paramagnético Tempol em meios de diferentes viscosidades. A partir do modelo de Stokes-Einstein é possível obter a seguinte equação para o tempo de correlação rotacional $\left(\tau_{c}\right)$ da sonda:

$$
\tau_{c}=\frac{4 \pi \eta r^{3}}{3 k_{B} T}
$$

onde $\eta$ é a viscosidade do meio, $k_{B}$ é a constante de Boltzmann, Té a temperatura e $r$ é o raio da molécula. 


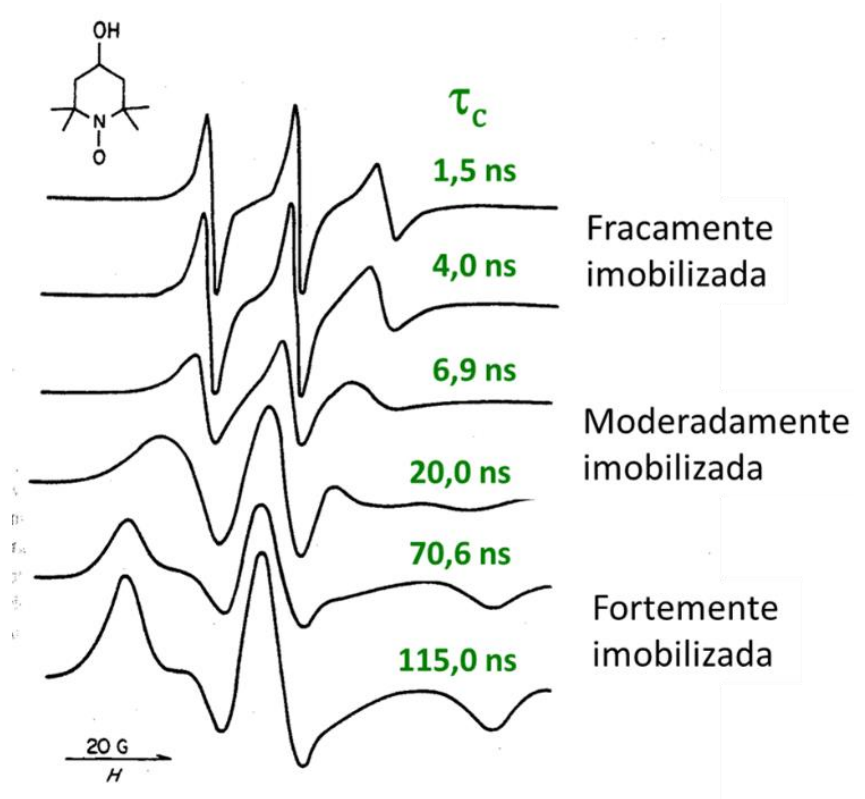

Figura 2.5.3: Espectros de RPE de Tempol em soluções de viscosidade crescentes de cima para baixo. Os valores de $\tau_{c}$ foram calculados pela equação 2.5.2. [Figura adaptada de Smith, 1972].

A partir da figura 2.5.3 vemos que o tempo de correlação pode influenciar tanto as larguras das linhas quanto o valor de $A_{z z}$. Para movimentos muito rápidos, $\tau_{\mathrm{c}}<10^{-11}$ s, o espectro apresenta as três linhas com iguais intensidades, sendo possível obter apenas os valores médios dos tensores $A$ e $g\left(\right.$ ao e $g$ ). Quando $10^{-11} \mathrm{~s}<\tau_{\mathrm{c}}<3.10^{-9} \mathrm{~s}$, sinal tipicamente encontrado na fase fluida de sistemas lipídicos, são observados alargamentos diferentes das linhas referentes às transições $\left(h_{-1}, h_{0}\right.$ e $\left.h_{+1}\right)$. E na fase gel, quando temos um movimento lento, $10^{-9} \mathrm{~s}<\tau_{\mathrm{c}}<3.10^{-7} \mathrm{~s}$, as linhas se alargam à medida que o movimento diminui e a posição dos picos também é alterada.

Dada a estrutura bidimensional da membrana lipídica, o movimento do marcador de spin é restrito, além de ser mais lento. O eixo z do nitróxido tende a alinharse paralelamente com à direção normal da bicamada e o radical livre que se encontra ligado à cadeia hidrocarbônica tem seu movimento restrito a um cone de ângulo de abertura $\beta$ (figura 2.5.4). Esse movimento cancela parte da anisotropia. Marcadores de spin em membranas apresentam um cancelamento parcial da anisotropia, sendo que, para $\beta \neq 0, A_{\|}$também contém contribuições de $A_{x x}$ e $A_{y y}$ e $A_{\perp}$ contém contribuições de $\mathrm{A}_{\mathrm{zz}}$. 


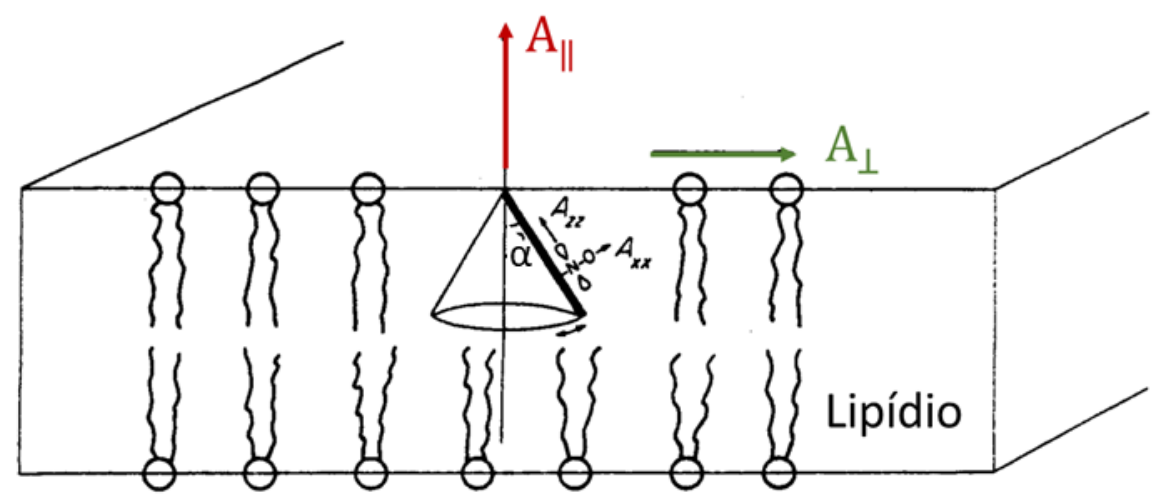

Figura 2.5.4: Marcador de spin inserido na bicamada lipídica, fazendo um ângulo $\alpha$ com a direção normal à bicamada. [Figura adaptada de Knowles et al., 1976].

O parâmetro de ordem S mede a distribuição angular média do eixo principal da molécula com relação ao eixo perpendicular à superfície da membrana, sendo que o parâmetro de ordem máximo $(S=1)$ é obtido quando a cadeia hidrocarbônica se encontra alinhada à direção normal da bicamada $(\alpha=0)$.

A polaridade do meio onde está o radical nitróxido também altera os tensores $A$ e $\boldsymbol{g}$, porque altera a distribuição dos elétrons ao redor do núcleo de nitrogênio (Riske, 2001). Medidas do desdobramento hiperfino, a0, servem como medidas da polaridade do meio, sendo que a assume valores maiores quanto mais polar é o solvente.

Quando o movimento dos marcadores é muito rápido (na fase fluida da bicamada), é possível obter a0 diretamente dos espectros de RPE, mas nos casos de pouca mobilidade, a 0 só pode ser obtido a partir de simulações teóricas dos espectros.

\subsection{Condutividade elétrica e mobilidade eletroforética}

(ver, por exemplo, Hiemenz, 1985)

A condutividade elétrica é uma medida da capacidade que os materiais possuem em conduzir ou transmitir corrente elétrica. No caso de soluções aquosas, a condução é iônica, isto é, a corrente elétrica é conduzida pelos íons (eletrólitos) da solução. Já a mobilidade eletroforética é uma medida de quão rápido uma partícula carregada se move quando submetida a um campo elétrico. Desta forma, enquanto medidas de 
condutividade elétrica estão relacionadas com as cargas totais presentes na dispersão, medidas da mobilidade eletroforética estão relacionadas com as partículas em solução.

Considerando o modelo mais simples para o deslocamento de íons, em que esses são tratados como esferas não interagentes, sujeitas a uma força elétrica $\left(\overrightarrow{F_{e}}=q \vec{E}\right)$, onde $q$ é a carga do íon e $E$ a intensidade do campo elétrico, e uma força de atrito viscoso $\left(\overrightarrow{F_{a}}=-b \vec{v}\right)$, sendo $b$ o coeficiente de atrito viscoso da partícula no meio e $V$ sua velocidade. Quando $\left|\overrightarrow{F_{e}}\right|=\left|\overrightarrow{F_{a}}\right|$, o íon passa a se deslocar com velocidade constante de módulo:

$$
v=\frac{q E}{b}
$$

que também é conhecida como velocidade limite.

A mobilidade eletroforética $(\mu)$ é definida por:

$$
\mu=\frac{v}{E}
$$

isto é, quanto maior $\mu$, maior é a velocidade do íon. Usando as equações 2.6 .1 e 2.6.2, podemos escrever:

$$
\mu=\frac{v}{E}=\frac{q}{b} .
$$

Considerando-se que a força de atrito sentida por esferas carregadas é regida pela lei de Stokes:

$$
\overrightarrow{F_{a}}=-6 \pi \eta R \vec{v}
$$

onde $\mathrm{R}$ é o raio efetivo da partícula e $\eta$ é a viscosidade do meio. Neste caso, temos que:

$$
b=6 \pi \eta R .
$$

E, portanto, a equação 2.6 .3 pode ser escrita por:

$$
\mu=\frac{q}{6 \pi \eta R} .
$$

A partir da equação 2.6.6 vemos que a mobilidade eletroforética depende da carga efetiva e do raio efetivo da partícula e da viscosidade do meio. 
No caso da condutividade, podemos calcular a densidade de corrente elétrica $J$ como:

$$
J=\frac{I}{A}=\frac{N \cdot q}{A \cdot t}=\frac{n \cdot A \cdot v \cdot t \cdot q}{A \cdot t} \rightarrow J=n \cdot q \cdot v
$$

onde $I$ é a corrente elétrica, $N$ é o número de íons que atravessam o volume de um cilindro cuja área da base é $A$ em um intervalo de tempo $t$. Desta forma, $n$ é o número de íons por unidade de volume.

Como pela lei de Ohm microscópica temos que $J=\sigma E$, podemos juntar as equações 2.6 .3 e 2.6 .7 e obter a seguinte expressão para a condutividade:

$$
\sigma=\frac{n q v}{E}=\frac{n q^{2}}{b}=\frac{n q^{2}}{6 \pi \eta R}
$$

A partir da equação 2.6 .8 vemos que a condutividade depende do número de íons, da carga e do raio efetivo e também da viscosidade do meio.

Considerando que os agregados em solução são íons grande e que há presença de contraíons livres em solução, provenientes das cabeças polares dos lipídios dos agregados, além dos íons do próprio solvente, a condutividade da dispersão $(\sigma)$ será dada pela soma das contribuições do solvente $\left(\sigma_{0}\right)$, dos agregados $\left(\sigma_{\mathrm{v}}\right)$ e de seus contraíons $\left(\sigma_{c}\right)$ :

$$
\sigma=\sigma_{0}+\sigma_{v}+\sigma_{c}
$$

Desta forma, mudanças na condutividade elétrica estão relacionadas à associação/dissociação dos lipídios (variação do número de contraíons), ao tamanho e/ou forma dos agregados (variação da velocidade dos íons) e à mudança na viscosidade do meio.

\subsection{Cálculos das distâncias entre vesículas e fração volume}

O número de vesículas na dispersão pode ser calculado pela razão entre o número total de lipídios na solução $\left(\mathrm{n}_{\mathrm{T}}\right)$ e o número de lipídios por vesícula ( $\left.\mathrm{n}_{\text {ext }}+\mathrm{n}_{\text {int }}\right)$ :

$$
n_{v}=\frac{n_{T}}{n_{\text {ext }}+n_{\text {int }}}
$$


onde next é o número de lipídios da camada externa da vesícula e nint o da interna.

$\mathrm{n}_{\mathrm{T}}$ é facilmente obtido multiplicando a concentração lipídica molar pelo número de Avogadro e pelo volume de solução $\left(n_{T}=[D M P G] . N_{A} \cdot V\right)$ e supondo vesículas esféricas de raio externo $\mathrm{R}$ e espessura da bicamada $\mathrm{d}_{B}$ temos:

$$
4 \pi R^{2}=n_{e x t} a
$$

e

$$
4 \pi\left(R-d_{B}\right)^{2}=n_{\text {int }} a
$$

sendo $a$ a área ocupada pela cabeça polar de cada lipídio.

Assim, obtemos o número de vesículas:

$$
n_{v}=\frac{a[D M P G] N_{A} V}{4 \pi\left[R^{2}+\left(R-d_{B}\right)^{2}\right]}
$$

Considerando que as vesículas ocupam volumes iguais na solução, o volume ocupado por cada vesícula é:

$$
\frac{V}{n_{v}}=\frac{4 \pi\left[R^{2}+\left(R-d_{B}\right)^{2}\right]}{a[D M P G] N_{A}}
$$

De modo que a distância entre os centros de vesículas vizinhas $\left(D_{V}\right)$ é dada por:

$$
D_{V}=\sqrt[3]{\frac{4 \pi\left[R^{2}+\left(R-d_{B}\right)^{2}\right]}{a \cdot[D M P G] N_{A}}} .
$$

A fração de volume interno das vesículas $(\phi)$ é dada pela razão do volume ocupado pelas vesículas e do volume total de solução. Considerando vesículas esféricas:

$$
\phi=\frac{4}{3} \pi R^{3} \cdot n_{v} \cdot \frac{1}{V}
$$

Como $n_{V}$ é dado pela equação 2.7.4:

$$
\phi=\frac{N_{A} \cdot a \cdot R^{3}[D M P G]}{3\left[R^{2}+\left(R-d_{B}\right)^{2}\right]} .
$$




\section{Capítulo 3 - Materiais e métodos}

Neste capítulo apresentamos a lista de materiais utilizados, o modo como as amostras foram preparadas e a descrição de como os experimentos foram realizados e os dados analisados. 


\subsection{Materiais}

Lipídios: sal de sódio DMPG (1,2 - Dimiristoil-sn-glícero-3-[Fosfo-rac-(1-glicerol)]) adquirido da Avanti Polar Lipids.

Solventes: clorofórmio e metanol, ambos P.A. comprados da Merck.

Tampão: HEPES (ácido de N-(2-Hidroxietil)-Piperazina-N-2-etano sulfônico), comprado da Sigma Chemical, EDTA (ácido etilenodiamido tetra-acético) da Sigma Chemical e Hidróxido de Sódio - NaOH (Casa Americana) para o ajuste do pH.

Sais: Cloreto de sódio - $\mathrm{NaCl}$ da Sigma Chemical e Cloreto de potássio $-\mathrm{KCl}$ da Quimica Analitica Ltda.

Suspensões de microesferas poliméricas de poliestireno de diâmetros $(21,0 \pm 1,5)$ $\mathrm{nm},(46,0 \pm 2,0) \mathrm{nm}$ e $(92,0 \pm 3,7) \mathrm{nm}$ da Duke Scientific Corporation.

Filtros: 0,1 $\mu \mathrm{m}$ (Acrodisc Syringe Filter-Super Membrane Low Protein Binding NonPyrogenic), para filtrar a Água Mili-Q e filtro de policarbonato $0.1 \mu \mathrm{m}$ (Nuclepore, TrackEtch Membrane da Whatman Schleicher \& Schuelle) e pré-filtros da Avanti Polar Lipids, usados no extrusor.

Água Milli-Q: Água ultrapura, destilada, deionizada e filtrada, obtida a partir de Milli-Q plus ultra pure water system - Millipore filtradas 3 vezes por filtros Acrodisc Syringe Filter de $0.1 \mu \mathrm{m}$.

Sondas paramagnéticas: 5-PCSL e 16-PCSL (1-palmitoil-2-estearoil (5- ou 16- doxil)sn-glícero-3- fosfatidilcolina) da Avanti Polar Lipids, Inc.

Para as medidas da curvatura espontânea também foi necessário o uso do lipídio DOPE (1,2-dioleoil-sn-glícero-3- fosfatidiletanolamina), adquirido da Avanti Polar Lipids e do cis-9-Tricoseno, da Sigma-Aldrich, Austria. 


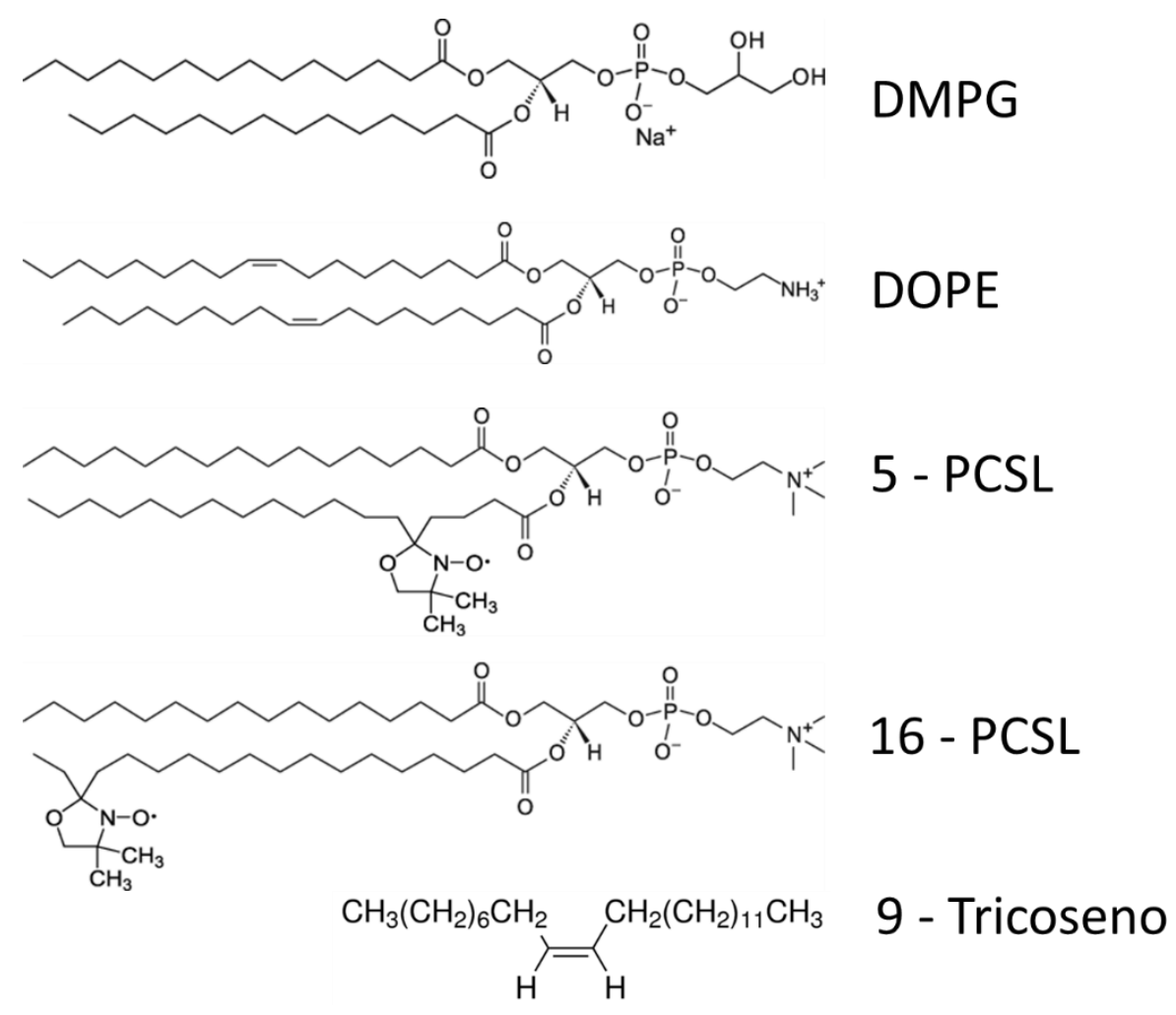

Figura 3.1.1: Estrutura molecular dos lipídios (DMPG e DOPE), dos marcadores de spin (5 e 16-PCSL) e do alceno tricoseno utilizados. [Fonte: avantilipids.com e chemicalbook.com (tricoseno)]

\subsection{Métodos}

\subsubsection{Preparação das amostras}

Para a preparação de vesículas, o lipídio (juntamente com o marcador de spin, se desejado) é diluído em clorofórmio, e depois submetido a um fluxo de nitrogênio, para a formação de um filme fino na parede do tubo de ensaio. O filme é então submetido à baixa pressão por pelo menos três horas, para evaporação do solvente orgânico. Em seguida, é adicionado o solvente desejado (água ou tampão HEPES), e o tubo contendo a solução é resfriado em gelo (DMPG em água) ou aquecido em banho térmico a $50^{\circ} \mathrm{C}$ (DMPG em tampão HEPES) e depois agita-se a solução por cerca de 5 minutos em vórtex.

Quando desejado, com o uso de um mini-extrusor (Avanti Polar Lipids, Inc.), passamos a dispersão lipídica 31 vezes por um filtro de policarbonato com poros de 100 ou $30 \mathrm{~nm}$. Esse processo, em geral, forma vesículas unilamelares (LUVs) de tamanho relativamente bem determinado, de acordo com o diâmetro dos poros. Foi desenvolvido 
pelo Dr. Evandro Duarte, em colaboração com a oficina mecânica do DFGE do IFUSP, um dispositivo que foi acoplado ao mini-extrusor da Avanti, automatizando o processo de extrusão (Figura 3.2.1), sendo possível selecionar o número de vezes que a amostra passa pelo filtro, a temperatura e a velocidade da extrusão. Para a extrusão das dispersões de DMPG em água, de modo a atingir temperaturas baixas $\left(\sim 5^{\circ} \mathrm{C}\right)$, apoiou-se placas de gelo no extrusor, enquanto as extrusões das dispersões de DMPG em tampão foram realizadas a $45^{\circ} \mathrm{C}$. É interessante observar que o número de vezes que a amostra é passada pelo filtro deve sempre ser um número ímpar, de modo que se termine a extrusão do lado oposto ao do início, evitando a presença de resquícios de amostra que não passaram pelo filtro.

A extrusão das amostras, processo anteriormente realizado apenas para as medidas de espalhamento de luz, foi empregada neste trabalho nas diversas técnicas experimentais, pois diminui a polidispersidade da amostra, obtendo-se dispersões com agregados de tamanhos mais homogêneos e, em geral, de tamanhos bem definidos pelo tamanho do filtro utilizado. Nesta tese, quando não especificado o tamanho do filtro utilizado na extrusão, utilizou-se o filtro com poros de $100 \mathrm{~nm}$.

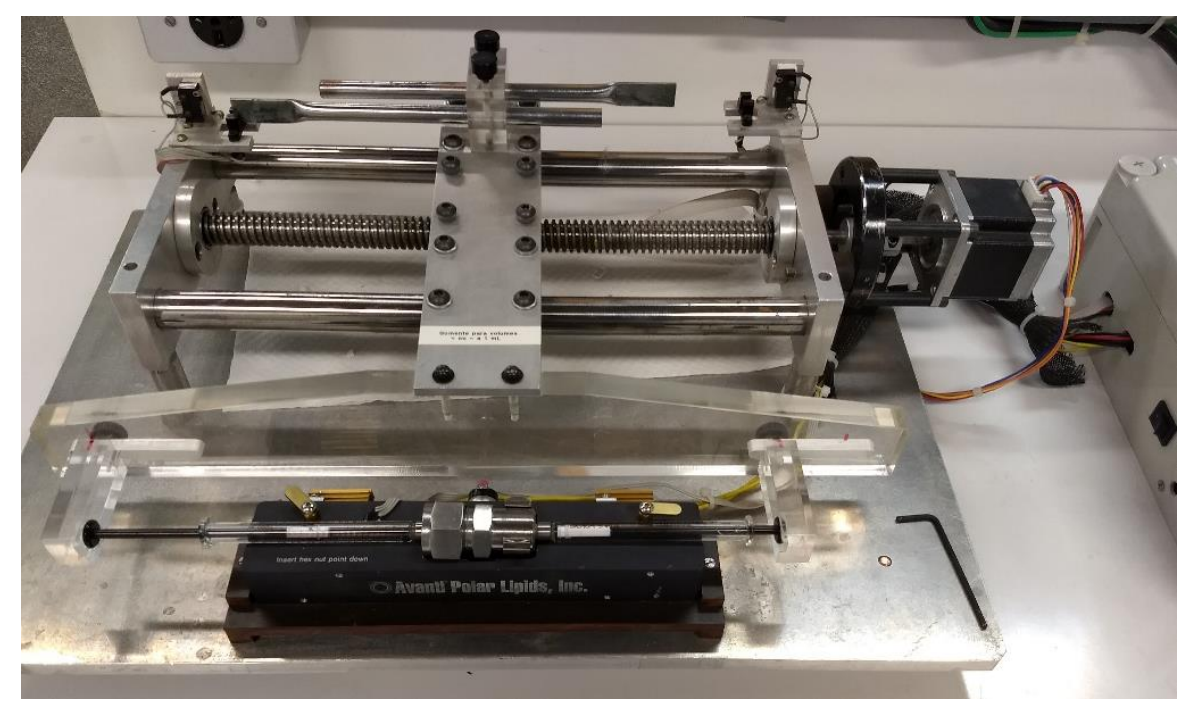

Figura 3.2.1: Dispositivo acoplado ao mini-extrusor da Avanti para a realização da extrusão de forma automatizada. O dispositivo empurra a amostra de uma seringa para a outra, forçando-a a passar pelo filtro com poros do tamanho escolhido. Neste dispositivo é possível selecionar o número de vezes que a amostra passa pelo filtro, a temperatura da placa de apoio do extrusor e a potência do motor que realiza o movimento. 
O tampão HEPES utilizado foi preparado com 10 mM de HEPES e $1 \mathrm{mM}$ de EDTA ou $2 \mathrm{mM}$ de $\mathrm{NaCl}$, tendo o $\mathrm{pH}$ ajustado para 7,41 com o acréscimo de hidróxido de sódio $\mathrm{NaOH}$.

As amostras de DMPG em água pura tinham o $\mathrm{pH}$ verificado antes e depois de sua utilização nas diversas técnicas, obtendo-se valores de pH entre 6,5 e 8,0 para todas as amostras, uma vez que essas dispersões não estão tamponadas.

Para o experimento de medida da curvatura espontânea do DMPG, as amostras foram preparadas utilizando o método de troca rápida de solvente (rapid solvent exchange - RSE) que foi desenvolvido em Buboltz e Feigenson, 1999 e posteriormente otimizado em Rieder et al., 2015. Primeiramente preparou-se duas soluções estoque, uma de DMPG e a outra de DOPE dissolvidos em uma mistura de 9 partes de clorofórmio para 1 de metanol. As amostras foram preparadas com diferentes razões DOPE/DMPG, variando de 0\% de DMPG (amostra de DOPE puro) até 40 mol\% de DMPG e adicionouse o tricoseno $12 \%$ peso. Os tubos de ensaio contendo $250 \mu \mathrm{L}$ do solvente desejado (água ou tampão) eram pré-aquecidos a $50^{\circ} \mathrm{C}$ por 5 minutos e então adicionava-se a mistura de lipídios e tricoseno ao tubo e este era imediatamente inserido no aparato de RSE do laboratório do Insitute of Molecular Biosciences, da University of Graz, Áustria. Para a formação da fase hexagonal reversa, o tubo de ensaio contendo a amostra foi conectado a uma bomba de vácuo e submetido a valores constantes de fluxo de argônio, pressão (350 mbar), temperatura $\left(50^{\circ} \mathrm{C}\right)$ e sendo agitado pelo vórtex a uma velocidade de 600 rpm, por 6 minutos, sendo tempo suficiente para a remoção de todo o solvente orgânico. As amostras foram seladas e mantidas à temperatura ambiente por uma semana antes da realização das medidas e um exemplo das amostras obtidas após esse processo é mostrado na figura 3.2.2.

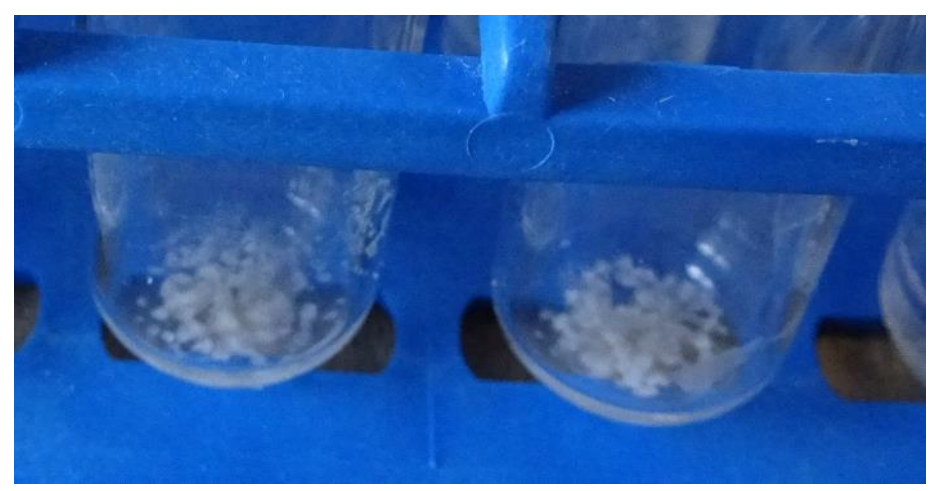

Figura 3.2.2: Exemplo de amostras utilizadas no experimento de curvatura espontânea do DMPG. 


\subsubsection{Medidas de Calorimetria Diferencial de Varredura (DSC)}

Medidas de calorimetria foram realizadas no aparelho Microcal VP-DSC do Laboratório de Biofísica, IFUSP a uma taxa de aquecimento de $20^{\circ} \mathrm{C} / \mathrm{h}$ para as dispersões de 10 mM de DMPG. Conforme mostrado em Barroso, 2010, esta taxa de aquecimento é adequada para medidas de DSC de dispersões de até $30 \mathrm{mM}$ de DMPG, obtendo-se resultados idênticos mesmo aquecendo-se a amostra mais lentamente, sendo que para as dispersões de $50 \mathrm{mM}$ de DMPG foi usada a taxa de $10^{\circ} \mathrm{C} / \mathrm{h}$. Nesta técnica preenchemos uma cela com o solvente (referência) e outra cela com a dispersão desejada, sendo que cada cela tem volume de $0,51 \mathrm{~mL}$ e ambas as celas estão sob isolamento térmico. As duas celas são então aquecidas a uma taxa constante e a diferença de potência entre as duas celas é gravada em função da temperatura e a partir desta obtêm-se a capacidade térmica, e então o calor específico em função da temperatura (ver Plotnikov et al., 1997). As análises foram feitas utilizando o software Microcal adicionado ao Origin 7.0 (Riske et al., 2009b). Primeiramente fazemos a correção da curva obtida pelo erro do equipamento, subtraindo da curva medida para a dispersão o resultado obtido quando preenchemos as duas celas com o solvente, estando o resultado em variação de capacidade térmica $\left(\Delta C_{P}\right)$, em cal $/{ }^{\circ} \mathrm{C}$, em função da temperatura (Fig. 3.2.3 a)). De modo a obter o gráfico de variação do calor específico $\left(\Delta c_{P}\right)$, deve-se dividir a curva de capacidade térmica pela razão concentração lipídica/volume de amostra, que representa o número de mols de DMPG na amostra,

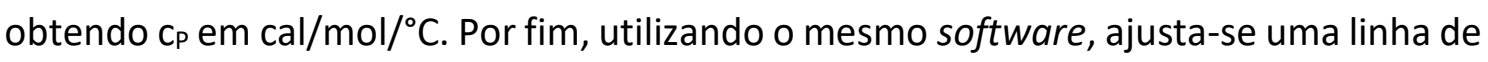
base, por um polinômio de $3^{\circ}$ grau (Fig. 3.2 .3 b)) que também é subtraída da curva de interesse. 

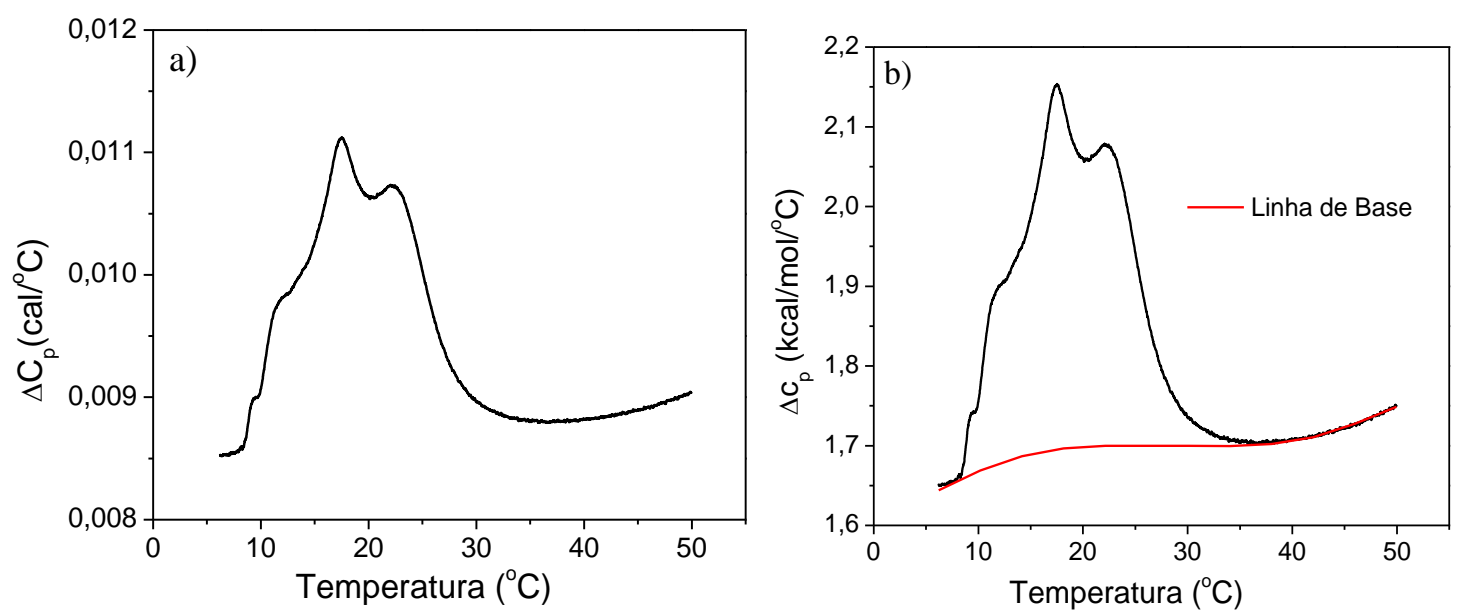

Figura 3.2.3: a) Variação da capacidade térmica em função da temperatura de uma dispersão de 10 mM de DMPG em água, já subtraída da referência (água). b) variação do calor específico obtido após a divisão da capacidade térmica pelo número de mols na amostra e linha de base cúbica criada pelo software da Microcal, sendo esta linha de base subtraída da curva experimental.

A entalpia envolvida no processo de transição (equação 2.1.6) corresponde à área sob a curva de calor específico em função da temperatura e foi calculada usando o software Origin, selecionando-se as temperaturas inicial e final da transição principal (figura 3.2.4).
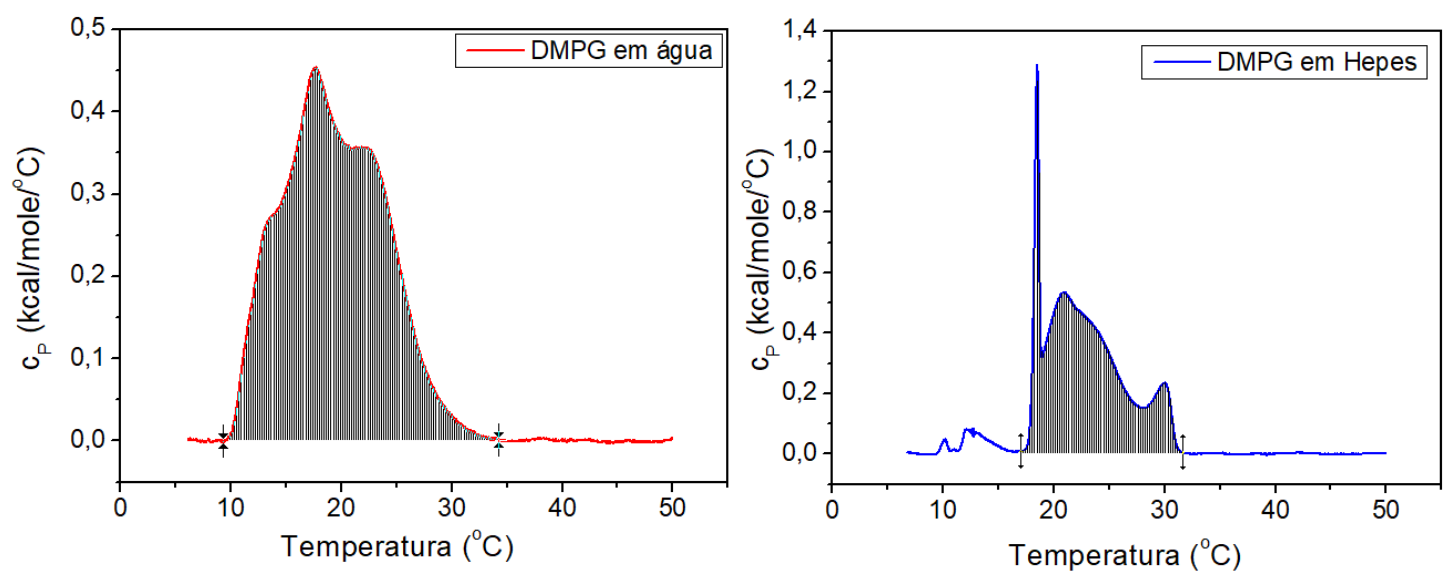

Figura 3.2.4: Os valores de entalpia das transições foram obtidos pelo cálculo das áreas sob a curva de capacidade térmica, hachuradas na figura. 


\subsubsection{Medidas de Viscosidade}

O aparato utilizado nas medidas de viscosidade é da Schott Instruments e conta com 3 partes: o viscosímetro de Ostwald, o banho térmico (modelo CT52) e um cronômetro automático (modelo Visocloth D - 55122) (ver figura 3.2.5).

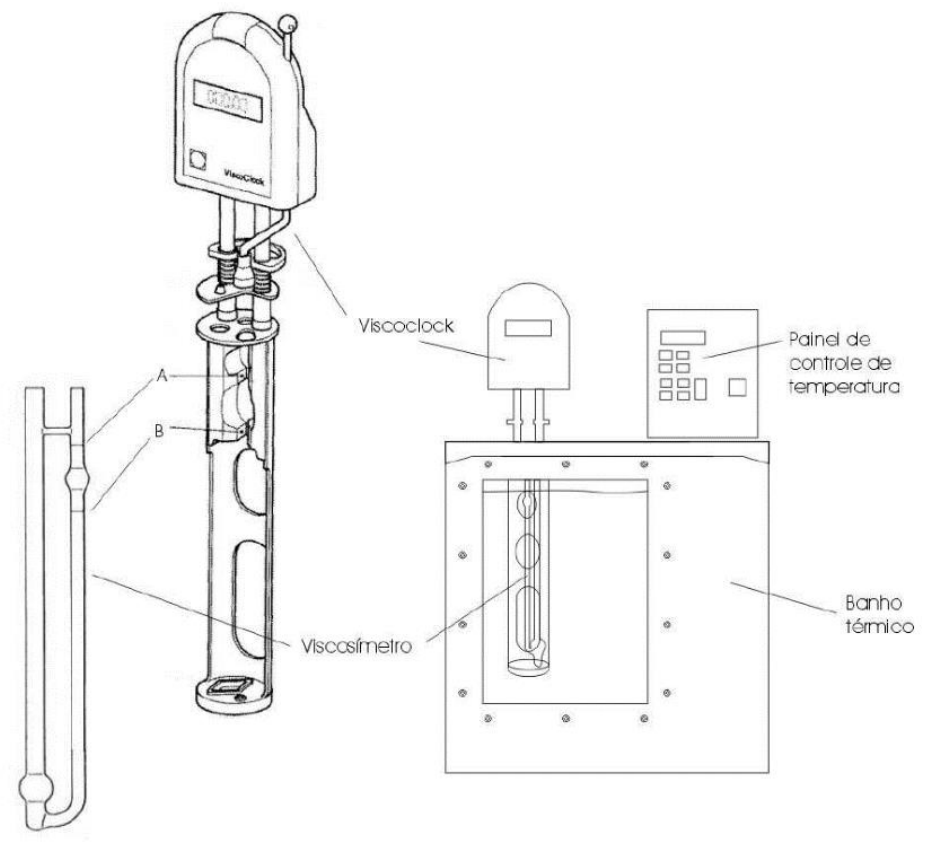

Figura 3.2.5: aparato experimental utilizado nas medidas de viscosidade (Fonte: Barroso, R.P., tese de doutorado, 2010)

Encaixa-se o viscosímetro no cronômetro e insere-se o conjunto no banho térmico. Injeta-se um pequeno fluxo de ar no viscosímetro utilizando-se uma pequena bomba manual, de modo a empurrar o líquido até uma altura maior do que o primeiro sensor do cronômetro (item A na figura 3.2.5). Retira-se o fluxo de ar, de modo que o líquido flui sob ação exclusiva da gravidade. Quando o líquido passa pelo primeiro sensor (A), o cronômetro dispara automaticamente e quando o líquido passa pelo segundo sensor (B) o cronômetro para. Faz-se a leitura do tempo de fluxo (t) e calcula-se a viscosidade cinemática a partir da fórmula:

$$
\eta=K t
$$

onde Ké uma constante que depende da geometria do capilar do viscosímetro. O tempo de termalização entre cada medida foi de 10 minutos. 


\subsubsection{Medidas de Condutividade Elétrica}

As medidas de condutividade elétrica foram feitas em um condutivímetro da WTM, modelo inoLab Cond 730. Mede-se a condutividade utilizando-se uma ponteira com quatro eletrodos ( 2 eletrodos de corrente e 2 eletrodos de tensão - modelo TetraCon 325), que também conta com um sensor de temperatura. Insere-se 3,5 $\mathrm{mL}$ de amostra em um cilindro de vidro com diâmetro pouco maior que o da ponteira, que é imersa no cilindro até que a amostra cubra seus eletrodos. Prende-se o cilindro e a ponteira com fita do tipo parafilm, de modo a evitar a evaporação de amostra. Inserese então esse conjunto em um porta-amostra com água, que está ligado a um banho térmico (modelo HP25 da Julabo) e inserido dentro de uma caixa de isopor, preenchida com isolante térmico.

O condutivímetro armazena os valores da condutividade e da temperatura automaticamente, a cada intervalo de tempo definido pelo usuário. Neste trabalho, definiu-se esse intervalo de tempo em 5 minutos e programou-se a temperatura do banho térmico para aumentar $1^{\circ} \mathrm{C}$ a cada 15 minutos.

Neste equipamento aplica-se uma corrente $(\Lambda$ alternada nos eletrodos de corrente e mede-se os valores de tensão elétrica ( $V$ ) entre os eletrodos de tensão. A condutância $(G)$, que é dada pelo inverso da resistência elétrica, é obtida a partir da relação:

$$
G=\frac{I}{V}
$$

A partir do valor de $\mathrm{G}$, obtém-se a condutividade elétrica $(\sigma)$ da dispersão através da equação:

$$
\sigma=G \cdot K
$$

onde $K$ é uma constante de calibração do aparelho, obtida a partir de medidas de uma solução padrão de $0,01 \mathrm{M}$ de $\mathrm{KCl}$. A calibração foi realizada precedendo as medidas de condutividade elétrica de cada dispersão. 


\subsubsection{Medidas de Absorbância (Turbidez)}

As medidas de Absorbância foram realizadas no espectrofotômetro modelo Varian Cary 50 Bio. A amostra foi inserida em uma cubeta de quartzo, sendo de $2 \mathrm{~mm}$ o caminho óptico percorrido pela luz incidente na dispersão. As temperaturas foram ajustadas através do banho térmico modelo Julabo HP25 acoplado ao espectrofotômetro, sendo necessário o uso de fluxo de nitrogênio para temperaturas abaixo de $15^{\circ} \mathrm{C}$. O tempo de termalização entre cada medida foi de 5 minutos. Os valores de Absorbância nas várias temperaturas foram medidos em $\lambda=350 \mathrm{~nm}$.

\subsubsection{Medidas de $\mathrm{pH}$}

As medidas de $\mathrm{pH}$ foram realizadas com o medidor de $\mathrm{pH}$ da Mettler Toledo, modelo S20 SevenEasy, utilizando o eletrodo de pH InLab Micro Pro, também da Mettler Toledo, que possui corpo de vidro e sensor de temperatura integrado. A ponteira é imersa em 1,5 mL de amostra, que se encontra em um tubo de ensaio, e prende-se a ponteira e o tubo de ensaio com fita do tipo parafilm, de modo a evitar a evaporação de amostra. Insere-se então esse conjunto em um porta-amostra com água, que é inserido dentro de uma caixa de isopor, preenchida com isolante térmico e está ligado a um banho térmico (modelo HP25 da Julabo).

As medidas foram feitas quando a saída do sensor se estabilizava (o valor mostrado no "display" não variava mais) e anotou-se o valor da temperatura e do $\mathrm{pH}$. Para cada temperatura repetiu-se a medição três vezes, não se obteve variações maiores que 0,02 para o valor de $\mathrm{pH}$ de uma mesma temperatura.

O aparelho é constituído por um eletrodo e um circuito potenciômetro. O eletrodo possui uma solução eletrolítica de referência ( $3 \mathrm{M}$ de $\mathrm{KCl}$ ) em sua parte interna e faz-se a calibração utilizando-se tampões de pH 4, 7 e 10. Quando o eletrodo é imerso na amostra de interesse, faz-se a leitura da tensão (em $\mathrm{mV}$ ) gerada, sendo esse valor convertido para uma escala de $\mathrm{pH}$.

$\mathrm{O}$ pH é uma escala para a medida do potencial hidrogênico de uma solução aquosa, indicando sua acidez ou basicidade e é expressa por: 


$$
\mathrm{pH}=-\log \left[\mathrm{H}^{+}\right]
$$

onde $\left[\mathrm{H}^{+}\right]$ou $\left[\mathrm{H}_{3} \mathrm{O}^{+}\right]$é a concentração de íons de hidrogênio na solução.

\subsubsection{Medidas de Mobilidade eletroforética}

As medidas de mobilidade eletroforética foram realizadas no aparelho Zetasizer Nano ZS90, da Malvern, utilizando-se a célula capilar descartável (DTS 1060), também da Malvern. A medida é realizada através da microeletroforese Doppler a laser, onde aplica-se um campo elétrico que faz os agregados em solução moverem-se em direção aos eletrodos. O feixe de laser incidente é espalhado pelos agregados, gerando uma flutuação ao longo do tempo entre o feixe incidente e espalhado, sendo esta flutuação proporcional à velocidade dos agregados.

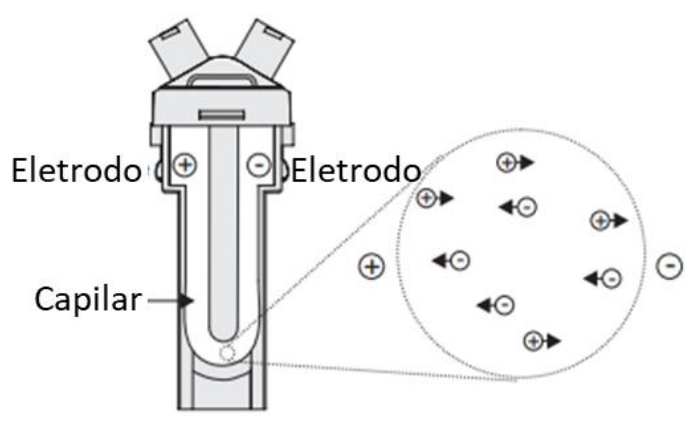

Figura 3.2.6: Ilustração do capilar da Malvern utilizado para as medidas de mobilidade eletroforética.

Para medidas abaixo de $15^{\circ} \mathrm{C}$ foi necessário o uso de um fluxo constante de Nitrogênio para evitar condensação de água na cubeta. Acima de $30^{\circ} \mathrm{C}$ prestou-se atenção a pequenas bolhas de ar que se formavam e grudavam nas paredes do capilar, interferindo na medida, sendo necessário a retirada dessas bolhas antes da realização das medidas com pequenas batidas nas paredes da célula. Também tomou-se cuidado em verificar se os eletrodos permaneciam intactos, sem sinal de oxidação e manchas escuras, após cada medida. 
A mobilidade dos contraíons $\left(\mu^{\mathrm{Na}+}\right)$, foi calculada pela equação empírica (Harned \&Owen, 1967):

$$
\mu^{N a^{+}}=\frac{50,11+1,0916(T-25)+0,004715(T-25)^{2}-0,0000115(T-25)^{3}}{N_{A} e}
$$

\subsubsection{Medidas de Espalhamento de Luz}

Medidas de espalhamento de luz dinâmico (DLS), estático (SLS) e da razão de despolarização da luz espalhada foram realizadas no aparelho da Brookhaven Instruments Corporation, que é composto por um laser diodo compacto (mini-L30), polarizado verticalmente e de $\lambda_{0}=637 \mathrm{~nm}$ e potência de $30 \mathrm{~mW}$, um goniômetro motordrive $\mathrm{BI}$-200SM (permite variação de ângulos entre $8^{\circ}$ e $155^{\circ}$ ), um detector de fotodiodo de avalanche (BI-APDX) e um correlator digital BI-9000AT. O tubo de ensaio, contendo $2 \mathrm{ml}$ da amostra de interesse, é inserido em uma cuba de vidro que está preenchida com decalina (deca-hidro naftaleno), líquido cujo índice de refração é próximo ao do vidro, diminuindo reflexões na parede do tubo. Acoplados a essa cuba, estão um banho térmico (Poly Science) para o controle de temperatura da amostra, e um filtro para a decalina. Este equipamento dispõe de alguns softwares para a aquisição e análise de dados, e para o controle de alinhamento do sistema óptico. É possível o ajuste manual da abertura de um pin-hole, de um filtro que seleciona o comprimento de onda e um polarizador que seleciona a orientação da luz espalhada que incide no detector. Uma foto deste aparato experimental é mostrada na figura 3.2.7. 


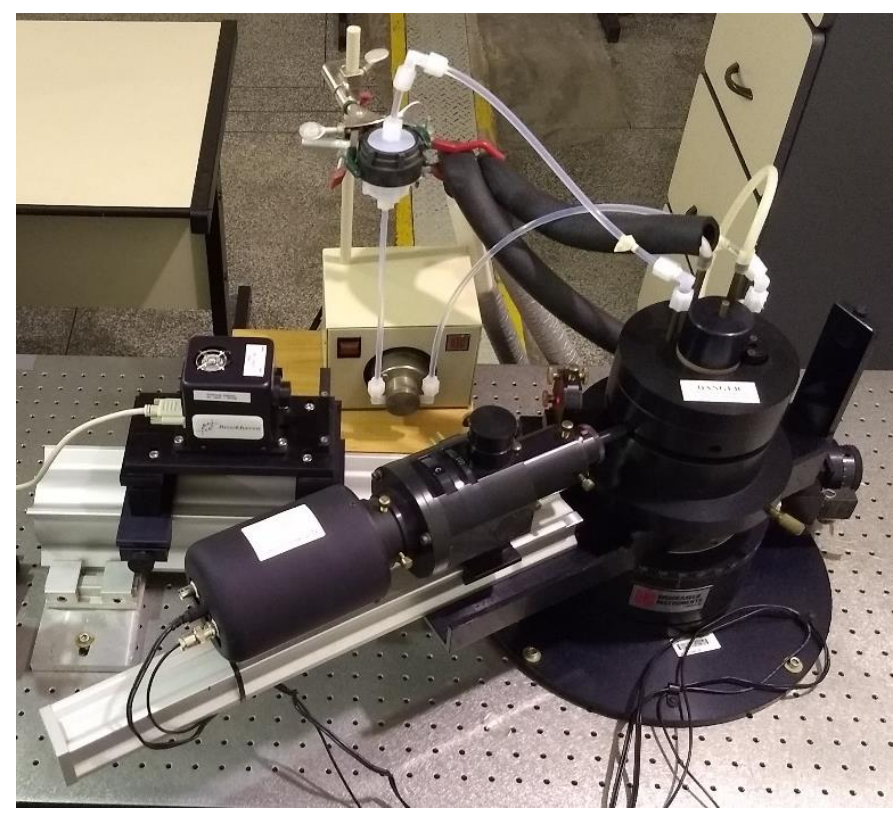

Figura 3.2.7: Aparelho de espalhamento de luz da Brookhaven Instruments Corporation.

Antes do início dos experimentos, o laser foi ligado por 30 minutos, filtrou-se a decalina por cerca de 5 minutos e, utilizando os softwares da Brookhaven, verificou-se o alinhamento do aparelho bem como a estabilidade do laser incidente. Nas medidas de DLS, determinamos o tempo de duração das medidas de 1 minuto e ajustamos o tempo inicial e final da função de autocorrelação conforme o sistema estudado. Para as medidas de espalhamento de luz estático, cada ponto experimental é a média entre 3 medidas realizadas, sendo esta média calculada diretamente pelo software. Se desejado, foram realizadas medidas variando-se o ângulo de espalhamento entre $40 \mathrm{e}$ $140^{\circ}$, região angular onde o alinhamento do sistema óptico foi verificado.

De modo a verificar uma possível anisotropia das partículas espalhadoras de luz, utilizamos o mesmo aparato experimental das medidas de DLS e SLS e fez-se uso do polarizador que se encontra acoplado ao detector de luz espalhada. Sabendo que a luz do laser é verticalmente polarizada, medimos a razão entre a intensidade de luz espalhada perpendicularmente $\left(\mathrm{I}_{\mathrm{VH}}\right)$ e paralelamente $\left(\mathrm{I}_{\mathrm{Vv}}\right)$ à luz incidente. Como forma de controle, antes das medidas, foi verificado o valor de $\mathrm{IVH}_{\mathrm{VH}} / \mathrm{IVV}_{\mathrm{VV}}=0,26$ para uma amostra de benzeno, que é uma razão conhecida na literatura.

O uso do aparelho de espalhamento de luz da Brookhaven apresenta muitas vantagens no estudo de sistemas coloidais, principalmente por permitir a realização de medidas de intensidade de luz espalhada em diferentes ângulos e por disponibilizar um 
maior controle sobre os parâmetros utilizados. Entretanto, uma limitação que enfrentamos foi a impossibilidade de realizar medidas abaixo de $10^{\circ} \mathrm{C}$ (fase gel do DMPG em água), devido ao embaçamento da cuba de vidro. Tentativas de desumidificar o ambiente e de utilizar um fluxo de nitrogênio foram realizadas, mas além do alto gasto de nitrogênio, não foi possível evitar totalmente a condensação de água no vidro.

De modo a obter resultados de DLS nas termperaturas de 5 a $45^{\circ} \mathrm{C}$, realizou-se medidas no aparelho Zetasizer Nano ZS9O, da Malvern. Trata-se de um aparelho mais simples e compacto (ver figura 3.2.8), tendo em seu interior um Laser HeNe de potência $4 \mathrm{~mW}$ e $\lambda_{0}=633 \mathrm{~nm}$, o atenuador, o detector, o correlator, e o controle de temperatura. Para as temperaturas abaixo de $15^{\circ} \mathrm{C}$, utilizou-se um fluxo de Nitrogênio para evitar o embaçamento das cubetas descartáveis de plástico da Malvern, que foram preenchidas com 1,5 mL de amostra. Neste aparelho só é possível realizar medidas com o detector a $90^{\circ}$ do feixe incidente. Este equipamento dispõe de alguns softwares para a aquisição e análise de dados e vários parâmetros experimentais, tais como a intensidade do laser, duração da medida e tempos mínimo e máximo da função de autocorrelação, são automaticamente ajustados pelo software no início do experimento. Além disto, os resultados finais são as médias de várias medidas realizadas, sendo que o número de repetições e duração de cada medida podem ser determinadas pelo usuário ou automaticamente pelo software de aquisição de dados.

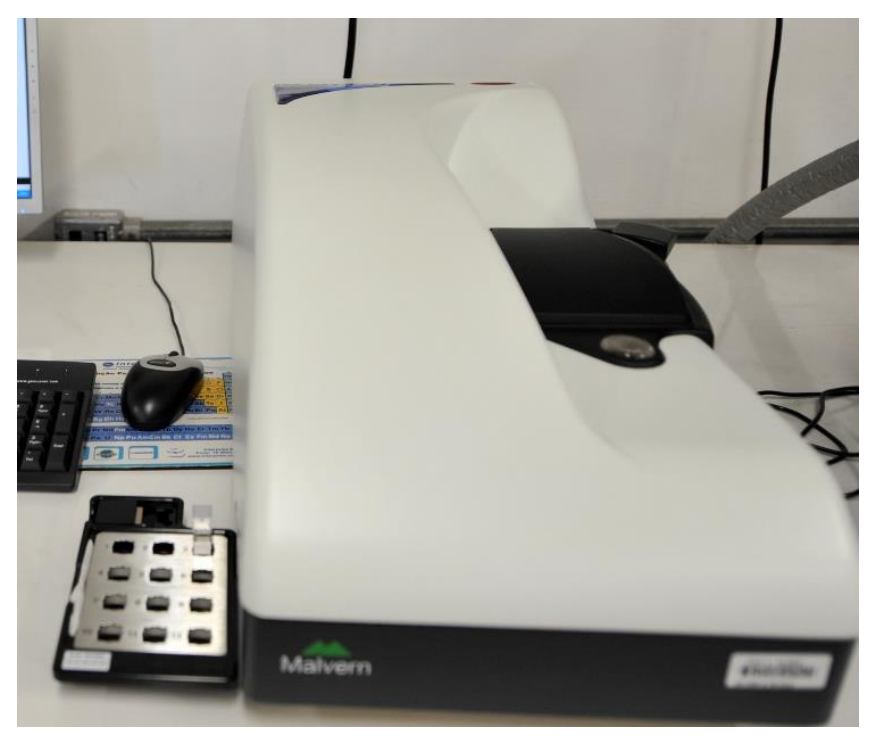

Figura 3.2.8: Aparelho Zetasizer Nano ZS9O, da Malvern, que foi utilizado para medidas de DLS e de mobilidade eletroforética. 
Durante estágio realizado em Graz, Áustria, foi possível realizar medidas de DLS e da razão de despolarização da luz espalhada em colaboração com o Prof. Dr. Otto Glatter e a Dra. Angela Chemelli, no Institute of Inorganic Chemistry da Graz University of Technology, Áustria. O aparato experimental (figura 3.2.9) foi montado pelo próprio professor Glatter e é constituído por um potente laser de luz verde (coherent Verdi V5, $\lambda$ = $532 \mathrm{~nm}$, potência máxima de $5 \mathrm{~W}$ ), um goniômetro com sistema de detecção ótica de fibra monomodo (OZ da GMP, Zurique, Suiça). A luz espalhada foi detectada por um fotomultiplicador (ALV/SO-SIPD/DUAL) no modo de pseudo correlação cruzada e um correlator ALV 5000/E com sistema de rápida expansão que permite um menor intervalo de tempo de correlação $(12,5$ ns) na função de autocorrelação. Neste aparato experimental só é possível medir a intensidade de luz espalhada no ângulo de $90^{\circ}$. Preencheu-se um pequeno frasco de vidro com $1 \mathrm{~mL}$ de amostra e inseriu-se em uma cuba de vidro preenchida com decalina, que estava conectada a um banho térmico de água e ao filtro de decalina.

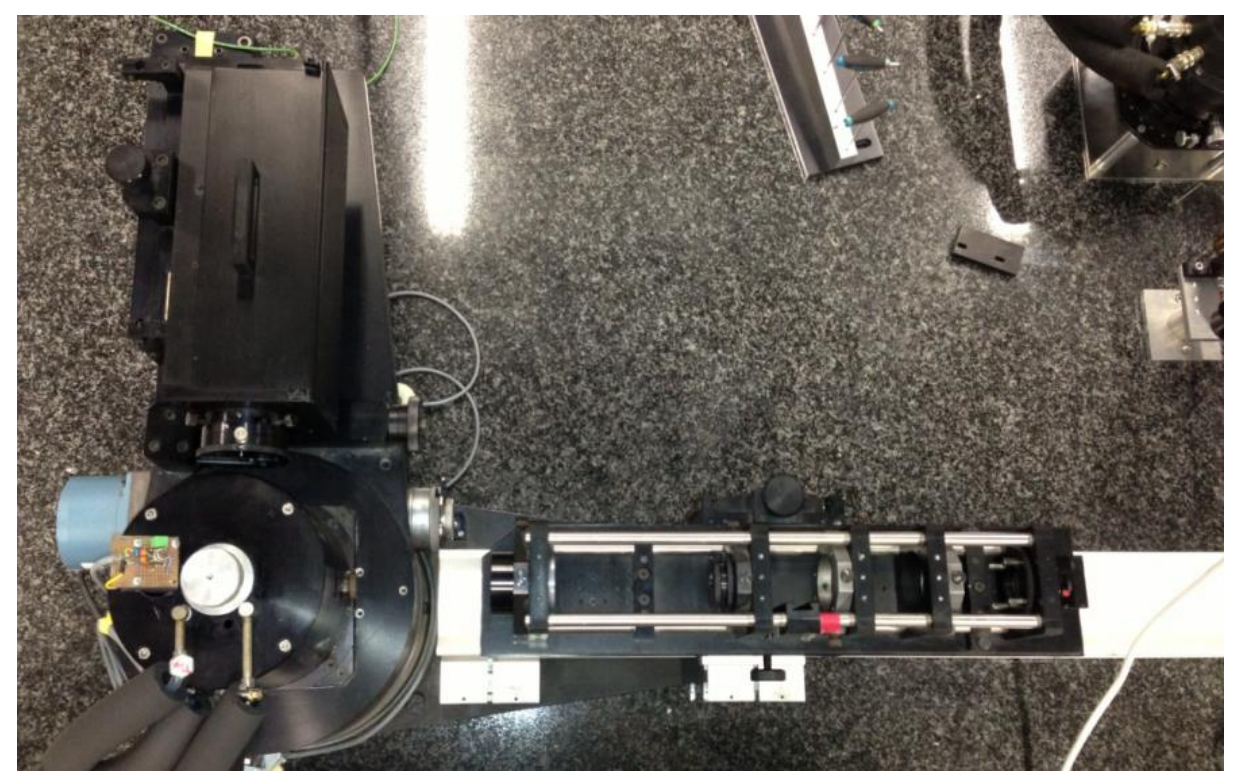

Figura 3.2.9: Aparato experimental para medidas de DLS do Institute of Inorganic Chemistry da Graz University of Technology, Áustria.

O tempo de termalização foi de 15 minutos e foram realizadas 10 medidas com duração de 30 segundos cada, sendo utilizada a função de correlação média das 10 medidas para as análises que foram realizadas pela Dra. Angela Chemelli no programa ORTLight Light Scattering Analysis Software (desenvolvido na Graz University of Technology por Meisenbichler C., Glatter O., Chemelli A. e Uhlig F., sendo uma adaptação do programa ORT - Optimized Regularization Technique, descrito em 
Schnablegger \& Glatter, 1991). Para as medidas de razão de despolarização da luz espalhada colocou-se um polarizador na frente do detector.
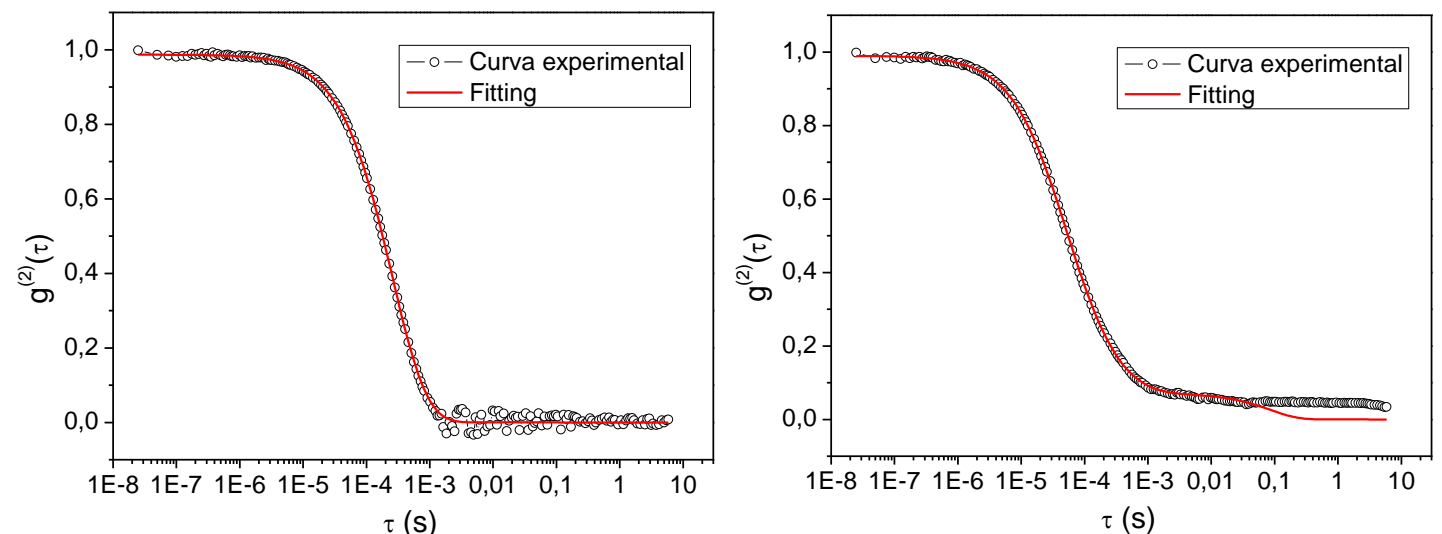

Figura 3.2.10: Exemplos de ajustes da função de autocorrelação da luz espalhada a $90^{\circ}$ obtidos pela Dra. Angela Chemelli no programa ORTLight. No gráfico da esquerda para a dispersão de $1 \mathrm{mM}$ de DMPG em água e no gráfico da direita para a dispersão de 10 $\mathrm{mM}$ de DMPG em água, ambos em $\mathrm{T}=20^{\circ} \mathrm{C}$.

\subsubsection{Medidas de Ressonância Paramagnética Eletrônica (RPE) de marcadores de spin}

Os experimentos de RPE foram realizados no espectrômetro EMX da Bruker em banda-X. Cerca de $50 \mu \mathrm{L}$ de amostra era inserida em um capilar de quartzo, que era selado em um bico de Bunsen, e colocava-se o capilar na cavidade ressonante retangular, onde havia circulação de nitrogênio gasoso para o ajuste da temperatura, que era controlada pelo aparelho BVT-2000 da Bruker, sendo o campo magnético medido pelo dispositivo Bruker ER 035 NMR. A variação do campo magnético foi de $100 \mathrm{G}$ (entre 3302 e $3402 \mathrm{G}$ ), a amplitude de modulação foi de $1 \mathrm{G}$ e a potência do feixe incidente foi de $10 \mathrm{~mW}$. Os espectros foram obtidos utilizando o software da Bruker Win-EPR Aquisition. 


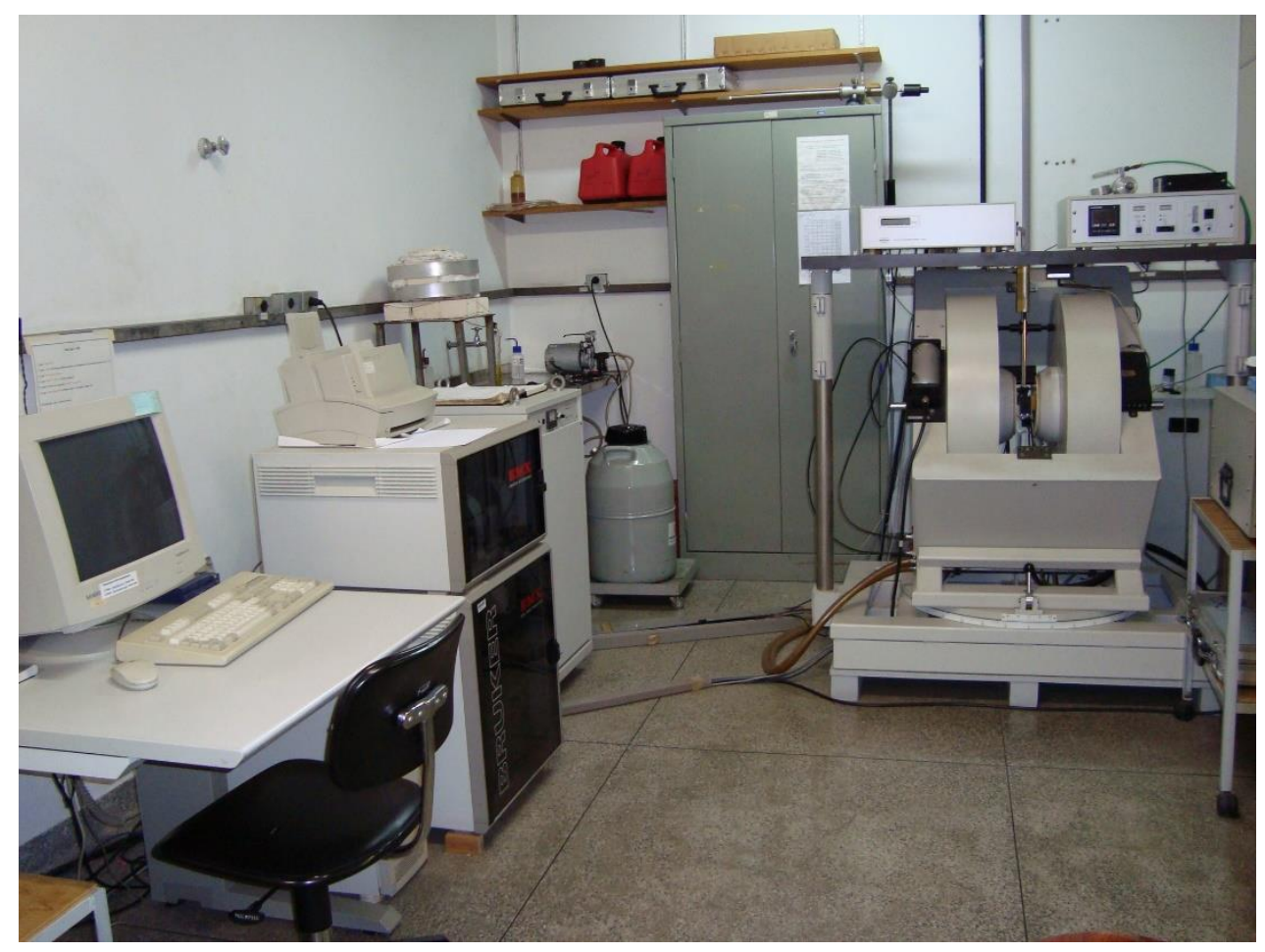

Figura 3.2.11: Aparato experimental utilizado nas medidas de RPE.

Uma primeira análise dos dados de RPE foi feita medindo-se alguns parâmetros de interesse diretamente a partir dos espectros, usando o software Win-EPR da Bruker. No caso das dispersões de DMPG com o marcador de spin 5-PCSL mediu-se o desdobramento hiperfino máximo $\left(\mathrm{A}_{\max }\right)$ em todas as temperaturas e o desdobramento hiperfino mínimo (Amin), que só pode ser medido na fase fluida $\left(T>28^{\circ} \mathrm{C}\right)$, conforme indicado na figura 3.2.12. 


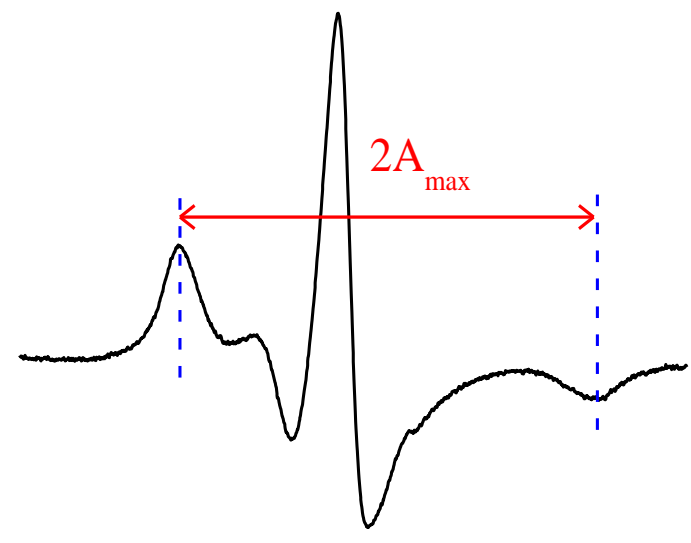

$\mathrm{T}=5^{\circ} \mathrm{C}$ (fase gel)

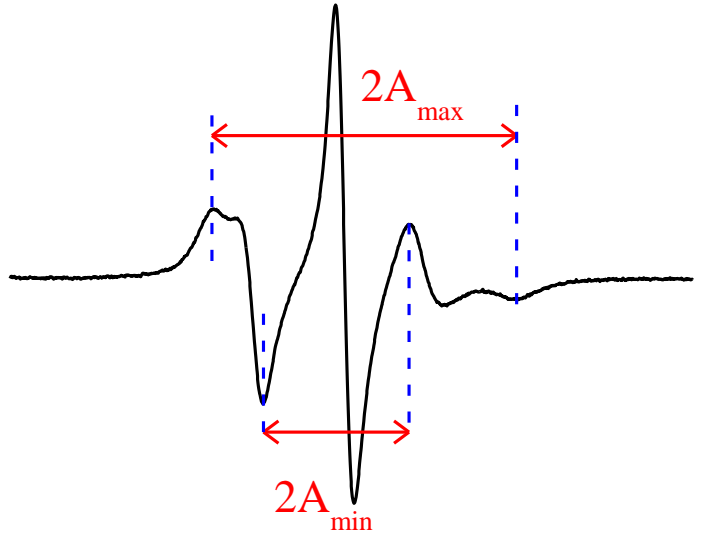

$\mathrm{T}=50^{\circ} \mathrm{C}$ (fase fluida)

Figura 3.2.12: Espectros de RPE de uma dispersão de $10 \mathrm{mM}$ de DMPG + 0,8 mol\% do marcador 5-PCSL em água, mostrando os desdobramentos hiperfinos máximo $\left(A_{\max }\right)$ e mínimo $\left(A_{\min }\right)$.

Com os valores de $A_{\max }$ e $A_{\min }$, calculou-se o parâmetro de ordem efetivo ( $\mathrm{S}_{\mathrm{ef}}$ ) a partir da equação (Knowles et al., 1976; Gaffney, 1976; Smith et al., 1976):

$$
S_{e f}=\frac{A_{\|}-A_{\perp}}{A_{z z}-(1 / 2)\left(A_{x x}+A_{y y}\right)} \cdot \frac{a_{0}^{\prime}}{a_{0}}
$$

onde $a_{0}$ é o desdobramento hiperfino isotrópico experimental, dado por:

$$
a_{0}=\frac{1}{3}\left(A_{\|}+2 A_{\perp}\right)
$$

a'o é o desdobramento hiperfino isotrópico teórico:

$$
a_{0}^{\prime}=\frac{1}{3}\left(A_{x x}+A_{y y}+A_{z z}\right)
$$

$A_{\|}$é o desdobramento hiperfino externo, sendo que $A_{\|}=A_{\max }$, e $A_{\perp}$ é calculado por:

$$
A_{\perp}=A_{\text {min }}+1,4\left[1-\frac{A_{\text {max }}-A_{\text {min }}}{A_{z z}-(1 / 2)\left(A_{x x}+A_{y y}\right)}\right] .
$$

Utilizou-se os valores principais do tensor hiperfino mostrados na tabela 2.1 para $A_{x x}, A_{y y}$ e $A_{z z}$. 
Para os espectros de DMPG com o marcador de spin 16-PCSL, mediu-se a partir dos espectros as alturas das linhas das interações hiperfinas $h+1$ e $h 0$ para todas as temperaturas e $\mathrm{h}_{-1}$ apenas na fase fluída e a largura $\mathrm{a}_{0}$, esta última apenas para $\mathrm{T}>45^{\circ} \mathrm{C}$.
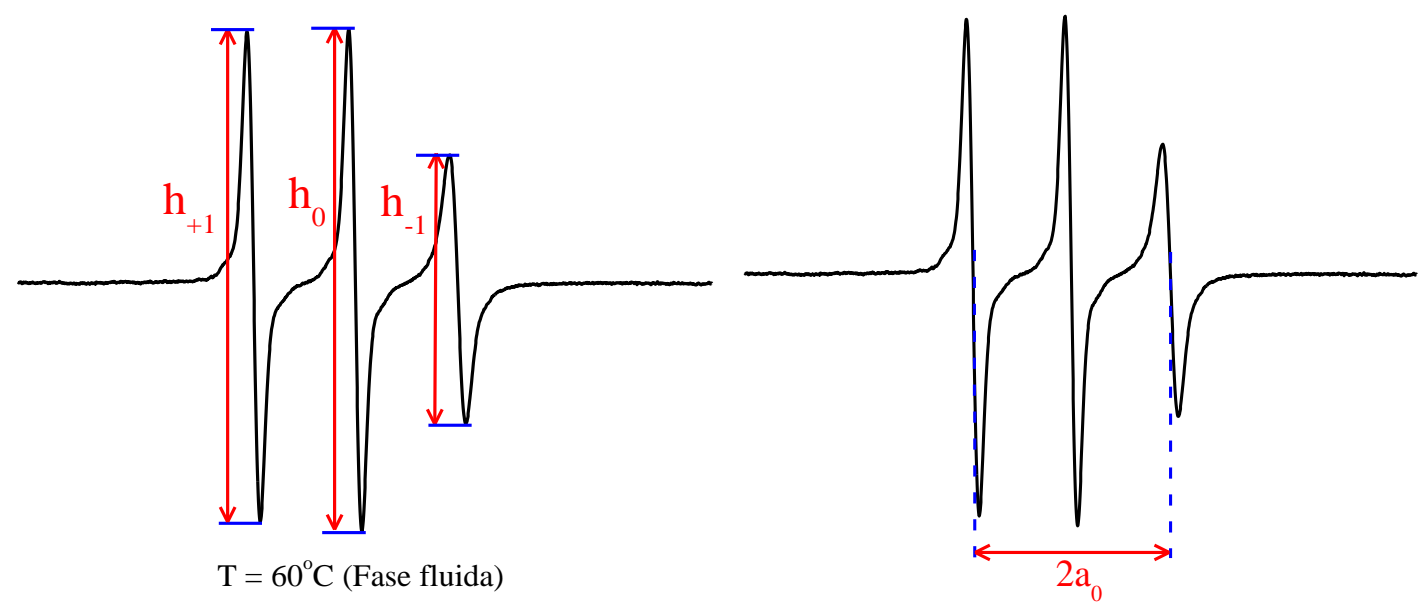

Figura 3.2.13: Espectro de RPE de uma dispersão de $10 \mathrm{mM}$ de DMPG + 0,3 mol\% do marcador $16-\mathrm{PCSL}$ em água a $60^{\circ} \mathrm{C}$, mostrando como os parâmetros $\mathrm{h}_{+1}, \mathrm{~h}_{0}, \mathrm{~h}_{-1}$ e a0 foram medidos a partir dos espectros experimentais.

Para realizar um estudo mais rigoroso dos resultados de RPE, realizou-se simulações teóricas, com o programa Multi-Component EPR Fitting, desenvolvido por Christian Altenbach (Altenbach, 2017), que é baseado na teoria desenvolvida pelo grupo do Freed (Freed, 1976; Fernandez, et al., 2000; Oliveira et al., 2011).

\subsubsection{Medidas de Espalhamento de Raio-X}

Parte das medidas de espalhamento de Raio-X a baixo ângulo (SAXS) foram realizadas no Laboratório Nacional de Luz Síncrotron (LNLS, Campinas - SP) na linha SAXS-1 em duas oportunidades, na primeira utilizando a distância amostra-detector de $1 \mathrm{~m}$ e posteriormente utilizando a máxima distância possível, que é de $3 \mathrm{~m}$, de modo a estudar melhor a região de menores ângulos de espalhamento. O comprimento de onda da radiação incidente é $\lambda=1,55 \AA$. Utilizou-se o porta amostra de mica, que utiliza aproximadamente $300 \mu \mathrm{L}$ de amostra, acoplado a um banho térmico de água, esperando-se 10 minutos após a temperatura de interesse ser atingida para iniciar a medida. Dado que a temperatura no porta amostra se mostrou diferente da indicada 
pelo banho térmico, usou-se um termopar próximo ao porta amostra para fazer a leitura da temperatura da amostra. Utilizou-se o tempo de exposição de $300 \mathrm{~s}$ para as medidas de água, tampão e amostras de DMPG $1 \mathrm{mM}$ e para as demais concentrações lipídicas (10, 30, 40, 50 e 60 mM) utilizou-se exposição de 200 s. Para a distância de 3 m, dado a maior distância amostra-detector, algumas das medidas ficaram demasiadamente ruidosas e não foi possível observar o pico de interesse na região de baixo q.

Outras medidas de SAXS e WAXS foram realizadas no laboratório do Insitute of Molecular Biosciences, Biophysics Division, na University of Graz, Graz, Áustria, sob supervisão do Prof. Dr. Georg Pabst durante o estágio de pesquisa que foi realizado. 0 aparelho utilizado foi o SAXSpace, da Anton Paar, Graz, Áustria. Este instrumento utiliza um feixe de raios- $X \operatorname{com} \lambda=1,54 \AA$ e foi possível realizar medidas de espalhamento a baixos ângulos (SAXS $\rightarrow$ aproximadamente de $0,04^{\circ}$ a $10^{\circ}$ ), usando a distância amostradetector de $308 \mathrm{~mm}$ e altos ângulos (WAXS, até $74^{\circ}$ ), com a distância amostra-detector de $112 \mathrm{~mm}$. A temperatura foi controlada por uma placa de Peltier e o tempo de termalização foi de 10 minutos.

Para a realização destas medidas, preencheu-se uma " $\mu$-Cell" (Anton Paar) com aproximadamente $10 \mu \mathrm{L}$ de amostra e a aquisição de dados foi realizada fazendo-se 4 medidas com $1800 \mathrm{~s}$ de exposição cada, nas diferentes temperaturas (de 5 a $45^{\circ} \mathrm{C}$ ), nas diferentes distâncias amostra-detector (112 e $308 \mathrm{~mm}$ ). O solvente foi medido nas mesmas condições e as correções de background foram realizadas utilizando o software PRIMUS.
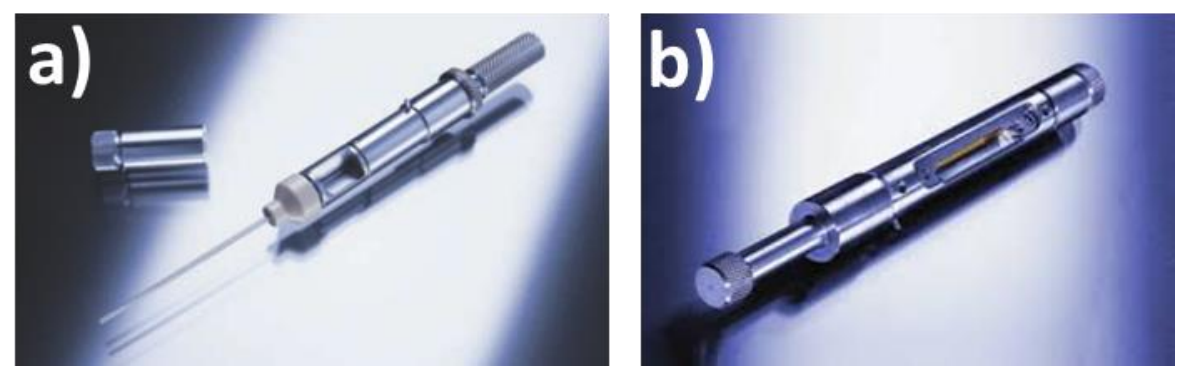

Figura 3.2.14: a) " $\mu$-Cell" e b) "Paste Cell", ambas da Anton Paar.

Para as medidas de curvatura espontânea, utilizou-se a "Paste Cell" (Anton Paar), que é especial para amostras pastosas e o capilar de $1 \mathrm{~mm}$ de diâmetro também da 
Anton Paar para as medidas dos solventes. Foram realizadas 3 medidas com $600 \mathrm{~s}$ de duração cada, para cada amostra em cada temperatura $\left(20,30,40\right.$ e $\left.50^{\circ} \mathrm{C}\right)$ e a distância amostra-detector foi de $308 \mathrm{~mm}$.

As curvas de SAXS e WAXS foram combinadas usando o software PRIMUS, resultando em curvas de SWAXS.

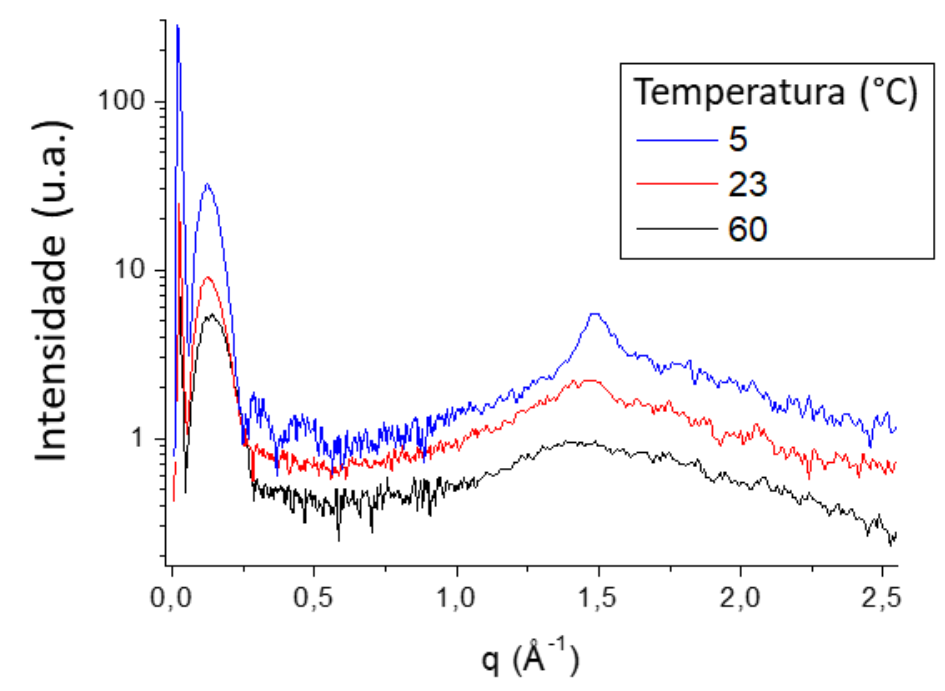

Figura 3.2.15: Exemplo de curvas de SWAXS obtidas para dispersões de DMPG $50 \mathrm{mM}$ em água, na fase gel $\left(5^{\circ} \mathrm{C}\right)$, na transição de fase $\left(23^{\circ} \mathrm{C}\right)$ e na fase fluida $\left(60^{\circ} \mathrm{C}\right)$.

Para a análise dos dados, consideramos 3 diferentes intervalos de $q$, similar ao mostrado na figura 3.2.12: a região a muito baixo q (abaixo de $0,04 \AA^{-1}$ ), a região de ângulo pequeno (entre 0,04 e $0,5 \AA^{-1}$ ) e, para as medidas de SWAXS, a região de alto ângulo (entre 0,5 e 2,6 $\AA^{-1}$ ). A partir dos dados de cada região, podemos obter diferentes informações do sistema. Simulações foram realizadas com o programa GAP (Global Analysis Program), que foi desenvolvido pelo Prof. Dr. Georg Pabst durante o seu doutorado (ver Pabst et al., 2000, 2003 e Pabst, 2006). 


\section{Capítulo 4 - Resultados e discussões:}

\section{algumas técnicas utilizadas em}

\section{dispersões de DMPG em água}

Neste capítulo apresentamos e discutimos os resultados obtidos para dispersões de DMPG em água pura, através das técnicas de DSC, medidas de viscosidade, condutividade elétrica, mobilidade eletroforética e turbidez para amostras antes e depois da extrusão, isto é, mais e menos polidispersas, aumentando e diminuindo a temperatura. Apresentamos também medidas de DLS, SLS e da razão de despolarização da luz espalhada para dispersões extrusadas de DMPG em água.

As amostras de DMPG em água pura tiveram o $\mathrm{pH}$ verificado, uma vez que essas dispersões não estão tamponadas, antes e depois de sua utilização nas diversas técnicas experimentais e também variando-se a temperatura de 5 a $60^{\circ} \mathrm{C}$, obtendo-se valores de $\mathrm{pH}$ entre 5,3 e 8,0 para todas as amostras, sendo estes valores maiores que o $p K_{a}=4,1$ (Watts et al., 1978) do DMPG, mostrando que não há desprotonação nas temperaturas consideradas. 


\subsection{Calorimetria Diferencial de Varredura (DSC)}

A técnica de DSC nos fornece informações termodinâmicas acerca de possíveis transições de fase, ou fenômenos que envolvam variações de calor absorvido ou emitido pela amostra, com relação ao solvente puro.
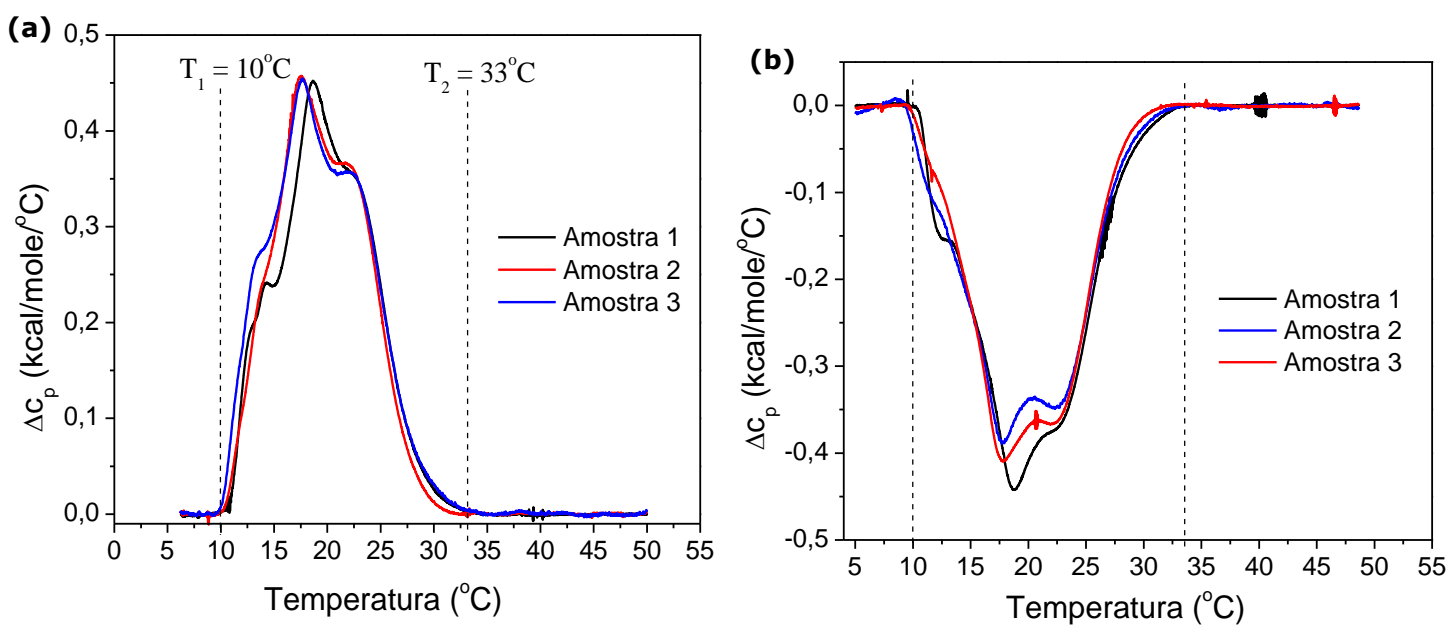

Figura 4.1.1: Curvas da variação do calor específico em função da temperatura para três amostras distintas de DMPG $10 \mathrm{mM}$ em água, após a extrusão. (a) As curvas foram medidas com a temperatura aumentando a uma taxa de $20^{\circ} \mathrm{C} / \mathrm{h}$ (b) As curvas foram medidas com a temperatura diminuindo a uma taxa de $20^{\circ} \mathrm{C} / \mathrm{h}$.

Observando as curvas apresentadas na figura 4.1.1, para três amostras diferentes de DMPG com concentração de 10 mM em água, após a extrusão, notamos uma larga região de "transição de fase", que se inicia em $\sim 10^{\circ} \mathrm{C}$ e se estende até $\sim 33^{\circ} \mathrm{C}$ e é caracterizada pela presença de 3 picos de calor específico visíveis. Chamaremos essa região de "região de transição de fase", apesar de sua baixa cooperatividade, pois mostraremos mais adiante, por medidas de RPE, que a baixas temperaturas $\left(5^{\circ} \mathrm{C}\right)$ os lipídios estão muito mais empacotados (característica da fase gel) do que a temperaturas acima de $30^{\circ} \mathrm{C}$ (fase fluida). Como não é possível distinguir os picos de variação de calor especifico com clareza, optamos apenas por indicar por $\mathrm{T}_{1} \mathrm{O}$ início da transição de fase e por $T_{2}$, o final da transição de fase.

A entalpia da transição foi calculada a partir das áreas das curvas da figura 4.1.1a) entre 10 e $33^{\circ} \mathrm{C}$ e obteve-se o valor de 4,9 (3) $\mathrm{kcal} / \mathrm{mol}$. A escolha de uma linha de base adequada é essencial para o cálculo correto da entalpia, sendo que às vezes é necessário fazer uma escolha subjetiva dos limites dos eventos térmicos, principalmente quando estamos lidando com uma transição "larga", como é o nosso caso (Heimburg, 2007). 
Também notamos que as curvas com a temperatura subindo (Figura 4.1.1 (a)) e descendo (figura 4.1.1 (b)) são bastante semelhantes entre si, mostrando a reversibilidade dos eventos térmicos, uma vez que os picos coincidem. De modo a padronizar as comparações, optei por utilizar as curvas obtidas com a temperatura aumentando.

Foram realizadas medidas sucessivas, aumentando e depois diminuindo a temperatura, sendo que o intervalo de tempo entre o início de cada varredura foi de $\sim 3 h$.
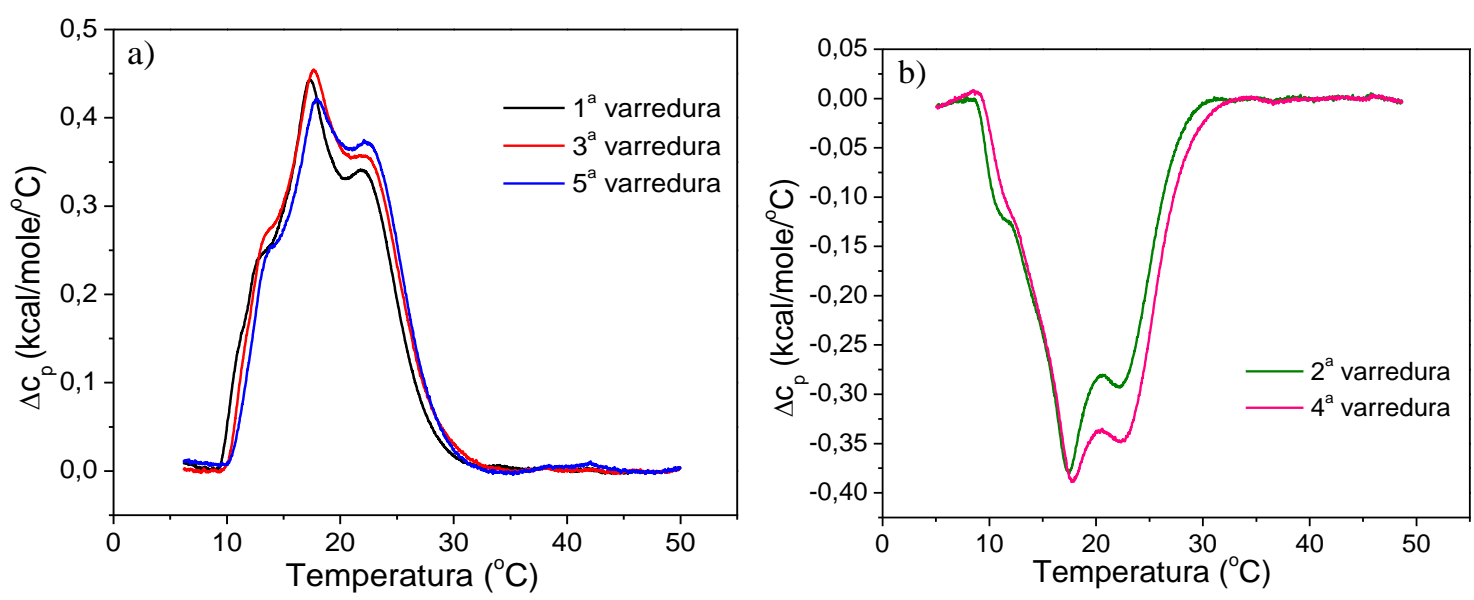

Figura 4.1.2: Varreduras sucessivas da amostra 3 (figura 4.1.1) aumentando (gráfico a) e diminuindo (gráfico b) a temperatura a uma taxa de $20^{\circ} \mathrm{C} / \mathrm{h}$.

Ao repetir-se o processo de esquentar e esfriar a amostra, a transição de fase, os picos térmicos característicos e as entalpias da transição não se alteram, no intervalo de tempo de $\sim 15$ horas, apenas a curva se desloca ligeiramente para temperaturas mais altas com o passar do tempo, mostrando que podemos considerar o sistema razoavelmente estável nesse intervalo de tempo.

Dada a desconfiança que as dispersões de DMPG em água formam vesículas majoritariamente pequenas (menores que $100 \mathrm{~nm}$ ), baseada na facilidade em realizar a extrusão e nos resultados de DLS, que mostram vesículas de diâmetro da ordem $50 \mathrm{~nm}$, mesmo a extrusão sendo feita por filtros de $100 \mathrm{~nm}$, indicando que o processo de extrusão está apenas filtrando algumas vesículas maiores, realizou-se medidas de DSC para dispersões de DMPG $10 \mathrm{mM}$ em água antes da extrusão e após extrusar-se as amostras por filtros de 100 e $30 \mathrm{~nm}$. 


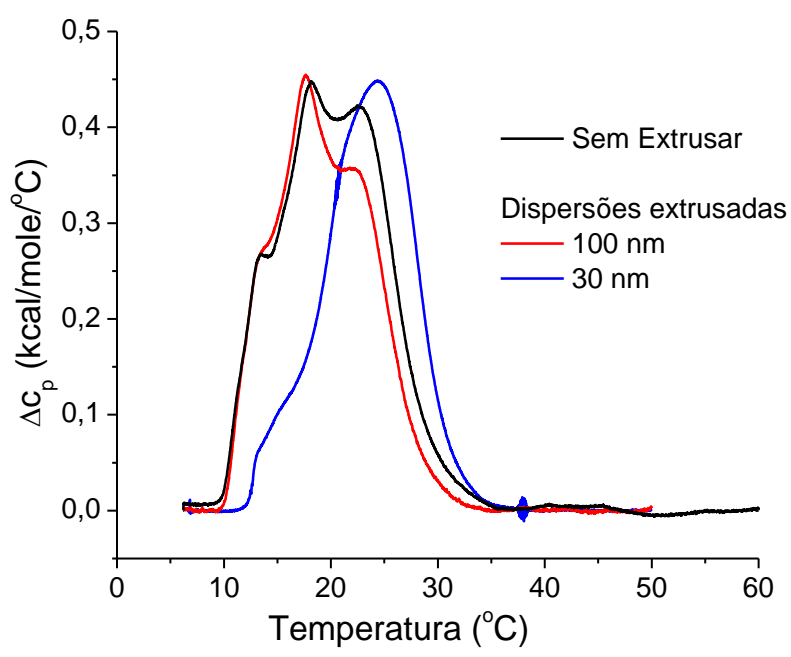

Figura 4.1.3: Típicos perfis de DSC de dispersões de $10 \mathrm{mM}$ de DMPG antes da extrusão (curva preta), após extrusão por filtros de 100 nm (curvas vermelhas) e após extrusão por filtros de $30 \mathrm{~nm}$ (curva azul) em água.

As entalpias calculadas a partir das curvas da figura 4.1 .3 resultaram em $\Delta \mathrm{H}=5,9(3) \mathrm{kcal} / \mathrm{mol}$ para a dispersões que não foram extrusadas, $\Delta \mathrm{H}=4,9$ (3) $\mathrm{kcal} / \mathrm{mol}$ para as dispersões extrusadas por filtro de $100 \mathrm{~nm}$ e $\Delta \mathrm{H}=4,6$ (3) $\mathrm{kcal} / \mathrm{mol}$ para a dispersão extrusada por filtro com poros de $30 \mathrm{~nm}$. Vemos que a entalpia da transição diminui um pouco ao extrusar-se as dispersões por filtros cada vez menores, mostrando que a transição de fase necessita de menos energia para ocorrer. Podemos atribuir este resultado à presença de um maior número de vesículas menores e, portanto, com maior raio de curvatura. Vemos que há uma pequena diferença no perfil de DSC após extrusarse a dispersão pelo filtro de $100 \mathrm{~nm}$, onde possivelmente elimina-se alguns poucos agregados maiores, sendo que uma diferença mais significativa é observada após a extrusão pelo filtro de $30 \mathrm{~nm}$. Entretanto, é interessante notar que mesmo para a dispersão extrusada por $30 \mathrm{~nm}$ a larga região de transição de fase pouco cooperativa ainda é observada e o valor parecido para a entalpia da transição das dispersões extrusadas por filtros de 30 e $50 \mathrm{~nm}$ indicam a presença de agregados com curvaturas semelhantes.

Dado que realizamos medidas de SAXS com dispersões de $50 \mathrm{mM}$ de DMPG, também realizamos medidas de DSC de dispersões de $50 \mathrm{mM}$ de DMPG em água, após a extrusão e o resultado é apresentado na figura 4.1.4. 

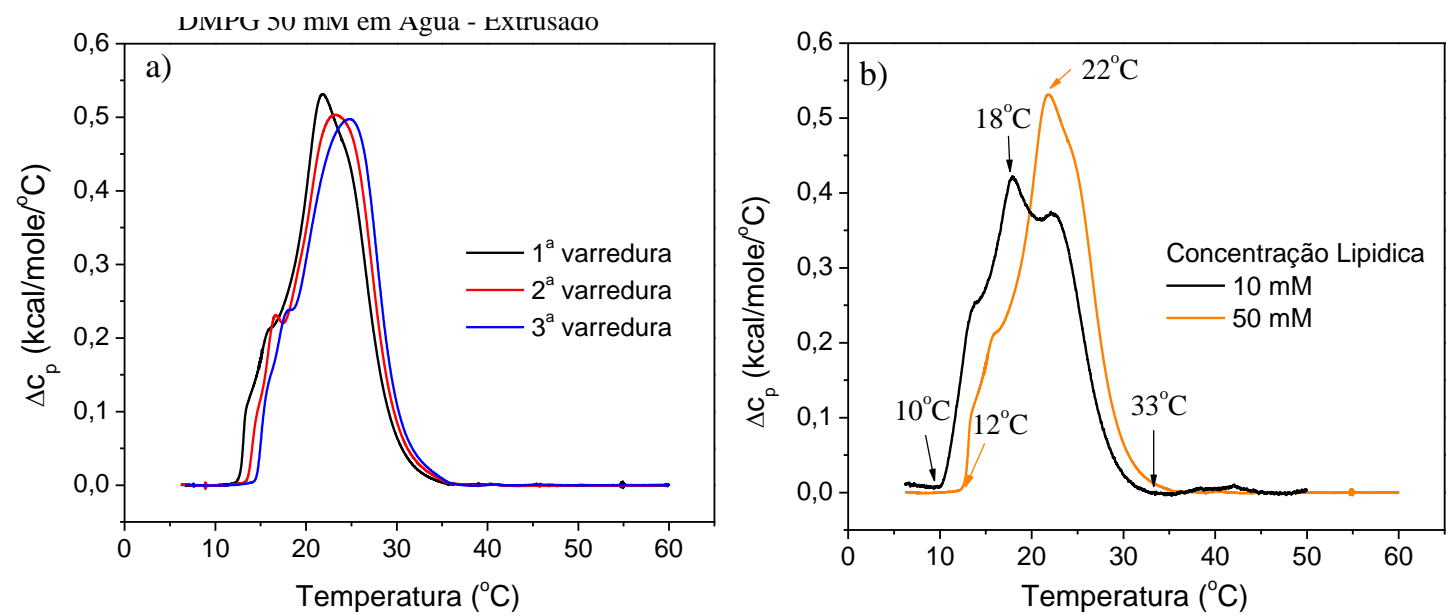

Figura 4.1.4: a)Típicas curvas de DSC para uma dispersão de $50 \mathrm{mM}$ de DMPG em água, extrusada por filtro de $100 \mathrm{~nm}$ a uma taxa de $10^{\circ} \mathrm{C} / \mathrm{h}$, sendo o intervalo de tempo entre a 1a e a 2- varredura e entre a 2a e a $3^{3}$ a varredura de $\sim 11$ horas. b) Comparação dos resultados obtidos para as dispersões de 10 e 50 mM de DMPG, depois da extrusão.

Os resultados de DSC mostrados na figura 4.1.4 também foram realizados esfriando a amostra e a reversibilidade dos eventos térmicos foi observada (resultado não mostrado aqui). Vemos que a larga região de transição de fase também está presente nas dispersões de DMPG 50 mM em água após a extrusão, sendo ligeiramente mais estreita que o observado para 10 mM de DMPG. Além disso, a entalpia calculada foi de 5,2 (4) kcal/mol, semelhante a entalpia obtida para as dispersões extrusadas de $10 \mathrm{mM}$ de DMPG em água, que foi de e 4,9 (3) kcal/mol, mostrando que a entalpia da transição independe da concentração lipídica da dispersão.

Realizamos também medidas de DSC de dispersões de 10 mM de DMPG em água com o acréscimo de pouquíssimo sal $(0,1$ e 0,5 $\mathrm{mM}$ de $\mathrm{NaCl})$ e comparamos os resultados obtidos com os apresentados para a água pura, antes e depois da extrusão (figura 4.1.5). 

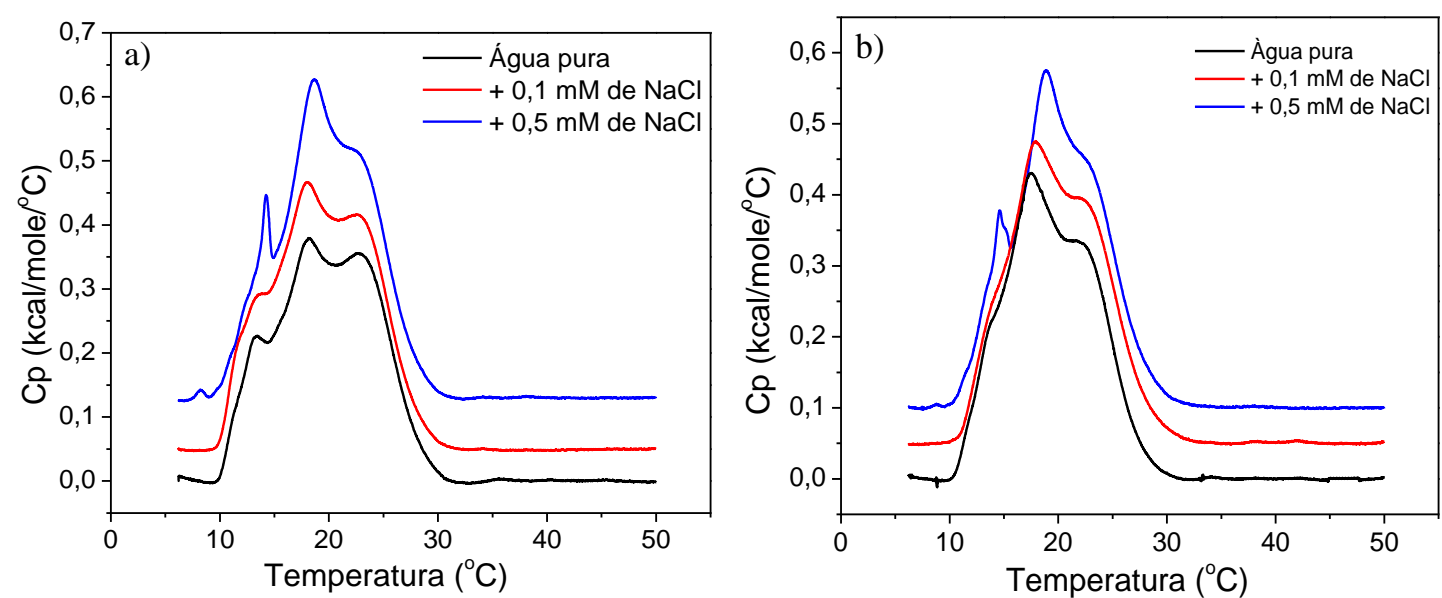

Figura 4.1.5: Curvas de DSC de dispersões de $10 \mathrm{mM}$ de DMPG em água (curvas pretas) e em água com o acréscimo de 0,1 mM (curvas vermelhas) e 0,5 mM (curvas azuis) de $\mathrm{NaCl}$, antes (gráfico a) e depois (gráfico b) da extrusão, sendo esquentadas a uma taxa de $20^{\circ} \mathrm{C} / \mathrm{h}$. As curvas foram deslocadas verticalmente para uma melhor visualização.

A partir da figura 4.1.5, notamos que o acréscimo de $0,1 \mathrm{mM}$ de sal não causou mudanças significativas na curva de DSC. Com o acréscimo de 0,5 $\mathrm{mM}$ de $\mathrm{NaCl}$ a maior diferença é que o primeiro pico fica mais estreito e pronunciado, sendo que este provavelmente é o pico cooperativo observado na transição de fase para o DMPG em tampão a baixa força iônica. Após a extrusão, o primeiro "ombrinho" da transição aparece de maneira mais suave do que antes da extrusão, sendo quase imperceptível, sendo que para a dispersão com acréscimo de $0,5 \mathrm{mM}$ de $\mathrm{NaCl}$ este primeiro pico é menos estreito e menos pronunciado que antes da extrusão. 


\subsection{Viscosidade}

Dado que uma das peculiaridades do DMPG à baixa força iônica é a sua alta viscosidade na região de transição de fase (Heimburg \& Biltonen, 1994; Schneider et al., 1999; Barroso et al., 2010), investigamos se o mesmo ocorre para o DMPG em água e os resultados são mostrados a seguir.

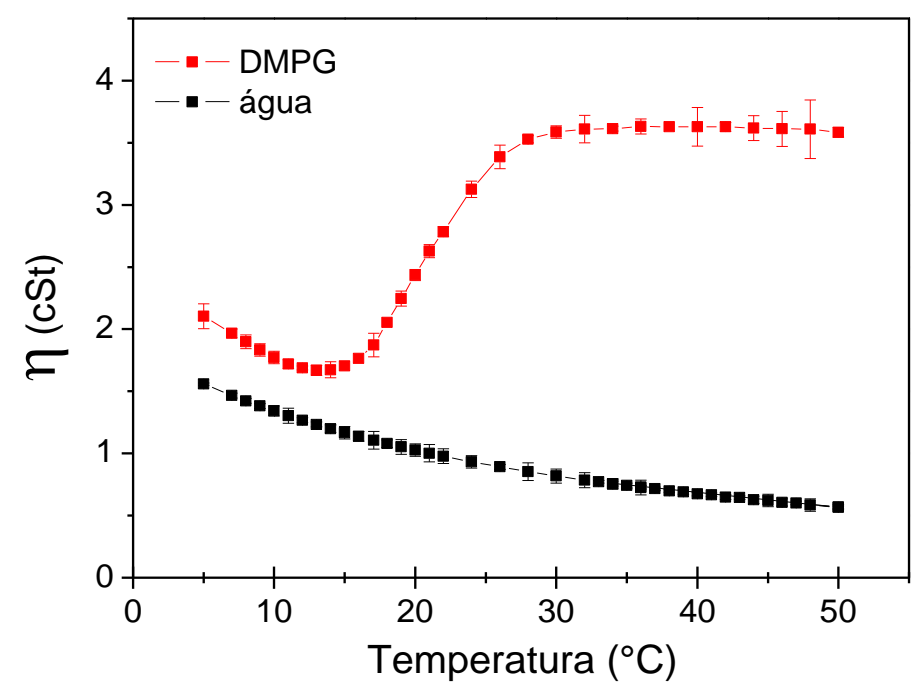

Figura 4.2.1: Viscosidade cinemática em função da temperatura para dispersões extrusadas de $10 \mathrm{mM}$ de DMPG em água e de água pura. Cada curva é a média entre medidas de duas amostras distintas e a incerteza é dada pelo desvio padrão das medidas.

De modo a destacar a contribuição do DMPG no aumento da viscosidade, vamos trabalhar com o incremento da viscosidade relativa $\left(\eta_{i}\right)$ :

$$
\eta_{i}=\frac{\eta-\eta_{0}}{\eta_{0}}
$$

onde $\eta$ e $\eta_{0}$ são as viscosidades da dispersão e do solvente, respectivamente. $\eta_{i}$ indica o quanto a viscosidade do solvente aumenta devido à presença do soluto na dispersão (Barroso, 2010).

Comparamos então os valores do incremento da viscosidade relativa em função da temperatura para dispersões de $10 \mathrm{mM}$ de DMPG em água, antes e depois da extrusão e o resultado é mostrado na figura 4.2.2. 


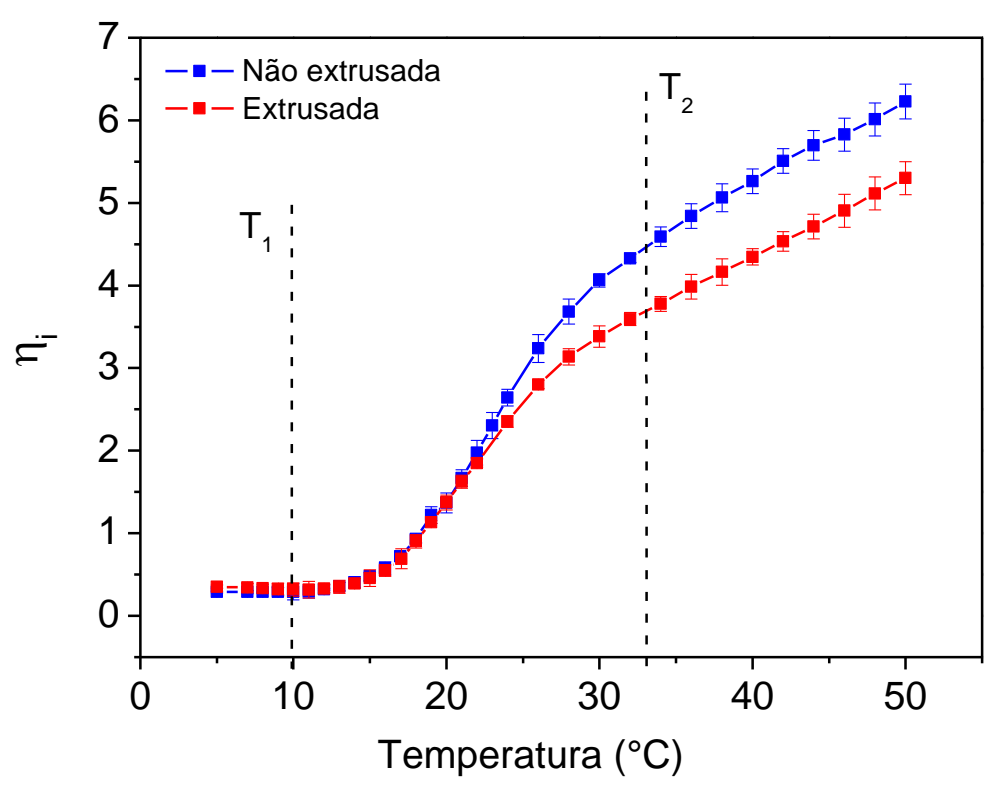

Figura 4.2.2: Medidas do incremento da viscosidade relativa para dispersões de $10 \mathrm{mM}$ de DMPG em água, antes (pontos azuis) e depois (pontos vermelhos) da extrusão. Cada curva é a média entre medidas de duas amostras distintas e a incerteza é dada pelo desvio padrão das medidas.

A partir do gráfico da figura 4.2.2 podemos tirar informações muito interessantes. Notamos que nas dispersões de DMPG em água, o aumento da viscosidade da dispersão devido à presença dos agregados de DMPG é muito grande e aumenta com o aumento da temperatura. Por exemplo, em $\mathrm{T}=30^{\circ} \mathrm{C}$, o aumento da viscosidade na dispersão não extrusada é de $\sim 400 \%$ em relação à viscosidade da água pura.

Devido a esse comportamento anômalo da viscosidade das dispersões de DMPG em água em função da temperatura, na preparação das amostras devemos resfriar a solução (em gelo, conforme descrito em materiais e métodos) de modo a facilitar a suspensão do filme de DMPG em água, que é o procedimento oposto ao adotado na suspensão de filme de DMPG em tampão, onde aquecemos a solução até atingir a fase fluida.

Na figura 4.2.2, vemos que $\eta_{i}$ das amostras antes e depois da extrusão são iguais até $22^{\circ} \mathrm{C}$ e para temperaturas mais altas o aumento da viscosidade com a dispersão extrusada é ligeiramente menor que na dispersão não extrusada, mas ambas as curvas seguem as mesmas tendências, como visto nos resultados de DSC (figura 4.1.3). 
Os resultados discutidos anteriormente para a viscosidade foram obtidos com a temperatura aumentando, mas realizamos também medidas de viscosidade aumentando e depois diminuindo a temperatura, conforme pode ser visto na figura 4.2.3.

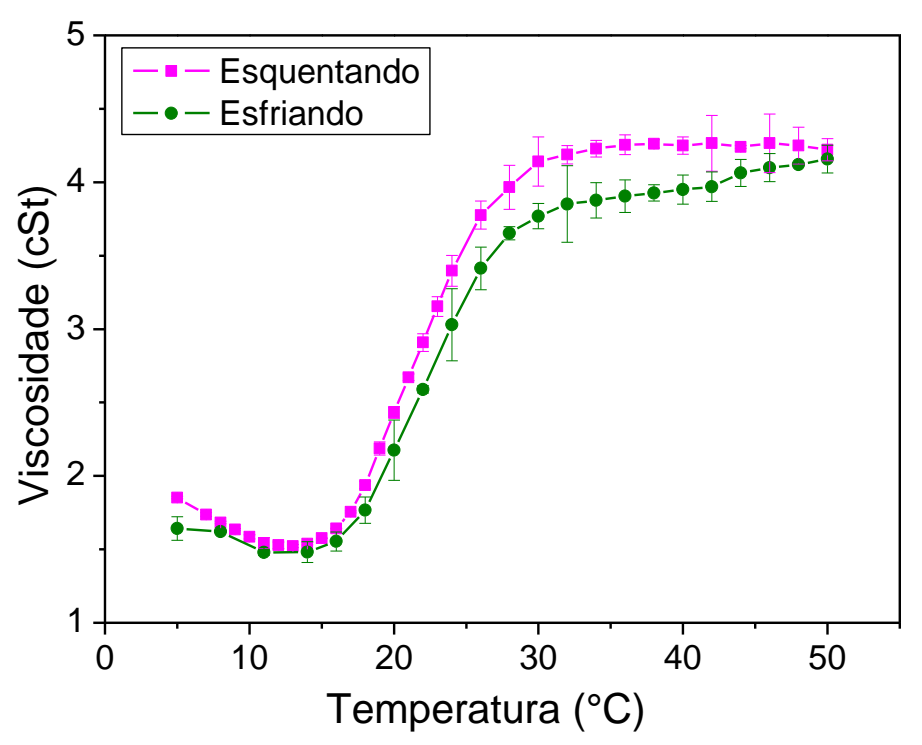

Figura 4.2.3: Viscosidade cinemática de uma dispersão extrusada de $10 \mathrm{mM}$ de DMPG em água, com a temperatura aumentando (pontos rosas) e depois diminuindo (pontos verdes).

Na figura 4.2.3 vemos que as curvas obtidas para a viscosidade cinemática com a temperatura aumentando e diminuindo são muito similares entre si, dentro das incertezas da técnica, mostrando que os eventos são reversíveis. 


\subsection{Condutividade Elétrica}

Outra característica bastante peculiar de dispersões de DMPG à baixa força iônica é a alta condutividade na região da transição de fase, fato que foi atribuído à dissociação de contraíons $\mathrm{Na}^{+}$que se encontravam nas cabeças polares (Riske et al., 1997; Riske et al., 1999; Tamashiro et al., 2005; Barroso, 2010). Verificamos se o mesmo comportamento é observado para as dispersões de DMPG em água e os resultados são apresentados a seguir.

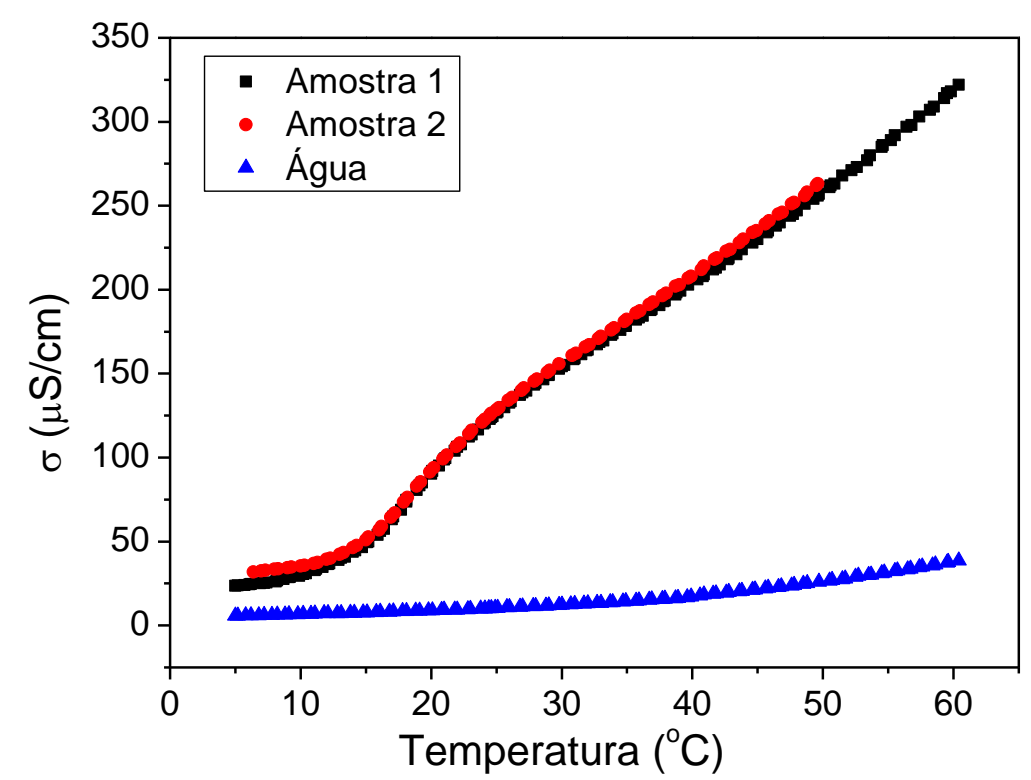

Figura 4.3.1: Medida de condutividade elétrica em função da temperatura para duas dispersões extrusadas de $10 \mathrm{mM}$ de DMPG em água e para água pura.

Na figura 4.3.1 vemos que as medidas de condutividade elétrica foram reprodutíveis, uma vez que os valores medidos para as amostras 1 e 2 são muito semelhantes, sendo que a amostra 2 foi medida entre 6 e $50^{\circ} \mathrm{C}$ e a amostra 1 entre 5 e $60^{\circ} \mathrm{C}$. Também é possível observar que a condutividade da água pura é bem baixa, como esperado, uma vez que estamos na ausência de sais. De modo a facilitar a visualização da mudança na condutividade da dispersão com a presença de DMPG na solução, vamos descontar a contribuição do solvente (água) calculando uma condutividade reduzida ( $\left.\sigma_{\text {red }}\right)$, tal que:

$$
\sigma_{\text {red }}=\frac{\Delta \sigma}{\sigma_{0}}
$$

onde $\Delta \sigma$ é a diferença entre a condutividade da dispersão e do solvente $\left(\sigma_{0}\right)$. 
Como a condutividade da água é muito baixa, não iremos considerar, na condutividade reduzida (equação 4.3.1), os íons da solução que se encontram no volume interno aquoso das vesículas, que não contribuem para a condutividade, uma vez que esta diferença seria muito pequena.

Comparamos então os valores da condutividade reduzida em função da temperatura para dispersões de 10 mM de DMPG em água, antes e depois da extrusão (figura 4.3.2).

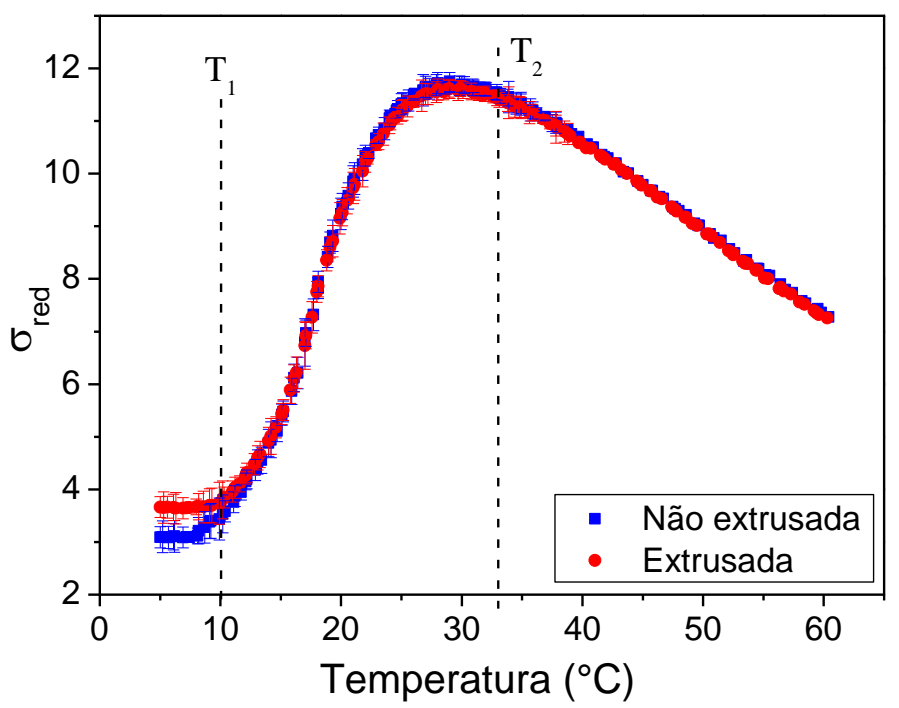

Figura 4.3.2: Medidas de condutividade reduzida para dispersões de $10 \mathrm{mM}$ de DMPG em água antes (pontos azuis) e depois (pontos vermelhos) da extrusão.

A partir da figura 4.3.2, temos indicação de que as vesículas de DMPG em água devem ser MUITO carregadas (vide as escalas). Desde a fase gel, o aumento da condutividade devido ao DMPG na água é bastante significativo, sofrendo um aumento abrupto a partir de $T_{1}$ e diminuindo mais lentamente a partir de $T_{2}$. Mesmo na fase fluída, as vesículas continuam bastante carregadas, comportamento similar ao observado nas medidas de incremento da viscosidade relativa, que, entretanto, apresentou valores mais altos na fase fluida do que na fase gel (Figura 4.2.2). Curiosamente, o incremento da viscosidade relativa em água é crescente até $50{ }^{\circ} \mathrm{C}$, contrário à condutividade reduzida, que começa a cair em $\sim 30^{\circ} \mathrm{C}$, onde acabam os picos no perfil de DSC (Fig. 4.1.1) O comportamento das dispersões em água antes e depois da extrusão é bastante semelhante. 
Realizamos também medidas com a temperatura aumentando e depois diminuindo e o resultado obtido é mostrado na figura 4.3.3.

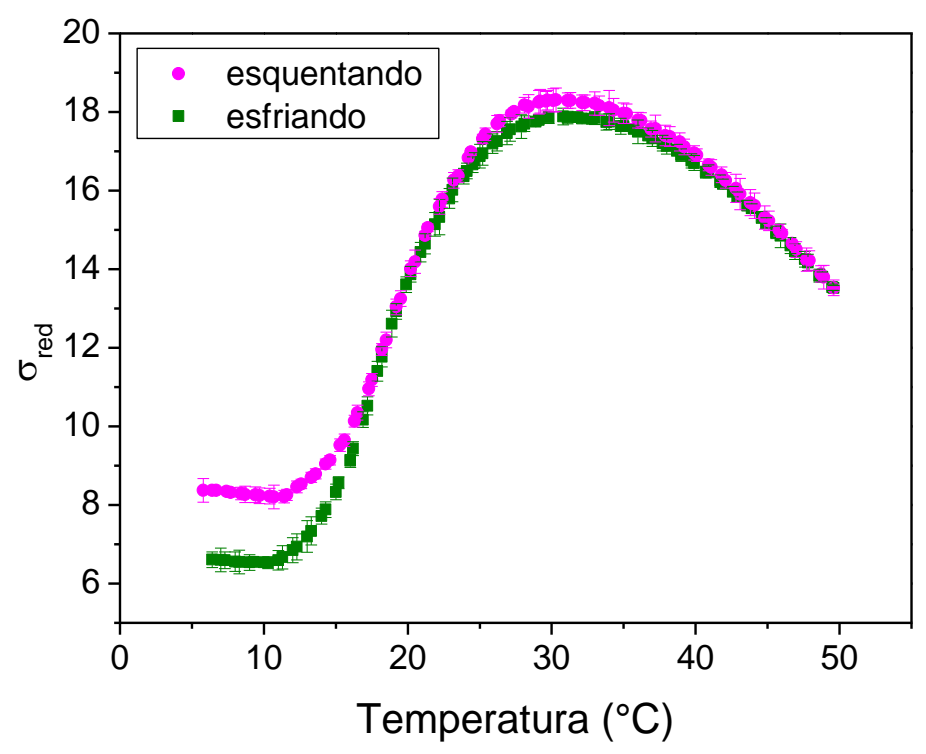

Figura 4.3.3: Condutividade reduzida de uma dispersão de $10 \mathrm{mM}$ de DMPG em água, extrusada, com a temperatura aumentando (pontos rosas) e depois diminuindo (pontos verdes).

Observando a figura 4.3.3, notamos que o comportamento da condutividade reduzida é bem semelhante quando esquentamos e esfriamos a amostra, com uma pequena diferença nos valores obtidos na região de temperaturas mais baixa, confirmando a reversibilidade dos fenômenos observados. 


\subsection{Mobilidade eletroforética}

Para o estudo das cargas dos agregados lipídicos, realizamos medidas de mobilidade eletroforética de dispersões extrusadas de DMPG em água.

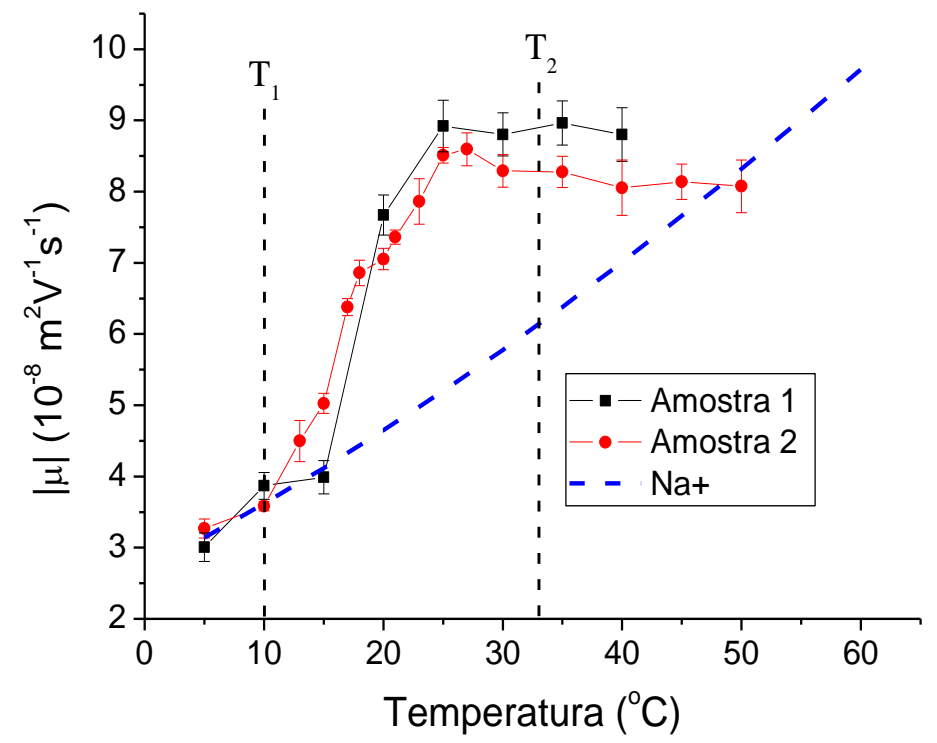

Figura 4.4.1: Medidas de mobilidade eletroforética $(\mu)$ para duas amostras distintas de $10 \mathrm{mM}$ de DMPG em água depois da extrusão e $\mu$ dos contraíons $\mathrm{Na}^{+}$calculados usando a equação 3.2.5.

Na figura 4.4.1 vemos que a mobilidade dos íons de sódio aumenta com o aumento da temperatura, o que está relacionado com o decréscimo da viscosidade do solvente na mesma condição. Para vesículas lipídicas, espera-se que haja uma descontinuidade na dependência térmica de $\mu$ na transição de fase, indicando mudança na carga da partícula e/ou alterações em suas dimensões (Tatulian, 1987; Sierra-Martins et al., 2006).

As medidas da amostra 1 da figura 4.4 .1 foram realizadas somente até $40^{\circ} \mathrm{C}$ porque a partir desta temperatura pequenas bolhas de ar começam a se formar dentro do capilar, provavelmente devido à alta viscosidade das amostras em altas temperaturas (Figura 4.2.2), impossibilitando a obtenção de resultados confiáveis. Já para a amostra 2, foi possível medir a mobilidade eletroforética até $50^{\circ} \mathrm{C}$, tomando-se cuidado e retirando-se as pequenas bolhas que se formaram no capilar com leves batidas na parede do capilar.

$\mathrm{Na}$ figura 4.4.1, vemos que o resultado foi reprodutível com duas amostras distintas de 10 mM DMPG em água. Notamos que a mobilidade eletroforética apresenta 
um aumento significativo a partir de $10-15^{\circ} \mathrm{C}$, relacionado com a transição de fase das membranas. Esse aumento é bastante evidente quando comparado ao aumento da mobilidade do $\mathrm{Na}^{+}$com a temperatura, indicando que ocorrem mudanças nos agregados de DMPG na transição de fase, podendos estas estar relacionadas à forma, carga e/ou tamanho.

Na tentativa de realizar a correção da mobilidade da dispersão pela sua dependência com a temperatura, assim como fizemos com as medidas de condutividade e viscosidade, vamos calcular o que chamaremos de mobilidade corrigida:

$$
\mu_{c o r r} \equiv \frac{|\mu|}{\mu_{N a^{+}}}
$$

onde $|\mu|$ é a mobilidade eletroforética medida para a dispersão e $\mu_{\mathrm{Na}+}$ é a mobilidade eleforética calculada para os íons de sódio. Desta forma, calculamos a mobilidade corrigida da amostra 2 da figura 4.4.1 e o resultado é apresentado na figura 4.4.2.

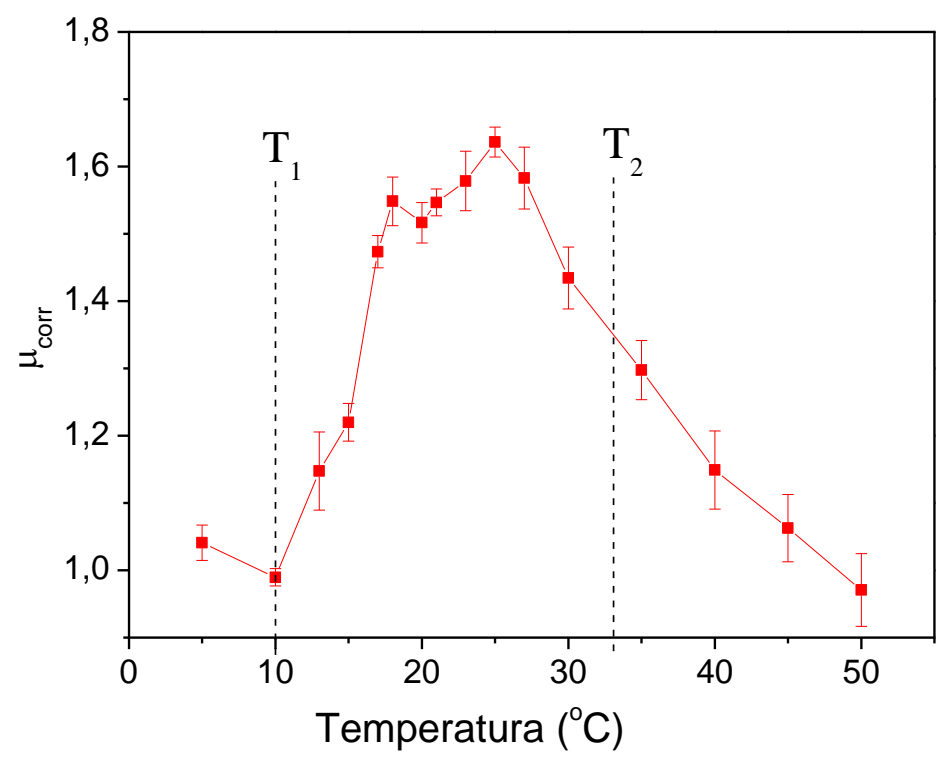

Figura 4.4.2: Mobilidade eletroforética corrigida de uma dispersão extrusada de $10 \mathrm{mM}$ de DMPG em água.

A partir da figura 4.4.2 vemos que a mobilidade corrigida da dispersão de DMPG aumenta bruscamente partir de $T_{1}$, sofrendo um decréscimo mais suave entre 25 e $50^{\circ} \mathrm{C}$. Este aumento na mobilidade dos agregados de DMPG em água pode estar relacionado como o aumento da carga ou com a diminuição do tamanho dos agregados, conforme a equação 2.6.6. Como será mostrado nas medidas de DLS, os agregados de DMPG em 
água aumentam de tamanho com o aumento da temperatura, de modo que este aumento visto na mobilidade eletroforética deve indicar o aumento da carga das vesículas de DMPG a partir de $\mathrm{T}_{1}$ e uma diminuição da mesma a partir de $\sim 25^{\circ} \mathrm{C}$, estando de acordo com o aumento e posterior redução da condutividade reduzida (figura 4.3.2), sendo que vesículas mais carregadas contribuem de maneira mais significativa para a condutividade elétrica da dispersão, juntamente com os contraíons que se dissociaram das cabeças polares (equação 2.6.9).

Para nos certificarmos que os eletrodos não foram danificados durante as medidas e para verificarmos se os eventos são reversíveis, realizamos medidas das mesmas amostras da figura 4.4.1 diminuindo a temperatura e os dados obtidos esfriando as amostras são muito parecidos com os obtidos esquentando as amostras (resultados não mostrados aqui), indicando que o evento que causa esse aumento na mobilidade eletroforética é reversível (como atestado pelas outras técnicas experimentais utilizadas) e que os eletrodos não foram afetados no decorrer das medidas. 


\subsection{Turbidez}

À baixa força iônica, dispersões de DMPG apresentam baixa turbidez na região de transição de fase (Riske et al., 1997; Alakoskela \& Kinnunen, 2007; Alakoskela et al., 2010; Barroso, 2010). Verificamos o comportamento da absorbância a $350 \mathrm{~nm} \mathrm{em}$ função da temperatura, de uma dispersão de $10 \mathrm{mM}$ de DMPG em água antes e depois da extrusão.

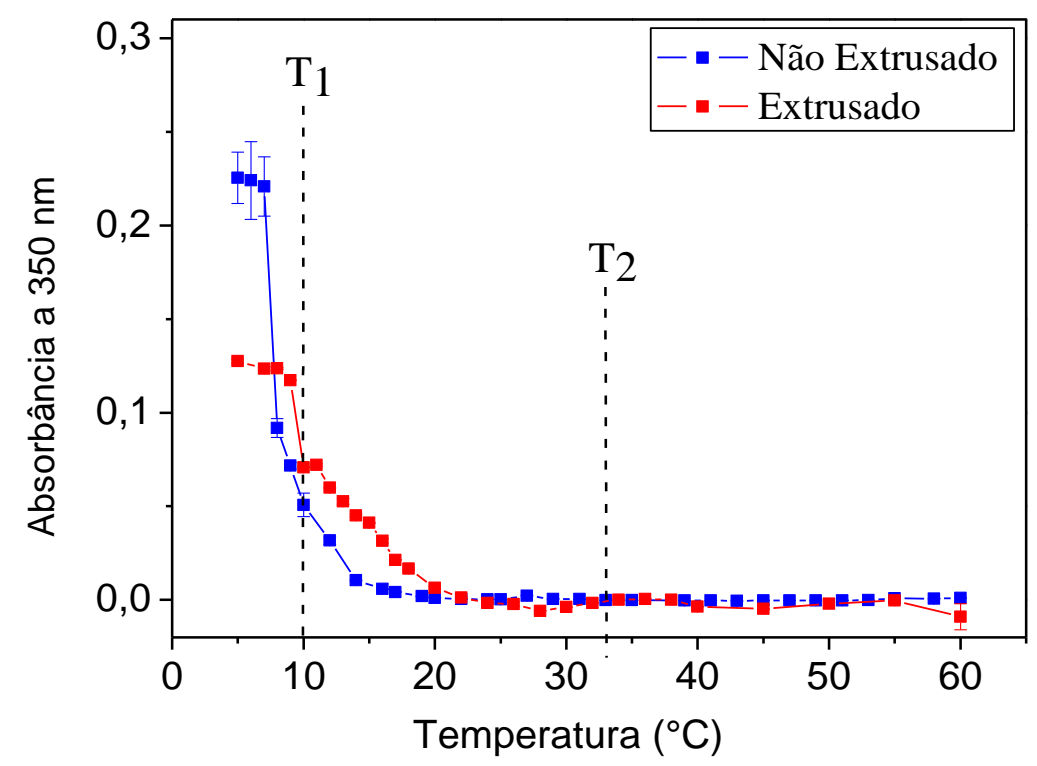

Figura 4.5.1: Medidas de absorbância a $350 \mathrm{~nm}$, em função da temperatura, de dispersões de $10 \mathrm{mM}$ de DMPG em água, antes (pontos azuis) e depois (pontos vermelhos) da extrusão, sendo o caminho óptico de $2 \mathrm{~mm}$.

A partir da figura 4.5.1, vemos que nas dispersões em água a absorbância tem uma brusca queda após $T_{1}$, indo para valores próximos a zero, sendo visivelmente transparentes, e a dispersão permanece transparente para temperaturas até $60^{\circ} \mathrm{C}$.

Diferente do que aconteceu nas medidas de DSC, viscosidade e condutividade elétrica, vemos uma diferença significativa após a extrusão da amostra, na fase gel do DMPG em água. Como a turbidez é muito mais sensível à presença de partículas grandes, devemos ter alguns pouco agregados maiores que são eliminados após a extrusão. 


\subsection{Espalhamento de Luz}

Em Enoki et al., 2012 foi observado o aumento no tamanho dos agregados de DMPG em tampão à baixa força iônica na região de transição de fase, tanto por DLS quanto por SLS. Realizou-se um estudo com as mesmas técnicas para dispersões extrusadas, através de filtros de $100 \mathrm{~nm}$, de DMPG em água com diferentes concentrações lipídicas e os resultados são apresentados a seguir. Realizamos um estudo de DLS e SLS com nanoesferas de poliestireno de tamanhos conhecidos (ver apêndice A), de modo a verificar o correto funcionamento dos equipamentos do Laboratório de Biomembranas do IFUSP e aprender mais sobre estas técnicas e suas limitações.

\subsubsection{Espalhamento de Luz Dinâmico (DLS)}

Estas primeiras medidas foram realizadas no Institute of Inorganic Chemistry da Graz University of Technology, Graz, Áustria, em colaboração com o Prof. Dr. Otto Glatter e a Dra Angela Chemelli. Realizou-se medidas de dispersões de 1 e $10 \mathrm{mM}$ de DMPG em água, extrusadas por filtros de $100 \mathrm{~nm}$, nas temperaturas de $5^{\circ} \mathrm{C}$ (fase gel), 15,20 e $30^{\circ} \mathrm{C}$ (região de transição de fase) e $45^{\circ} \mathrm{C}$ (fase fluida). 

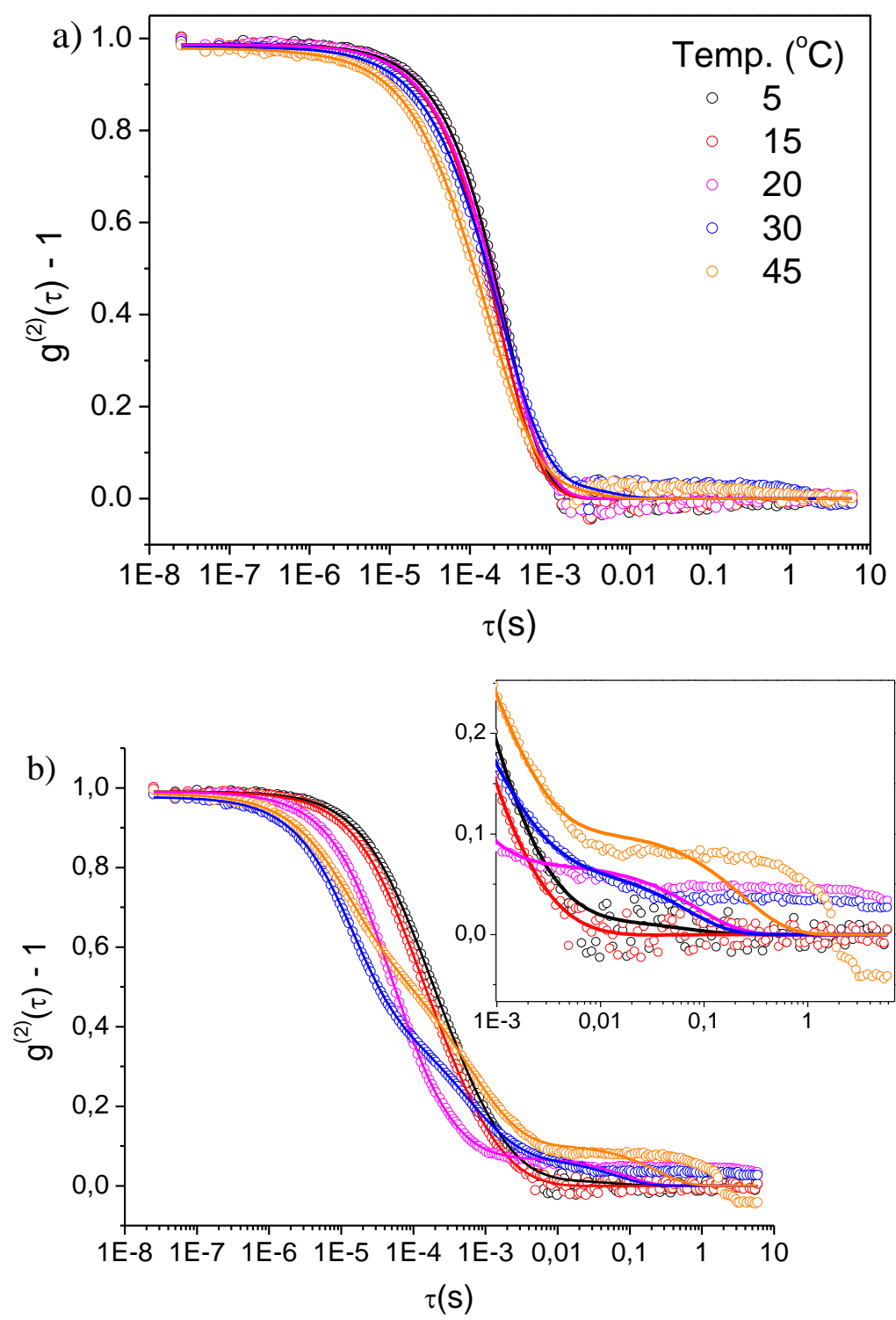

Figura 4.6.1: Funções de autocorrelação da luz espalhada normalizadas para dispersões extrusadas de DMPG em água com diferentes concentrações lipídicas: a) $1 \mathrm{mM}$ e em b) $10 \mathrm{mM}$, sendo mostrado em destaque a região de maiores $\tau$, onde o ajuste não é satisfatório. As linhas sólidas representam os ajustes obtidos via software Ortlight e os círculos representam os dados experimentais em diferentes temperaturas: 5, 15, 20, 30 e $45^{\circ} \mathrm{C}$.

A partir de $g^{(2)}(\tau)$ é possível obter a $g^{(1)}(\tau)$ (equação 2.3.3) e, utilizou-se o software ORTlight para o cálculo da transformada inversa de Laplace e obtenção da distribuição de tamanhos dos agregados das dispersões (análises realizadas pela Drá Angela Chemelli). 

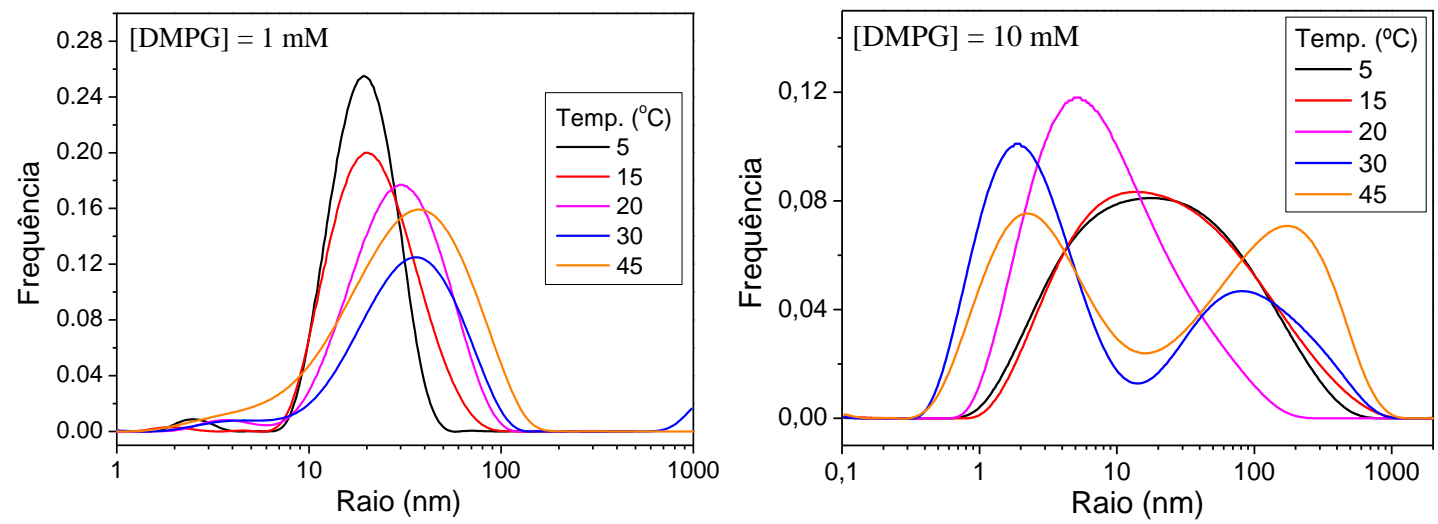

Figura 4.6.2: Distribuição de tamanhos dos agregados de DMPG obtidos pela transformada inversa de Laplace, para uma dispersão de $1 \mathrm{mM}$ (gráfico da esquerda) e $10 \mathrm{mM}$ (gráfico da direita) nas temperaturas $5,15,20,30$ e $45^{\circ} \mathrm{C}$.

A partir da figura 4.6.2, vemos que as distribuições de tamanho para a dispersão de $10 \mathrm{mM}$ são demasiadamente largas, mostrando a presença de agregados com raios que variam de 1 a $1000 \mathrm{~nm}$, e dado que os ajustes das funções de correlação não são razoáveis (ver figura 4.6.1b), não é possível obter resultados confiáveis para o tamanho de agregados a partir desta técnica. Certamente, a dispersão de 10 mM de DMPG está fora da aproximação que considera o sistema suficientemente diluído e não interagente.

Para a dispersão de $1 \mathrm{mM}$ de DMPG foi possível obter bons ajustes para a função de correlação e, ajustando-se os picos de distribuição de tamanhos por gaussianas, utilizando o software OriginLab, determinou-se a posição central dos picos juntamente com sua incerteza e os resultados para as diferentes temperaturas são apresentados na tabela 4.1.

Tabela 4.1: Raio efetivo e diâmetro dos agregados da dispersão de 1 mM de DMPG em água em diferentes temperaturas. A incerteza é dada pelo desvio de duas medidas da mesma amostra.

\begin{tabular}{ccc}
\hline Temperatura $\left({ }^{\circ} \mathbf{C}\right)$ & $\mathbf{R}_{\text {eff }}(\mathbf{n m})$ & Diâmetro $(\mathbf{n m})$ \\
\hline 5 & $20,9 \pm 1,5$ & $42 \pm 3$ \\
\hline 15 & $21,6 \pm 1,6$ & $43 \pm 3$ \\
\hline 20 & $28,5 \pm 3,0$ & $57 \pm 6$ \\
\hline 30 & $35,9 \pm 3,5$ & $72 \pm 7$ \\
\hline 45 & $37,5 \pm 5,0$ & $75 \pm 10$ \\
\hline
\end{tabular}

Apesar da extrusão através de filtros com poros de $100 \mathrm{~nm}$ de diâmetro ser realizado em baixa temperatura $\left(\sim 5^{\circ} \mathrm{C}\right)$, vemos na tabela 4.1 , que nesta temperatura 
temos agregados de diâmetro $42 \mathrm{~nm}$, bem menores que o esperado após filtrar a dispersão pelo filtro de $100 \mathrm{~nm}$, indicando a formação de agregados pequenos, mesmo antes da extrusão, o que pode estar relacionado com o fato das medidas de DSC, viscosidade e condutividade antes e depois da extrusão serem tão similares. Também na tabela 4.1 vemos o aumento no tamanho dos agregados de DMPG com o aumento da temperatura, sendo que na fase fluida $\left(45^{\circ} \mathrm{C}\right)$, o tamanho é cerca de 1,8 vezes maior do que na fase gel $\left(5^{\circ} \mathrm{C}\right)$.

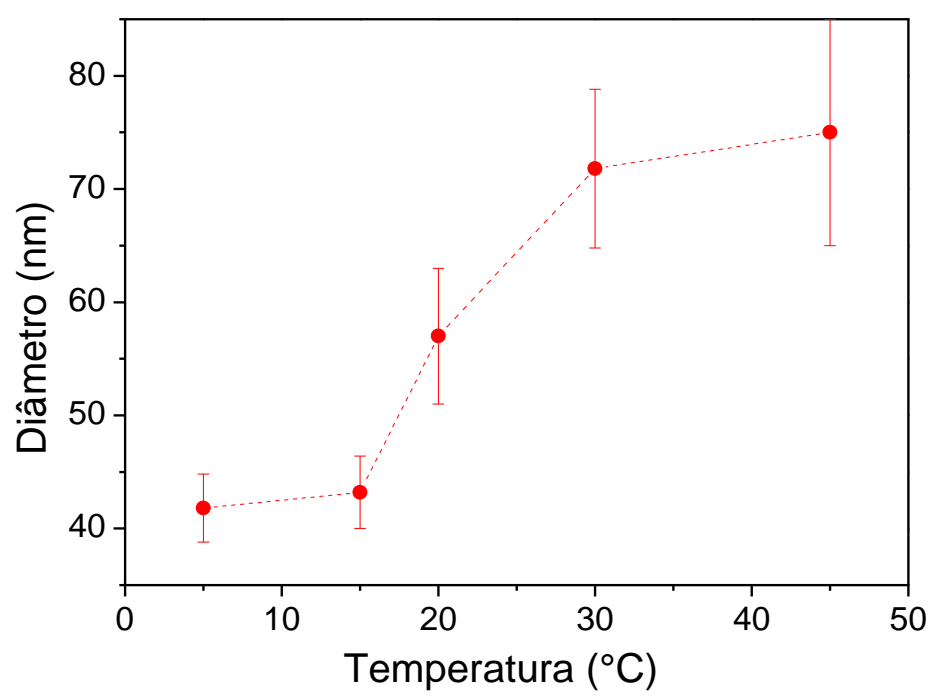

Figura 4.6.3: Resultados de DLS obtidos para uma dispersão de 1 mM de DMPG em água, mostrados na tabela 4.1 .

Utilizando a mesma dispersão de $1 \mathrm{mM}$ de DMPG em água (tabela 4.1 e figura 4.6.3), repetiu-se a medida de DLS uma semana após a preparação da amostra, sendo que neste período a amostra foi mantida na bancada, em temperatura ambiente. Mesmo após 1 semana do dia da preparação da amostra, não há mudanças significativas no tamanho dos agregados e o aumento do tamanho em função da temperatura ainda é observado, mostrando que os agregados não devem mudar muito neste intervalo de tempo.

Resultados de DLS com dispersões de diferentes concentrações lipídicas de DMPG em água são apresentados no apêndice $B$ desta tese. 


\subsubsection{Espalhamento de Luz Estático (SLS)}

Para as medidas de SLS, pela aproximação de Zimm (equação 2.3.14), é necessário a obtenção da razão dn/dc. Este incremento do índice de refração da solução pela concentração da amostra foi obtido utilizando-se o refratômetro diferencial da Brookhaven e o software de aquisição "Differential Refratometer".

Primeiramente fez-se a calibração do aparelho com dez diferentes concentrações de $\mathrm{KCl}$ em água, a $30^{\circ} \mathrm{C}$ e obteve-se a constante de calibração $\mathrm{k}=(3,26 \pm$ 0,01).10-4 $\mathrm{V}^{-1}$. Em seguida, medimos o $\mathrm{dn} / \mathrm{dc}$ para dois conjuntos de amostras de DMPG em água, o primeiro conjunto variando-se as concentrações lipídicas de 6 a $12 \mathrm{mM}$ (alta concentração) e outro conjunto variando-se as concentrações de 0,5 a 3 mM (baixa concentração) nas temperaturas de 20,30 e $45^{\circ} \mathrm{C}$.

Tabela 4.2: Valores para o incremento do índice de refração da solução pela concentração da amostra, variando-se a concentração de lipídios de 6 a $12 \mathrm{mM}$ (alta concentração) e de 0,5 a 3 mM (baixa concentração).

\begin{tabular}{|c|c|c|}
\hline & \multicolumn{2}{|c|}{$\mathbf{d n} / \mathbf{d c}(\mathbf{m L} / \mathbf{g})$} \\
\hline Temp. $\left({ }^{\circ} \mathbf{C}\right)$ & alta concentração & baixa concentração \\
\hline $\mathbf{2 0}$ & $0,158 \pm 0,009$ & $0,254 \pm 0,017$ \\
\hline $\mathbf{3 0}$ & $0,179 \pm 0,007$ & $0,169 \pm 0,014$ \\
\hline $\mathbf{4 5}$ & $0,146 \pm 0,016$ & $0,121 \pm 0,017$ \\
\hline
\end{tabular}

Esses valores de dn/dc foram utilizados nas análises de Zimm (equação2.3.14), feitas via software Static Light Scattering da Brookhaven. 
Os resultados para o conjunto "alta concentração" (de 6 a 12 mM de DMPG) nas temperaturas de seguir.20, 30,45 e $60^{\circ} \mathrm{C}$ são mostrados na figura 4.6.4.
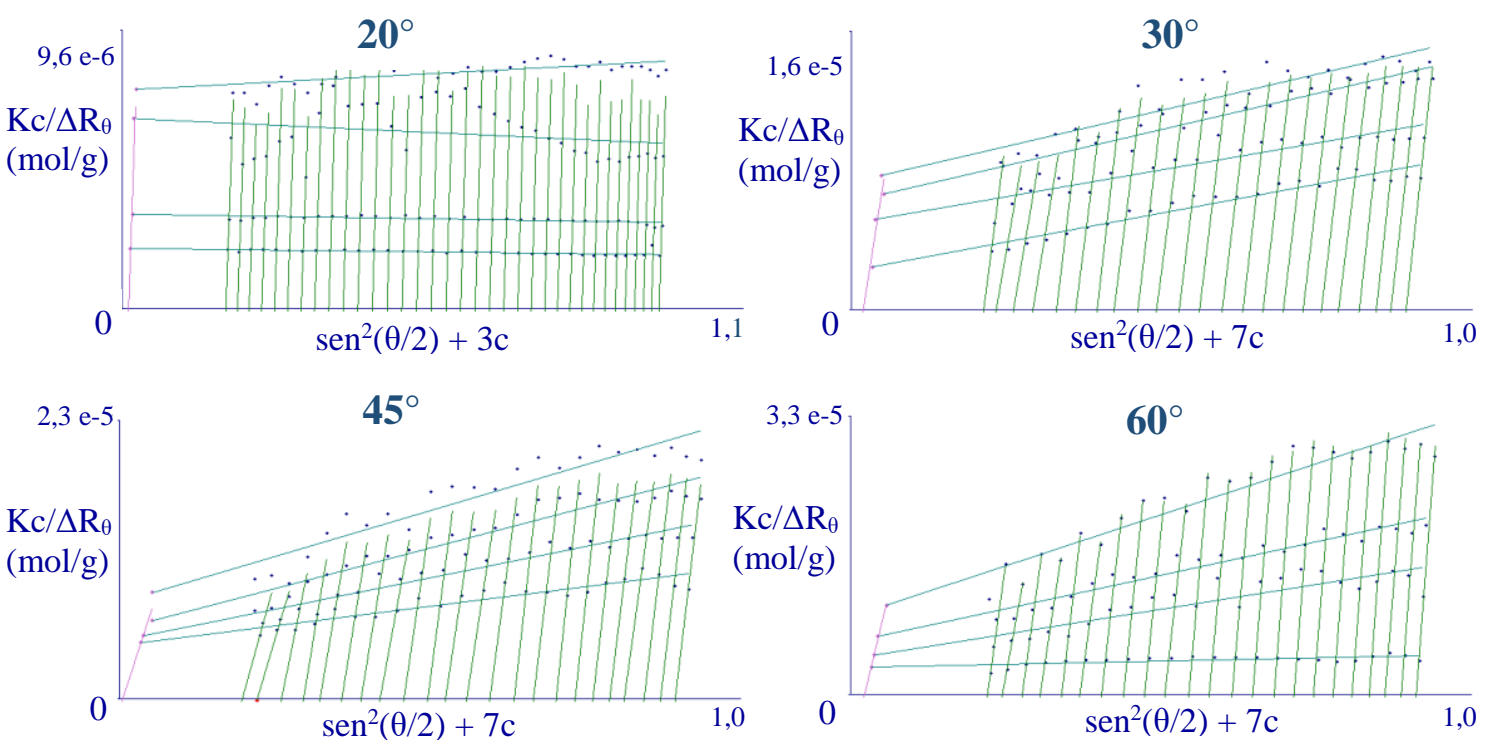

Figura 4.6.4: Gráfico de Zimm para dispersões de DMPG em água nas concentrações: 4,$82 ; 12,4 ; 13,8$ e $16,5 \mathrm{mg} / \mathrm{mL}$, variando o ângulo de 40 a $140^{\circ}$ e em diferentes temperaturas $\left(20,30,45\right.$ e $\left.60^{\circ} \mathrm{C}\right)$.

Os parâmetros de interesse na metodologia de Zimm são obtidos a partir de retas nas extrapolações do ângulo indo a zero (equação 2.3.15) e da concentração indo a zero (equação 2.3.16). Na figura 4.6.4, onde utilizamos dispersões com concentrações próximas a $10 \mathrm{mM}$ de DMPG, não foi possível a obtenção dessas retas extrapoladas, provavelmente, pelas fortes interações entre as vesículas na dispersão. 
Desta forma, repetimos as medidas para o conjunto "baixa concentração" ( 0,5 a 3,0 mM de DMPG) e os resultados são mostrados na figura 4.6.5.

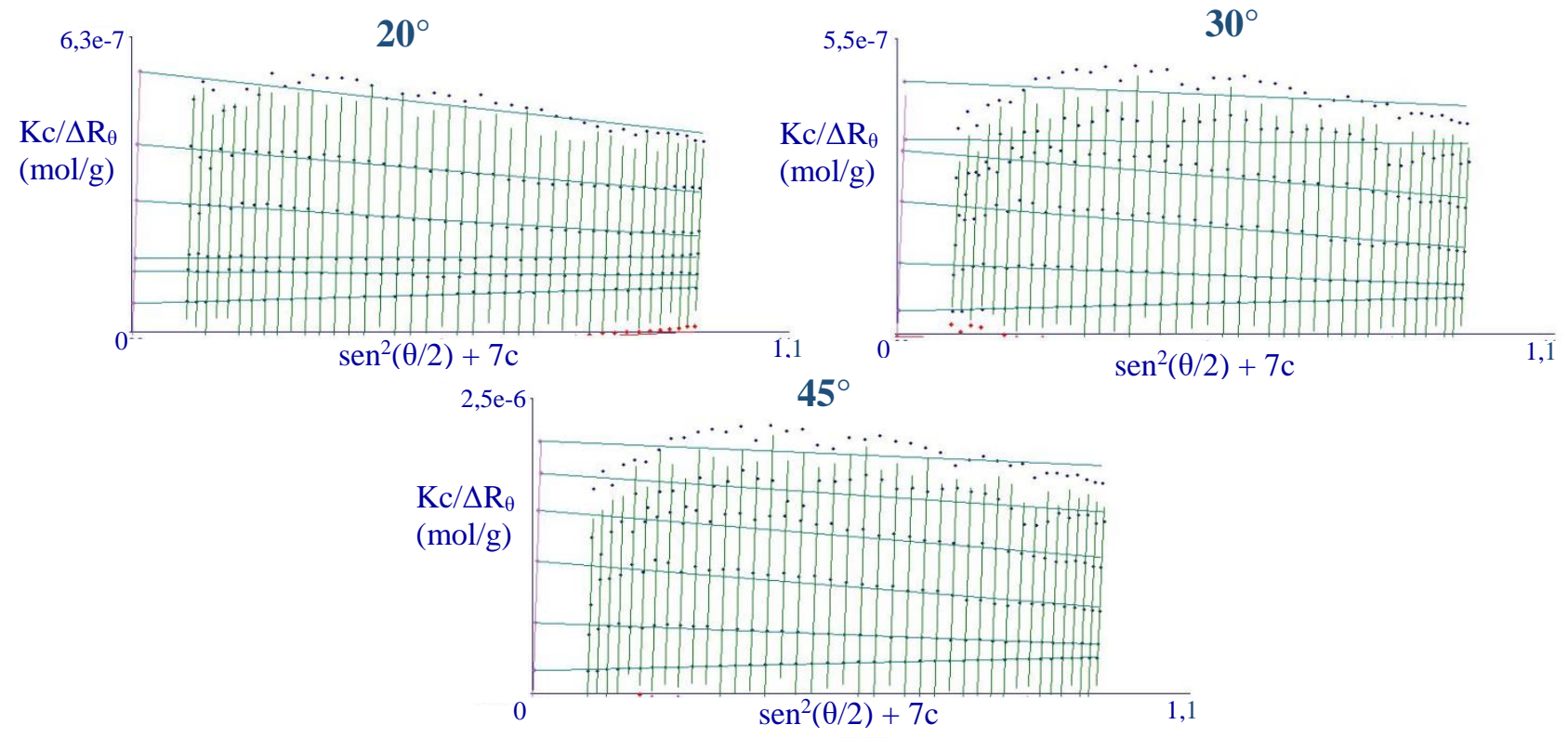

Figura 4.6.5: Gráfico de Zimm para dispersões de DMPG em água nas concentrações: 0,$34 ; 0,69 ; 1,03 ; 1,38 ; 1,72$ e $2,07 \mathrm{mg} / \mathrm{mL}$, variando o ângulo de 40 a $140^{\circ}$ e em diferentes temperaturas $\left(20,30\right.$ e $\left.45^{\circ} \mathrm{C}\right)$.

Nos resultados da figura 4.6.5, novamente não foi possível a obtenção das retas extrapoladas pelo método de Zimm, mesmo utilizando concentrações lipídicas mais baixas $(0,5$ a 3,0 mM). Com estas concentrações foi possível utilizar este método na análise de dispersões de DMPG em HEPES, baixa força iônica (Enoki et al., 2012), sendo que possivelmente as fortes interações entre os agregados no caso do DMPG em água estão impossibilitando a obtenção das retas limites por esta metodologia. Entretanto, mesmo os dados em HEPES serão re-descutidos na seção 5.6.2 desta tese.

De acordo com a metodologia de Zimm (equação 2.3.14), espera-se que o comportamento de $K c / \Delta R_{\theta} \times \operatorname{sen}^{2}(\theta / 2)$ seja linear. Graficamos os dados obtidos para as concentrações de 0,$05 ; 0,5 ; 1,0$ e $1,5 \mathrm{mM}$ de DMPG em água a $20^{\circ} \mathrm{C}$ na figura 4.6.6. 


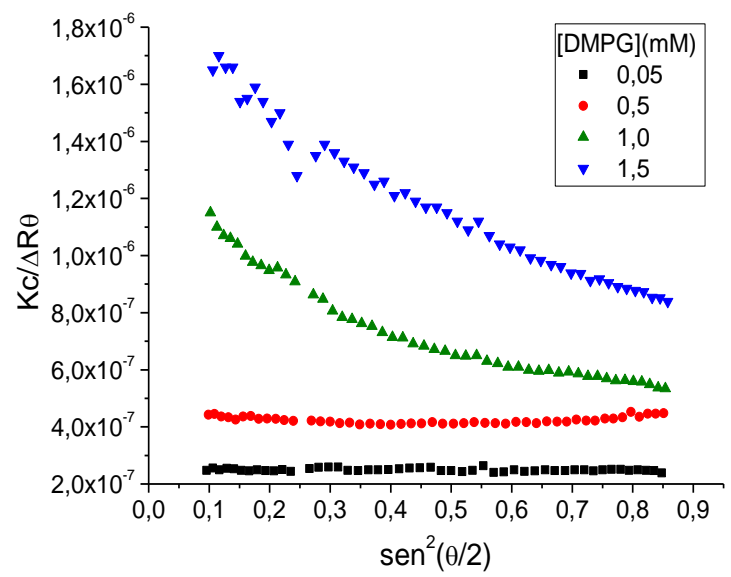

Figura 4.6.6: Gráfico de Zimm obtido para diferentes concentrações lipídicas: 0,05; 0,5; 1,0 e $1,5 \mathrm{mM}$ de DMPG a $20^{\circ} \mathrm{C}$.

Vemos que os resultados da figura 4.6.6 estão bastante fora da aproximação de Zimm, não sendo possível obter informações confiáveis, uma vez que a aproximação linear não é suficiente para descrever os dados obtidos. A única concentração em que foi possível ajustar uma reta crescente com o ângulo foi a de $0,05 \mathrm{mM}$ e obteve-se um raio de giro $R_{g}=9,8(5) \mathrm{nm}$, sendo o raio de giro de uma casca esférica dado por:

$$
R_{g}^{2}=\frac{3}{5} R_{e f}^{2} \frac{1-\left(1-\frac{d}{R_{e f}}\right)^{5}}{1-\left(1-\frac{d}{R_{e f}}\right)^{3}}
$$

onde d é a espessura da bicamada e Ref é o Raio da vesícula.

A partir da equação 4.6.1, calculamos que o Raio efetivo da vesícula, equivalente a $R_{g}=9,8(5) n m$ seria $R_{e f}=12$ (1) $n m$, que é um valor muito pequeno, menos que metade do raio obtido por DLS $(28,5 \pm 1,7 \mathrm{~nm})$. Por ser uma dispersão bastante diluída, 0,05 mM ou $0,034 \mathrm{mg} / \mathrm{mL}$, pode ser que a intensidade de luz espalhada seja muito baixa para obtermos informações confiáveis quanto às vesículas em solução.

De modo a observar o comportamento do espalhamento de luz estático de uma dispersão bastante interagente, realizamos medidas de uma dispersão extrusada de 10 $\mathrm{mM}$ de DMPG em água, nas temperaturas 20,30 e $45^{\circ} \mathrm{C}$ (figura 4.6.7). 


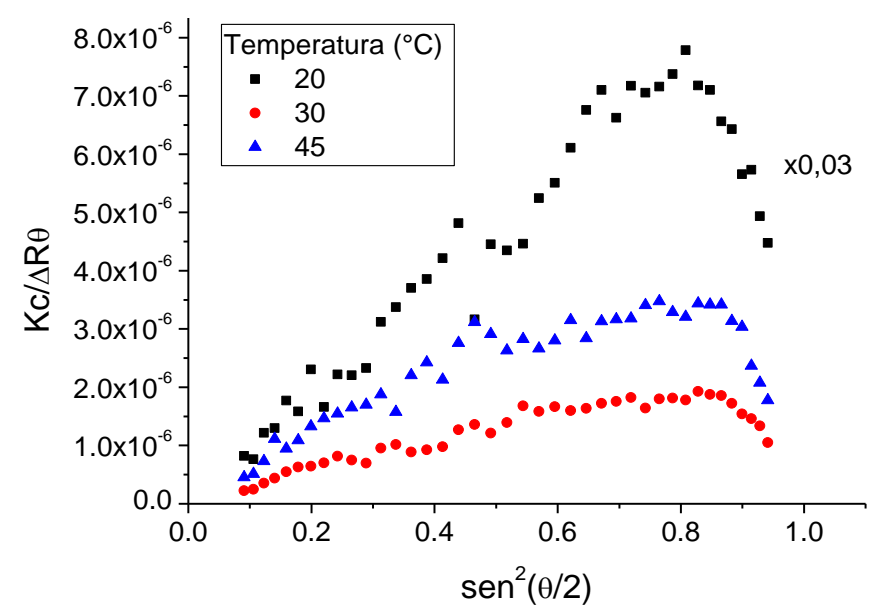

Figura 4.6.7: Gráficos de espalhamento de luz estático para dispersão extrusada $10 \mathrm{mM}$ ) de DMPG em água em diferentes temperaturas $\left(20,30\right.$ e $\left.45^{\circ} \mathrm{C}\right)$.

Para o DMPG em água (figura 4.6.6 e 4.6.7), a dependência da luz espalhada com o ângulo de espalhamento indica uma forte correlação entre as partículas (Reed, 1994; Riske et al., 1997), claramente fora da aproximação do Zimm plot, como foi observado anteriormente para dispersões não extrusadas de $10 \mathrm{mM}$ de DMPG em água (Riske et al., 1997).

\subsubsection{Medidas da razão de despolarização da luz espalhada ( $\left.\mathrm{IVH}_{\mathrm{VH}} / \mathrm{IVv}_{\mathrm{vv}}\right)$}

A razão de despolarização da luz espalhada é sensível à anisotropia dos centros espalhadores, sendo que para moléculas isotrópicas as polarizações da luz incidente e espalhada são paralelas e para moléculas anisotrópicas, a luz espalhada tem componentes em todas as direções, mesmo quando a luz incidente é polarizada em uma direção. Uma partícula anisotrópica despolariza significantemente a luz incidente (ver, por ex., Williams, 1962; Carlson e Flory, 1977; Enoki, 2010).

De modo a verificar uma possível anisotropia das partículas espalhadoras de luz, utilizamos o mesmo aparato experimental das medidas de DLS e SLS e fizemos uso do polarizador que se encontra acoplado ao detector de luz espalhada. Sabendo que a luz do laser é verticalmente polarizada, medimos a razão entre a intensidade de luz espalhada perpendicularmente ( $\mathrm{IVH}_{\mathrm{VH}}$ ) e paralelamente (Ivv) à luz incidente. Como forma de controle, antes das medidas, foi verificado o valor de $\mathrm{IVH}_{\mathrm{vH}} / \mathrm{I}_{\mathrm{vV}}=0,26$ para uma amostra de benzeno, que é uma razão conhecida na literatura. 
Medimos e calculamos as razões de despolarização da luz espalhada para dispersões extrusadas de 1 e 10 mM de DMPG em água nas temperaturas de 20, 30 e $45^{\circ} \mathrm{C}$. Comparamos os resultados com os obtidosa pela aluna de doutorado Thais $\mathrm{A}$. Enoki e publicados no trabalho Enoki et al., 2012.
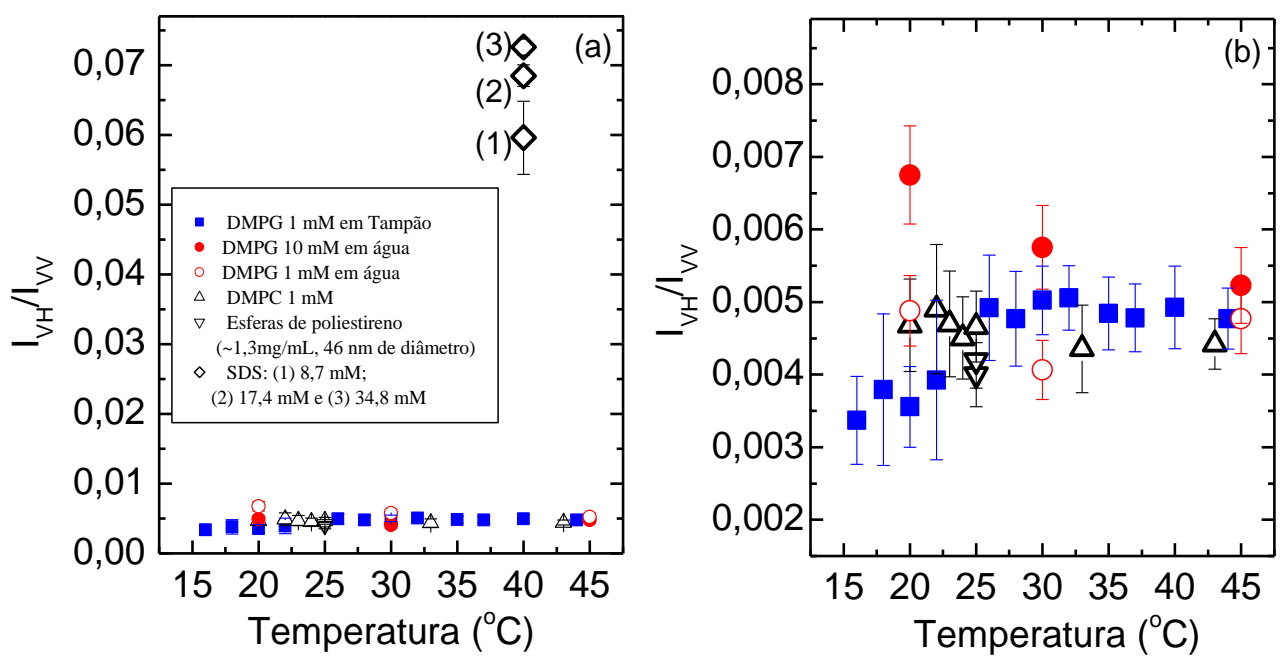

Figura 4.6.8: a)Comparação entre as razões $I_{V H} / I_{v v}$ para dispersões de DMPG em água (pontos em vermelho), de DMPG em HEPES (pontos azuis), de nanoesferas de poliestireno, de DMPC e de micelas de SDS em diferentes concentrações. Em (b) temos uma ampliação da região com razão de despolarização próxima a 0,005. [figura modificada de Enoki et al., 2012].

Da figura 4.6.8, vemos que a razão de despolarização da luz espalhada das dispersões de DMPG em água, tanto para 1 quanto para $10 \mathrm{mM}$, é muito semelhante ao que é observado para as dispersões de DMPG 1 mM em HEPES (buffer), de nanoesferas de poliestireno (isotrópicas) e de DMPC, que supostamente forma vesículas esféricas. As micelas de SDS em água, nas concentrações apresentadas e na temperatura de $40^{\circ} \mathrm{C}$ são conhecidas por formar elipsoides (Bergntröm and Pedersen, 1999), que dada a sua anisotropia apresenta a razão de despolarização maior.

Também realizamos medidas da razão de despolarização da luz espalhada em Graz, para dispersões de 1 e $10 \mathrm{mM}$ nas temperaturas de 5, 15, 20, 30 e $45^{\circ} \mathrm{C}$ (figura 4.6.9). 


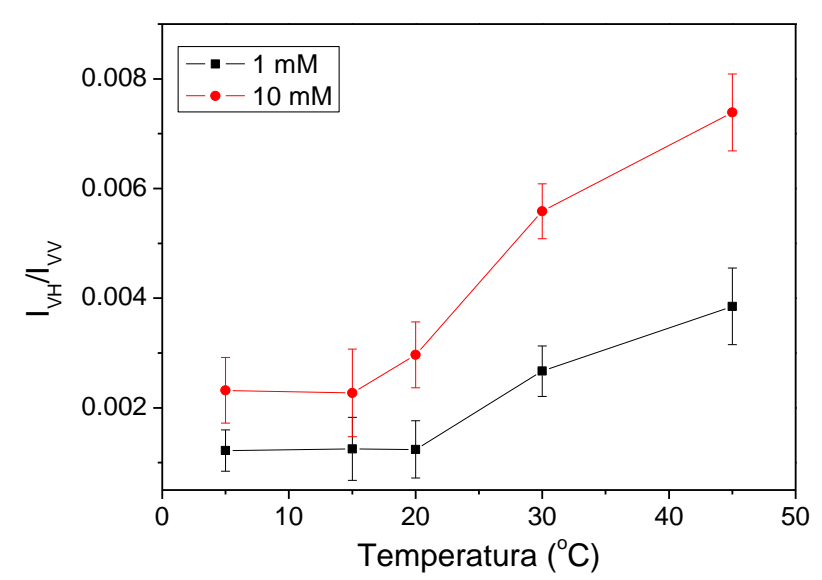

Figura 4.6.9: Razão de despolarização ( $\left.\mathrm{I}_{\mathrm{VH}} / \mathrm{I}_{\mathrm{Vv}}\right)$ de dispersões de 1 e $10 \mathrm{mM}$ de DMPG em água, medidas no "Institute of Inorganic Chemistry" da Graz University of Technology, Graz, Áustria.

Nas figuras 4.6.8b) e 4.6 .9 não notamos diferenças significativas entre os valores de $\mathrm{IVH}_{\mathrm{VH}} / \mathrm{IVv}_{\mathrm{v}}$ para as dispersões de DMPG em água e os demais sistemas isotrópicos. Além disto, as amostras da figura 4.6.9 foram medidas novamente (resultado mostrado na figura 5.6.8) após serem deixadas por 1 semana em temperatura ambiente e novamente os valores da razão de despolarização foi bastante baixo, com valores similares aos apresentados na figura 4.6.9. Dessa forma, temos a indicação de que os agregados de DMPG em água são isotrópicos nas temperaturas medidas (de 5 a $45^{\circ} \mathrm{C}$ ). Esses agregados poderiam ser micelas, mas como será mostrado por resultados de RPE, não são micelas, pois os lipídios apresentam duas fases: uma mais rígida/imóvel a baixas temperaturas e outra mais fluida/móvel para temperaturas acima de $40^{\circ} \mathrm{C}$. Podemos dizer então que são vesículas, sendo este um resultado bastante importante, pois mostramos a presença de vesículas e não bicelas como foi proposto em Epand et al.,1986. 


\subsection{Resumo dos resultados obtidos neste capítulo}

De modo a observamos possíveis correlações entre os comportamentos térmicos dos resultados obtidos pelas diferentes técnicas experimentais usadas neste capítulo, apresentamos os resultados obtidos para as dispersões extrusadas de DMPG em água sobrepostos e normalizados, de modo que o maior valor obtido com cada técnica coincidisse com um e o menor valor com zero.

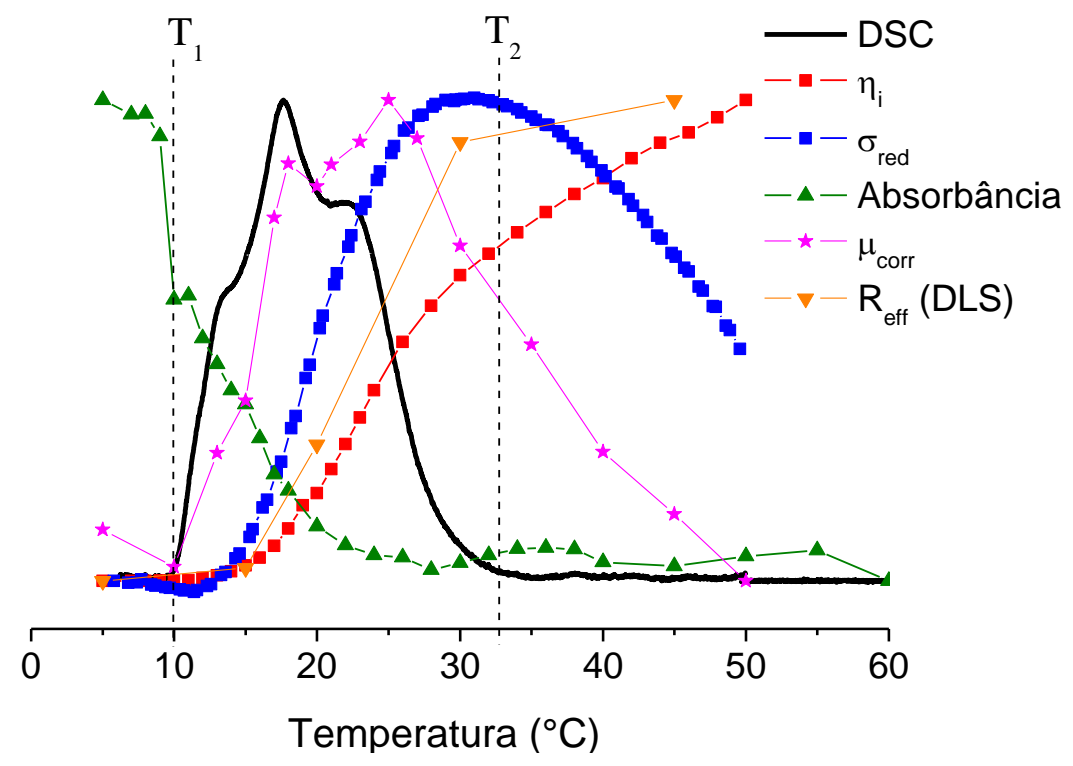

Figura 4.7.1: Sobreposição dos resultados de DSC, incremento da viscosidade relativa $\left(\eta_{i}\right)$, condutividade reduzida ( $\left.\sigma_{\text {red }}\right)$, absorbância a $350 \mathrm{~nm}$, mobilidade corrigida ( $\left.\mu_{\text {corr }}\right)$ e raio efetivo $\left(R_{\text {eff }}\right.$ ) calculado por DLS de dispersões extrusadas de 10 mM (1 mM para a medida de $R_{\text {eff }}$ ) de DMPG em água.

A partir da figura 4.7.1 vemos que um processo termo-estrutural tem início com o começo dos picos de absorção de calor de $\operatorname{DSC}\left(T_{1}\right)$, sendo que entre 10 e $15^{\circ} \mathrm{C}$ é observada a diminuição da turbidez da amostra, e o aumento da viscosidade e da condutividade elétrica da dispersão, e da mobilidade eletroforética e do raio efetivo da vesícula de DMPG, mostrando que um processo é disparado com o início da transição de fase vista por DSC. Da mesma forma, esse processo parece terminar após o fim da transição de fase, em $\mathrm{T}_{2} \sim 33^{\circ} \mathrm{C}$, quando a viscosidade passa a aumentar de maneira menos brusca, a mobilidade eletroforética da vesícula e a condutividade da dispersão decrescem, o raio efetivo da vesícula para de aumentar e a turbidez da amostra permanece com valores próximos a zero. Entretanto, diferente de dispersões de DMPG 
em tampão a baixa força iônica, como será discutido no capítulo 5, o comportamento das grandezas medidas na fase fluida não é semelhante ao da fase gel da bicamada.

Os resultados de DSC, viscosidade e condutividade elétrica foram muito semelhantes para as dispersões extrusadas e não extrusadas, somado a este fato a facilidade em se realizar a extrusão de dispersões de DMPG em água, podem estar relacionados com a formação de uma maioria de agregados pequenos de DMPG em água.

Pelos resultados de RPE (capítulo 6), mostramos que são vesículas e pelos resultados da razão de despolarização da luz espalhada (figura 4.6.8) que são esféricas. Como mostraremos nos capítulos a seguir, medidas de WAXS e RPE mostram a mudança de uma fase ordenada/imóvel que vai para uma fase desordenada/móvel com o aumento da temperatura, sendo que os picos de repetição de SAXS já aparecem a partir de $5^{\circ} \mathrm{C}$, não estando relacionados à região de transição de fase, mas eles mudam de posição a partir de $T_{1}$, indo para valores maiores de $q$. Portanto, não temos indicação de que os fenômenos peculiares monitorados com as diferentes técnicas aqui apresentadas estejam relacionados com abertura de poros na bicamada lipídica das vesículas de DMPG em água na "região de transição de fase" da bicamada lipídica. A diminuição da turbidez pode ser devida à perda de contraste óptico conforme a bicamada fica mais frouxa, de modo que a passagem de água faz com o que o índice de refração da bicamada seja próximo ao da água.

Apesar de ainda não ser possível propor um modelo final, o comportamento anômalo observado para as dispersões de DMPG em baixíssima força iônica, isto é, em água pura, deve se relacionar com os efeitos das cargas das vesículas, que não estão blindadas pela presença de sais no solvente. 


\section{Capítulo 5 - Resultados e discussões:}

\section{dispersões de DMPG em tampão}

comparadas com dispersões em água

Neste capítulo comparamos os resultados obtidos com dispersões de $10 \mathrm{mM}$ de DMPG em tampão HEPES, baixa força iônica (HEPES $10 \mathrm{mM}+\mathrm{NaCl} 2$ $m M)$, após a extrusão, com os resultados obtidos para dispersões não extrusadas (Barroso, 2010), portanto, mais polidispersas. Além disto, os resultados de dispersões extrusadas em tampão serão comparados com os resultados das dispersões extrusadas de DMPG em água (apresentados no capítulo 4 desta tese).

Na seção 5.8 deste capítulo são apresentados e discutidos os resultados obtidos com dispersões extrusadas de 50 mM de DMPG em tampão a baixa força iônica, sendo feita a comparação destes resultados com os resultados de dispersões não extrusadas de 50 mM de DMPG em tampão (Barroso, 2010). 


\subsection{Calorimetria Diferencial de Varredura (DSC)}

De modo a verificar mudanças no perfil de DSC ocorridas após o processo de extrusão das amostras, realizamos as seguintes medidas de dispersões de DMPG em tampão HEPES a baixa força iônica (HEPES $10 \mathrm{mM}+2 \mathrm{mM}$ de $\mathrm{NaCl}$ ).
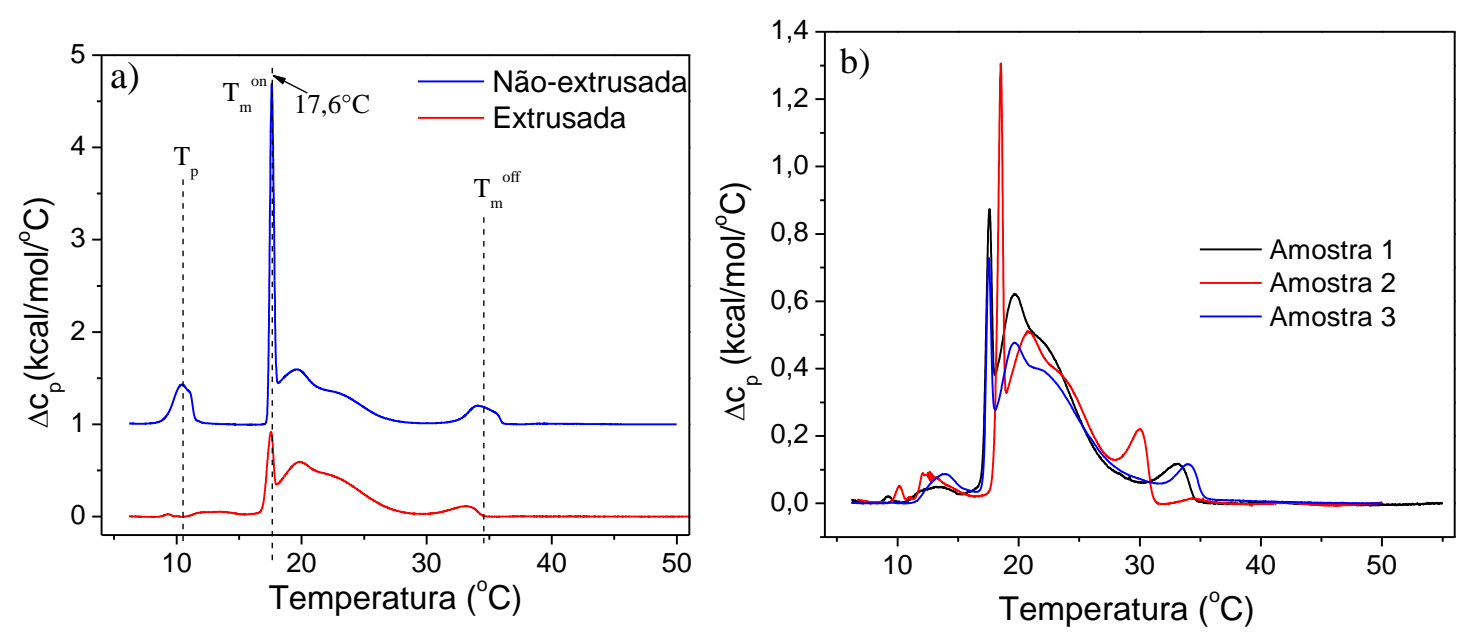

Figura 5.1.1: a) Comparação de curvas de DSC de dispersões de DMPG $10 \mathrm{mM}$ em tampão a baixa força iônica antes e depois da extrusão, sendo que a curva não extrusada foi deslocada verticalmente para melhor visualização. b) Resultados obtidos com diferentes amostras extrusadas de DMPG $10 \mathrm{mM}$. Todas as curvas foram obtidas aquecendo-se as amostras a uma taxa de $20^{\circ} \mathrm{C} / \mathrm{h}$.

Conforme mostrado anteriormente em diferentes trabalhos (Salonen et al., 1989; Heimburg \& Bitonenm 1994; Riske et al., 2001, 2009; Lamy-Freund \&Riske, 2003; Alakoskela \& Kinnunen, 2007; Kinoshita et al., 2008; Barroso et al., 2010; Enoki et al., 2012) dispersões de DMPG em meio de baixa força iônica apresentam uma larga região de transição de fase, tendo o primeiro e mais proeminente pico em $\mathrm{T}_{\mathrm{m}}{ }^{\mathrm{on}} \sim 18^{\circ} \mathrm{C}$ e o último pico em $\mathrm{Tm}_{\mathrm{m}}{ }^{\text {ff }} \sim 35^{\circ} \mathrm{C}$. Comparando as curvas obtidas para as dispersões antes e depois da extrusão (figura 5.1.1 a)), notamos que os perfis são muito semelhantes. Entretanto, após a extrusão há uma diminuição no pico da pré-transição de fase (que aparece em $T_{p}$ ), a intensidade do pico em $T_{m}{ }^{\text {on }}$ diminuiu e o pico ficou menos estreito, 0 que pode ser explicado pelo fato de ao realizar a extrusão, aumentarmos o número de agregados menores, que apresentam curvatura da bicamada maior, e consequentemente menor cooperatividade (Heimburg, 2007; Enoki, 2010).

Quando trabalhamos com vesículas grandes, onde podemos considerar que as bicamadas são praticamente planas, temos que, durante a transição de fase, a 
probabilidade de encontrarmos lipídios na fase fluida na monocamada superior é a mesma que na monocamada inferior, e a cooperatividade é alta. Ao aumentar a curvatura da bicamada, à medida que aquecemos a amostra, aumentamos a probabilidade de encontrar lipídios na fase fluida na camada interior, sendo que a camada interior tem maior curvatura, e com isso, diminuímos a cooperatividade na transição (Heimburg, 2007; Enoki, 2010).

A figura 5.1 .1 b) mostra os resultados de DSC obtidos com diferentes amostras extrusadas de $10 \mathrm{mM}$ de DMPG em tampão a baixa força iônica. No decorrer do desenvolvimento desta tese foi necessário utilizar diferentes frascos de DMPG da Avanti Polar Lipids, sendo verificado o perfil de DSC antes da utilização dos mesmos em outras técnicas. Conforme podemos observar, apesar de notarmos algumas diferenças no perfil de DSC de amostras de DMPG de diferentes lotes, no que diz respeito às posições e calor específico dos picos, vemos que o comportamento térmico é característico ao observado para dispersões de DMPG a baixa força iônica e a entalpia da transição foi de $5,0(5) \mathrm{kcal} / \mathrm{mol}$ considerando todas as amostras.

Como visto em Enoki et al., 2012, os agregados de DMPG em tampão a baixa força iônica apresentam diâmetros próximos a $50 \mathrm{~nm}$, mesmo com a extrusão sendo realizada por filtro com poros de $100 \mathrm{~nm}$. Realizamos medidas de DSC com amostras de 10 mM de DMPG antes da extrusão e após a extrusão por filtros de 30 e $100 \mathrm{~nm}$ e os resultados são mostrados na figura 5.1.2. 


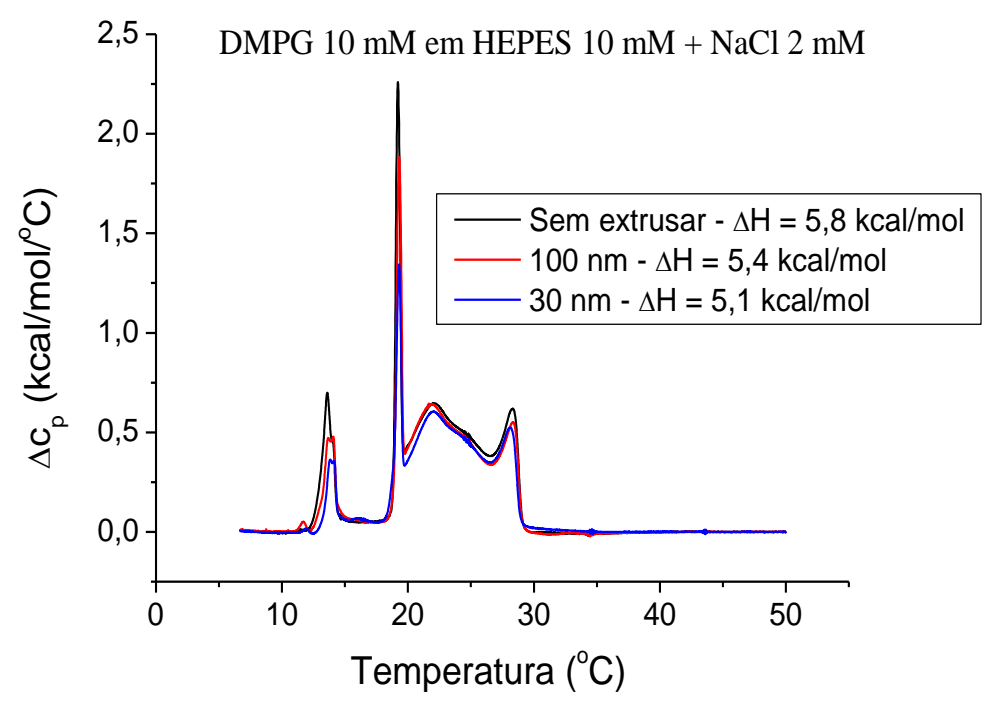

Figura 5.1.2: DSC de dispersões de $10 \mathrm{mM}$ de DMPG antes da extrusão (curva preta), após extrusão por filtros de $100 \mathrm{~nm}$ (curvas vermelhas) e após extrusão por filtros de 30 nm (curvas azuis) em tampão a baixa força iônica, com os respectivos valores de entalpia da transição de fase.

A partir dos resultados da figura 5.1.2 vemos que ao realizar a extrusão por filtros cada vez menores, há uma diminuição na intensidade do pico estreito em $\mathrm{T}_{\mathrm{m}}{ }^{\text {on }}$, indicando a diminuição na cooperatividade da transição e também na intensidade do pico em $T_{p}$. Além disto, a entalpia da transição diminui, sendo $\Delta H=5,8(3) \mathrm{kcal} / \mathrm{mol}$ para a dispersão não extrusada, 5,4 (4) kcal/mol para a dispersão extrusada pelo filtro de 100 $\mathrm{nm}$ e 5,1 (5) $\mathrm{kcal} / \mathrm{mol}$ para a dispersão extrusada pelo filtro de $30 \mathrm{~nm}$. Comparando estes valores de $\Delta \mathrm{H}$ com as entalpias que foram calculadas para as dispersões de DMPG em água, na figura 4.1.3, vemos que os valores são muito próximos, mostrando que apesar do perfil calorimétrico ser bastante diferente para as dispersões em água e em tampão a baixa força iônica, a entalpia da transição de fase é a mesma e diminui quando realizamos a extrusão por filtros menores. Também é interessante notar que os valores de entalpia calculadas para as dispersões de DMPG não extrusadas são compatíveis com os valores mostrados em Barroso, 2010, que foi de $\Delta H=6,1(5) \mathrm{kcal} / \mathrm{mol}$. Os resultados da figura 5.1.2 foram obtidos com um mesmo lote de DMPG e neste caso, o pico de prétransição continua bem visível mesmo após a extrusão, diferente do que foi observado para as amostras da figura 5.1.1, e a entalpia calculada para a transição da dispersão extrusada pelo filtro de $100 \mathrm{~nm}$ foi um pouco mais alta do que a média calculada na 
figura 5.1.1 b). Este lote de DMPG, especificamente, só foi utilizado para a realização deste experimento.

Os experimentos (figuras 4.1.3 e 5.1.2) realizados após a extrusão das dispersões por filtros de $30 \mathrm{~nm}$ nos mostrou que mesmo com vesículas da ordem de $30 \mathrm{~nm}$, ainda é possível observar a região de transição de fase, tanto para as dispersões em água quanto em tampão, e que os valores de $\Delta \mathrm{H}$ são muito parecidos com os calculados para a transição das dispersões extrusadas pelo filtro de $100 \mathrm{~nm}$, indicando que os agregados devem apresentar curvaturas parecidas e indicando que o DMPG de fato se organiza como vesículas pequenas em meios aquosos de baixa força iônica.

Na figura 5.1.3 apresentamos a comparação de resultados típicos de DSC obtidos para dispersões extrusadas de $10 \mathrm{mM}$ de DMPG em água e em tampão HEPES a baixa força iônica.

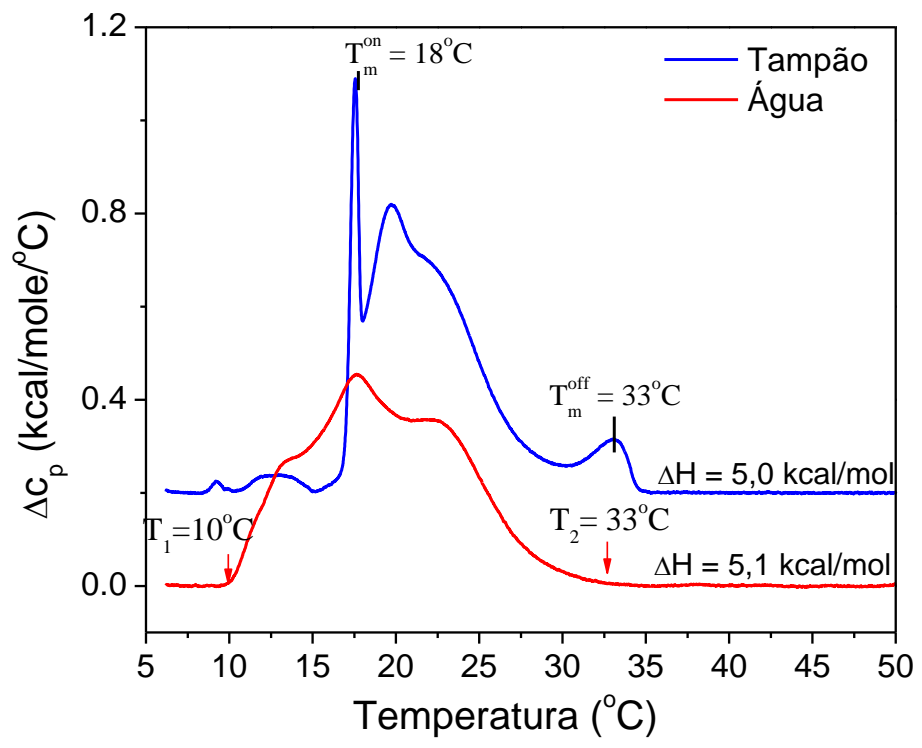

Figura 5.1.3: Comparação de curvas típicas de DSC de dispersões extrusadas de $10 \mathrm{mM}$ de DMPG em água (curva vermelha) e em tampão a baixa força iônica (curva azul). 0 resultado em tampão foi deslocado verticalmente para melhor visualização.

$\mathrm{Na}$ figura 5.1.3, comparando os resultados para o DMPG em água com o resultado para o DMPG em tampão, vemos que para o sistema em água a transição de fase é muito menos cooperativa, dada a ausência de picos estreitos e intensos de variação de calor específico. Isto pode estar relacionado com os agregados de DMPG em água apresentarem grande curvatura da bicamada, tratando-se de agregados menores, 
em sua maioria, do que os obtidos em tampão. A forte repulsão eletrostática entre as cabeças polares aumentaria a distância entre os lipídios, diminuindo as interações entre as caudas carbônicas e também a cooperatividade da transição. Entretanto, a entalpia para ocorrer a transição de fase é a mesma para os meios de diferente força iônica $(\Delta \mathrm{H}=5,0(5) \mathrm{kcal} / \mathrm{mol})$.

Ainda sobre a figura 5.1.3, notamos que a "região de transição de fase" é ainda mais larga para as dispersões em água, iniciando-se em temperaturas bem mais baixas $\left(\sim 10^{\circ} \mathrm{C}\right)$. O fato da transição se iniciar em uma temperatura mais baixa pode estar relacionado com uma maior carga superficial dos agregados de DMPG em água, o que aumentaria a área por cabeça polar dos lipídios, devido à repulsão eletrostática entre as cabeças polares, diminuindo as interações das cadeias hidrocarbônicas e, desta forma, desestabilizando a fase gel da bicamada (Jahnig, 1976; Trauble et al., 1976). Além disto, o estreitamento do intervalo de temperaturas da região de transição de fase de dispersões de DMPG com o aumento da força iônica do meio já foi reportado anteriormente (Kodama \& Miyata, 1995; Lamy-Freund \& Riske, 2003; Barroso, 2010), sendo que em meio de alta força iônica observa-se para o DMPG uma transição de fase altamente cooperativa (Lamy-Freund \& Riske, 2003) e semelhante ao do lipídio DMPC, que é neutro. 


\subsection{Viscosidade}

De modo a caracterizar o comportamento térmico da viscosidade de dispersões extrusadas de DMPG em tampão a baixa força iônica, realizamos medidas da viscosidade cinemática em função da temperatura para dispersões de 10 mM de DMPG.

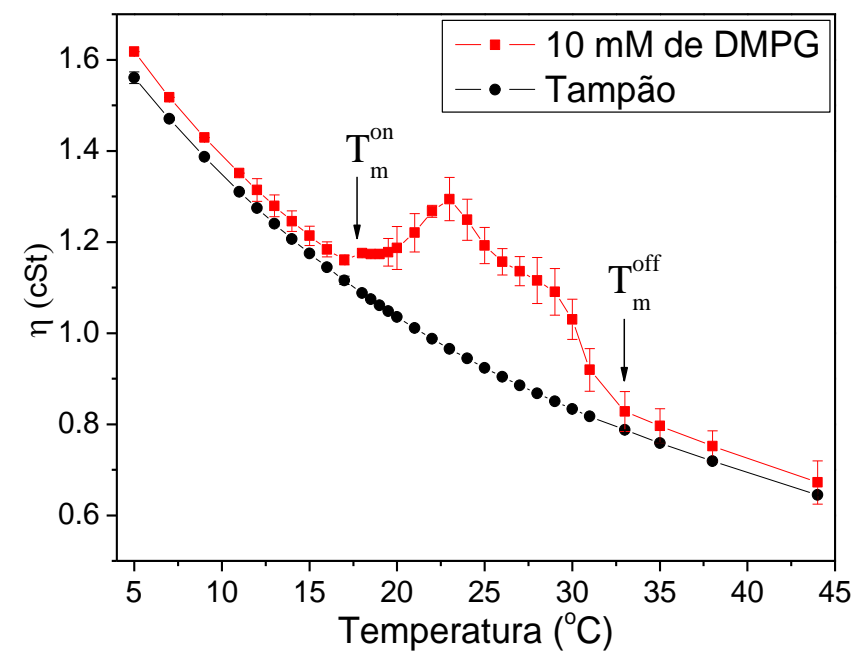

Figura 5.2.1: Viscosidade cinemática em função da temperatura para dispersões extrusadas de 10 mM de DMPG em tampão (curva vermelha) e do tampão (curva preta). Cada curva é a média entre medidas de duas amostras distintas e a incerteza é dada pelo desvio padrão das medidas.

A partir da figura 5.2.1 vemos que a viscosidade cinemática de dispersões extrusada de 10 mM de DMPG em tampão HEPES é muito semelhante à viscosidade do tampão nas temperaturas abaixo de $\mathrm{T}_{\mathrm{m}}{ }^{\text {on }}$ (fase gel) e nas temperaturas acima de $\mathrm{T}_{\mathrm{m}}{ }^{\text {off }}$ (fase fluida), apresentando um aumento nas temperaturas da "região de transição de fase". As medidas de viscosidade cinemática também foram realizadas esfriando as amostras (resultados não apresentados aqui) e nenhuma diferença significativa foi observada em relação aos resultados obtidos aumentando-se a temperatura.

$\mathrm{Na}$ figura 5.2.2 comparamos os valores do incremento da viscosidade relativa (equação 4.2.1) em função da temperatura para dispersões de $10 \mathrm{mM}$ de DMPG em tampão HEPES a baixa força iônica antes (resultados de Barroso, 2010) e depois da extrusão. 


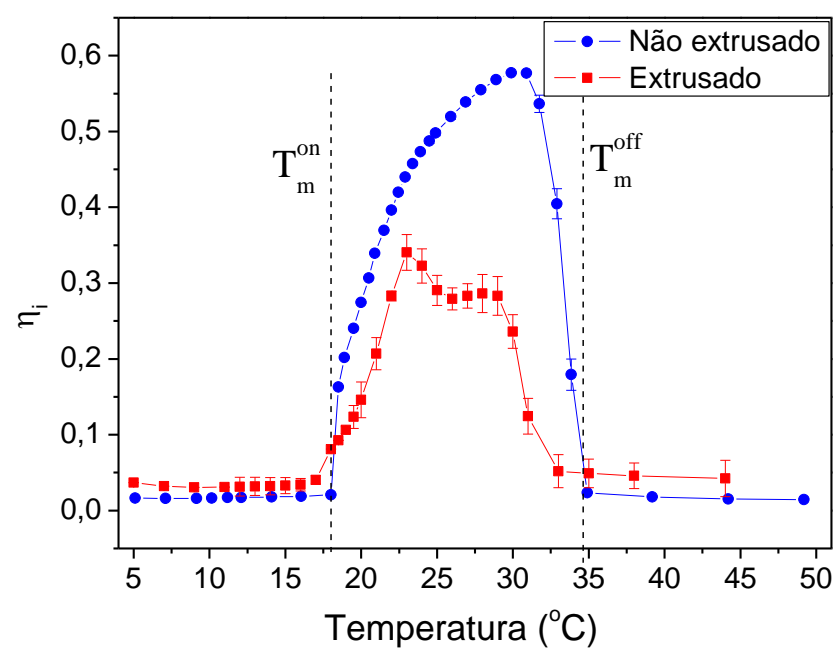

Figura 5.2.2: Incremento da viscosidade relativa com a temperatura para dispersões de $10 \mathrm{mM}$ de DMPG antes (curva azul, extraídas de Barroso, 2010) e depois (curva vermelha) da extrusão. As temperaturas indicadas para $\mathrm{T}_{\mathrm{m}}{ }^{\text {on }}$ e $\mathrm{T}_{\mathrm{m}}{ }^{\text {off }}$ são as mesmas dos gráficos de DSC (figura 5.1.3).

A partir do gráfico da figura 5.2.2 observamos um comportamento semelhante para o incremento da viscosidade relativa de dispersões extrusadas e não extrusadas de 10 mM de DMPG, mas não idêntico. Vemos que há um aumento abrupto no incremento da viscosidade relativa a partir de $\sim 18^{\circ} \mathrm{C}$, que é a temperatura do início da transição de fase vista por DSC (figura 5.1.1a), sendo que para o sistema extrusado, a viscosidade aumenta até $\sim 22^{\circ} \mathrm{C}$, sofre uma pequena diminuição e diminui abruptamente a partir de $\sim 30^{\circ} \mathrm{C}$, atingindo o valor próximo ao do solvente a partir de $33^{\circ} \mathrm{C}$, que é a posição de $\mathrm{T}_{\mathrm{m}}{ }^{\text {off }}$ para a dispersão extrusada da figura 5.1.1a). Já para a dispersão não extrusada, $\eta_{\mathrm{i}}$ aumenta até $30^{\circ} \mathrm{C}$ e, após atingir o máximo, a viscosidade diminui muito mais rapidamente que seu aumento até uma temperatura próxima a $\mathrm{T}_{\mathrm{m}}{ }^{\text {off. Enquanto em }}$ $\mathrm{T}=30^{\circ} \mathrm{C}$, o aumento da viscosidade devida à presença de DMPG na dispersão não extrusada é de cerca de $60 \%$, para a dispersão extrusada este valor diminui para $30 \%$, sendo que, no intervalo de temperaturas da transição de fase, $\eta_{i}$ é sempre maior para a dispersão não extrusada. Portanto, medidas de viscosidade confirmam a modificação das dispersões após a extrusão, como visto por DSC (figura 5.1.1).

A seguir apresentamos a comparação entre as medidas do incremento de viscosidade relativa para dispersões extrusadas de $10 \mathrm{mM}$ de DMPG em água e em tampão a baixa força iônica. 


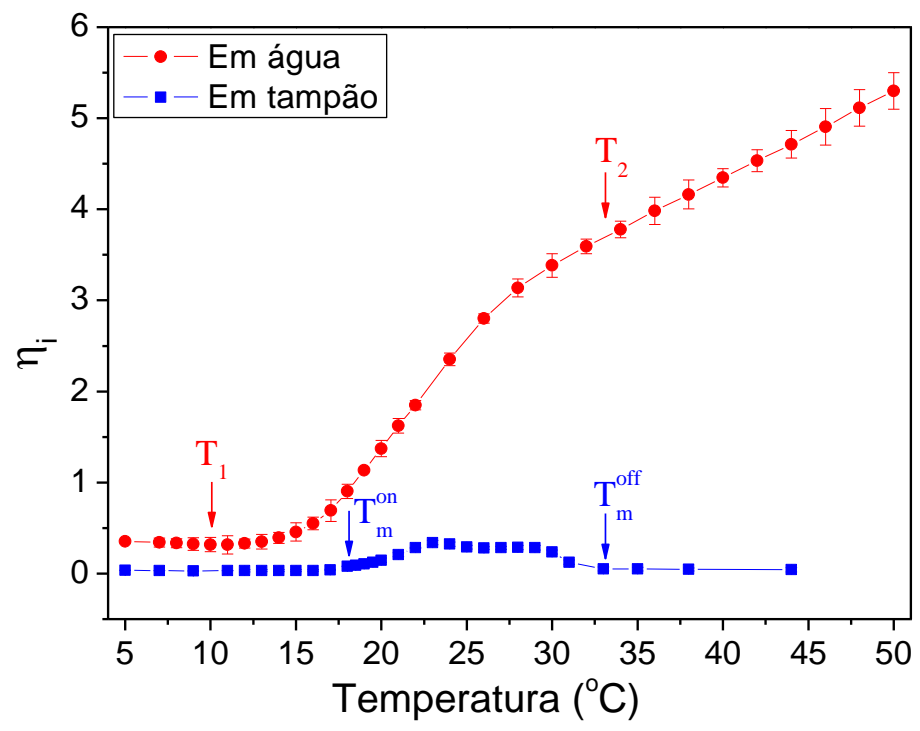

Figura 5.2.3: Comparação do incremento da viscosidade relativa de dispersões extrusadas de $10 \mathrm{mM}$ de DMPG em água e em tampão a baixa força iônica. As setas indicam as temperaturas de início e final da transição de fase, vistas por DSC.

Comparando os resultados obtidos para as dispersões em água e em tampão a baixa força iônica, notamos que o incremento da viscosidade relativa é muito maior nas dispersões de DMPG em água (vide as escalas), enquanto em $30^{\circ} \mathrm{C}$ o aumento da viscosidade devida à presença de DMPG na dispersão em tampão é de $\sim 30 \%$, na dispersão em água, esse aumento é de $\sim 350 \%$ ! Além disso, nas dispersões em tampão, a contribuição do DMPG na viscosidade do solvente só se dá na região de transição de fase (entre $T_{m}{ }^{\text {on }}$ e $T_{m}{ }^{\text {off }}$ ), sendo a viscosidade da dispersão similar à do solvente tanto na fase gel quanto na fase fluida, o que não ocorre para as dispersões em água, onde a viscosidade aumenta até, pelo menos, $50^{\circ} \mathrm{C}$, temperatura muito acima do final dos picos de absorção de calor (figura 4.1.1). É interessante notar que o efeito da extrusão é muito mais notado nas medidas de viscosidade das dispersões em tampão (figura 5.2.2) do que em água (figura 4.2.2) sendo mais um indicativo da presença de uma maioria de agregados menores em água, mesmo antes da extrusão, meio de baixíssima força iônica.

Como a forma de um objeto influencia a maneira como ele flui, essas diferenças na viscosidade podem estar relacionadas com mudanças na forma e/ou tamanho dos agregados de DMPG. Além disso, as interações entre partículas também contribuem para a fluidez de uma dispersão. 


\subsection{Condutividade Elétrica}

A seguir apresentamos os resultados obtidos para a condutividade elétrica de dispersões extrusadas de 10 mM de DMPG em tampão a baixa força iônica (HEPES 10 $\mathrm{mM}+\mathrm{NaCl} 2 \mathrm{mM})$.

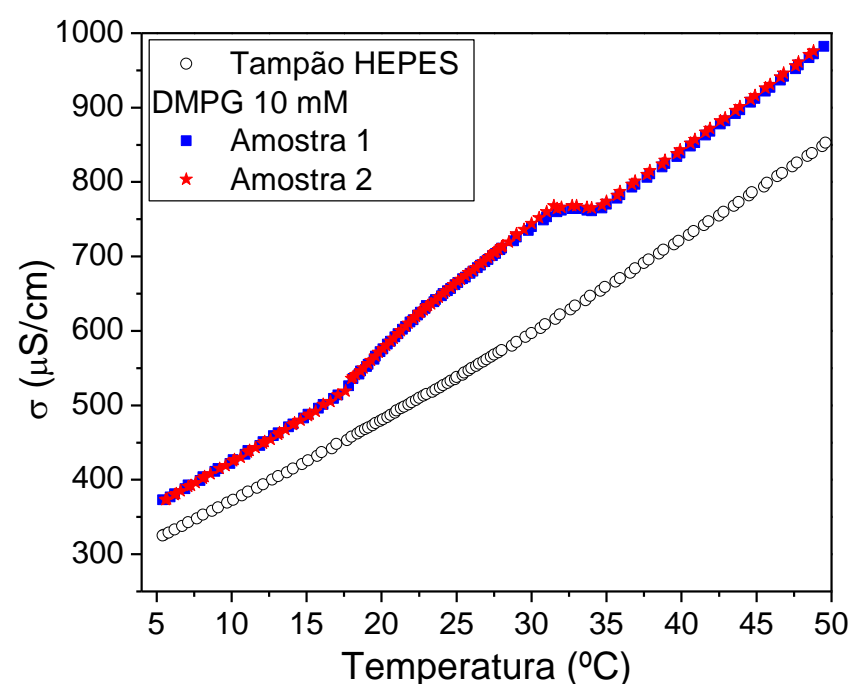

Figura 5.3.1: Medidas de condutividade elétrica do tampão HEPES e de duas amostras distintas de 10 mM de DMPG em tampão extrusadas.

A partir da figura 5.3.1 notamos o aumento anômalo da condutividade elétrica na região de transição de fase (entre 18 e $33^{\circ} \mathrm{C}$ ), sendo que este comportamento foi observado anteriormente para dispersões não extrusadas de DMPG a baixa força iônica e foi atribuído à dissociação de contraíons $\mathrm{Na}^{+}$que se encontravam nas cabeças polares dos lipídios (Barroso, 2010; Riske et al., 1997; Riske et al., 1999; Tamashiro et al., 2005). Da figura 5.3.1 a) observamos que as medidas de condutividade foram bastante reprodutíveis para amostras distintas. Foram realizadas medidas (dados não mostrados aqui) esfriando as amostras e os resultados foram muito semelhantes com os obtidos esquentando as amostras, mostrando reversibilidade dos eventos observados.

No caso das dispersões em tampão, devemos desconsiderar, no cálculo da condutividade reduzida, a contribuição dos íons do tampão que se encontram no interior das vesículas, uma vez que estes não contribuem para a condutividade da dispersão. Desta forma, vamos usar a equação:

$$
\sigma_{\text {red }}=\frac{\Delta \sigma}{\sigma_{0}(1-\phi)},
$$


onde $\Delta \sigma$ é a diferença entre a condutividade da dispersão $(\sigma)$ e do solvente $\left(\sigma_{0}\right)$ e $\phi$ (equação 2.7.8) é a fração de volume ocupada pelas vesículas de DMPG. Seguindo as considerações de Barroso et al., 2010, usamos $\phi=0,025$ para as dispersões de $10 \mathrm{mM}$ e $\phi=0,125$ para $50 \mathrm{mM}$ (seção 5.8), considerando-se vesículas unilamelares de $100 \mathrm{~nm}$ de diâmetro e a área por cabeça polar de 0,50 $\mathrm{nm}^{2}$.

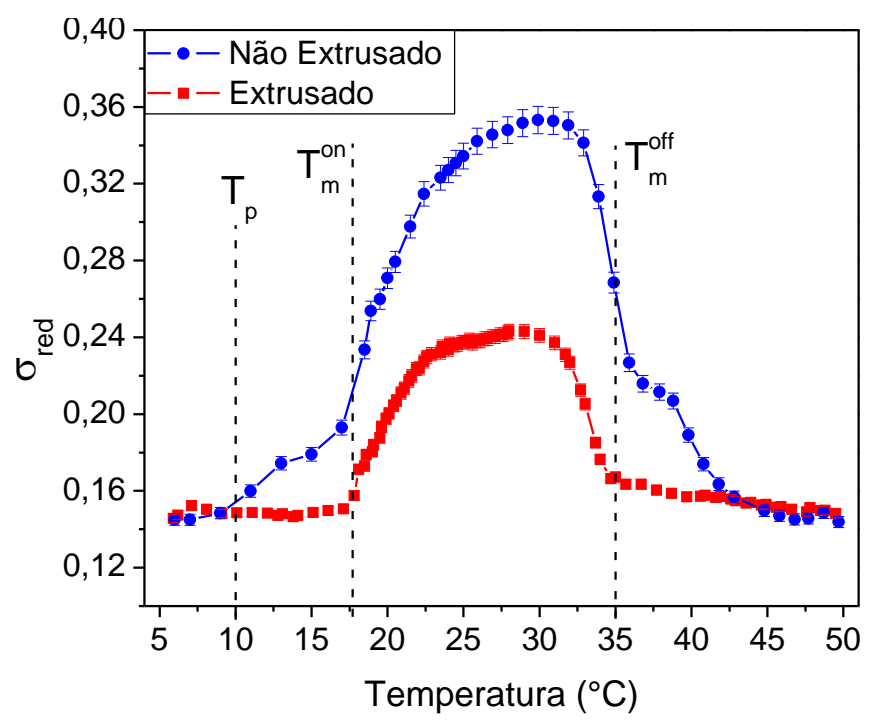

Figura 5.3.2: Condutividade reduzida de dispersões de $10 \mathrm{mM}$ de DMPG em tampão HEPES.

Para as dispersões não extrusadas, notamos um aumento na condutividade reduzida já a partir de $T_{p}$, chegando a um aumento de $19 \%$, relativo à condutividade do solvente. O mesmo não ocorre para o resultado de DMPG 10 mM extrusado, que como visto no DSC (figura 5.1.1 a) não apresenta o pico de pré-transição de fase muito intenso nos lotes utilizados neste trabalho.

Para as dispersões de $10 \mathrm{mM}$, vemos que a partir de $\mathrm{Tm}^{\text {on }}$ a condutividade aumenta bruscamente até atingir um máximo em $\sim 30^{\circ} \mathrm{C}$, e então começa a diminuir até uma temperatura próxima a $\mathrm{T}_{\mathrm{m}}{ }^{\text {off }}$, sendo que para a dispersão não extrusada, a condutividade reduzida continua decrescendo até $\sim 43^{\circ} \mathrm{C}$, mesmo após o fim da transição de fase vista por DSC (figura 5.1.1a). As principais diferenças observadas nos valores da condutividade reduzida após a extrusão, são a ausência de uma queda na condutividade após $T_{m}{ }^{\text {off }}$, mas não discutiremos possíveis causas para esta queda, nas dispersões não extrusadas, neste trabalho. Semelhante aos resultados de viscosidade (figura 5.2.2), os valores medidos são menores após a extrusão das amostras. 
Na figura 5.3.3 mostramos a comparação dos resultados obtidos com dispersões extrusadas de 10 mM de DMPG em água e em tampão a baixa força iônica.

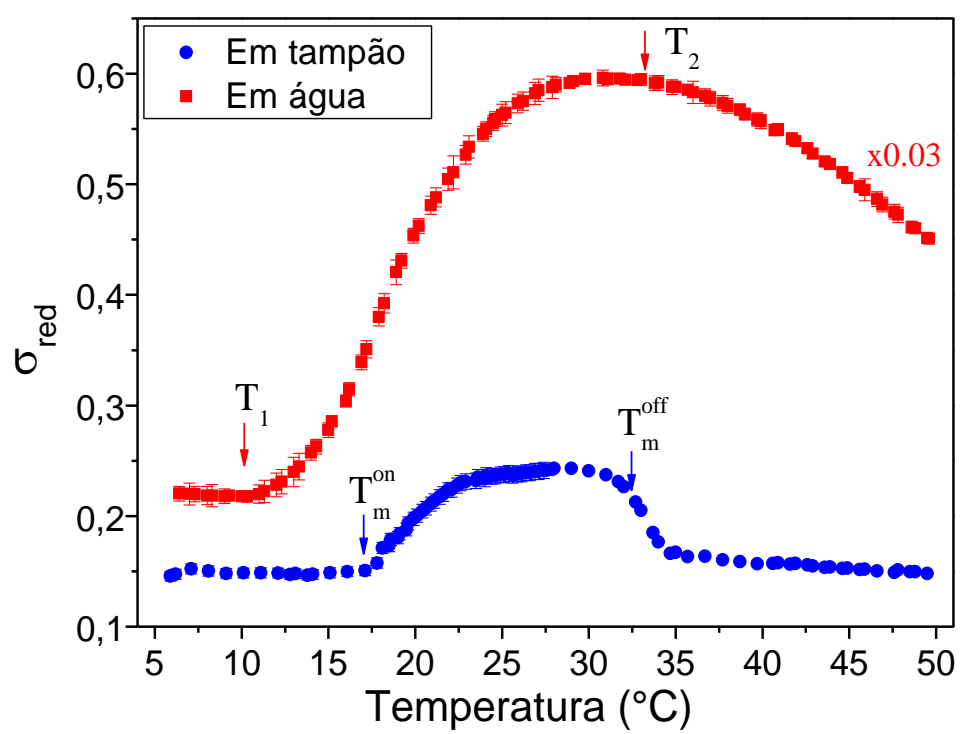

Figura 5.3.3: Comparação dos resultados de condutividade reduzida para dispersões extrusadas de $10 \mathrm{mM}$ de DMPG em água (curva vermelha) e em tampão (curva azul), sendo indicadas as temperaturas de início e final da transição de fase vista por DSC. 0 resultado em água foi multiplicado por 0,03 de modo a facilitar a comparação com o resultado em tampão.

Comparando os valores de condutividade reduzida para o sistema em água e em tampão, vemos que os valores em água são muito maiores do que em tampão, visto que os resultados tiveram que ser multiplicados por 0,03 para possibilitar a comparação entre os dois resultados. Enquanto a $30^{\circ} \mathrm{C}$ há um aumento de $\sim 24 \%$ na condutividade do tampão devido à presença de DMPG, na dispersão em água esse aumento chega a 1800\%! Enquanto a condutividade das dispersões de DMPG em tampão são muito parecidas com a do solvente nas fases gel e fluída, o mesmo não é observado para a condutividade da dispersão em água, onde apesar de $\sigma_{\text {red }}$ começar a diminuir em $T_{2}, 0$ valor da condutividade na fase fluída é muito maior do que na fase gel. 


\subsection{Mobilidade eletroforética}

Realizamos medidas da mobilidade eletroforética de dispersões de $10 \mathrm{mM}$ de DMPG em tampão baixa força iônica e comparamos com os resultados de dispersões não extrusadas (Barroso, 2010), conforme mostrado na figura 5.4.1.
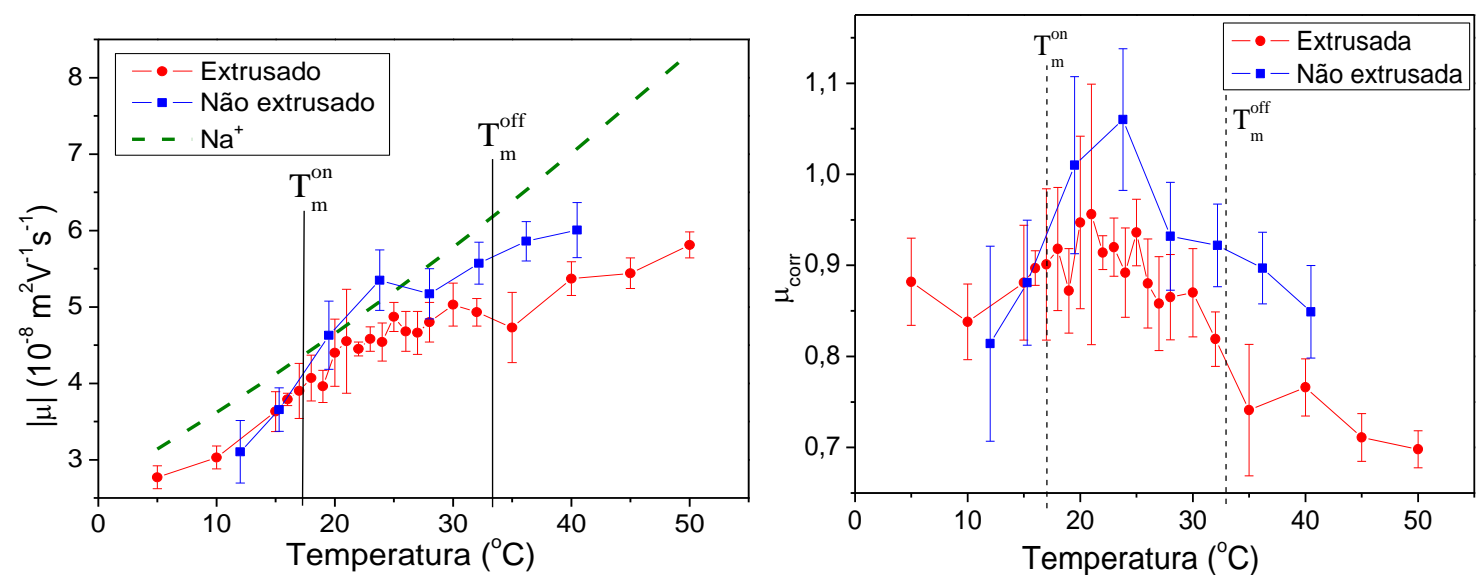

Figura 5.4.1: a) Comparação dos resultados de mobilidade eletroforética e b) mobilidade corrigida para dispersões de $10 \mathrm{mM}$ de DMPG extrusadas e não extrusadas (Barroso, 2010) em tampão HEPES.

Na figura 5.4.1 vemos que os dados de mobilidade eletroforética das dispersões de DMPG em tampão, antes e depois da extrusão apresentam um comportamento semelhante, sendo a mobilidade de dispersões não extrusada ligeiramente maior que das dispersões extrusadas. Apesar das grandes incertezas dos dados medidos, é possível observar o aumento da mobilidade eletroforética na região de transição de fase, principalmente comparando a mobilidade corrigida (equação 4.4.1), mostrando que a mobilidade da dispersão apresenta um aumento anômalo a partir de $10^{\circ} \mathrm{C}$ para a dispersão extrusada e não ficando claro o seu início na dispersão não extrusada, uma vez que estes dados foram medidos a partir de $12^{\circ} \mathrm{C}$.

$\mathrm{Na}$ figura 5.4.2 apresentamos a comparação das mobilidades corrigidas das dispersões extrusadas de 10 mM de DMPG em água e em tampão. 


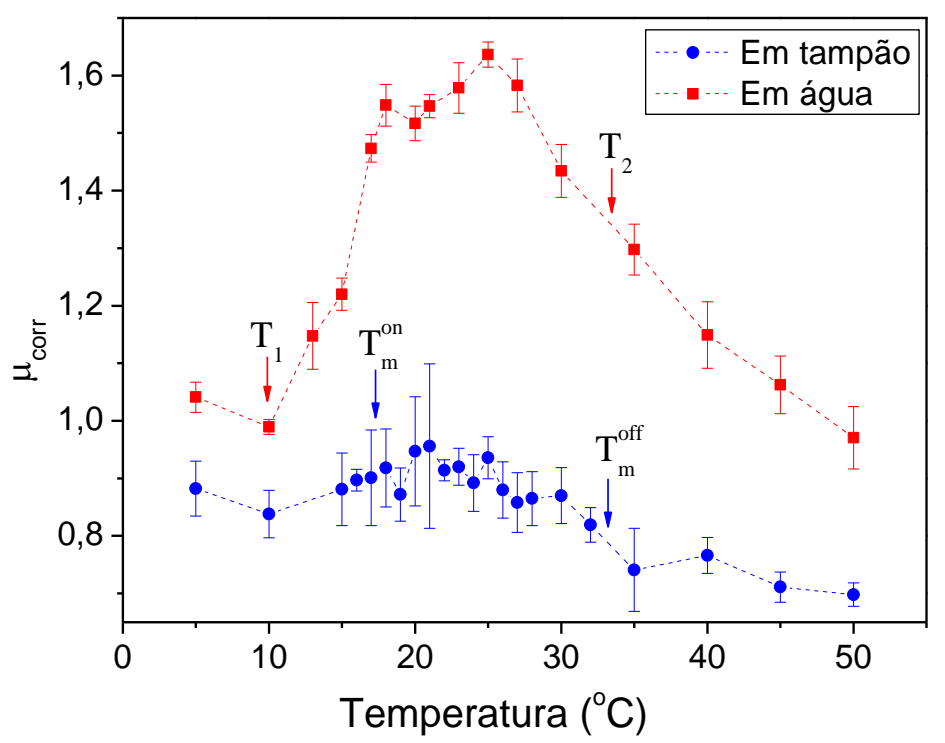

Figura 5.4.2: Comparação das mobilidades corrigidas das dispersões extrusadas de 10 mM de DMPG em água e em tampão HEPES baixa força iônica.

Relembrando da equação 2.6.6:

$$
\mu=\frac{q}{6 \pi \eta R}
$$

o maior valor da mobilidade eletroforética para as dispersões de DMPG em água do que em tampão, usando o modelo de Stokes para esferas rígidas e contínuas que se movem em um meio viscoso (equação 5.4.1), indicam que as vesículas de DMPG em água são mais carregadas e/ou menores que em tampão, uma vez que as viscosidades ( $\eta$ ) da água e do tampão são similares. Desta forma, caso os agregados em água sejam mais carregados, contribuiriam mais para a condutividade medida (equação 2.6.9), estando de acordo com o resultado mostrado na figura 5.3.3. Como na dispersão em água as cabeças polares do lipídio não estão blindadas por sais do solvente, o maior valor da mobilidade eletroforética era esperado, uma vez que a mobilidade é diretamente proporcional à carga da vesícula. 


\subsection{Turbidez}

Realizamos medidas de Absorbância a $350 \mathrm{~nm}$ em função da temperatura de dispersões extrusadas de 10 mM de DMPG em tampão a baixa força iônica.

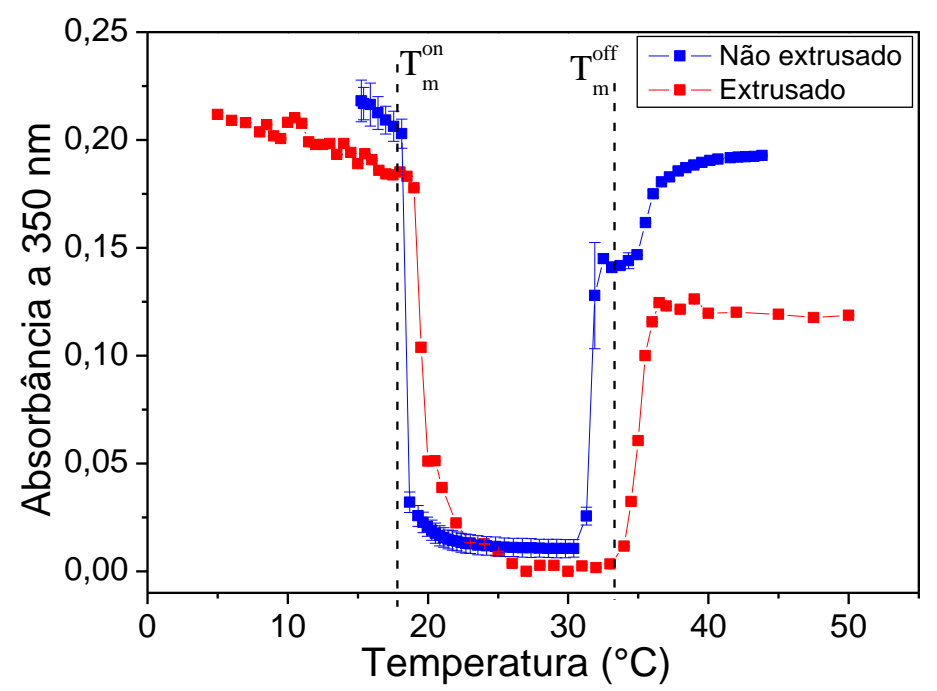

Figura 5.5.1: Medidas de absorbância a $350 \mathrm{~nm}$ em função da temperatura de dispersões de 10 mM de DMPG em tampão, antes (pontos azuis, dados de Barroso et al., 2010) e depois (pontos vermelhos) da extrusão. Cada curva é a média de 2 medidas de amostras distintas.

Na figura 5.5.1 vemos o comportamento que já foi observado anteriormente para dispersões de DMPG a baixa força iônica (Riske et al., 1997; Alakoskela \& Kinnunen, 2007; Alakoskela et al., 2010; Barroso, 2010), que é a baixa turbidez na região de transição de fase, sendo que o comportamento das dispersões antes e depois da extrusão é bastante parecido, apenas após $T_{m}{ }^{\text {off }}$ a dispersão não extrusada apresenta um patamar entre 33 e $35^{\circ} \mathrm{C}$, voltando a aumentar depois, o que não é observado para a dispersão extrusada, sendo que na fase fluída a turbidez da dispersão extrusada é ligeiramente menor do que na dispersão não extrusada.

Vemos que a absorbância na fase fluida é sempre menor que na fase gel, conforme era esperado dada a diferença no índice de refração das fases gel e fluído, devido a diminuição na espessura e na densidade da bicamada lipídica após a transição de fase (Yi and MacDonald, 1973; Disalvo, 1991). 
A seguir (figura 5.5.2) apresentamos a comparação das absorbâncias medidas para dispersão extrusadas de $10 \mathrm{mM}$ de DMPG em água e em tampão a baixa força iônica.

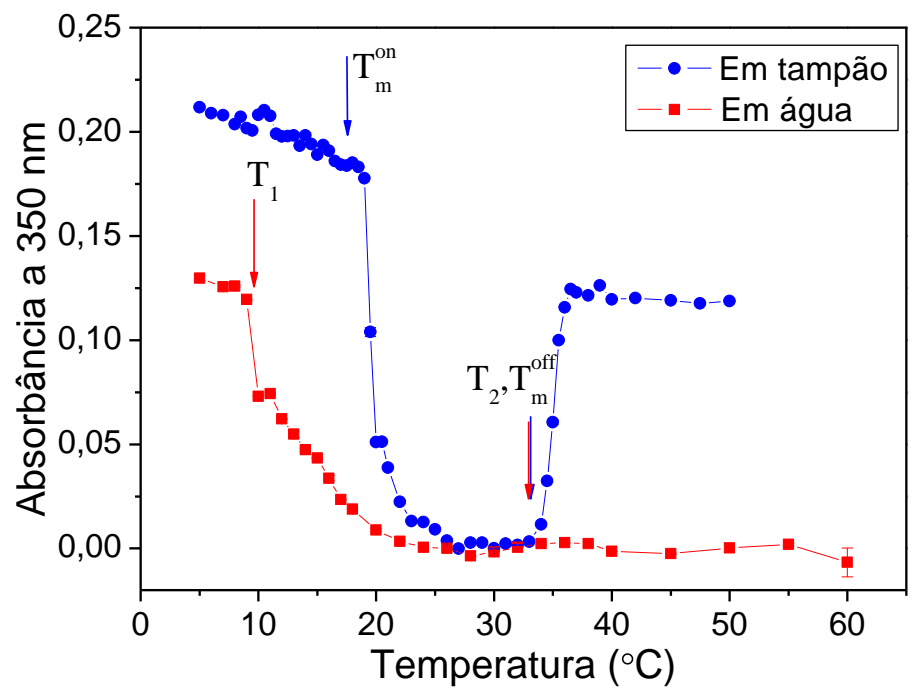

Figura 5.5.2: Comparação das medidas de absorbância à $350 \mathrm{~nm}$ para dispersões extrusadas de $10 \mathrm{mM}$ de DMPG em tampão (curva azul) e em água (curva vermelha).

Na figura 5.5.2 vemos que tanto nas dispersões em água, quanto em tampão, a absorbância tem uma brusca queda após $\mathrm{T}_{1}$ e $\mathrm{T}_{\mathrm{m}}{ }^{\text {on }}$, respectivamente, indo para valores próximos a zero, sendo visivelmente transparentes. Entretanto, na dispersão em tampão, a absorbância volta a aumentar em temperatura próxima a $T_{m}{ }^{\text {off }}$, apresentando valores próximos de turbidez na fase gel e na fase fluida, enquanto a dispersão em água permanece transparente para temperaturas até $60^{\circ} \mathrm{C}$. É interessante notar que, na fase gel, os valores da absorbância para as dispersões em água (figura 4.5.1) e tampão (figura 5.5.1a) das amostras não extrusadas são muito semelhantes, o que é uma forte indicação de que, nessas temperaturas, os dois sistemas tenham agregados similares. Entretanto, dada a facilidade em se realizar a extrusão de dispersões em água e o fato dos resultados de amostras não extrusadas e extrusadas apresentados no capítulo 4 serem semelhantes, pode ser que em água forme-se uma maior parte de agregados pequenos e poucos agregados maiores, que são eliminados pelo processo de extrusão, mas como a turbidez é muito mais sensível a presença de partículas grandes, mesmo sendo uma minoria, o espalhamento das partículas maiores prevalece sobre o espalhamento das menores. A menor turbidez vista na fase gel de dispersões extrusadas em água é um indício da presença de agregados menores em água do que em tampão. 


\subsection{Espalhamento de Luz}

Apesar de dispersões extrusadas de DMPG a baixa força iônica terem sido bem caracterizadas em Enoki, 2010 e Enoki et al., 2012, realizamos algumas novas medidas e discussões que julgamos relevantes no estudo deste sistema.

\subsubsection{Espalhamento de Luz Dinâmico (DLS)}

Durante visita ao Institute of Inorganic Chemistry da Graz University of Technology, Graz, Áustria, realizamos medidas de DLS de dispersões extrusadas de 1 mM de DMPG em tampão a baixa força iônica (HEPES $10 \mathrm{mM}+\mathrm{NaCl} 2 \mathrm{mM}$ ) e em tampão a alta força iônica (HEPES $10 \mathrm{mM}+\mathrm{NaCl} 250 \mathrm{mM}$ ) nas temperaturas de 5, 15, 20, 30 e $45^{\circ} \mathrm{C}$. Estas medidas foram realizadas em colaboração com o Prof. Dr. Otto Glatter e a Drạ Angela Chemelli.
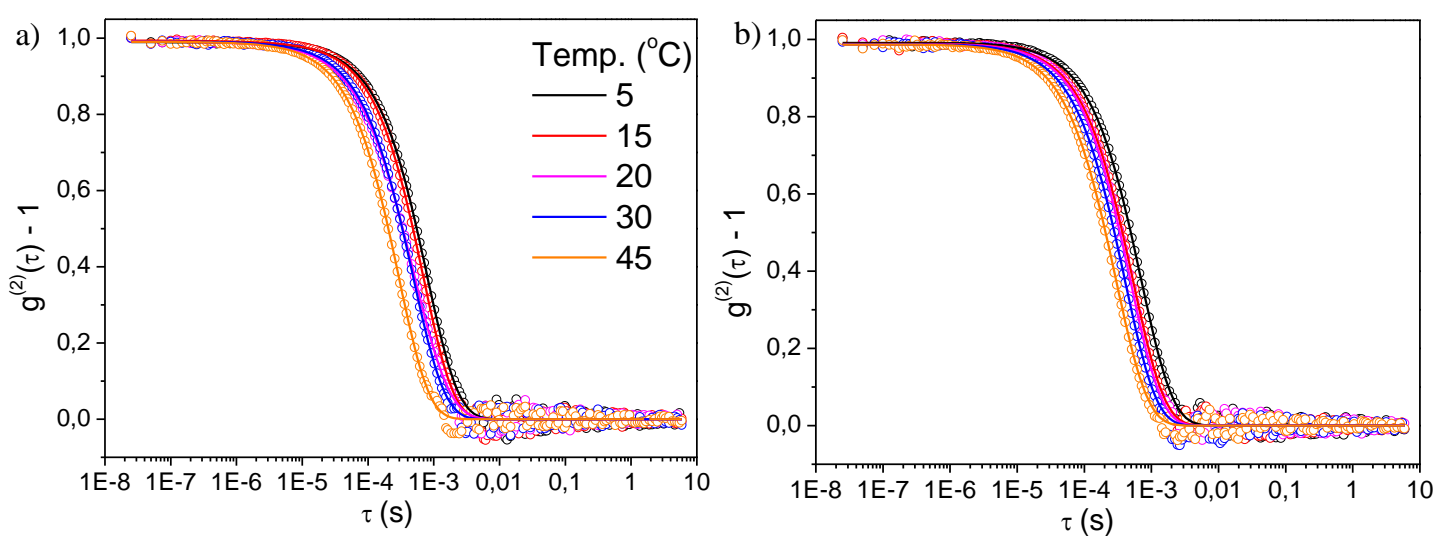

Figura 5.6.1: Funções normalizadas da autocorrelação da luz espalhada para dispersões extrusadas de $1 \mathrm{mM}$ de DMPG em diferentes temperaturas e diferentes solventes: a) em tampão a baixa força iônica e b) em tampão a alta força iônica. As linhas sólidas representam os ajustes obtidos via software Ortlight e os círculos representam as medidas experimentais.

A partir de $g^{(2)}(\tau)$, calcula-se $g^{(1)}(\tau)$ através da relação de Siegert (equação 2.3 .3 ) e, com o uso do software ORTLight obteve-se a distribuição de tamanhos dos agregados a partir do cálculo da transformada inversa de Laplace (análises realizadas pela Dra Angela Chemelli). 

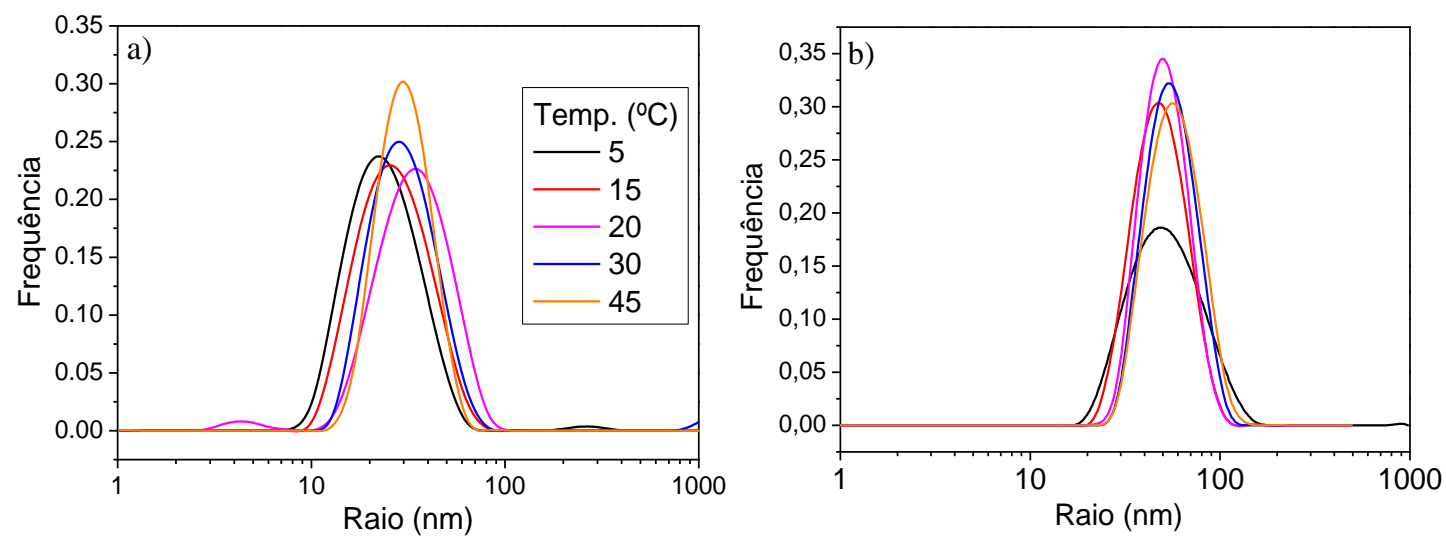

Figura 5.6.2: Distribuição de tamanhos dos agregados de DMPG obtidos pela transformada inversa de Laplace para dispersões extrusadas de $1 \mathrm{mM}$ de DMPG em diferentes temperaturas $\left(5,15,20,30\right.$ e $\left.45^{\circ} \mathrm{C}\right)$ e em diferentes meios: em a) em tampão HEPES a baixa força iônica e em b) em tampão HEPES a alta força iônica.

Ajustando-se os picos da figura 5.6.2 por gaussianas, utilizando o software Origin, representamos a posição central dos picos com suas incertezas na tabela 5.1, juntamente com os valores obtidos para a dispersão em água, que foram apresentados na tabela 4.1.

Tabela 5.1: Raios efetivos dos agregados de DMPG em dispersões extrusadas com $1 \mathrm{mM}$ de lipídio em diferentes meios: tampão HEPES a alta e baixa força iônica e em água pura em diferentes temperaturas: $5,15,20,30$ e $45^{\circ} \mathrm{C}$, medidos em Graz. A incerteza é dada pelo desvio de duas medidas da mesma amostra.

\begin{tabular}{cccc}
\hline $\begin{array}{c}\text { Temp. } \\
\left({ }^{\circ} \mathbf{C}\right)\end{array}$ & $\begin{array}{c}\text { Alta força iônica } \\
\mathbf{R}_{\text {eff }}(\mathbf{n m})\end{array}$ & $\begin{array}{c}\text { Baixa força iônica } \\
\mathbf{R}_{\text {eff }}(\mathbf{n m})\end{array}$ & $\begin{array}{c}\text { Água } \\
\mathbf{R}_{\text {eff }}(\mathbf{n m})\end{array}$ \\
\hline 5 & $49,1 \pm 1,8$ & $21,8 \pm 1,4$ & $20,9 \pm 1,5$ \\
15 & $49,3 \pm 1,8$ & $25,2 \pm 1,6$ & $21,6 \pm 1,6$ \\
20 & $51,4 \pm 1,9$ & $28,6 \pm 1,7$ & $28,5 \pm 3,0$ \\
30 & $55,3 \pm 2,0$ & $34,5 \pm 2,1$ & $35,9 \pm 3,5$ \\
45 & $56,8 \pm 2,8$ & $29,8 \pm 2,6$ & $37,5 \pm 5,0$ \\
\hline
\end{tabular}

Para uma melhor visualização dos resultados mostrados na tabela 5.1, graficamos os valores de raio efetivo em função da temperatura nos diferentes meios (figura 5.6.3). 


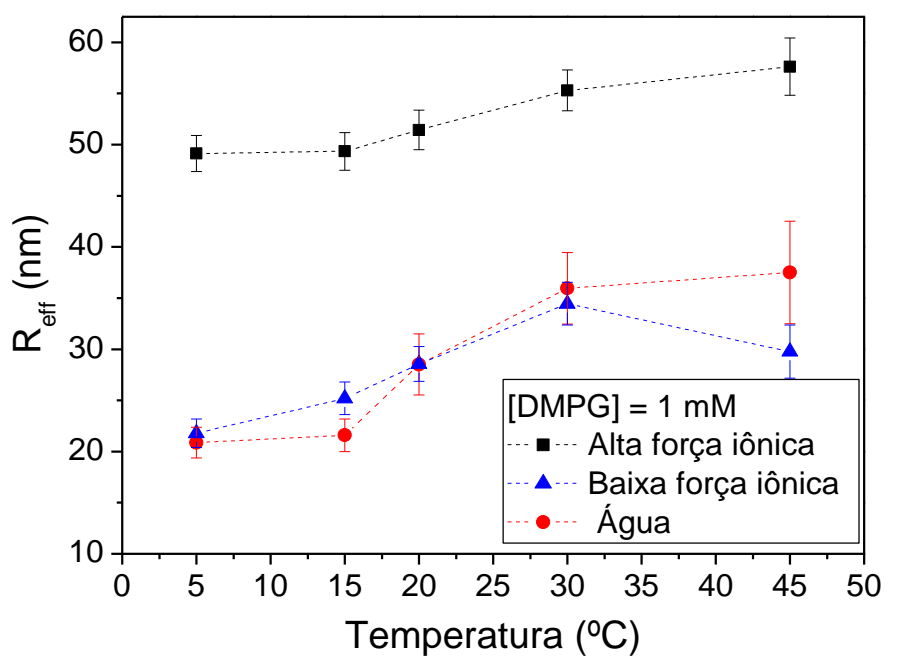

Figura 5.6.3: Raio efetivo ( $R_{\text {eff }}$ ) em função da temperatura de agregados de DMPG em meios de diferente força iônica, conforme valores da tabela 5.1.

Os resultados mostrados na tabela 5.1 e na figura 5.6.3 mostram que a força iônica do meio influencia bastante no tamanho dos agregados de DMPG visto por DLS. Para as dispersões de DMPG em tampão a alta força iônica (HEPES $10 \mathrm{mM}+\mathrm{NaCl} 250$ $\mathrm{mM}$ ) há um pequeno aumento no tamanho dos agregados após a transição da fase gel para a fase fluída, conforme é esperado uma vez que na fase fluida as cadeias hidrocarbônicas se encontram mais desordenadas e a área ocupada por cabeça polar é maior do que na fase gel, sendo que o diâmetro dos agregados é sempre próximo a 100 $\mathrm{nm}$, estando de acordo com a extrusão que foi realizada com filtros de poros de $100 \mathrm{~nm}$. Também é interessante observar que estes resultados para alta força iônica, são muito parecidos com os resultados de DLS obtidos em Enoki et al., 2012 para o lipídio zwiterionico DMPC em tampão a baixa força iônica, após a extrusão, que foi de $R_{\text {eff }}=(53$ $\pm 4) \mathrm{nm}$ em $20^{\circ} \mathrm{C}$ (fase gel) e $R_{\text {eff }}=(60 \pm 5) \mathrm{nm}$ a $45^{\circ} \mathrm{C}$ (fase fluída), mostrando que em meio de alta força iônica as vesículas de DMPG são praticamente neutras.

Para as dispersões de DMPG em tampão a baixa força iônica (HEPES 10 mM + $\mathrm{NaCl} 2 \mathrm{mM}$ ), observamos o aumento do raio efetivo na transição de fase e uma pequena diminuição na fase fluída. Estes resultados obtidos no equipamento do Prof. Otto Glatter e analisados via a transformada inversa de Laplace do programa ORTLight são bastante semelhantes aos resultados obtidos para este mesmo sistema no aparelho de espalhamento de luz da Brookhaven e analisados pelo método dos cumulantes que foram: $R_{\text {eff }}=(24 \pm 1) \mathrm{nm}$ a $16^{\circ} \mathrm{C} ;(29 \pm 1) \mathrm{nm}$ a $20^{\circ} \mathrm{C} ;(32 \pm 1) \mathrm{nm}$ a $30^{\circ} \mathrm{C}$ e $(28 \pm 3) \mathrm{nm}$ a 
$45^{\circ} \mathrm{C}$ (Enoki et al., 2012), indicando que as medidas e análises realizadas em Graz são confiáveis.

Conforme discutido na seção 4.6.1 desta tese, para a dispersão de DMPG em água pura, vemos um aumento no tamanho dos agregados com o aumento da temperatura, da mesma forma que foi observado o aumento da viscosidade, da condutividade elétrica, da mobilidade eletroforética e a baixa turbidez até temperaturas altas.

As medidas da figura 5.6.3 foram repetidas com as mesmas amostras após 1 semana e os resultados (não mostrados aqui) foram reprodutíveis.

Realizamos medidas de DLS no aparelho da Malvern de dispersões de $1 \mathrm{mM}$ de DMPG em tampão após a extrusão por filtro com poros de $100 \mathrm{~nm}$ e de $30 \mathrm{~nm}$ e o resultado é mostrado na figura 5.6.4.

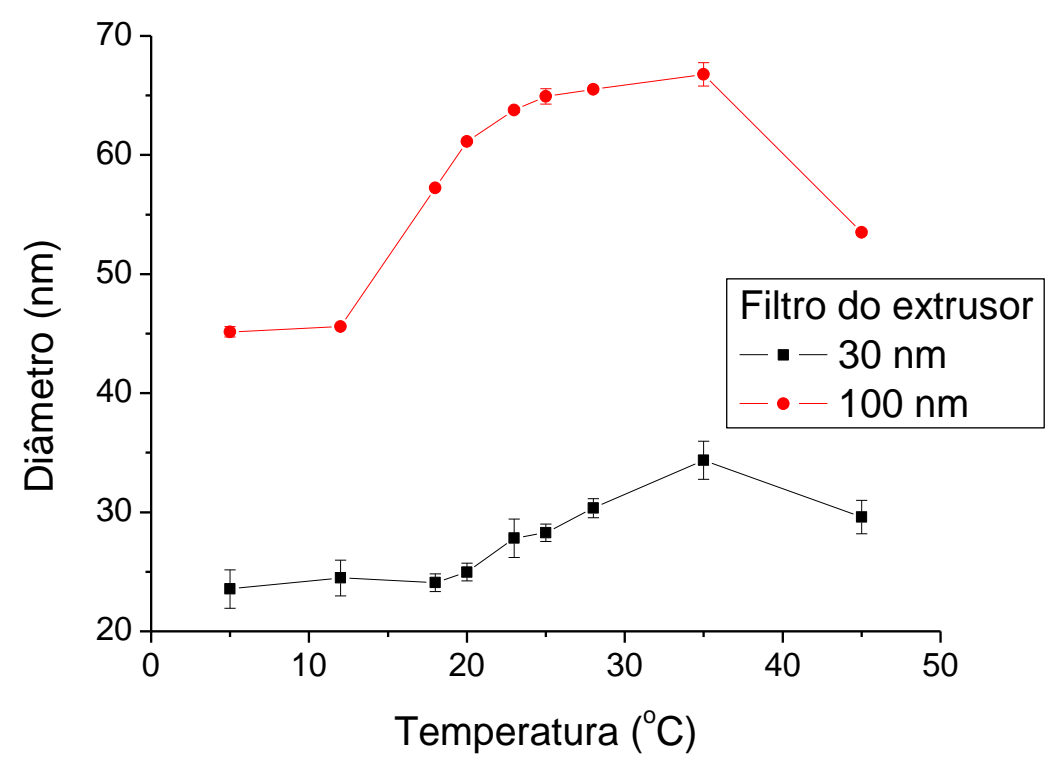

Figura 5.6.4: Medidas de DLS de dispersões de $1 \mathrm{mM}$ de DMPG em tampão extrusadas por filtros de 30 e $100 \mathrm{~nm}$.

Como mostrado na tabela 5.1, mesmo extrusando as dispersões de DMPG em tampão por filtros de 100 nm, os diâmetros medidos por DLS indicam vesículas de tamanhos menores que $100 \mathrm{~nm}$, chegando a um máximo de $69 \mathrm{~nm}$ durante a transição de fase. Novamente, este comportamento foi observado para uma dispersão distinta de 
1 mM de DMPG, media no aparelho da Malvern (figura 5.6.4), sendo os resultados muito semelhantes aos da tabela 5.1. Após a extrusão por filtro com poros de $30 \mathrm{~nm}$, os resultados (figura 5.6.4) mostram vesículas da ordem de $30 \mathrm{~nm}$ com perfil térmico semelhante ao observado para a dispersão extrusada por $100 \mathrm{~nm}$. Este resultado nos mostra que as dispersões de DMPG em tampão formam vesículas pequenas, da ordem de $50 \mathrm{~nm}$, sendo que a extrusão por filtros de $100 \mathrm{~nm}$ apenas exclui algumas poucas vesículas maiores, lembrando que o diâmetro médio obtido por DLS vem de um zaverage que dá um peso muito maior para as partículas maiores (equação 2.3.8).

\subsubsection{Espalhamento de Luz Estático (SLS)}

Apesar de não termos realizado medidas de SLS para dispersões de DMPG em tampão a baixa força iônica, revisitamos os dados de SLS de Enoki, 2010, que foram medidos no aparelho da Brookhaven, para dispersões de DMPG e DMPC em tampão a baixa força iônica. Desta forma, montamos os gráficos de $\Delta R_{\theta} / K c \times q^{2}$ para diferentes concentrações lipídicas e temperaturas.

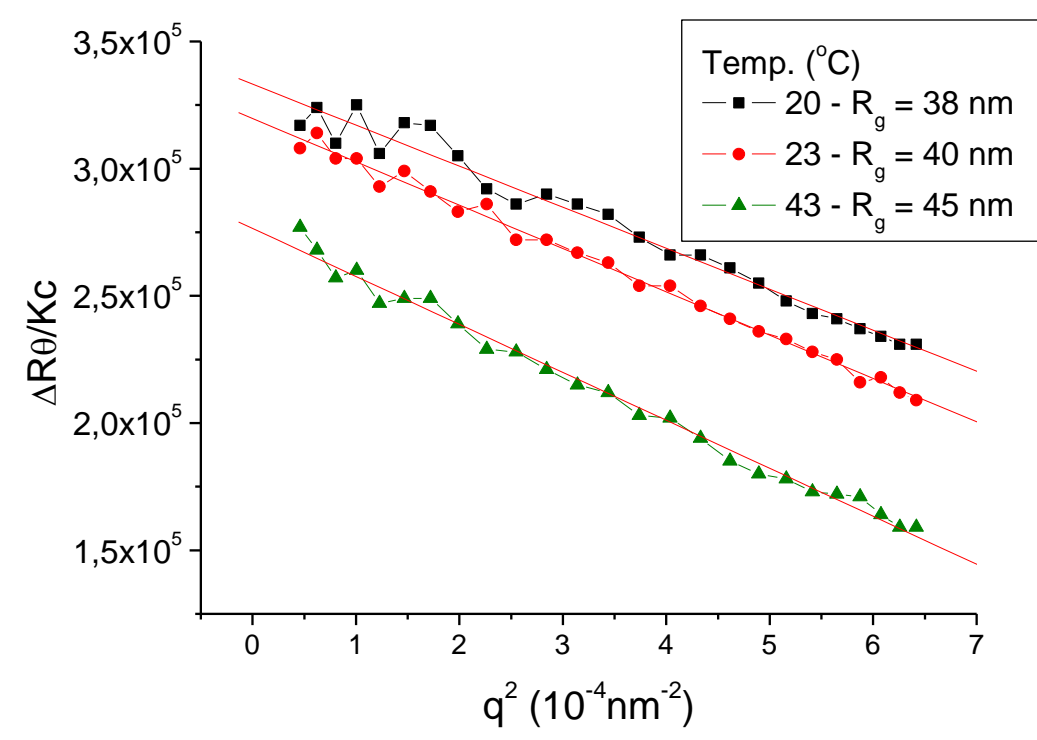

Figura 5.6.5: Curvas de espalhamento de luz estático de dispersão de DMPC em tampão, com concentração de $1,5 \mathrm{mM}$, nas temperaturas 20,23 e $43^{\circ} \mathrm{C}$.

Fizemos os ajustes das medidas de SLS para amostras de DMPC de diferentes concentrações lipídicas: 0,34; 0,68; 1,02; 1,36 e 1,70 mg/mL nas temperaturas $20^{\circ} \mathrm{C}$ (fase gel), $23^{\circ} \mathrm{C}$ (transição de fase) e $45^{\circ} \mathrm{C}$ (fase fluida). Em todos os casos, obtivemos bons 
ajustes por retas, conforme exemplificado na figura 5.6.5, estando de acordo com a equação 2.3.13, que foi utilizada para o cálculo do raio de giro $\left(R_{\mathrm{g}}\right)$. Portanto, essas amostras estão de acordo com as aproximações assumidas para a análise de SLS.

Já para as dispersões de DMPG, observamos que as curvas de espalhamento nas temperaturas da região de transição de fase $\left(20\right.$ e $\left.28^{\circ} \mathrm{C}\right)$ não são bem ajustadas por retas, estando mais próximas de polinômios de $2^{\circ}$ grau (figura 5.6.7) e, portanto, não estando de acordo com a equação 2.3.13.

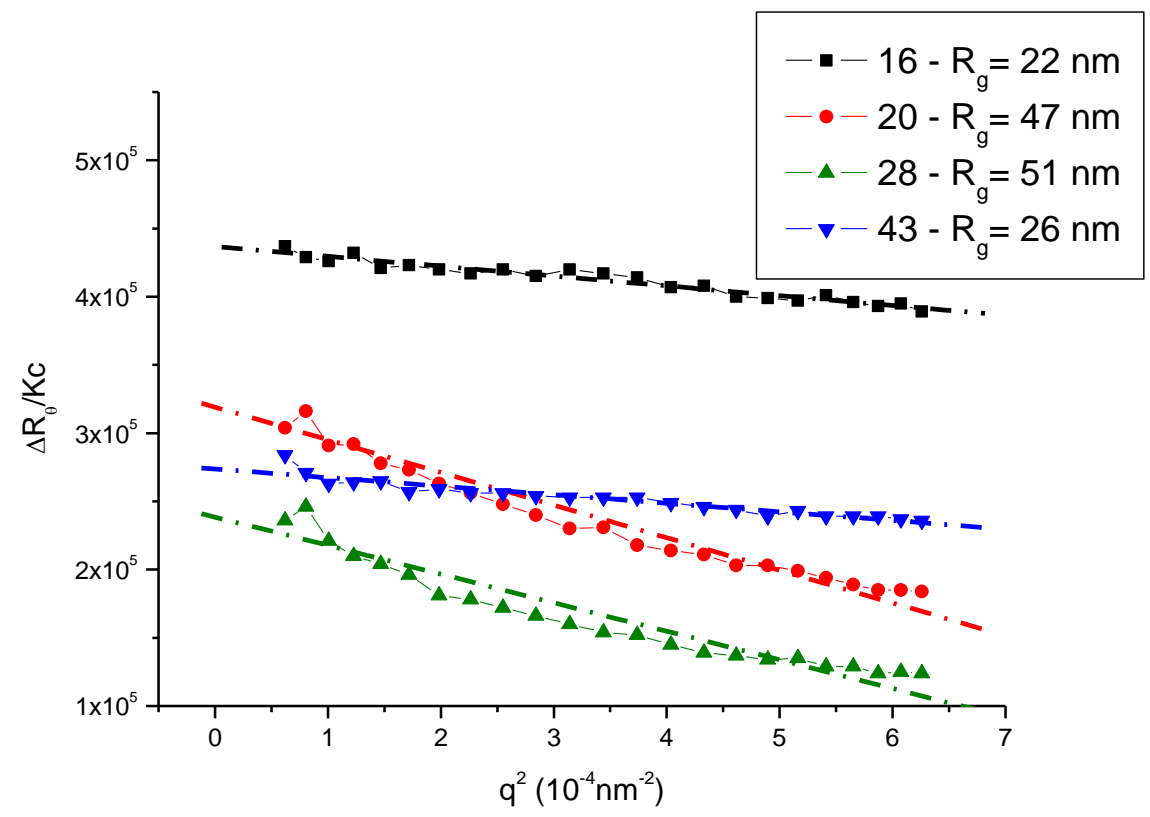

Figura 5.6.6: Curvas de espalhamento de luz estático de dispersão de $1 \mathrm{mM}$ de DMPG em tampão, nas temperaturas $16,20,28$ e $43^{\circ} \mathrm{C}$.

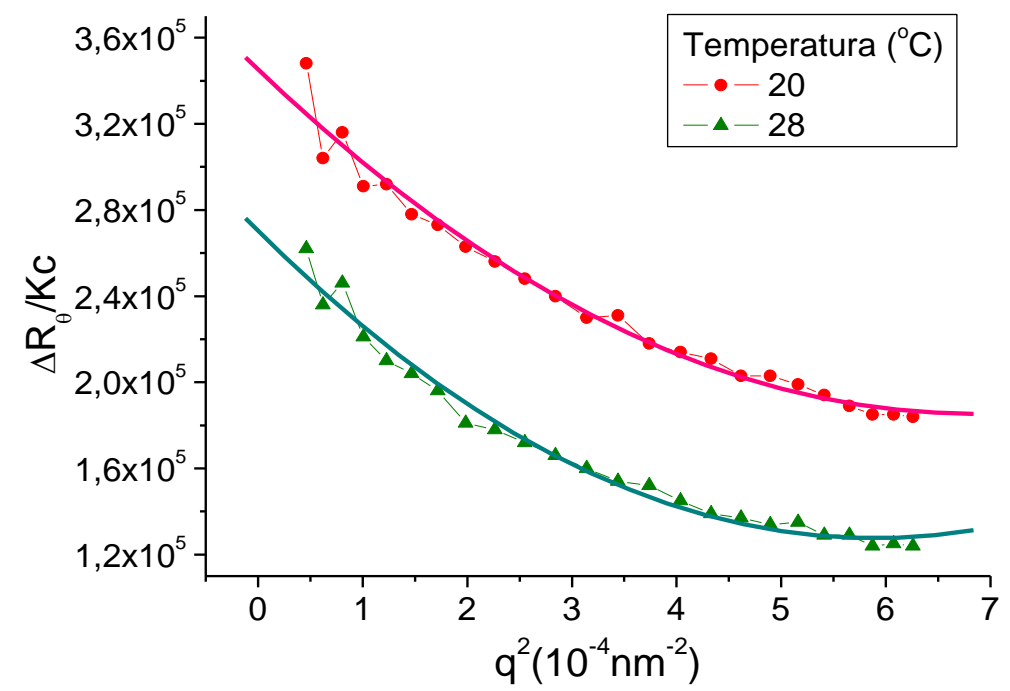

Figura 5.6.7: Destaque das medidas da figura 5.6.6 nas temperaturas de transição de fase: 20 e $28^{\circ} \mathrm{C}$ ajustadas por equações de $2^{\circ}$ grau. 
Esse mesmo comportamento foi observado para outras concentrações lipídicas de DMPG em tampão, 0,34; 0,69; 1,03; 1,38 e 1,72 mg/mL. Enquanto nas fases gel e fluida o comportamento linear é observado, o mesmo não ocorre para as temperaturas na região de transição de fase $\left(20\right.$ e $\left.28^{\circ} \mathrm{C}\right)$, mostrando que este método não é adequado para o cálculo de tamanho dos centros espalhadores nestas temperaturas. Como mostrado na figura 5.4.2, os valores da mobilidade eletroforética são maiores na região de transição de fase, o que pode aumentar as interações entre as partículas, fazendo com que não estejam de acordo com a teoria de Zimm. Um novo modelo que leve as interações em conta no fator de estrutura seria necessário para a obtenção dos tamanhos por SLS nas temperaturas dentro da região de transição de fase, sendo este um fato importante e que pode justificar a grande diferença entre os resultados de raio efetivo obtidos para o DMPG por DLS e SLS, sendo que a $28^{\circ} \mathrm{C}$ o Ref calculado por SLS foi quase 3 vezes maior que o obtido por DLS (Enoki et al., 2012).

\subsubsection{Medidas da razão de despolarização da luz espalhada (I $\left.\mathrm{IH}_{\mathrm{V}} / \mathrm{Ivv}_{\mathrm{vv}}\right)$}

Utilizando o aparato de espalhamento de luz de Graz, medimos a razão de despolarização da luz espalhada das dispersões extrusadas de $1 \mathrm{mM}$ de DMPG em tampão a alta e baixa força iônica, sendo estas comparadas com as medidas em água, mostradas na figura 4.6.9. 


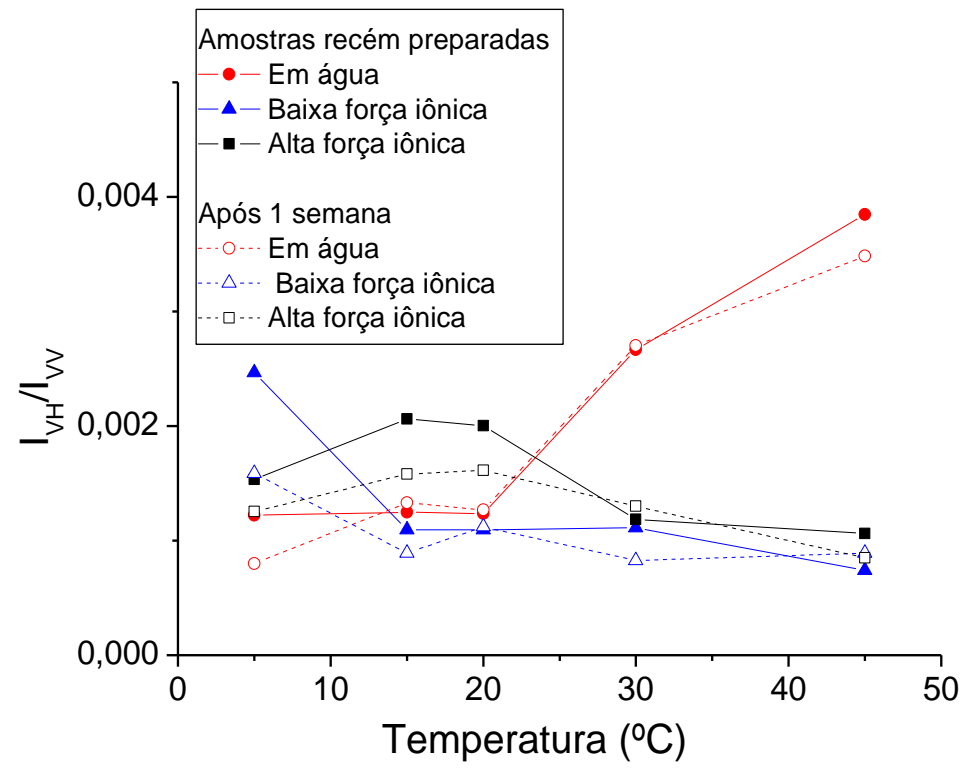

Figura 5.6.8: Razão de despolarização da luz espalhada ( $\mathrm{IVH}_{\mathrm{VH}} / \mathrm{IVv}_{\mathrm{Vv}}$ ) para vesículas de DMPG em água pura, em tampão a baixa força iônica e em tampão a alta força iônica em diferentes temperaturas $\left(5,15,20,30\right.$ e $\left.45^{\circ} \mathrm{C}\right)$. As medidas foram realizadas com as amostras recém preparadas (símbolos fechados) e após deixar as amostras durante 1 semana em temperatura ambiente (símbolos abertos).

A partir dos resultados da figura 5.6.8 vemos que a razão de despolarização da luz é baixa para as dispersões nos meios de diferentes força iônica e em todas as temperaturas medidas (de 5 a $45^{\circ} \mathrm{C}$ ), sendo os valores de $I_{V H} / I_{V v}$ comparáveis com os valores medidos para vesículas de DMPC e nanoesferas de poliestireno $\left(\mathrm{I}_{\mathrm{VH}} / \mathrm{IVV}_{\mathrm{VV}} \approx 0,005\right)$ (ver figura 4.6.8), indicando a presença de agregados isotrópicos de DMPG, mesmo após deixar as amostras na bancada durante 1 semana. 


\subsection{Resumo dos resultados obtidos com dispersões de $10 \mathrm{mM}$ de DMPG em tampão e em água}

Para observarmos o comportamento das diferentes técnicas utilizadas com a variação da temperatura, fizemos a sobreposição dos resultados apresentados nos capítulos 4 e 5 desta tese para dispersões extrusadas de $10 \mathrm{mM}$ de DMPG em água e 10 mM de DMPG em tampão a baixa força iônica, normalizando os valores de modo que o maior valor de cada técnica coincidisse com 1.

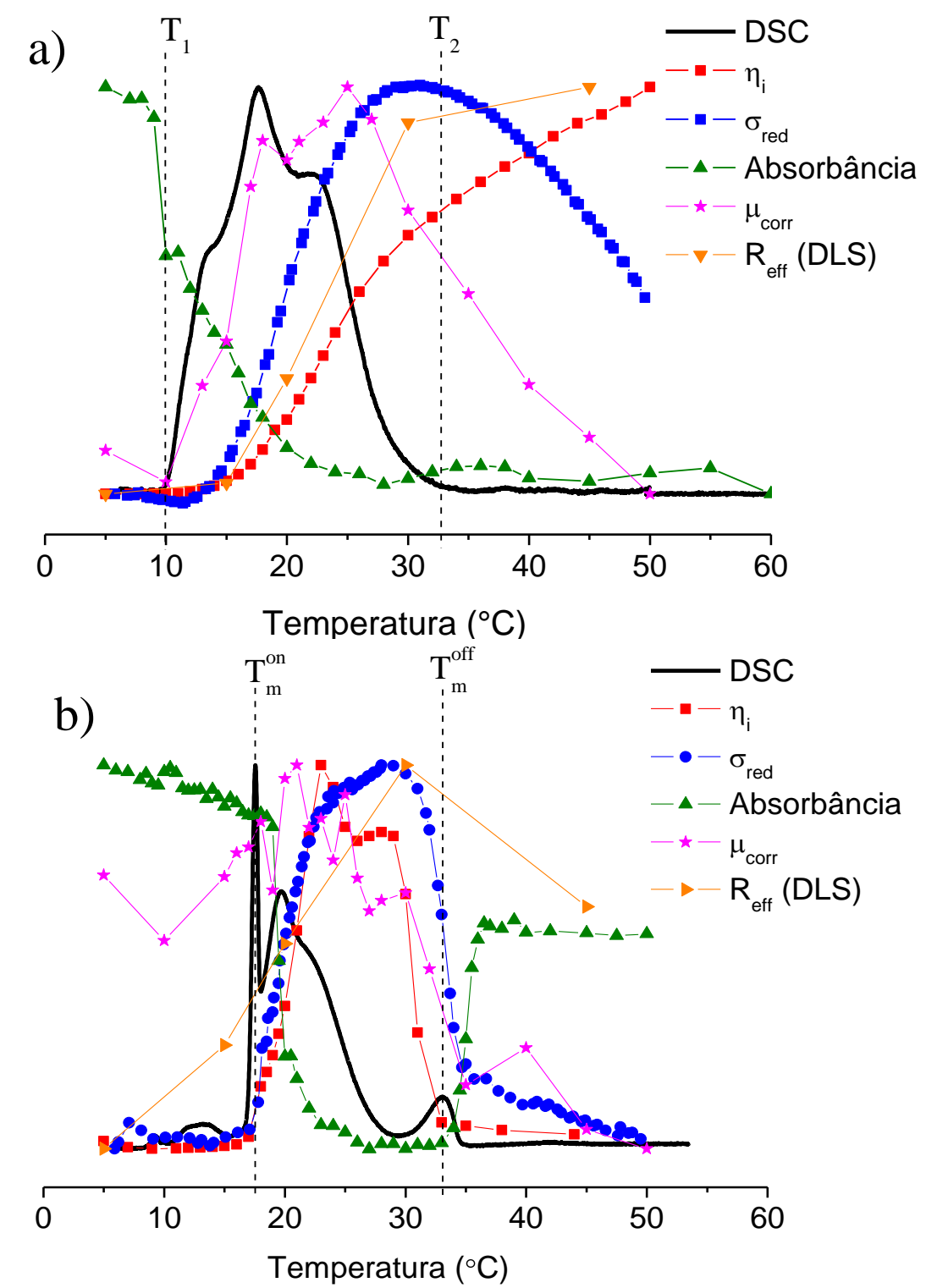

Figura 5.7.1: Sobreposição dos resultados de DSC, incremento da viscosidade relativa $\left(\eta_{i}\right)$, condutividade reduzida $\left(\sigma_{\text {red }}\right)$, absorbância a $350 \mathrm{~nm}$, mobilidade elefrorética ( $\mu_{\text {corr }}$ ) e raio efetivo ( $R_{\text {eff) }}$ calculado por DLS de dispersões extrusadas de $10 \mathrm{mM}$ (1 mM para a

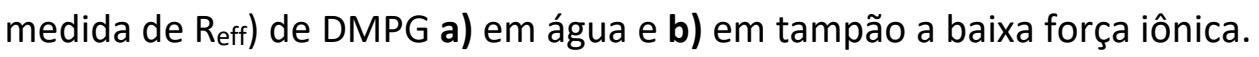


Podemos dizer que a força iônica tem um papel fundamental na estrutura dos agregados de DMPG em dispersões aquosas, uma vez que grandes diferenças são observadas para DMPG em HEPES em alta força iônica, para o DMPG em baixa força iônica (6 mM), e para o DMPG em muito baixa força iônica, em água pura.

Para dispersões extrusadas de $10 \mathrm{mM}$ de DMPG em água vemos, por DSC, uma larga região de transição de fase, que vai de 10 a $33^{\circ} \mathrm{C}$ aproximadamente. A turbidez da amostra já começa a diminuir a partir de $\mathrm{T}_{1}$ e continua diminuindo gradualmente até $\sim 25^{\circ} \mathrm{C}$, permanecendo próxima a zero até altas temperaturas. A mobilidade eletroforética aumenta a partir de $\mathrm{T}_{1}$ e permanece alta na fase fluída. Os valores de incremento da viscosidade relativa, condutividade reduzida e raio efetivo começam a aumentar em $\sim 15^{\circ} \mathrm{C}$, sendo que a viscosidade e o raio continuam aumentando com a temperatura enquanto a condutividade começa a decrescer de maneira sutil a partir de $T_{2}$.

No caso das dispersões extrusadas de 10 mM de DMPG em tampão a baixa força iônica, vemos comportamento semelhante ao observado para dispersões não extrusadas, sendo que os valores de incremento da viscosidade relativa e da condutividade reduzida aumentam a partir de $T_{m}{ }^{\text {on }}$, sendo que em $T_{m}{ }^{\text {off }}$ a viscosidade já decresceu para valores próximos ao do tampão, enquanto a condutividade continua decrescendo após $\mathrm{T}_{\mathrm{m}}{ }^{\text {ff }}$, mas de maneira mais suave. $\mathrm{O}$ raio efetivo das vesículas aumenta com a temperatura até $30^{\circ} \mathrm{C}$, diminuindo de tamanho na fase fluida. A turbidez decai de forma brusca ligeiramente após $\mathrm{T}_{\mathrm{m}}{ }^{\text {on }}$, permanecendo nula durante toda a transição de fase vista por DSC e sofre um aumento abrupto ligeiramente após $T_{m}{ }^{\text {off }}$.

Comparando os resultados das figuras 5.7.1 a) e b) notamos que o grande diferencial com a menor força iônica do meio é o fato das características anômalas que são observadas apenas na região de transição de fase para o sistema de DMPG em tampão a baixa força iônica permanecem nas medidas de DMPG em água até altas temperaturas, tais como: alta condutividade e viscosidade, maior raio efetivo e baixa turbidez, sendo que as mudanças parecem ocorrer de maneira menos abrupta do que as observadas em tampão baixa força iônica, ocorrendo de forma gradual com a mudança de temperatura. Medidas da razão de despolarização da luz espalhada indicaram a presença de agregados isotrópicos de DMPG para as temperaturas entre 5 e $45^{\circ} \mathrm{C}$ em água e em tampão. Também mostrou-se nos dois meios mesmo após extrusar 
as dispersões por filtros tão pequenos quanto $30 \mathrm{~nm}$ ainda é possível observar a transição de fase por medidas de DSC. Para ambos os sistemas, medidas de DSC, viscosidade, condutividade elétrica e mobilidade eletroforética realizadas aumentando e diminuindo a temperatura foram reprodutíveis, não sendo observados efeitos de histerese, mostrando a reversibilidade dos fenômenos observados. 


\subsection{Resultados de dispersões extrusadas de 50 mM de DMPG em tampão HEPES}

Visto que nas medidas de SAXS, que serão apresentadas no capítulo 7 desta tese, o pico de Bragg a baixo q, para as dispersões de DMPG em tampão a baixa força iônica, apareceu claramente apenas na dispersão de $50 \mathrm{mM}$ de DMPG, estando presente em todas as temperaturas no caso da dispersão extrusada, realizamos medidas de DSC, viscosidade, condutividade elétrica e turbidez de dispersões de DMPG 50 mM extrusadas por filtro de $100 \mathrm{~nm}$.

\subsubsection{Calorimetria Diferencial de Varredura (DSC)}

Foi mostrado em Barroso, 2010 que para dispersões de 50 mM de DMPG em tampão a baixa força iônica, a taxa de aquecimento de $20^{\circ} \mathrm{C} / \mathrm{h}$ não era adequada para caracterizar a transição de fase da bicamada com detalhes. Portanto, realizamos medidas de DSC com amostras distintas de 50 mM de DMPG após a extrusão, com diferentes taxas de aquecimento: $20^{\circ} \mathrm{C} / \mathrm{h}$ e $10^{\circ} \mathrm{C} / \mathrm{h}$ e o resultado é apresentado na figura 5.8.1.

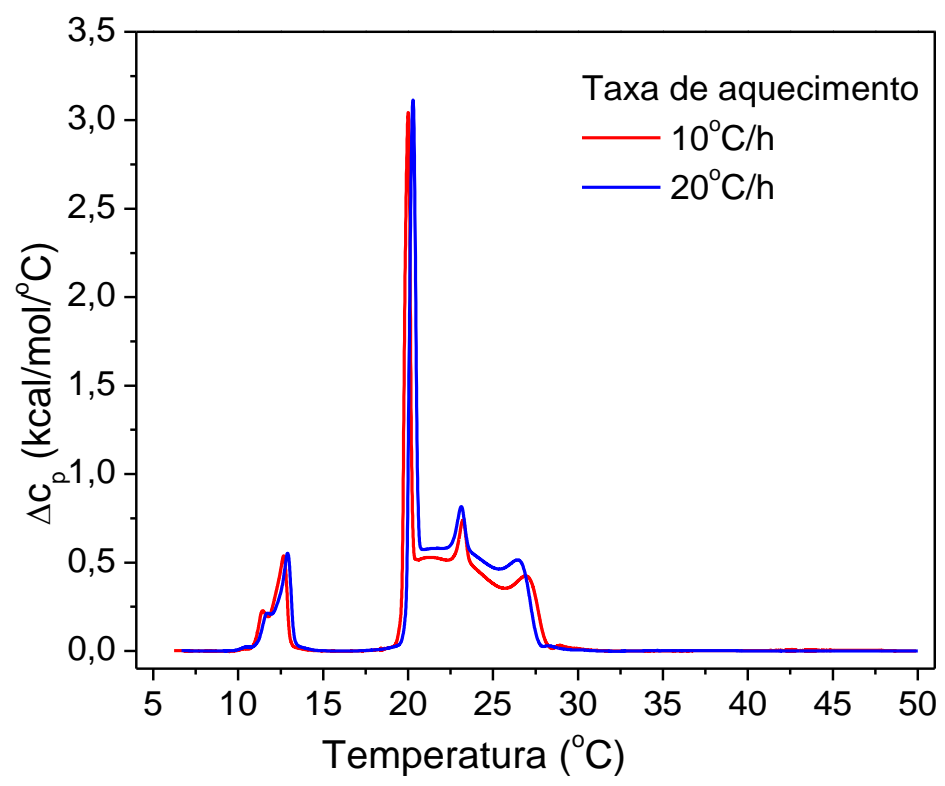

Figura 5.8.1: Curvas da variação de calor específico em função da temperatura para duas amostras distintas de DMPG com concentração lipídica de 50mM em tampão (HEPES $10 \mathrm{mM}+\mathrm{NaCl} 2 \mathrm{mM}$ ) após a extrusão. A curva vermelha foi medida aumentando-se a temperatura a uma taxa de $10^{\circ} \mathrm{C} / \mathrm{h}$ e a curva azul a $20^{\circ} \mathrm{C} / \mathrm{h}$. 
A partir da figura 5.8.1 vemos que para as dispersões extrusadas por filtros de $100 \mathrm{~nm}$, não há diferença significativa que justifique a realização da medida mais lentamente, a uma taxa de $10^{\circ} \mathrm{C} / \mathrm{h}$, sendo que a entalpia calculada pela área dos gráficos na transição principal foi de $4,8(5) \mathrm{kcal} / \mathrm{mol}$ para $10^{\circ} \mathrm{C} / \mathrm{h}$ e $5,1(5)$ para $20^{\circ} \mathrm{C} / \mathrm{h}$, valores compatíveis com o calculado para as dispersões extrusadas de 10 mM de DMPG em água $(5,0$ (3) kcal $/ \mathrm{mol})$ e em tampão $(5,0$ (5) kcal $/ \mathrm{mol})$.

Comparamos o resultado obtido com dispersões extrusadas de 50 mM de DMPG em tampão a baixa força iônica com o resultado de dispersões não extrusadas mostrado em Barroso, 2010 (figura 5.8.2).

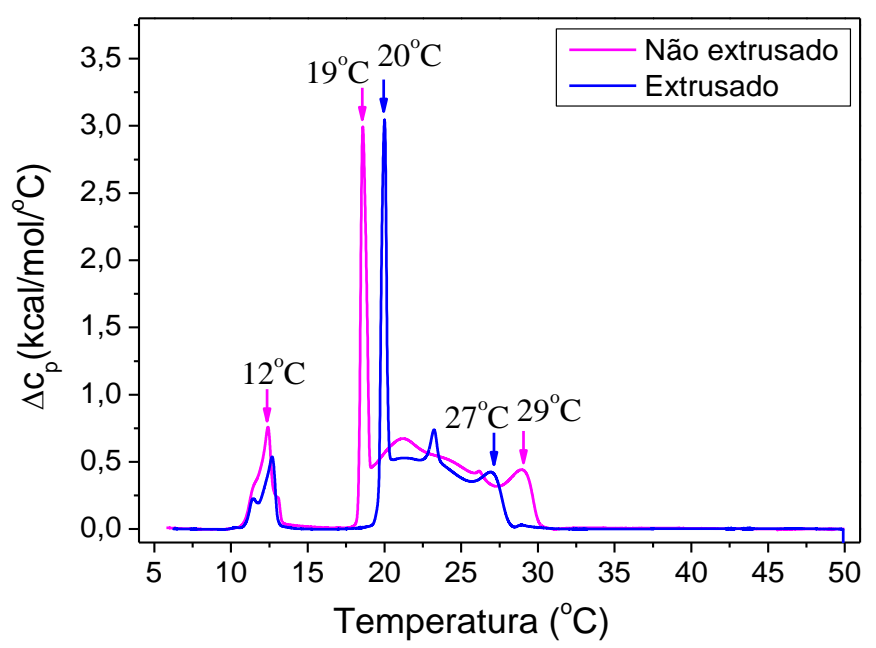

Figura 5.8.2: Comparação das curvas de DSC de dispersões extrusadas e não extrusadas (Barroso, 2010) de 50 mM de DMPG em tampão a baixa força iônica, sendo a taxa de aquecimento de $10^{\circ} \mathrm{C} / \mathrm{h}$.

Para as dispersões de $50 \mathrm{mM}$ de DMPG em tampão, o pico de pré-transição continua bastante visível mesmo após a extrusão e não houve mudança na intensidade do pico em $\mathrm{T}_{\mathrm{m}}{ }^{\text {on }}$. O intervalo de temperaturas da "região de transição de fase" diminui de 19 a $29^{\circ} \mathrm{C}$ para dispersões não extrusadas para 20 a $27^{\circ} \mathrm{C}$, após a extrusão e a entalpia da transição diminui de 6,0 (5) $\mathrm{kcal} / \mathrm{mol}$ para 4,8 (5) $\mathrm{kcal} / \mathrm{mol}$. Para as dispersões extrusadas um pico de variação de calor específico entre $T_{m}{ }^{\text {on }}$ e $T_{m}{ }^{\text {off }}$ fica mais evidente, mas não é claro se esse pode ser um efeito da extrusão das amostras ou do fato de serem amostras preparadas com diferentes lotes de DMPG.

Na figura 5.8.3 são apresentados os resultados de DSC obtidos para as dispersões extrusadas de $50 \mathrm{mM}$ de DMPG em tampão esquentando e esfriando a amostra e 
também a comparação entre curvas de DSC de dispersões de 10 (figura 5.1.1) e 50 mM de DMPG após a extrusão.
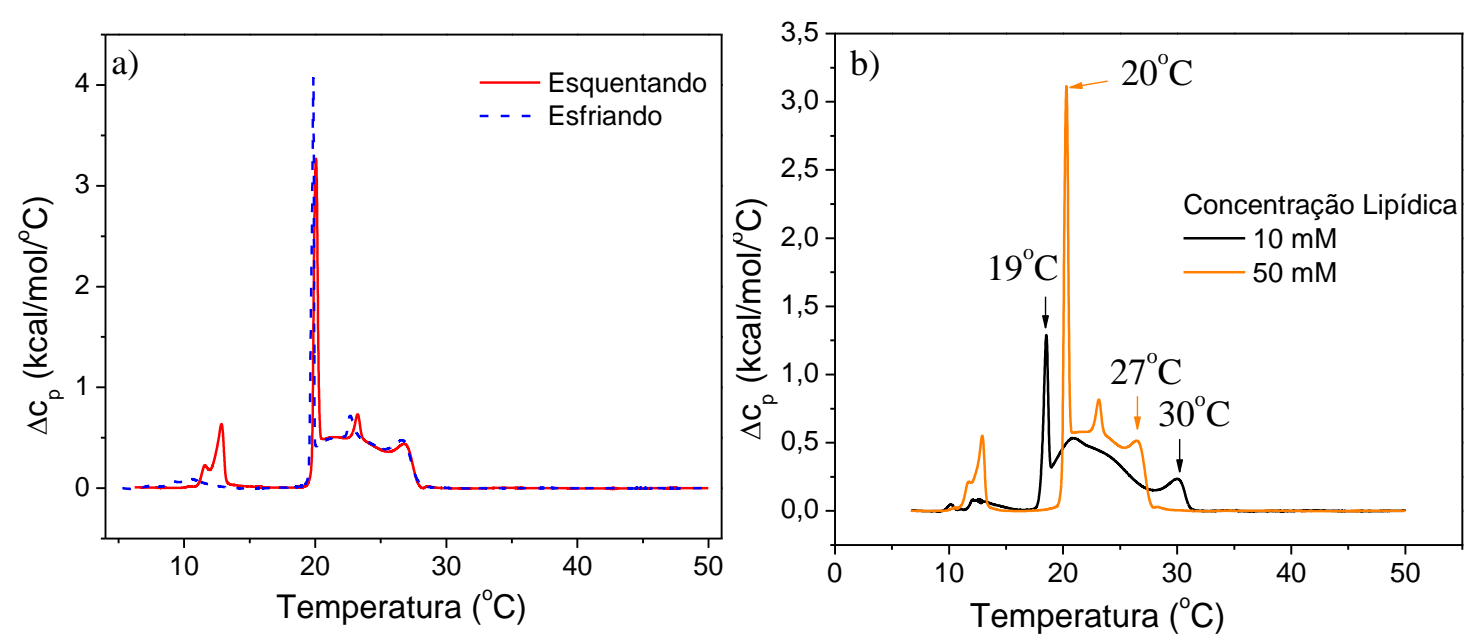

Figura 5.8.3: a) Curvas de DSC para a dispersão de $50 \mathrm{mM}$ de DMPG em tampão baixa força iônica extrusada, esquentando e esfriando. b) comparação dos resultados obtidos para as dispersões de 10 e 50 mM de DMPG, depois da extrusão. Taxa de variação da temperatura de $20^{\circ} \mathrm{C} / \mathrm{h}$.

Na figura 5.8.3 a) notamos que as curvas com a temperatura aumentando e diminuindo, sendo que esta foi invertida para facilitar a comparação, são bastante semelhantes entre si, mostrando a reversibilidade dos eventos térmicos, uma vez que os picos coincidem. A única diferença significativa, e que também foi observada em Bassoro, 2010 para dispersões não extrusadas, é no pico da pré-transição, que é bem menos intenso na medida esfriando a amostra. Na figura 5.8.3 b), em acordo com o que foi observado em Barroso, 2010 para as dispersões não extrusadas, com o aumento da concentração de DMPG a região de transição fica ligeiramente mais estreita, mas a entalpia calculada foi de 5,0 (5) kcal/mol independente da concentração lipídica, mostrando que as transições necessitam da mesma quantidade de calor para ocorrer. Apesar da diferença nas temperaturas de início $\left(T_{m}{ }^{o n}\right)$ e de final $\left(T_{m}{ }^{\text {off }}\right)$ da transição principal e o fato do pico intermediário entre $T_{m}{ }^{\text {on }}$ e $T_{m}$ off ficar mais evidente, vemos que a dispersão de $50 \mathrm{mM}$ ainda apresenta uma região de transição de fase, bastante semelhante ao observado nas concentrações lipídicas mais baixas.

Como mostrado em Barroso, 2010, aumentar-se a concentração lipídica de DMPG tem efeito semelhante ao observado com o aumento da força iônica do meio, devido ao maior número de contraíons $\mathrm{Na}^{+}$na dispersão, sua maior concentração, 
justificando o maior valor de $\mathrm{T}_{\mathrm{m}}{ }^{\text {on }}$ para a dispersão de $50 \mathrm{mM}$ de DMPG quando comparada com a dispersão de $10 \mathrm{mM}$, dada a maior blindagem das cabeças polares do DMPG.

Na figura 5.8.4 é feita a comparação de resultados de DSC para dispersões extrusadas de 50 mM de DMPG em água e em tampão HEPES a baixa força iônica.

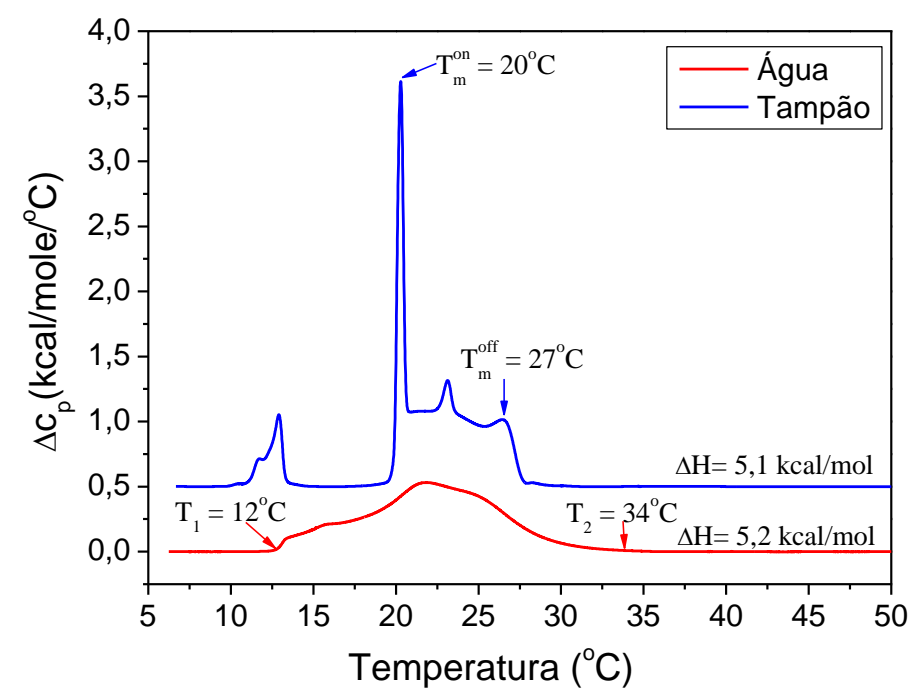

Figura 5.8.4: Comparação de curvas típicas de DSC de dispersões extrusadas de $50 \mathrm{mM}$ de DMPG em água (curva vermelha) e em tampão a baixa força iônica (curva azul). 0 resultado em tampão foi deslocado verticalmente para melhor visualização.

Similarmente ao que foi observado para dispersões extrusadas de $10 \mathrm{mM}$ de DMPG (figura 5.1.3), vemos na figura 5.7.4 que a transição de fase de dispersões de 50 mM de DMPG em água é menos cooperativa e abrange um intervalo bem maior de temperaturas na "região de transição de fase", sendo que esta tem início em uma temperatura mais baixa $\left(12^{\circ} \mathrm{C}\right)$, que coincide com a temperatura do pico de prétransição das dispersões de DMPG em tampão. Conforme discutido anteriormente, essas diferenças no perfil de variação do calor específico podem estar relacionadas com a forte repulsão eletrostática entre as cabeças polares do DMPG em água e/ou com a maior curvatura das vesículas de DMPG em água.

$\mathrm{Na}$ figura 5.1.3, comparando os resultados para o DMPG em água com o resultado para o DMPG em tampão, vemos que para o sistema em água a transição de fase é muito menos cooperativa, dada a ausência de picos estreitos e intensos de variação de calor específico. Isto pode estar relacionado com os agregados de DMPG em água apresentarem grande curvatura da bicamada, tratando-se de agregados menores, 
em sua maioria, do que os obtidos em tampão. A forte repulsão eletrostática entre as cabeças polares aumentaria a distância entre os lipídios, diminuindo as interações entre as caudas carbônicas e também a cooperatividade da transição.

Ainda sobre a figura 5.1.3, notamos que a "região de transição de fase" é ainda mais larga para as dispersões em água, iniciando-se em temperaturas bem mais baixas $\left(\sim 10^{\circ} \mathrm{C}\right)$. O fato da transição se iniciar em uma temperatura mais baixa pode estar relacionado com uma maior carga superficial dos agregados de DMPG em água, o que aumentaria a área por cabeça polar dos lipídios, devido à repulsão eletrostática entre as cabeças polares, diminuindo as interações das cadeias hidrocarbônicas e, desta forma, desestabilizando a fase gel da bicamada (Jahnig, 1976; Trauble et al., 1976), como já discutido. Além disto, o estreitamento do intervalo de temperaturas da região de transição de fase de dispersões de DMPG com o aumento da força iônica do meio já foi reportado anteriormente (Kodama \& Miyata, 1995; Lamy-Freund \& Riske, 2003; Barroso, 2010), sendo que em meio de alta força iônica observa-se para o DMPG uma transição de fase altamente cooperativa (Lamy-Freund \& Riske, 2003) e semelhante ao do lipídio DMPC, que é neutro.

Apesar das diferenças no perfil de DSC das amostras em meios de diferente força iônica e com diferentes concentrações lipídicas, a entalpia da transição foi de 5,0 (5) $\mathrm{kcal} / \mathrm{mol}$, mostrando que as transições necessitam da mesma quantidade de calor para ocorrer. 


\subsubsection{Viscosidade}

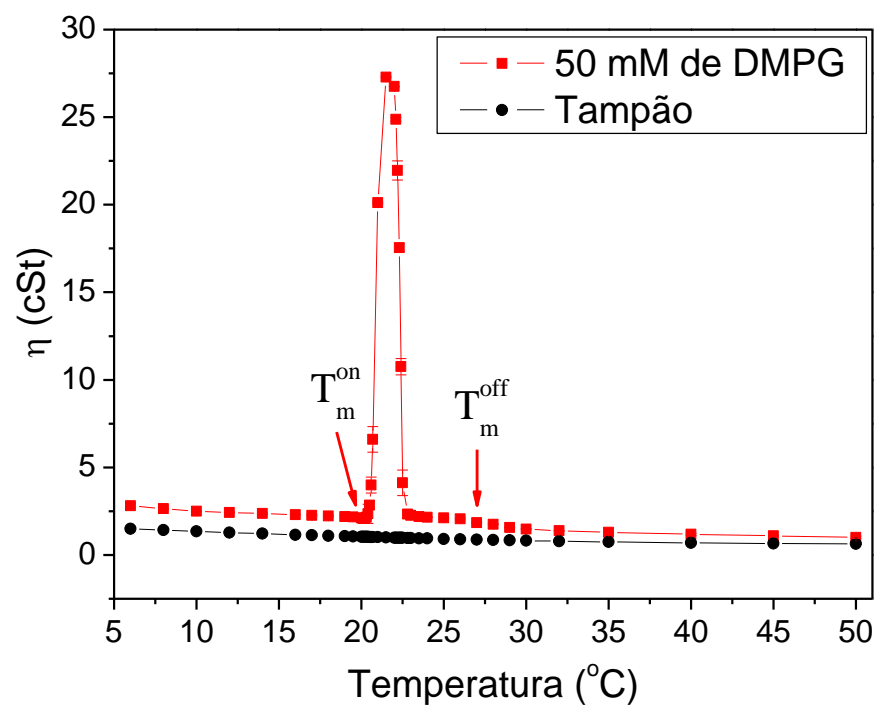

Figura 5.8.5: Viscosidade cinemática em função da temperatura para dispersões extrusadas de 50 mM de DMPG em tampão (curva vermelha) e do tampão (curva preta). Cada curva é a média entre medidas de duas amostras distintas e a incerteza é dada pelo desvio padrão das medidas.

A partir da figura 5.8.5 vemos que, curiosamente, para a dispersões extrusadas de $50 \mathrm{mM}$ de DMPG em tampão HEPES, a viscosidade sofre um grande aumento no início da transição de fase $\left(\sim 20^{\circ} \mathrm{C}\right)$, mas logo em seguida $\left(\sim 23^{\circ} \mathrm{C}\right)$ já cai para valores próximos ao da viscosidade do solvente, não ficando alta durante toda a região de transição de fase, diferente do observado para a concentração lipídica de 10 mM (figura 5.2.1). Medidas realizadas diminuindo-se a temperatura (dados não mostrados aqui) resultaram em valores muito semelhantes aos mostrados na figura 5.8.5.

De modo a verificar se o mesmo comportamento é observado para dispersões não extrusadas de $50 \mathrm{mM}$ de DMPG em tampão, calculamos o incremento de viscosidade relativa (equação 4.2.1) das dispersões extrusadas e comparamos com os resultados de Barroso, 2010 (figura 5.8.6). 


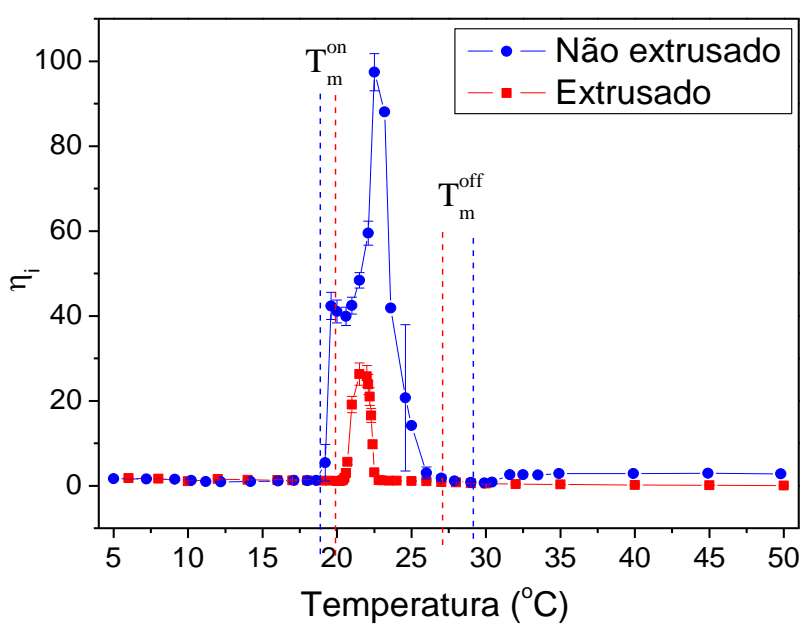

Figura 5.8.6: Incremento da viscosidade relativa com a temperatura para dispersões de 50 mM de DMPG antes (curva azul, extraídas de Barroso, 2010) e depois (curva vermelha) da extrusão. As linhas tracejadas vermelhas indicam $T_{m}{ }^{\text {on }}$ e $T_{m}{ }^{\text {off }}$ das dispersões extrusadas e as azuis das não extrusadas, de acordo com os gráficos de DSC da figura 5.7.2.

Na figura 5.8.6 vemos que o $\eta_{i}$ da dispersão extrusada é muito menor do que na dispersão não extrusada, sendo que o incremento da viscosidade relativa não permanece alto durante todo o intervalo entre $T_{m}{ }^{\text {on }}-T_{m}{ }^{\text {off }}$, tanto para as dispersões extrusadas quanto para as não extrusadas. Este comportamento da viscosidade é bastante diferente do observado para as dispersões de $10 \mathrm{mM}$ de DMPG em tampão (figura 5.2.2), onde o aumento e diminuição de $\eta_{i}$ acompanham as temperaturas de início e final da transição de fase. $O$ incremento da viscosidade relativa é muito mais alto (vide as escalas) para as dispersões de $50 \mathrm{mM}$ de DMPG do que para as dispersões de $10 \mathrm{mM}$ de DMPG. 


\subsubsection{Condutividade Elétrica}

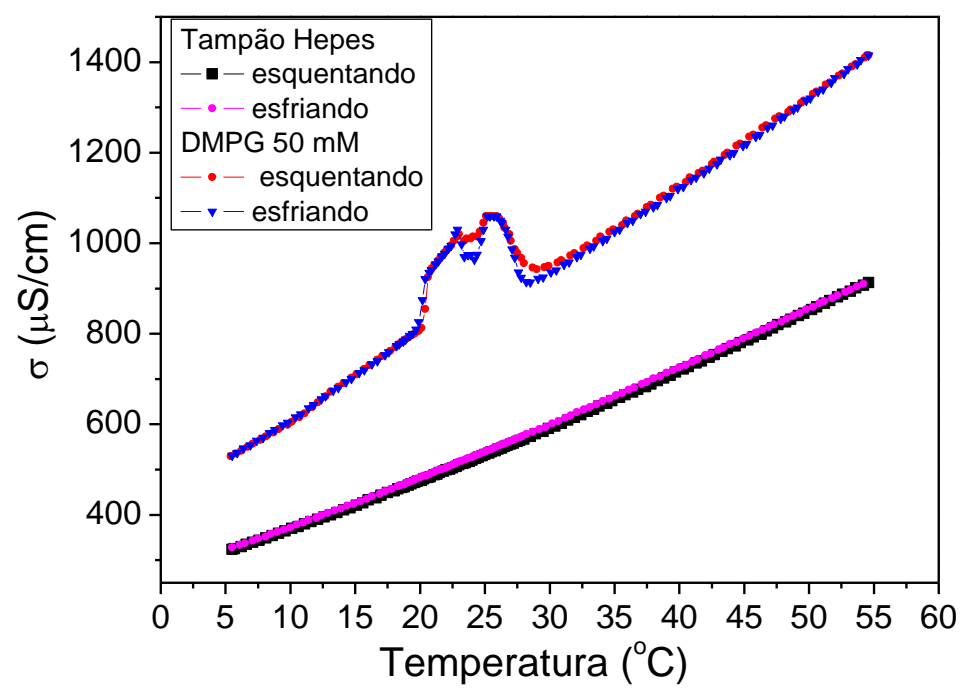

Figura 5.8.7: Medidas de condutividade elétrica aumentando e diminuindo a temperatura do tampão HEPES e de uma dispersão extrusada de 50 mM de DMPG em tampão.

A partir da figura 5.8.7 observamos o aumento anômalo da condutividade elétrica na região de transição de fase (entre 20 e $27^{\circ} \mathrm{C}$ ), da mesma forma que foi observado e discutido para dispersões de $10 \mathrm{mM}$ de DMPG (figura 5.3.1). Vemos que o comportamento com a temperatura foi muito semelhante quando aquecendo e esfriando a amostra, mostrando reversibilidade dos eventos observados e também foi verificada a reprodutibilidade dos resultados repetindo-se as medidas para uma amostra distinta (resultado não mostrado aqui).

Da mesma forma que foi feito para as dispersões de $10 \mathrm{mM}$ de DMPG, calculamos a condutividade reduzida pela equação 5.3.1 e comparamos os resultados com os de dispersões de 50 mM de DMPG não extrusadas, usando-se $\phi=0,125$ (Barroso, 2010). 


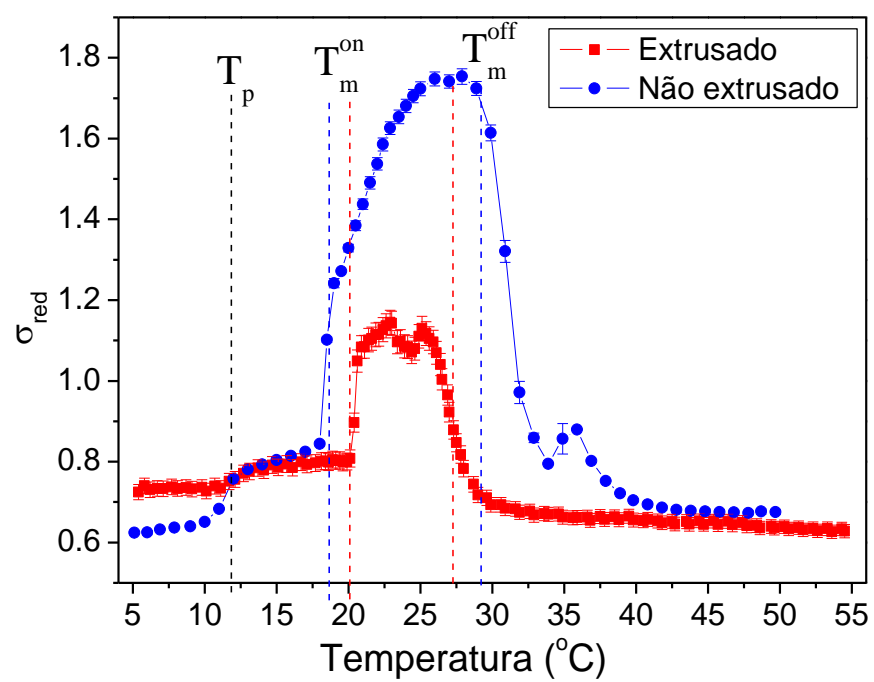

Figura 5.8.8: Condutividade reduzida de dispersões de $50 \mathrm{mM}$ de DMPG em tampão HEPES antes e depois da extrusão (Barroso, 2010). As linhas tracejadas vermelhas indicam $T_{m}{ }^{\text {on }}$ e $T_{m}{ }^{\text {off }}$ das dispersões extrusadas e as azuis das não extrusadas, de acordo com os gráficos de DSC da figura 5.7.2. Cada curva é a média entre medidas de duas amostras distintas e a incerteza é dada pelo desvio padrão das medidas.

A partir da figura 5.8.8, vemos que a condutividade reduzida já aumenta a partir de $T_{p}$, chegando a um aumento de $80 \%$, relativo à condutividade do solvente. Para as dispersões extrusadas, vemos que o aumento e diminuição da condutividade reduzida acompanham as temperaturas dos picos de calor específico de DSC (aumento a partir de $T_{p}$, aumento abrupto a partir de $T_{m}{ }^{\text {on }}$ e diminuição em $T_{m}{ }^{\text {off }}$ ). A mesma tendência descrita para dispersões extrusadas é observada para as dispersões não extrusadas, sendo que para temperaturas mais altas que $T_{m}{ }^{\text {off }}$, as dispersões não extrusadas ainda apresentam um pico na condutividade reduzida em $35,5^{\circ} \mathrm{C}$, após o fim da transição de fase, semelhante ao observado para dispersões não extrusadas de 10 mM (figura 5.3.2). Os valores da condutividade reduzida são menores após a realização da extrusão das amostras.

Vemos que a condutividade de dispersões de $50 \mathrm{mM}$ de DMPG é bem mais alta do que o obtido para dispersões de $10 \mathrm{mM}$ (figura 5.3.2), onde o $\sigma_{\text {red }}$ máximo foi de 0,24, para a dispersões extrusadas. Com o aumento da concentração lipídica aumentamos também o número de contraíons na solução, o que está relacionada com o aumento da condutividade medida. 


\subsubsection{Turbidez}

Realizamos medidas de Absorbância a $350 \mathrm{~nm}$ em função da temperatura de dispersões extrusadas de $50 \mathrm{mM}$ de DMPG em tampão a baixa força iônica e comparamos com os resultados obtidos para dispersões não extrusadas em Barroso, 2010.

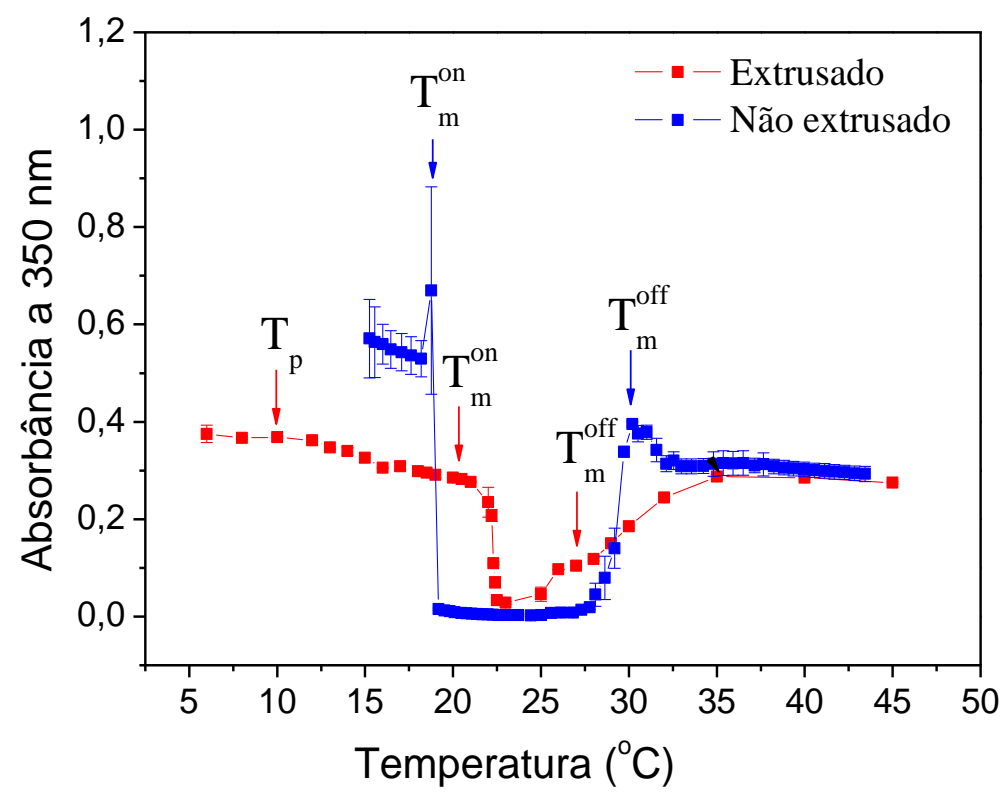

Figura 5.8.9: Medidas de absorbância a $350 \mathrm{~nm}$ em função da temperatura de dispersões de $50 \mathrm{mM}$ de DMPG em tampão, antes (pontos azuis, dados de Barroso et al., 2010) e depois (pontos vermelhos) da extrusão. Cada curva é a média de 2 medidas de amostras distintas.

Enquanto o comportamento das dispersões não extrusadas é semelhante ao das dispersões de $10 \mathrm{mM}$ de DMPG (figura 5.5.1), para as dispersões extrusadas de $50 \mathrm{mM}$ de DMPG (figura 5.7.9), notamos que uma queda sutil da turbidez já se inicia em $T_{p}$, seguido por uma queda brusca a partir de $\mathrm{T}_{\mathrm{m}}{ }^{\text {on }}$, ficando próxima a zero por um curto intervalo de temperatura (entre 22 e $25^{\circ} \mathrm{C}$ ) e depois volta a subir, de maneira menos brusca que a observada para dispersões não extrusadas. Vemos que a turbidez é menor na fase gel para as dispersões extrusadas, indicando a presença de agregados menores após a extrusão das amostras e que os valores da turbidez das dispersões de 50 mM são maiores do que das dispersões de $10 \mathrm{mM}$ (figura 5.5.1) nas fases gel e fluida, dada a maior concentração lipídica. 


\subsubsection{Resumo dos resultados obtidos para dispersões de $50 \mathrm{mM}$ de}

\section{DMPG}

Para a visualização dos resultados obtidos com as diferentes técnicas utilizadas, fizemos a sobreposição dos resultados obtidos para dispersões extrusadas de $50 \mathrm{mM}$ de DMPG em tampão a baixa força iônica, normalizando os valores de modo que o maior valor de cada técnica coincidisse com 1.

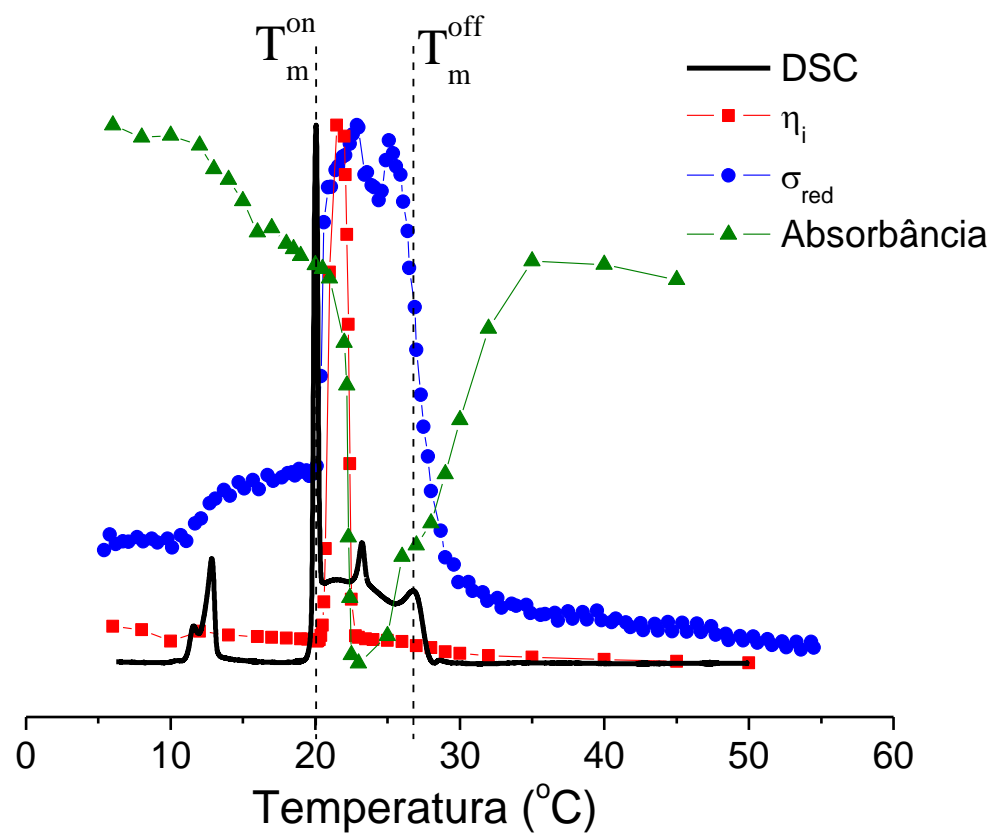

Figura 5.8.10: Sobreposição dos resultados de DSC, incremento da viscosidade relativa $\left(\eta_{i}\right)$, condutividade reduzida ( $\sigma_{\text {red }}$ ) e absorbância a $350 \mathrm{~nm}$ para dispersões de $50 \mathrm{mM}$ de DMPG 50 mM em tampão à baixa força iônica, após a extrusão.

Para dispersões extrusadas de 50 mM de DMPG em tampão HEPES a baixa força iônica (figura 5.8.10), vemos que há uma correlação entre o pico estreito de DSC, que indica o início da transição principal $\left(T_{m}{ }^{\text {on }}\right)$ com as mudanças bruscas observadas nas diferentes técnicas utilizadas. Vemos também que a condutividade e a turbidez apresentam mudanças já a partir do primeiro pico calorimétrico que representa a prétransição $\left(T_{p}\right)$, em torno de $12^{\circ} \mathrm{C}$.

Comparando os resultados para as dispersões de 50 mM de DMPG (Figura 5.8.10) com os resultados para $10 \mathrm{mM}$ de DMPG (Figura 5.7.1) vemos que para $50 \mathrm{mM}$ a alta viscosidade acontece em um intervalo de temperatura muito menor que o intervalo de temperatura da transição de fase, diferente do comportamento observado para $10 \mathrm{mM}$, 
onde a viscosidade só diminui no fim da transição de fase. Além disto, vemos que a turbidez da dispersão de $50 \mathrm{mM}$ não permanece em zero durante toda a transição, apresentando um aumento menos brusco que para $10 \mathrm{mM}$ de DMPG, mas nos dois sistemas a queda brusca da turbidez acontece um pouco depois do pico principal de DSC. Para $10 \mathrm{mM}$ a pré-transição fica praticamente imperceptível na medida de DSC e não influencia a condutividade e a turbidez, como mostrado para 50 mM. Apesar destas pequenas diferenças, vemos que existe uma região de transição de fase na dispersão extrusada de $50 \mathrm{mM}$, que é semelhante à observada em $10 \mathrm{mM}$, com exceção do comportamento da viscosidade. 


\section{Capítulo 6 - Resultados e discussões:}

\section{Ressonância \\ Paramagnética}

\section{Eletrônica (RPE) de marcadores de}

\section{spin}

Neste capítulo, apresentamos os resultados de RPE obtidos para dispersões de 10 mM de DMPG em água com os marcadores 5-PCSL, que monitora a região próxima às cabeças polares, e 16-PCSL, que monitora o centro da bicamada. As medidas foram realizadas em diversas temperaturas, entre 5 e $60^{\circ} \mathrm{C}$, para amostras extrusadas e não extrusadas, e cada medida foi repetida para duas amostras distintas. Os resultados obtidos com as dispersões de DMPG em água foram comparados com os resultados obtidos para dispersões extrusadas de $10 \mathrm{mM}$ de DMPG em tampão HEPES a baixa força iônica. Para os resultados com o marcador 16PCSL realizou-se algumas simulações teóricas, com o programa MultiComponent EPR Fitting. 


\subsection{Dispersões de DMPG com o marcador de spin 5-PCSL}

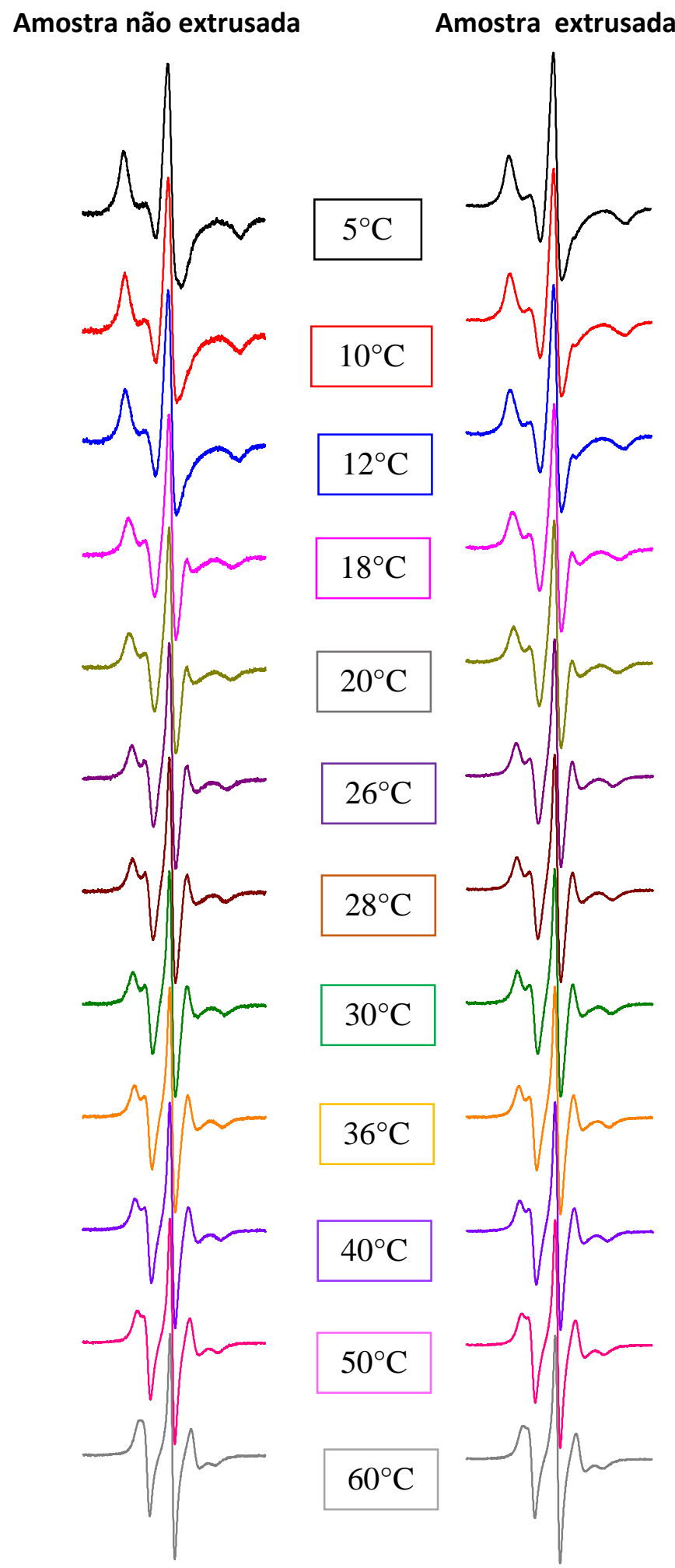

Figura 6.1.1: Típicos espectros de RPE para dispersões de $10 \mathrm{mM}$ de DMPG em água + 0,8 mol\% do marcador 5-PCSL, antes (curvas da esquerda) e depois (curvas da direita) da extrusão em diferentes temperaturas. 
O marcador de spin 5-PCSL é um fosfolipídio que contém o grupo paramagnético nitróxido ligado ao carbono 5, conforme mostrado em materiais e métodos, na figura 3.1.1. Desta forma, com este marcador, teremos informações quanto à ordem e mobilidade do grupo nitróxido, que por estar muito próximo à região da cabeça polar, possui uma mobilidade restrita.

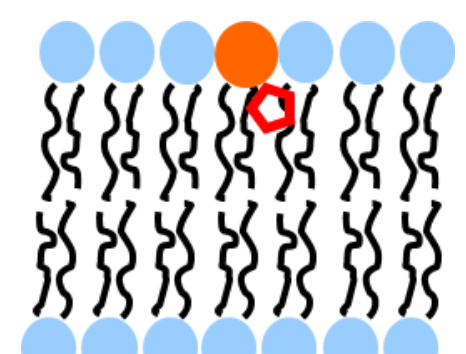

Figura 6.1.2: Ilustração que representa o marcador de spin 5-PCSL incorporado à bicamada lipídica.

Conforme descrito em materiais e métodos (figura 3.2.12), obtivemos os parâmetros $A_{\max }$ e $A_{\min }$ diretamente a partir dos espectros da figura 6.1.1.

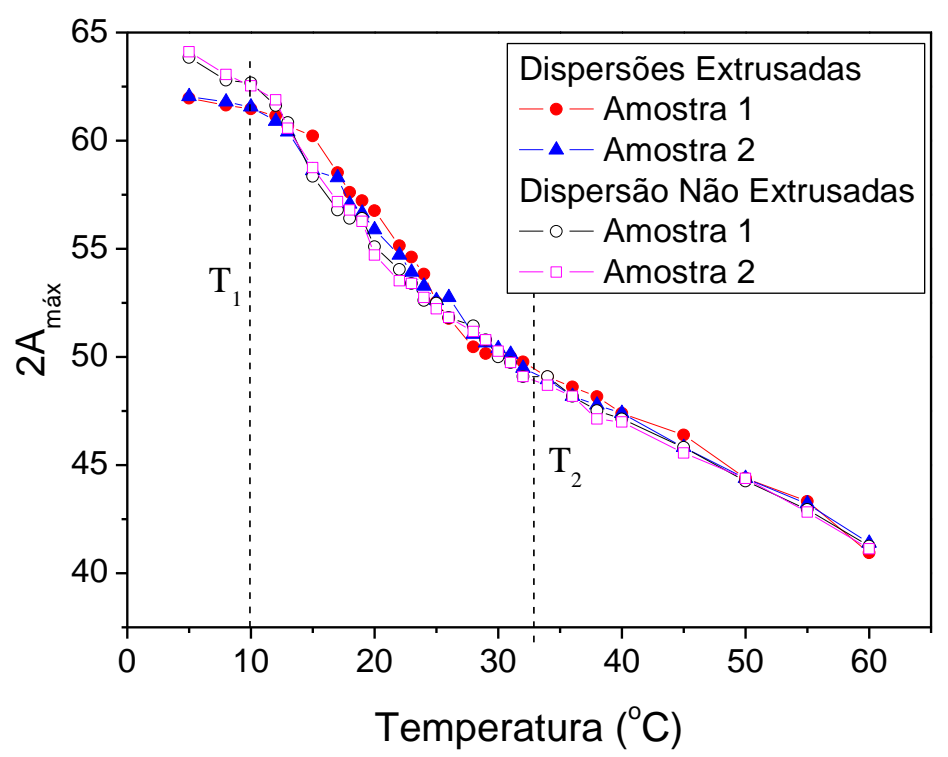

Figura 6.1.3: Desdobramento hiperfino máximo em função da temperatura para duas amostras distintas de dispersões extrusadas (símbolos fechados) e não extrusadas (símbolos abertos) de 10 mM de DMPG em água + 0,8 mol\% do marcador 5-PCSL.

A partir da figura 6.1.3 vemos que as medidas antes e depois da extrusão foram reprodutíveis, obtendo-se resultados muito semelhantes para amostras distintas de DMPG em água com o marcador 5-PCSL. Os valores de $A_{\max }$ para as dispersões 
extrusadas e não extrusadas são semelhantes para temperaturas acima de $12^{\circ} \mathrm{C}$, sendo que na fase gel Amax é ligeiramente maior para as amostras não extrusadas. Isto está de acordo com o desaparecimento de uma população de vesículas grandes após a extrusão. O parâmetro $A_{\max }$ é sensível à ordem e mobilidade do grupo nitróxido, sendo que quanto maior o seu valor, menor é a mobilidade, ou maior é a ordem, da região monitorada pelo marcador de spin. Desta forma, vemos a clara mudança de uma fase mais rígida/imóvel para temperaturas abaixo de $15^{\circ} \mathrm{C}$, para uma fase mais fluida/móvel com o aumento da temperatura, caracterizando a transição de fase gel-fluida das bicamadas, sendo difícil precisar onde se dá o fim desta transição a partir dos resultados de RPE.

De acordo com os espectros de RPE, os valores de Amin foram medidos para temperaturas maiores que $28^{\circ} \mathrm{C}$ e os resultados são apresentados na figura 6.1.4.

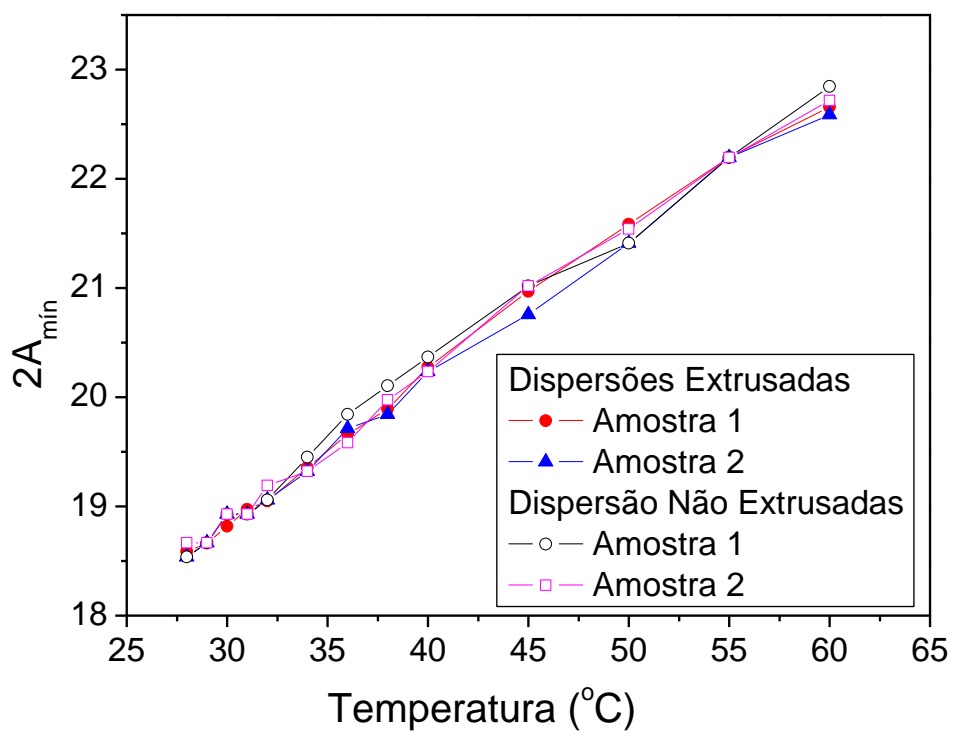

Figura 6.1.4: Desdobramento hiperfino mínimo em função da temperatura para duas amostras distintas de dispersões extrusadas (símbolos fechados) e não extrusadas (símbolos abertos) de 10 mM de DMPG em água + 0,8 mol\% do marcador 5-PCSL.

A partir da figura 6.1.4, vemos que os valores de $A_{\min }$ são muito parecidos para as dispersões extrusadas e não extrusadas e que os resultados foram reprodutíveis para amostras distintas. Com os valores de $A_{\max }$ e $A_{\min }$ das figuras 6.1.3 e 6.1.4 foi possível

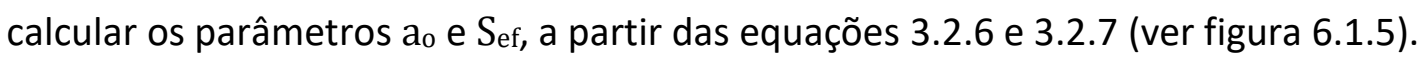



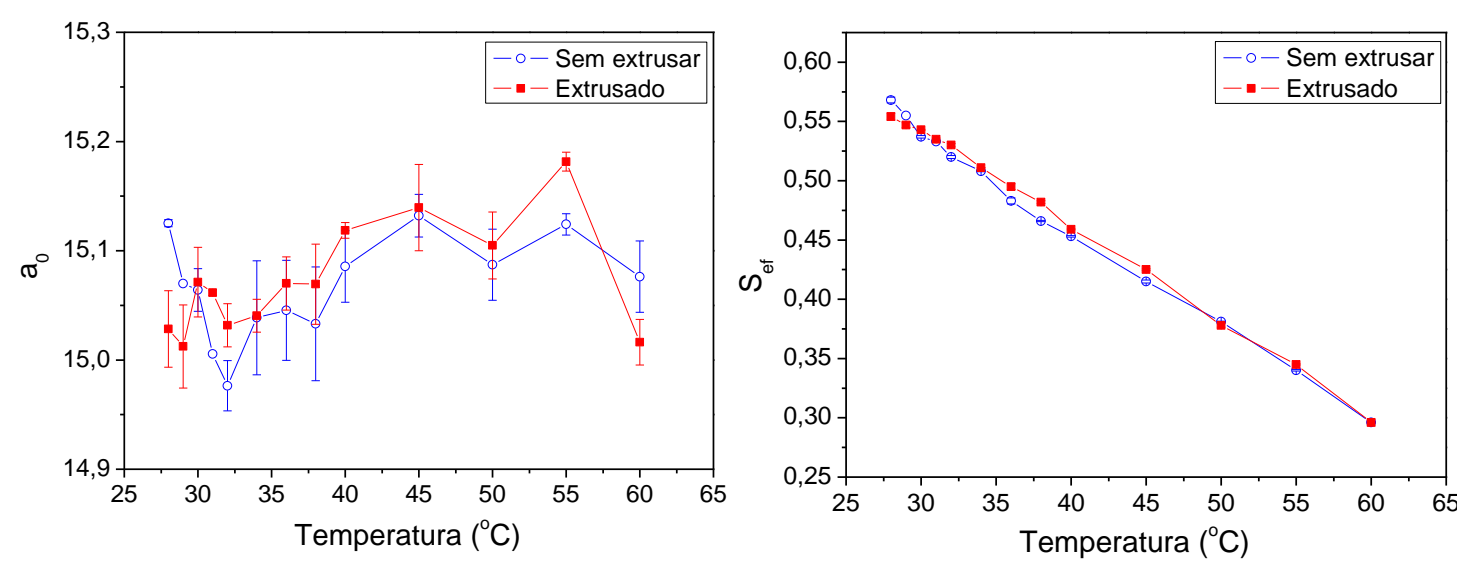

Figura 6.1.5: Média e desvio padrão dos valores calculados para os parâmetros ao e $S_{\text {ef }}$ para duas amostras distintas de 10 mM de DMPG antes e depois da extrusão em água, na fase fluida da bicamada.

Na figura 6.1.5 vemos que o desdobramento hiperfino isotrópico (ao), que está relacionado à polaridade do meio, permanece constante nas temperaturas de 28 a $60^{\circ} \mathrm{C}$, como esperado, variando em torno de $a_{0}=15,05$ G. O parâmetro de ordem efetivo $\left(\mathrm{S}_{\text {ef }}\right)$, que contém informações quanto à ordem e mobilidade da membrana, mostra a presença de bicamadas mais fluidas com o aumento da temperatura, sendo que os valores para as dispersões extrusadas e não extrusadas são muito parecidos, mostrando que o processo de extrusão não altera a ordem/mobilidade da bicamada na região próxima à cabeça polar na fase fluida.

Medidas de RPE de dispersões de $10 \mathrm{mM}$ de DMPG em tampão baixa força iônica (HEPES $10 \mathrm{mM}+\mathrm{NaCl} 2 \mathrm{mM}$ ) foram realizadas em Duarte et al., 2008 e como essas medidas foram realizadas com amostras não extrusadas, vamos comparar os resultados das dispersões não extrusadas em água com os resultados obtidos em Duarte et al., 2008, em tampão.

Comparando-se os espectros de RPE em água e em tampão em diferentes temperaturas (figura 6.1.6), notamos que os espectros são muito semelhantes. Além disto, os espectros apresentados na figura 6.1.6, na fase gel $\left(5^{\circ} \mathrm{C}\right)$ e na fase fluida $\left(45^{\circ} \mathrm{C}\right)$ são semelhantes aos espectros de vesículas do lipídio neutro DMPC com este mesmo marcador (Barroso et al., 2012), sendo típicos espectros de fases gel e fluida de bicamadas lipídicas, mostrando que há a transição de uma fase mais rígida/imóvel para uma fase mais frouxa/móvel, sendo um forte indício de que o DMPG se organiza como bicamadas, tanto em água como em tampão, e não como micelas. 


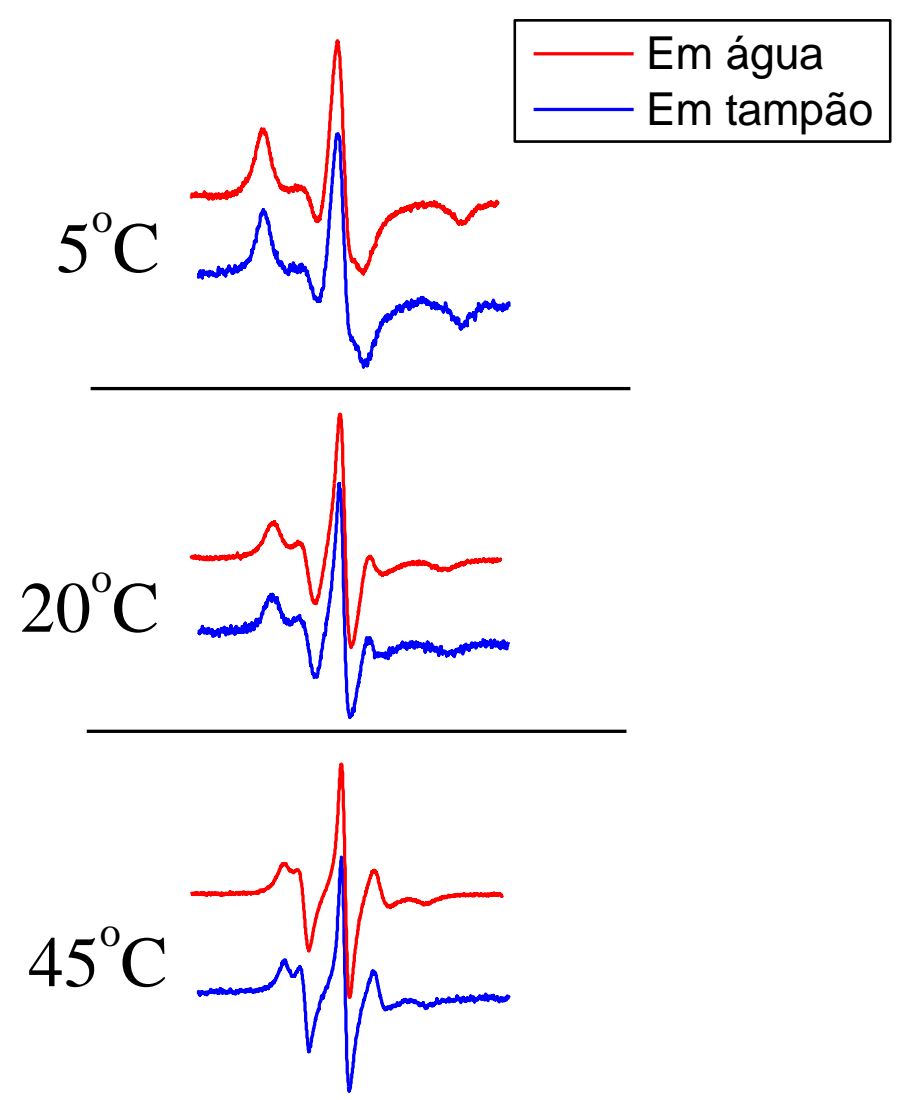

Figura 6.1.6: Espectros de RPE de dispersões não extrusadas de $10 \mathrm{mM}$ de DMPG com o marcador 5-PCSL em água (curvas vermelhas) e em tampão (curvas azuis) (Duarte et al., 2008) em diferentes temperaturas: na fase gel $\left(5^{\circ} \mathrm{C}\right)$, na região de transição de fase $\left(20^{\circ} \mathrm{C}\right)$ e na fase fluida $\left(45^{\circ} \mathrm{C}\right)$.

Comparamos os valores dos parâmetros Amax e Amin medidos nos espectros de DMPG em água e em tampão HEPES (Duarte et al., 2008). A comparação é mostrada na figura 6.1.7. 

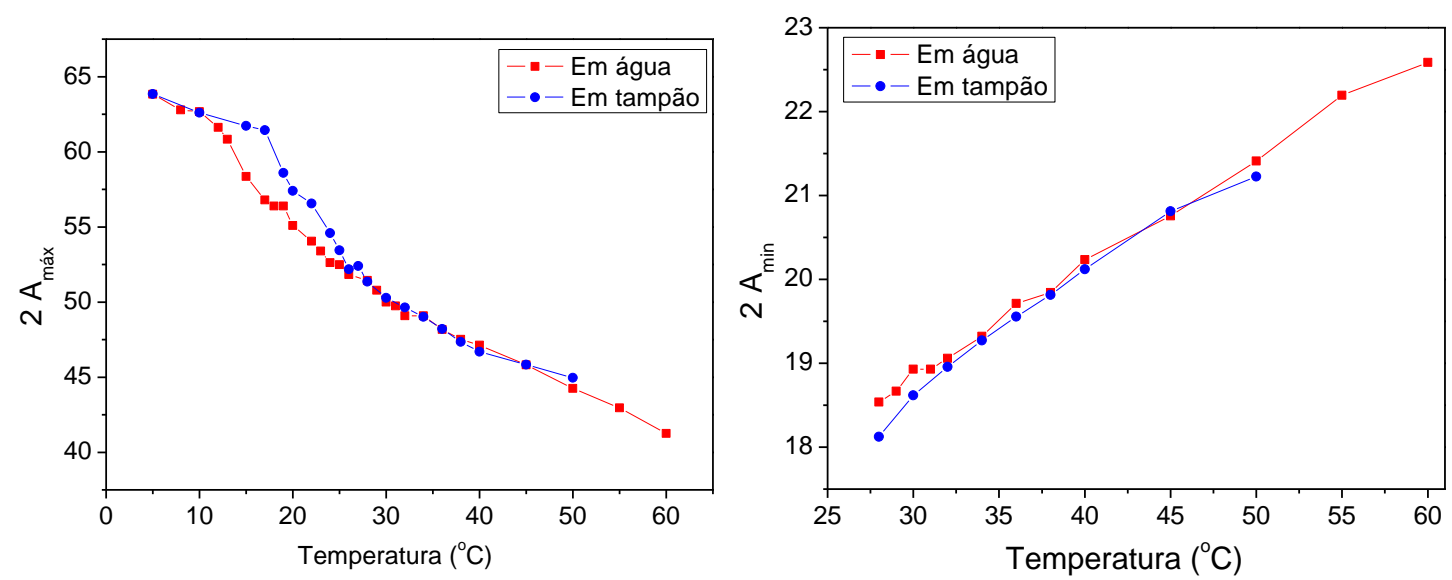

Figura 6.1.7: Comparação dos parâmetros $2 A_{\max }$ e $2 A_{\min }$ de medidas de RPE de dispersões de $10 \mathrm{mM}$ de DMPG em água (pontos vermelhos) e em tampão (pontos azuis).

A partir dos valores de $2 A_{\max }$ (figura 6.1.7), vemos que as dispersões em água e em tampão apresentam valores similares de $A_{\max }$ nas fases gel (até $10^{\circ} \mathrm{C}$ ) e na fase fluida (acima de $30^{\circ} \mathrm{C}$ ), sendo que $A_{\max }$ já começa a diminuir na dispersão em água a partir de $\sim 12^{\circ} \mathrm{C}$, enquanto na dispersão em tampão isso só ocorre depois de $17^{\circ} \mathrm{C}$, estando essas temperaturas de acordo com o início das transições de fase vistas por DSC (figura 5.1.5 a), mostrando que, de fato, as bicamadas de DMPG em água iniciam a transição de fase em temperaturas mais baixas que em tampão. $A_{\min }$, que só pode ser medido na fase fluida, apresenta valores semelhantes para os dois sistemas.

A partir dos valores da figura 6.1.7 para $A_{\max }$ e $A_{\min }$ calculamos os parâmetros $a_{\circ}$

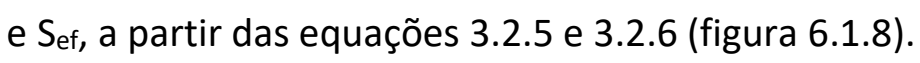
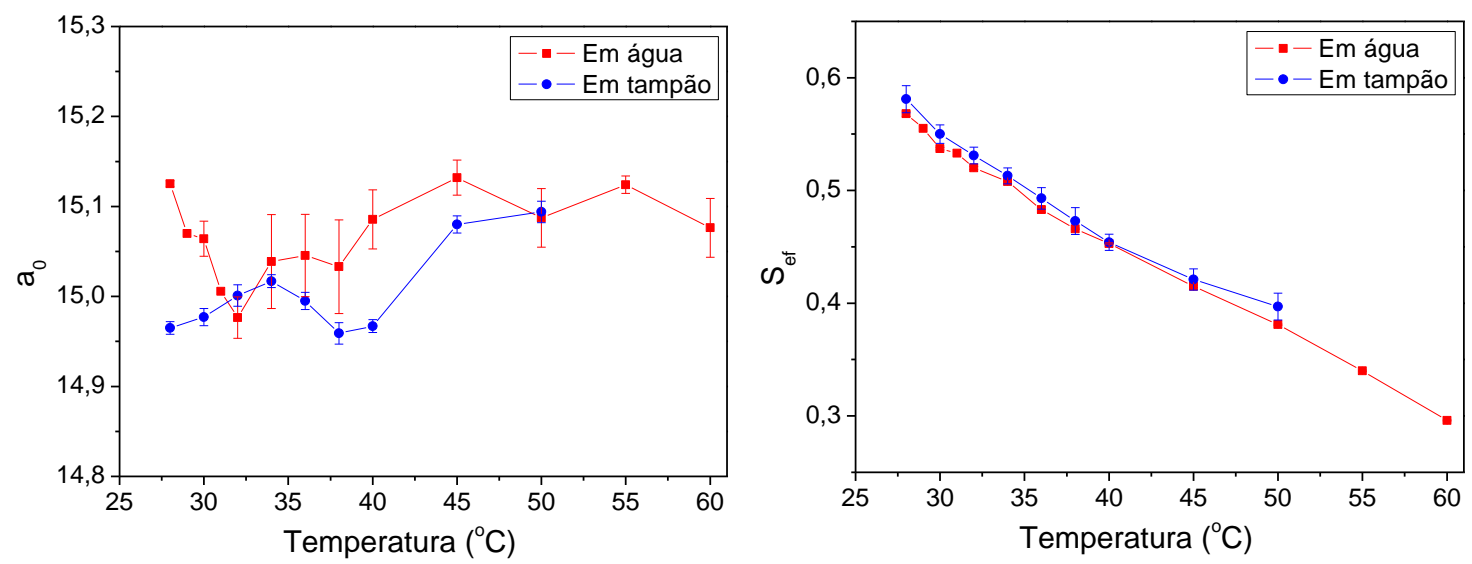

Figura 6.1.8: Comparação dos parâmetros $a_{o}$ e $S_{\text {ef }}$ para dispersões de $10 \mathrm{mM}$ de DMPG em água e em tampão baixa força iônica. 
A partir dos resultados da figura 6.1.8 vemos que os valores de ao são similares para as dispersões de DMPG em tampão e em água, não apresentando variação significativa com o aumento da temperatura (de 28 a $50^{\circ} \mathrm{C}$ para o DMPG em tampão e de 28 a $60^{\circ} \mathrm{C}$ para o sistema em água). Os valores do parâmetro de ordem efetivo ( $\left.\mathrm{S}_{\mathrm{ef}}\right)$ também são muito parecidos para o DMPG em tampão e em água, mostrando que as membranas de DMPG apresentam ordem/mobilidade parecidas nos dois solventes, na região próxima às cabeças polares. 
6.2 Dispersões de DMPG com o marcador de spin 16-PCSL

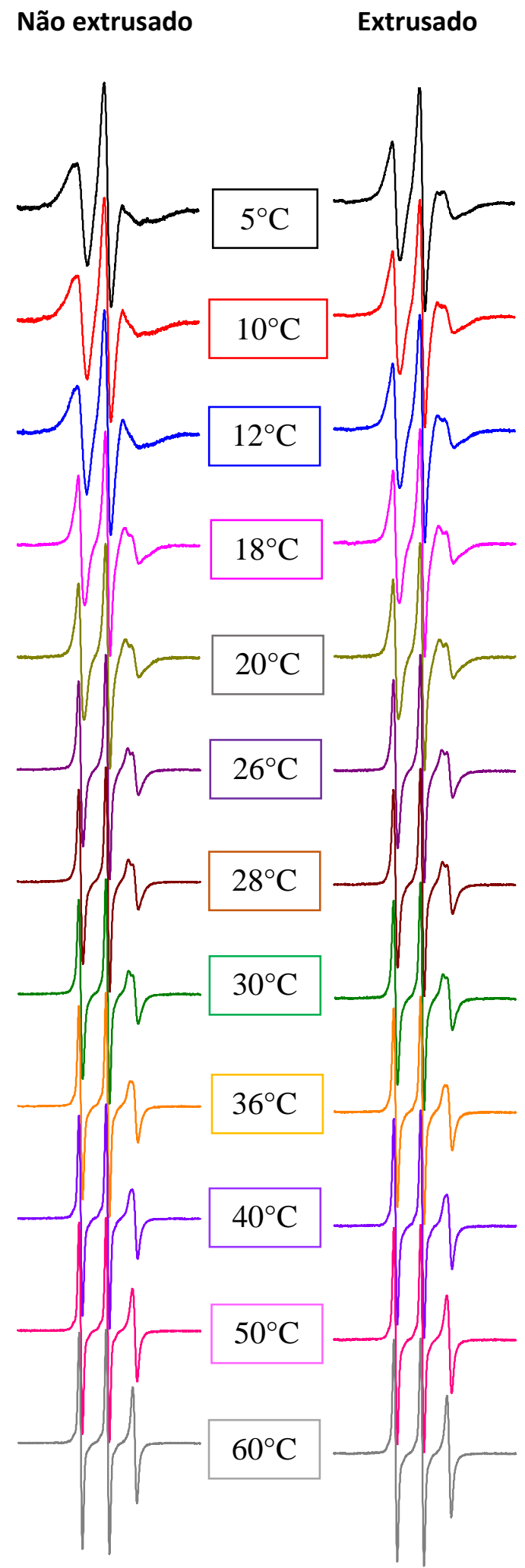

Figura 6.2.1: Típicos espectros de RPE para dispersões de $10 \mathrm{mM}$ de DMPG em água + 0,3 mol\% do marcador de spin 16-PCSL, não extrusadas (curvas da esquerda) e extrusadas (curvas da direita) em diferentes temperaturas. 
O marcador de spin 16-PCSL é um fosfolipídio que contém o grupo paramagnético nitróxido ligado ao carbono 16 de sua cauda hidrocarbônica, conforme mostrado em materiais e métodos, na figura 3.1.1. Quanto mais internamente localizado na bicamada lipídica, maior é a liberdade de movimento do marcador de spin, tornando-o mais sensível às mudanças de empacotamento e mobilidade das bicamadas lipídicas na transição de fase gel-fluida. Com este marcador teremos informações quanto à ordem e mobilidade no centro da bicamada de DMPG.

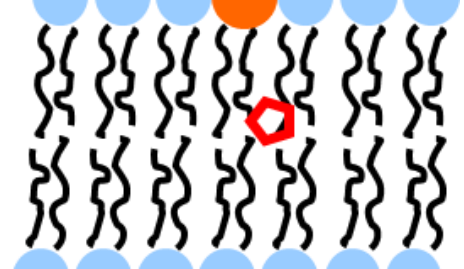

Figura 6.2.2: Ilustração que representa o marcador de spin 16-PCSL incorporado à bicamada lipídica.

A partir da figura 6.2.1, vemos que o marcador 16-PCSL monitora diferenças entre as dispersões extrusadas e não extrusadas na fase gel. De modo a observar com mais atenção os espectros de RPE antes e depois da extrusão, mostramos a comparação das curvas em algumas temperaturas: na fase gel $\left(5^{\circ} \mathrm{C}\right)$, na região de transição de fase $\left(20^{\circ} \mathrm{C}\right.$ ) e a na fase fluida $\left(45^{\circ} \mathrm{C}\right.$ ) (figura 6.2.3). Vemos que, aparentemente, a diferença nos espectros só aparece na fase gel, sendo que para a dispersão extrusada já é possível observar a coexistência de dois sinais, que podem indicar a presença de duas populações distintas na dispersão (Riske et al., 2003), desde $5^{\circ} \mathrm{C}$. Na fase gel, o espectro obtido com dispersões não extrusadas indica a presença de bicamadas mais empacotadas do que àquelas obtidas com dispersões extrusadas de DMPG. Os espectros a 20 e $45^{\circ} \mathrm{C}$ são bem parecidos antes e depois da extrusão, mas para um estudo mais cuidadoso, vamos comparar alguns parâmetros espectrais de interesse para as dispersões extrusadas e não extrusadas nas diferentes temperaturas. 


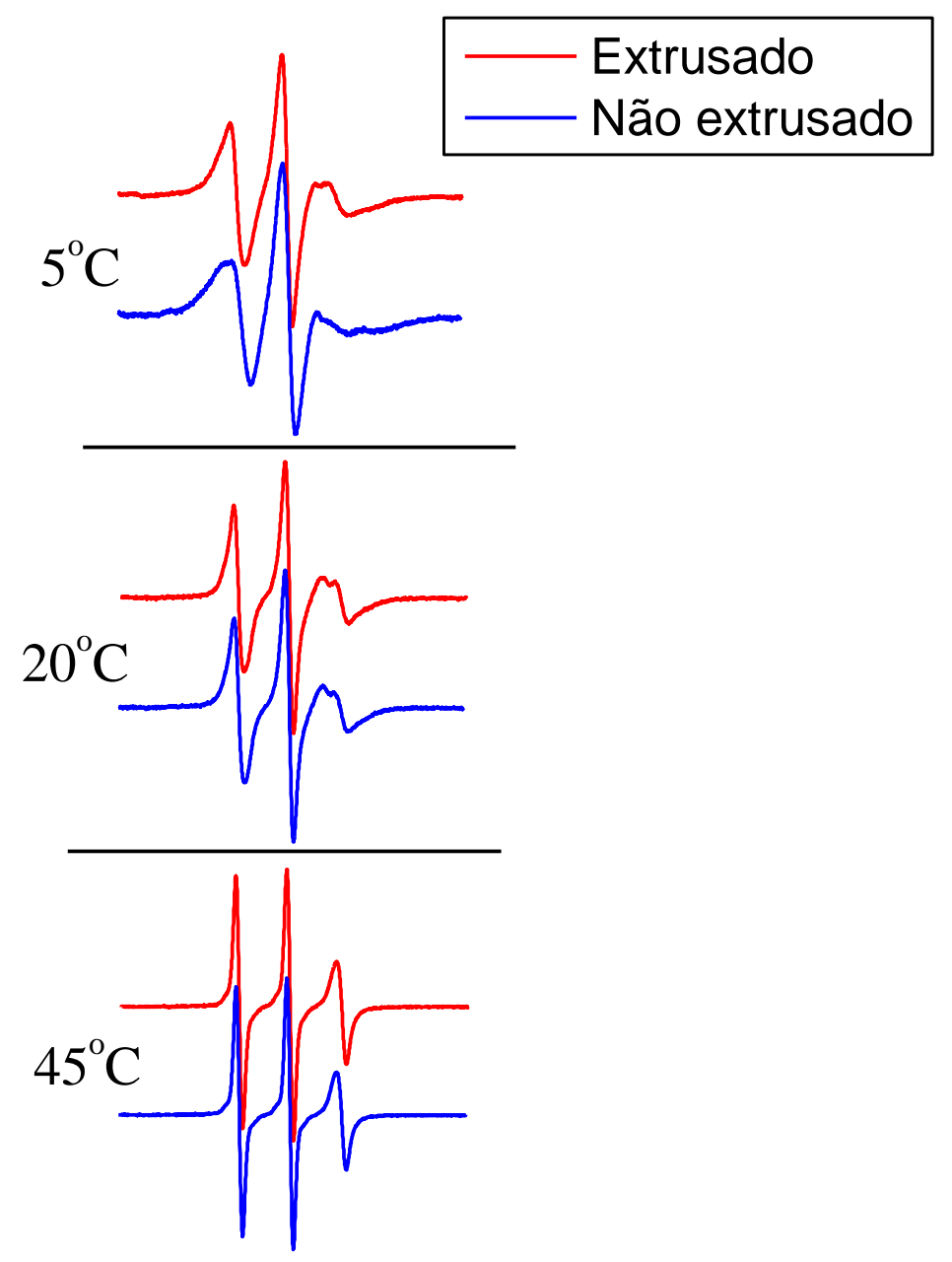

Figura 6.2.3: Espectros de RPE de dispersões de $10 \mathrm{mM}$ de DMPG em água com o marcador 16-PCSL extrusadas (curvas vermelhas) e não extrusadas (curvas azuis) em diferentes temperaturas: na fase gel $\left(5^{\circ} \mathrm{C}\right)$, na região de transição de fase $\left(20^{\circ} \mathrm{C}\right)$ e na fase fluida $\left(45^{\circ} \mathrm{C}\right)$.

De modo a verificar se existe diferença nos resultados mostrados na figura 6.2.1 quando esquentamos e esfriamos a amostra, fizemos medidas de uma dispersão extrusada de $10 \mathrm{mM}$ de DMPG + 0,3 mol\% de 16-PCSL em água aumentando a temperatura até $60^{\circ} \mathrm{C}$ e depois diminuindo a temperatura da amostra até $5^{\circ} \mathrm{C}$ (figura 6.2.4). 

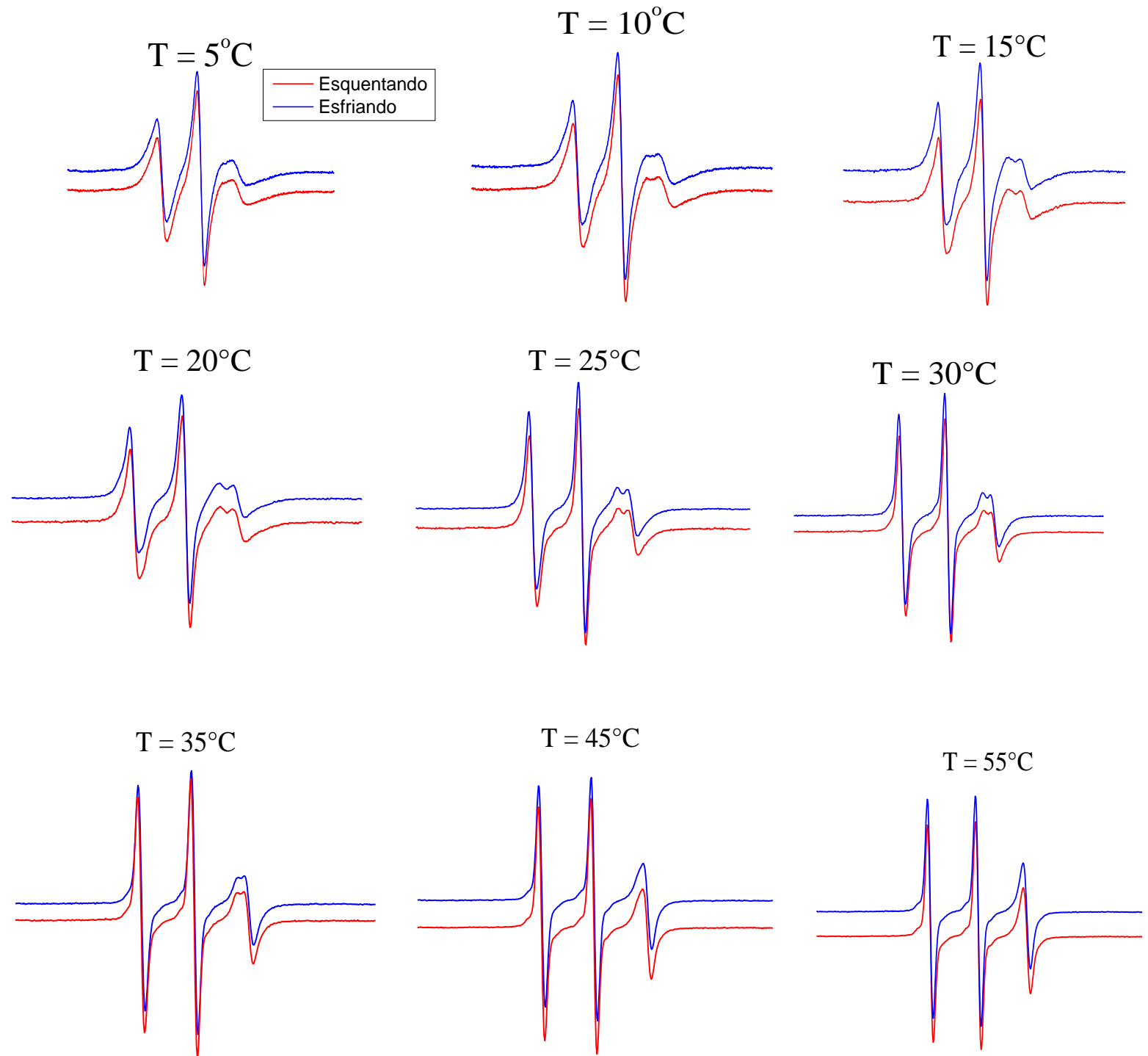

Figura 6.2.4: Medidas de RPE de uma dispersão extrusada de $10 \mathrm{mM}$ de DMPG em água $+0,3$ mol\% de $16-\mathrm{PCSL}$ quando aumentamos a temperatura de 5 a $60^{\circ} \mathrm{C}$ (curvas em vermelho) e quando diminuímos a temperatura de 60 a $5^{\circ} \mathrm{C}$ (curvas em azul).

A partir dos resultados mostrados na figura 6.2.4, vemos que, como observado nas demais técnicas experimentais, os eventos observados por RPE são reversíveis, uma vez que as curvas medidas quando aumentamos e diminuímos a temperatura são muito semelhantes.

Conforme mostrado em materiais e métodos (figura 3.2.13), a partir dos espectros da figura 6.2.1 medimos o parâmetro fenomenológico $h_{+1} / h_{0}$, que é um parâmetro sensível à mudança de empacotamento da bicamada, aproximando-se de 1 
para microambientes fluidos e desorganizados. Na figura 6.2.5 apresentamos os valores de $h_{+1} / h_{0}$ de dispersões extrusadas e não extrusadas de 10 mM de DMPG em água.

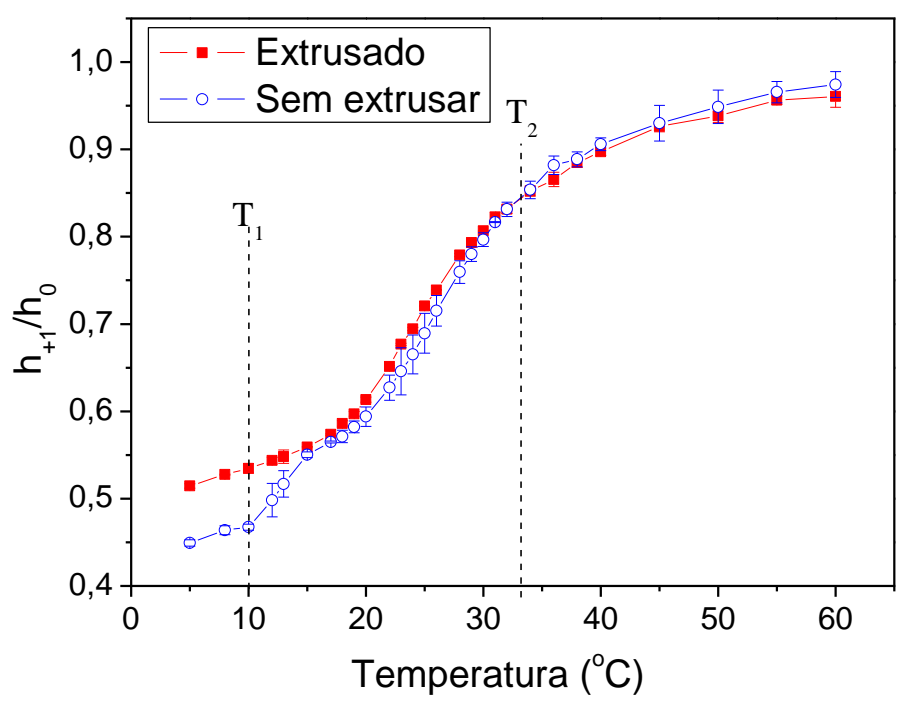

Figura 6.2.5: Razão entre as alturas do pico de campo baixo e central $\left(h_{+1} / h_{0}\right)$ de dispersões extrusadas e não extrusadas de $10 \mathrm{mM}$ de DMPG em água. Cada curva é a média entre as medidas de duas amostras distintas, sendo a incerteza dada pelo desvio padrão dos resultados.

Na figura 6.2.5 vemos que, assim como visto com o parâmetro $A_{\max }$ (figura 6.1.3), dispersões extrusadas de DMPG em água apresentam bicamadas menos rígidas/imóveis na fase gel do que dispersões não extrusadas, fato que deve estar relacionado com a maior curvatura de muitos dos agregados após a extrusão. Também na figura 6.2.5 vemos que o aumento da razão acontece gradualmente e não de forma abrupta, indicando a presença de uma fase intermediária entre a transição da fase gel para a fase fluida, sendo observada uma região de transição de fase com intervalo de temperaturas semelhante ao observado por DSC (figura 4.1.3).

Como mostraremos nas simulações realizadas, os dois sinais de RPE de populações distintas foram observadas até $40^{\circ} \mathrm{C}$ nas dispersões extrusadas de DMPG em água, de modo que os parâmetros espectrais $h_{-1}$ e ao, que são típicos de marcadores com grande mobilidade, só puderam ser medidos para temperaturas a partir de $45^{\circ} \mathrm{C}$. A razão $h_{-1} / h_{0}$ é sensível a pequenas variações no empacotamento da bicamada na fase fluida. 

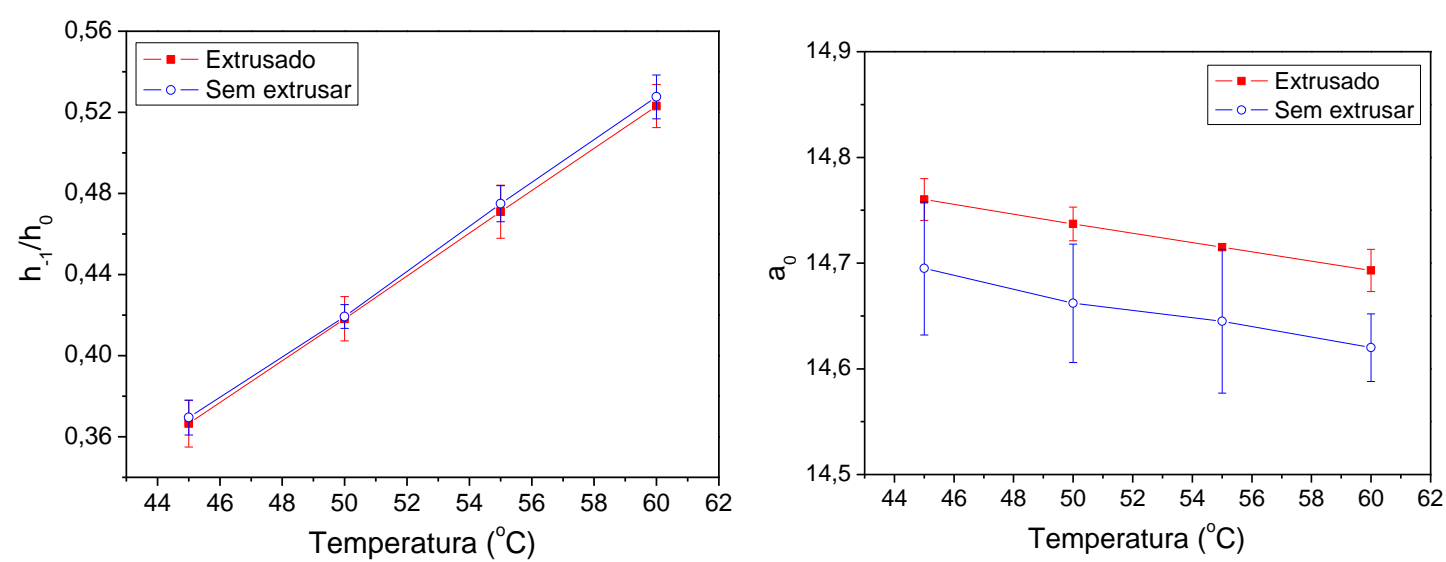

Figura 6.2.6: Razão entre as alturas do pico de campo alto e central $\left(h_{-1} / h_{0}\right)$ e ao de dispersões extrusadas e não extrusadas de $10 \mathrm{mM}$ de DMPG em água para temperaturas a partir de $45^{\circ} \mathrm{C}$. Cada curva é a média entre as medidas de duas amostras distintas, sendo a incerteza dada pelo desvio padrão dos resultados.

$\mathrm{Na}$ figura 6.2.6 vemos que ao apresenta uma variação pequena entre as temperaturas de 45 a $60^{\circ} \mathrm{C}$, mostrando que a distância medida é de fato o desdobramento hiperfino médio e não variações no grau de liberdade do marcador. ao é ligeiramente menor para as amostras não extrusadas, mas apresenta uma grande incerteza se comparada com a incerteza das amostras extrusadas. A razão $h_{-1} / h_{0}$ é muito parecida para dispersões extrusadas e não extrusadas, mostrando que na fase fluida o empacotamento da bicamada é similar para os dois sistemas.

Estes parâmetros obtidos para dispersões extrusadas de 10 mM de DMPG com o marcador 16-PCSL em água serão comparados com os parâmetros obtidos para dispersões extrusadas de 10 mM de DMPG em tampão baixa força iônica (figura 6.2.7). 


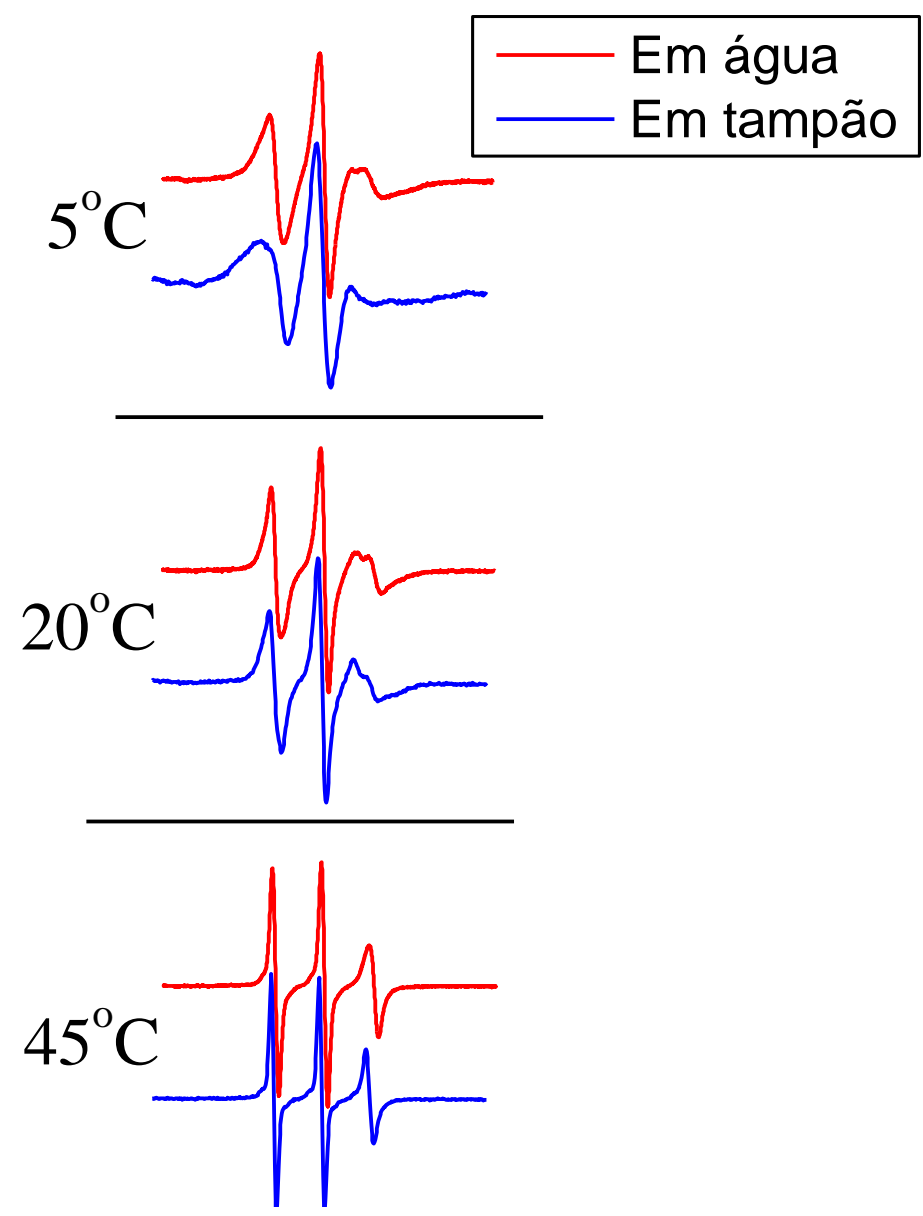

Figura 6.2.7: Espectros de RPE de dispersões extrusadas de $10 \mathrm{mM}$ de DMPG com o marcador 16-PCSL em água (curvas vermelhas) e em tampão (curvas azuis) em diferentes temperaturas: na fase gel $\left(5^{\circ} \mathrm{C}\right)$, na região de transição de fase $\left(20^{\circ} \mathrm{C}\right)$ e na fase fluida $\left(45^{\circ} \mathrm{C}\right)$.

A partir da comparação dos espectros da figura 6.2.7, notamos algumas diferenças nos espectros obtidos em água e em tampão, sendo que para dispersões em água, é possível observar um duplo pico desde $5^{\circ} \mathrm{C}$, sendo que em tampão o sinal é mais rígido/imóvel do que em água. Vemos também que a $45^{\circ} \mathrm{C}$ o espectro em tampão é de um sinal mais fluido/móvel do que para a dispersão em água. 


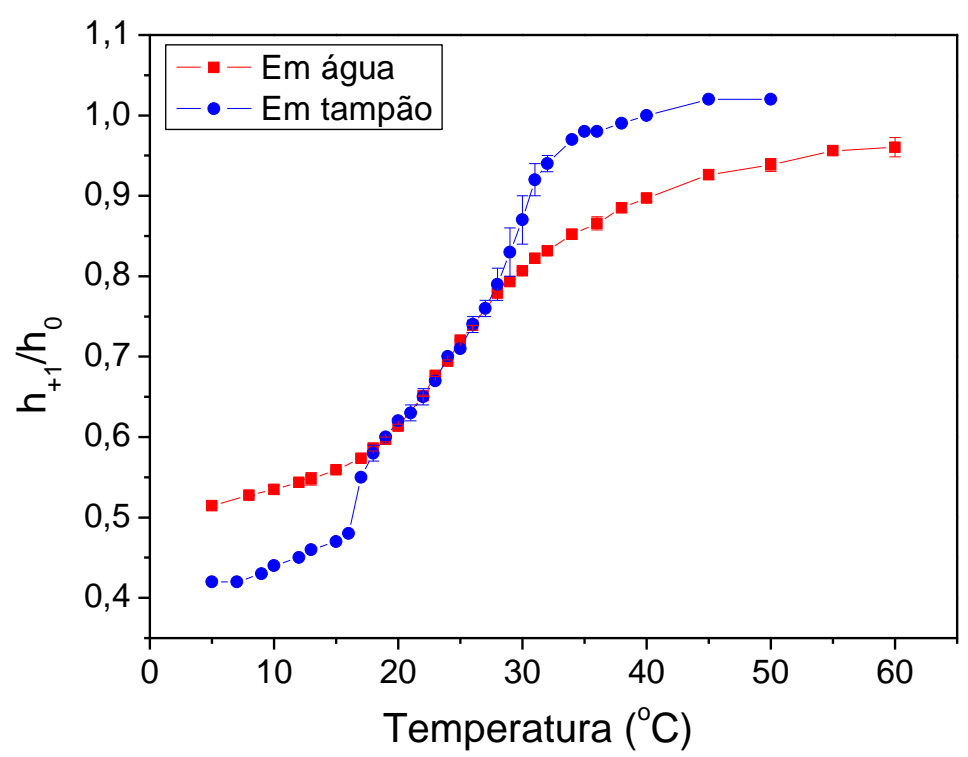

Figura 6.2.8: Razão entre as alturas do pico de campo baixo e central $\left(h_{+1} / h_{0}\right)$ de dispersões extrusadas de $10 \mathrm{mM}$ de DMPG com o marcador 16 - PCSL em água (pontos vermelhos) e em tampão (pontos azuis). Cada curva é a média entre as medidas de duas amostras distintas, sendo a incerteza dada pelo desvio padrão dos resultados.

A partir dos resultados da figura 6.2.8 vemos que, na fase gel, a membrana é mais rígida/imóvel na dispersão de DMPG em tampão do que em água, o que pode estar relacionada com a transição de fase mais cooperativa vista por DSC (figura 5.1.5), sendo que na fase fluida, acima de $30^{\circ} \mathrm{C}$, curiosamente, o sinal de RPE é mais frouxo/móvel para as dispersões em tampão do que em água.
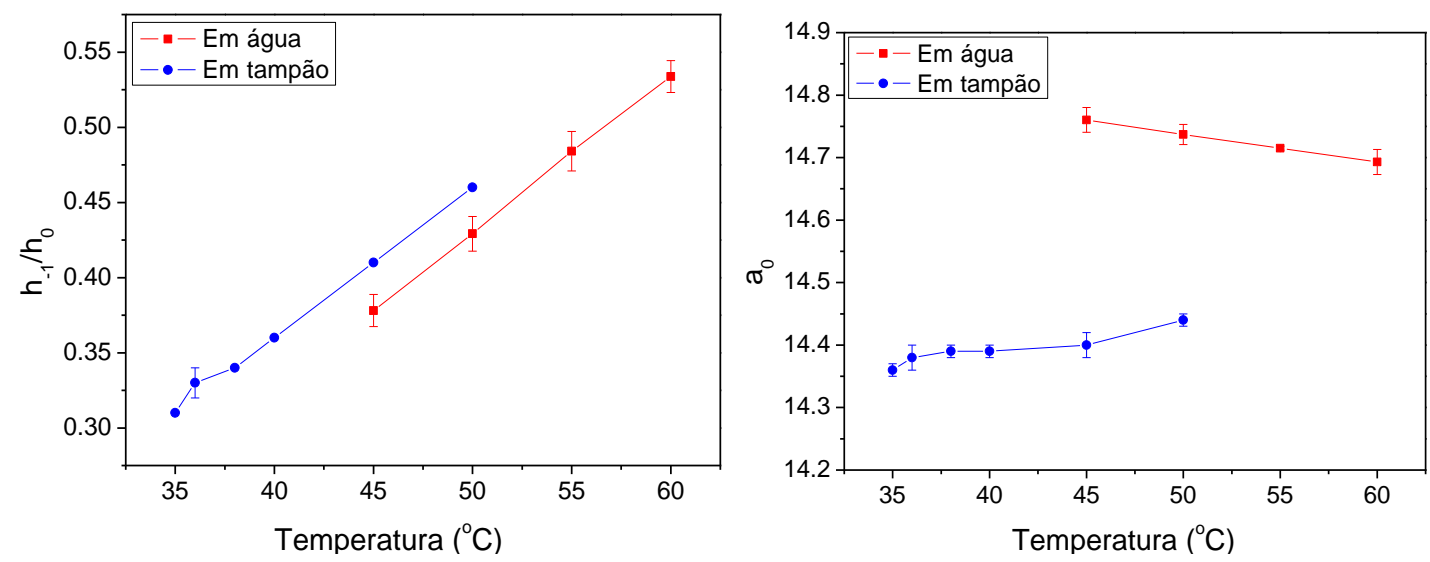

Figura 6.2.9: Razão $h_{-1} / h_{0}$ e $a_{0}$ de dispersões extrusadas de $10 \mathrm{mM}$ de DMPG em água (temperaturas de 45 a $60^{\circ} \mathrm{C}$ ) e em tampão (temperaturas de 35 a $50^{\circ} \mathrm{C}$ ). Cada curva é a média entre as medidas de duas amostras distintas, sendo a incerteza dada pelo desvio padrão dos resultados. 
Nos resultados da figura 6.2.9, é interessante observar que enquanto a razão $h$ 1/ $/ h_{0}$ é menor para as dispersões de DMPG em água do que em tampão, enquanto a polaridade é consideravelmente maior para as dispersões em água. Concordando com os dados de $h_{+1} / h_{0}$ (figura 6.2.8), esses dados indicam bicamadas mais empacotadas nas dispersões em água, na fase fluida da bicamada. Entretanto, $a_{0}$ é significativamente maior em dispersões em água, $\sim 14,75 \mathrm{G}$, comparado com $\sim 14,40 \mathrm{G}$ para as dispersões de DMPG em tampão a baixa força iônica. Importante lembrar que foi medido o valor de $\sim 14,35$ G (Duarte et al., 2008) para dispersões não extrusadas de DMPG em tampão HEPES a alta força iônica (100 mM de $\mathrm{NaCl}$ ), sendo que mudanças no valor de a estão relacionadas com posições diferentes do marcador na bicamada lipídica ou diferentes quantidades de moléculas de água no interior da bicamada. Quanto mais moléculas de água formam pontes de hidrogênio com o radical nitróxido do marcador, maior é o valor de ao (Riske, 2001).

A partir destes resultados, pode-se especular que, nas dispersões de DMPG em água, mais moléculas de água penetram a bicamada lipídica, sendo que este fato leva a um aumento na ordem ou diminuição da mobilidade das cadeias carbônicas no interior da bicamada, ao mesmo tempo em que aumenta a polaridade na região central da bicamada (Fernandez \& Lamy-Freund, 2000). Este fato poderia explicar os resultados da baixa turbidez medida para DMPG em água (figura 5.5.2), sendo que a maior quantidade de água na bicamada causa a perda do contraste óptico que permanece até altas temperaturas. 


\subsection{Simulações}

Realizamos simulações das curvas de RPE de dispersões extrusadas de $10 \mathrm{mM}$ de DMPG em água + 0,3 mol\% do marcador 16-PCSL, em algumas temperaturas, utilizando o software Multi-Component EPR Fitting, que usa a equação estocástica de Louville (Freed, 1976) para simular os espectros de RPE.

Após muitas tentativas de simular a curva de RPE obtida para $5^{\circ} \mathrm{C}$ com apenas um sinal de RPE, o melhor resultado que conseguimos é mostrado a seguir:

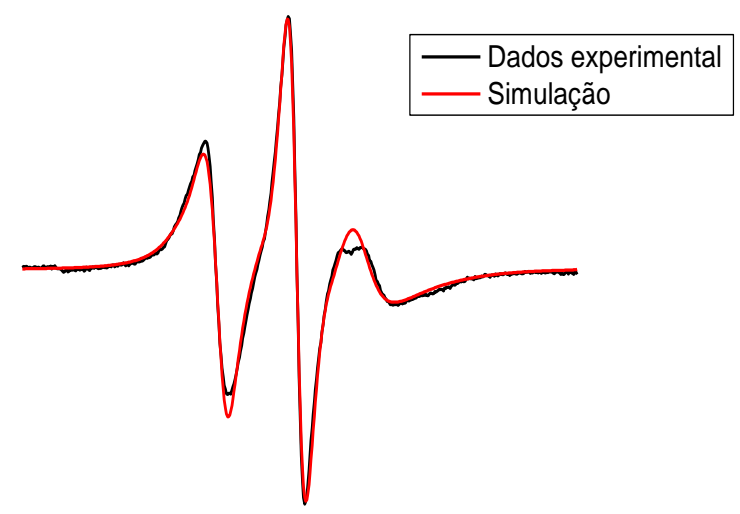

Figura 6.3.1: Dado experimental e simulação da curva de RPE da dispersão extrusada de $10 \mathrm{mM}$ de DMPG em água a $5^{\circ} \mathrm{C}$, considerando-se um único sinal de RPE.

Vemos pela figura 6.3.1 que a simulação não descreve bem o dado experimental, principalmente o ultimo pico do espectro, onde parece haver dois picos pequenos. Desta forma, tentamos simular a mesma curva usando dois sinais de RPE de populações distintas que se somam e o resultado é mostrado na figura 6.3.2. 


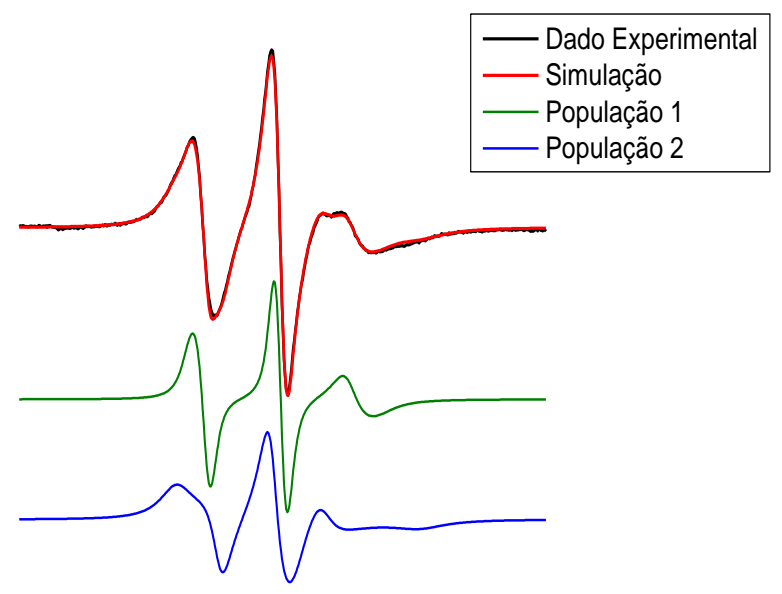

Figura 6.3.2: Dado experimental e simulação dada pela soma dos sinais da população 1 e 2 da curva de RPE da dispersão extrusada de $10 \mathrm{mM}$ de DMPG em água a $5^{\circ} \mathrm{C}$, considerando-se dois sinais de RPE, sendo a população 1 mais frouxa e a população 2 mais rígida.

Vemos que a simulação da figura 6.3.2 descreve bem melhor a curva experimental do que a da figura 6.3.1. Para obter este resultado foi necessário considerarmos a presença de uma população mais rígida (população 2) e uma população mais fluida (população 1), sendo a curva medida dada pela soma destes dois sinais, que devem coexistir na dispersão. Este resultado é bastante curioso, pois, para o DMPG 10 mM em tampão HEPES foi observado a coexistência de dois sinais distintos de RPE apenas para as temperaturas na região de transição de fase (Riske et al., 2003 e medidas e simulações recentes feitas pelo Dr. Evando Duarte).

Continuando com a simulação para as demais temperaturas (de 5 a $60^{\circ} \mathrm{C}$ ), sempre fazendo tentativas de ajustar os dados experimentais usando apenas um sinal de RPE, notamos a necessidade de usarmos a soma de dois sinais de RPE para descrever os dados experimentais nas temperaturas entre $5^{\circ} \mathrm{C}$ (fase gel) até $45^{\circ} \mathrm{C}$ (fase fluída). Nas simulações em diferentes temperaturas (de 5 a $45^{\circ} \mathrm{C}$ ) manteve-se fixo $\mathrm{a}_{0}=14,73 \mathrm{G}$ para o sinal fluido e $a_{0}=14,06 \mathrm{G}$ para o sinal rígido, sendo que o tensor $\mathbf{g}$ foi mantido fixo em todas as temperaturas. Para as temperaturas de 50 a $60^{\circ} \mathrm{C}$ foi possível obter um bom ajuste considerando-se apenas a população mais móvel na simulação, mantendo-se os parâmetros do sinal fluido. 


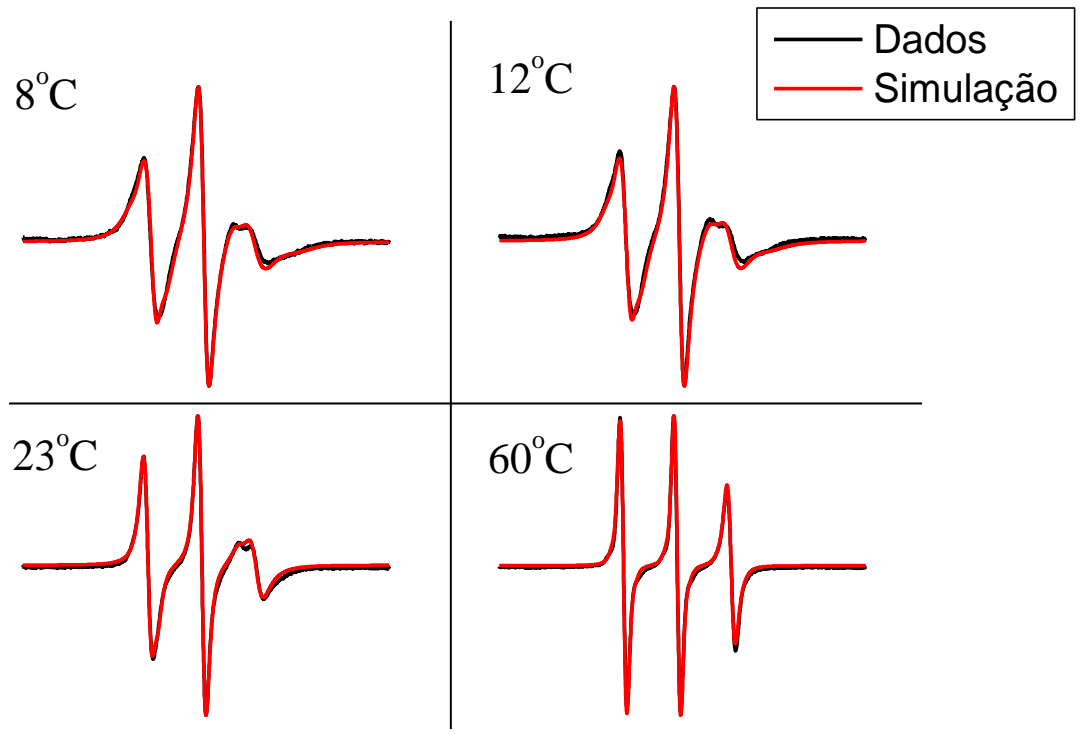

Figura 6.3.3: Dados experimentais e ajustes obtidos pelas simulações teóricas de espectros de RPE de dispersões extrusadas de $10 \mathrm{mM}$ de DMPG + 0,3 mol\% de 16-PCSL em algumas temperaturas.

Conforme pode ser visto na figura 6.3.3, foi possível obter bons ajustes para os dados experimentais simulando-se os espectros com duas populações (curvas a 5, 12 e $23^{\circ} \mathrm{C}$ apresentadas) e com uma população para $60^{\circ} \mathrm{C}$. Na figura 6.3 .3 apresentamos alguns parâmetros que foram obtidos a partir das simulações dos espectros de RPE, sendo que o tempo de correlação rotacional $(\tau)$ está relacionado com a largura de linhas do espectro, o parâmetro de ordem $\mathrm{S}_{0}$, está relacionado à ordem da bicamada e a porcentagem das populações indica a contribuição das populações mais e menos rígidas no espectro simulado. 


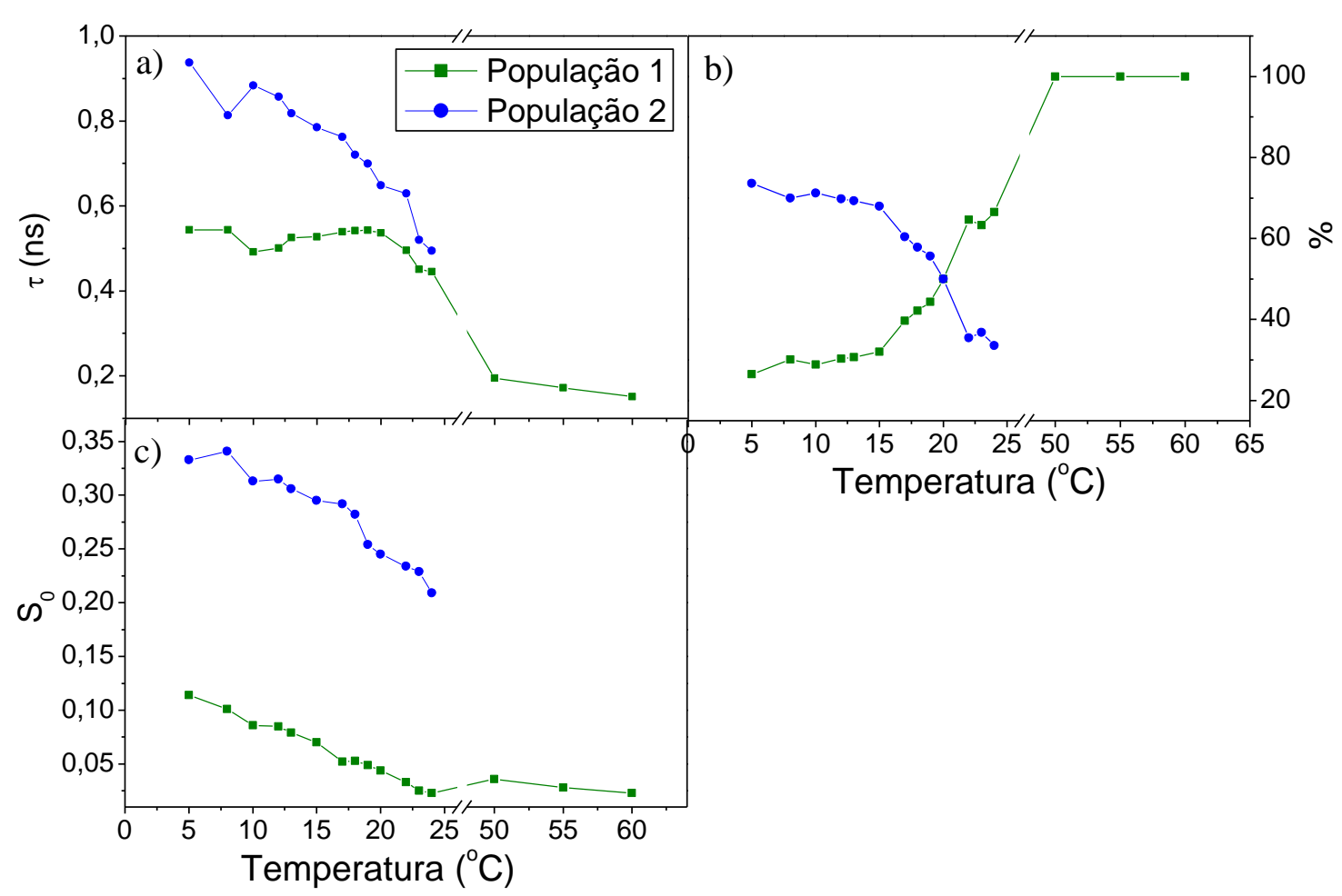

Figura 6.3.4: Parâmetros obtidos das simulações dos espectros de RPE, sendo apresentados os resultados de 5 a $24^{\circ} \mathrm{C}$ e de 50 a $60^{\circ} \mathrm{C}$. A população 1 ( $\square$ ) representa o sinal mais frouxo e a população 2 ( ) o sinal mais rígido. Em a) tempo de correlação rotacional, $\tau$, em b) porcentagem de cada população e em c) parâmetro de ordem, $\mathrm{S}_{0}$.

Na figura 6.3.4 são apresentados alguns dos parâmetros que foram obtidos a partir das simulações de RPE e apenas em algumas temperaturas (de 5 a $24^{\circ} \mathrm{C}$ e de 50 a $60^{\circ} \mathrm{C}$ ), sendo que as demais temperaturas serão melhor analisadas e simuladas em um futuro próximo, bem como os espectros obtidos para as dispersões de DMPG em tampão a baixa força iônica.

A partir dos parâmetros da figura 6.3.4 vemos que as simulações se mostraram coerentes, sendo que a população mais frouxa (população 1) apresenta menor parâmetro de ordem $\left(\mathrm{S}_{0}\right)$, menor $\tau$ e maior polaridade $(14,73 \mathrm{G}$, como mencionado anteriormente). Sendo que, com o aumento da temperatura, há a diminuição de $S_{0}$, de $\tau$ e da porcentagem da população mais rígida. Vemos que, em $5^{\circ} \mathrm{C}$, o espectro já é composto por $25 \%$ da população mais frouxa, sendo que esta proporção aumenta a partir de $15^{\circ} \mathrm{C}$, de acordo com o início das mudanças observadas pelas outras técnicas experimentais, até atingir $100 \%$ de população fluida em $50^{\circ} \mathrm{C}$. É interessante notar que a polaridade da população fluida obtida a partir das simulações, é muito próxima da polaridade medida a partir dos espectros (figura 6.2.9). 
A partir dos resultados de RPE foi possível observar que os espectros obtidos nas fases gel e fluida são muito semelhantes ao observado para amostras de DMPG e DMPC com os marcadores 5- e 16 - PCSL em Barroso et al., 2012, sendo que a $5^{\circ} \mathrm{C}$ há a clara presença de uma região mais densa e/ou organizada, que não caracteriza micelas, e os espectros na fase fluida apresentam alto parâmetro de ordem, típico de bicamadas lipídicas. De fato, comparando estes resultados com os espectros obtidos para micelas de $\mathrm{C}_{18} \mathrm{TAB}$ (octadecil trimetil amônio brometo) (Benatti et al, 2001) monitoradas nessas mesmas regiões, vemos que são bem diferentes, sendo observado uma ordem maior nos espectros de DMPG.

Além disto, foi observado que as bicamadas de DMPG em água são mais frouxas que em tampão na fase gel, mas mais empacotadas na fase fluida, sendo que a polaridade medida é maior nas dispersões em água. Desta forma, supomos que as vesículas em água são mais hidratadas, com maior quantidade de água em sua bicamada, sendo que a água é responsável por diminuir a mobilidade das caudas hidrofóbicas na região central da bicamada, e também, diminuir a turbidez da amostra (figura 4.5.1).

As simulações mostraram a presença de sinais de duas populações distintas nos espectros de RPE de dispersões extrusadas em água de 5 a $45^{\circ} \mathrm{C}$, sendo uma população menos móvel e mais ordenada e outra população mais móvel e desordenada, sendo que a porcentagem da população mais móvel aumenta com o aumento da temperatura e chega a $100 \%$ em $50^{\circ} \mathrm{C}$. Apesar de não ser possível determinar a origem dos sinais distintos, podemos supor que eles estejam relacionados com vesículas de diferentes tamanhos, uma vez que, como discutido anteriormente, existe a desconfiança que se formem vesículas pequenas de DMPG em água, de modo que a extrusão exclui apenas algumas vesículas maiores, podendo haver variações nos tamanhos das vesículas obtidas, mesmo após a extrusão por filtros de $100 \mathrm{~nm}$, uma vez que as medidas de DLS indicaram a presença de agregados bem menores que $100 \mathrm{~nm}$. Outra hipótese é de que hajam flutuações e deformações nas bicamadas de DMPG, sendo que essas diferenças na curvatura podem originar sinais de populações mais e menos rígidas. 


\section{Capítulo 7 - Resultados e discussões:}

\section{Espalhamento de raios-X a alto}

\section{(WAXS) e a baixo (SAXS) ângulo}

Neste capítulo, apresentamos os resultados e discussões de medidas de SAXS e WAXS de dispersões extrusadas de DMPG em meios de diferente força iônica: água, tampão HEPES a baixa (HEPES $10 \mathrm{mM}+\mathrm{NaCl} 2 \mathrm{mM}$ ) e alta (HEPES $10 \mathrm{mM}+\mathrm{NaCl} 250 \mathrm{mM}$ ) força iônica em diferentes temperaturas. 


\subsection{Espalhamento de raios-X a alto ângulo (WAXS)}

A partir da posição e da largura dos picos de WAXS é possível obter informações sobre a mobilidade e empacotamento das cadeias hidrocarbônicas no interior das bicamadas, sendo que um pico mais estreito se relaciona com cadeias ordenadas, típicas da fase gel e um pico mais largo e em posições menores de q está relacionado com a fase fluída da bicamada lipídica (Luzzati, 1968).

Realizamos medidas de WAXS de dispersões extrusadas de 50 mM de DMPG em água e em tampão a baixa força iônica, sendo que os picos foram ajustados por gaussianas utilizando-se o software Origin (figura 7.1.1).
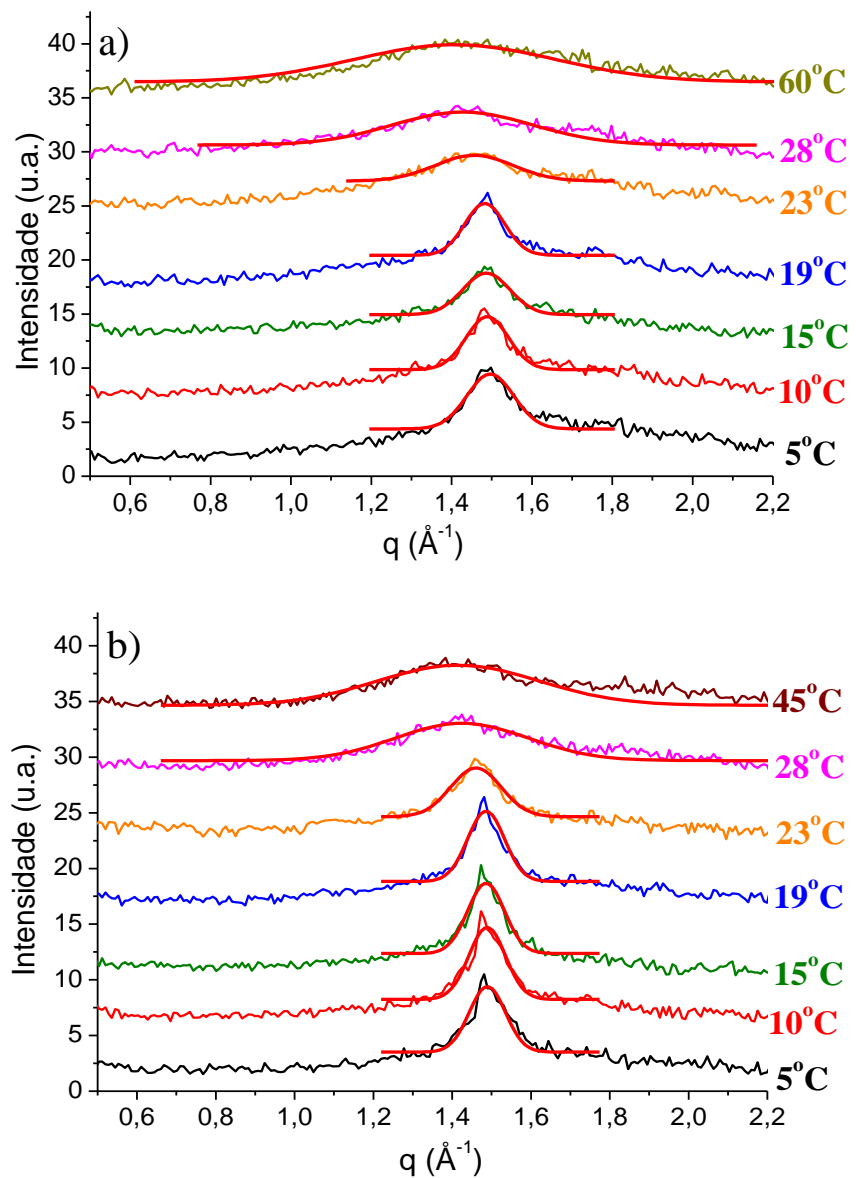

Figura 7.1.1: Picos de WAXS em $q \sim 1,5 \AA^{-1}$ e ajustes por gaussianas de dispersões extrusadas de $50 \mathrm{mM}$ de DMPG em a) água e em b) tampão a baixa força iônica. As curvas a diferentes temperaturas foram deslocadas verticalmente para uma melhor visualização dos picos.

Na figura 7.1.1, apesar do ruído dos dados experimentais, é possível observar o alargamento e deslocamento dos picos de WAXS para valores menores de q com o 
aumento da temperatura, mostrando a mudança de uma fase gel, mais ordenada, para uma fase fluida da bicamada lipídica. Comparamos os valores das posições dos picos ajustados $\left(q_{c}\right)$ e de suas larguras em função da temperatura para as dispersões em água e em tampão a baixa força iônica (figura 7.1.2).
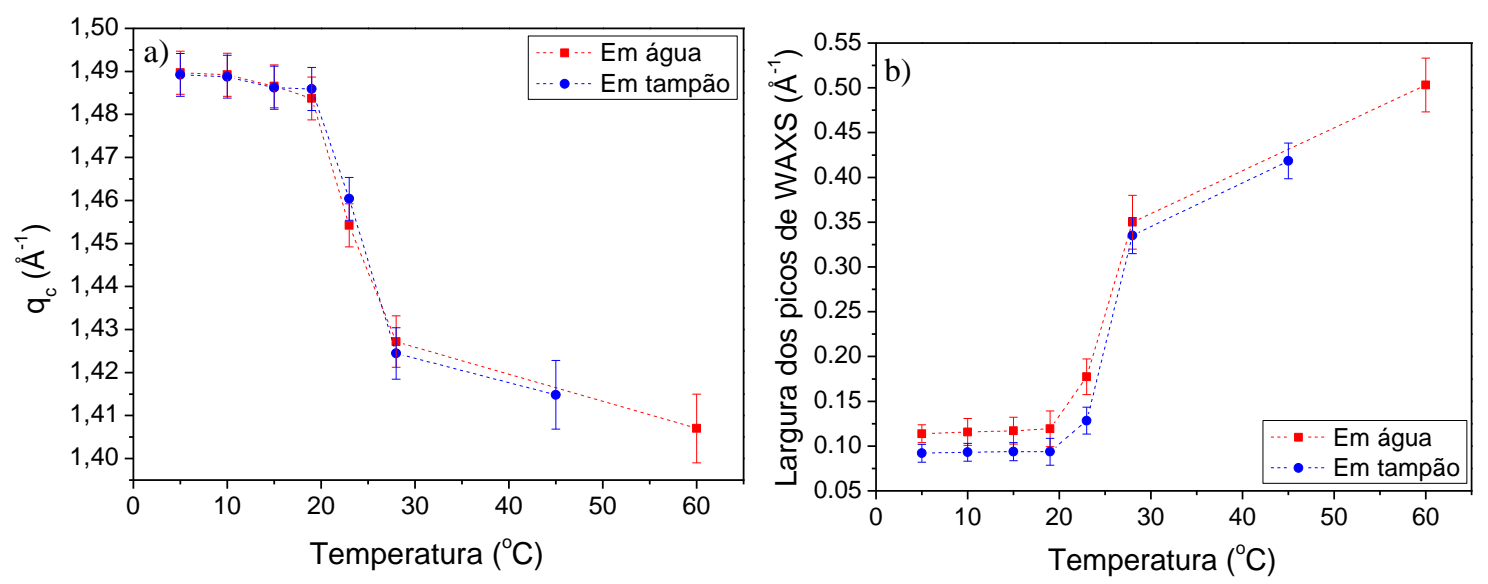

Figura 7.1.2: a) Posição e b) largura dos picos de WAXS para dispersões extrusadas de 50 mM de DMPG em água em tampão a baixa força iônica.

A partir dos valores dos parâmetros mostrados na figura 7.1.2, vemos que, apesar das dispersões de DMPG em água e em tampão a baixa força iônica apresentarem perfis de DSC diferentes (figura 5.8.4), as mudanças nos picos de WAXS são muito semelhantes para os dois sistemas. Os picos são estreitos até $19^{\circ} \mathrm{C}$ e se encontram centrados em $q \sim 1,49 \AA^{-1}$, acima desta temperatura é observado o alargamento dos picos e seu deslocamento para valores menores de $q$, sendo que na fase fluída o centro dos picos está em q $\sim 1,41 \AA^{-1}$. Estes valores estão de acordo com os esperados para as fases gel e fluida de bicamadas, respectivamente (Luzatti, 1968; Riske et al., 2004). Diferente do observado por RPE, pelas medidas de WAXS não foi possível observar diferenças no empacotamento da bicamada para dispersões de DMPG em água e em tampão e nem detectar o início da transição de fase em temperaturas mais baixas para a dispersão em água, como foi visto por DSC (figura 5.8.4). Estes resultados indicam que até $19^{\circ} \mathrm{C}$ as bicamadas de DMPG em água ainda estão na fase gel.

A transição de uma fase mais ordenada e rígida para uma fase mais fluida e frouxa foi observada para os dois sistemas. Portanto, semelhante ao observado com RPE, os dados de WAXS confirmam a presença de bicamadas de DMPG tanto em HEPES a baixa força iônica como em água. 
De modo a observar melhor os picos de WAXS na "região de transição de fase", realizamos medidas de WAXS em mais temperaturas com uma nova dispersão extrusada de 50 mM de DMPG em tampão a baixa força iônica e os resultados são mostrados na figura 7.1.3.

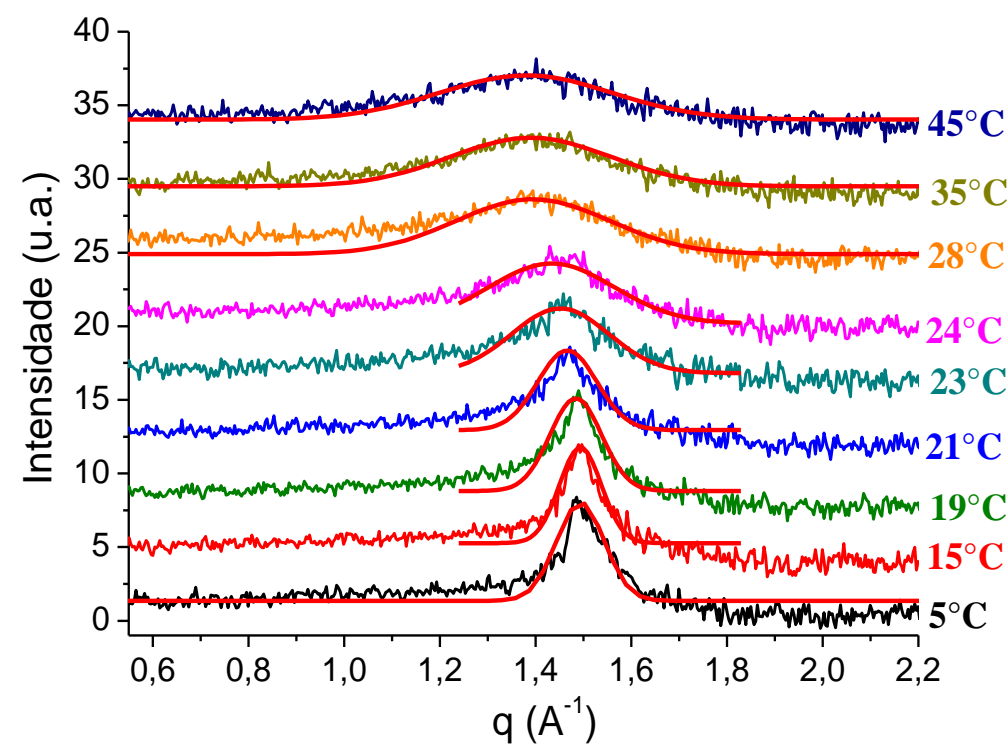

Figura 7.1.3: Picos de WAXS ajustados por gaussianas para uma dispersão extrusada de 50 mM de DMPG em tampão a baixa força iônica. As curvas a diferentes temperaturas foram deslocadas verticalmente para uma melhor visualização dos picos.

Da mesma forma que foi feito anteriormente, graficamos os valores das posições e larguras dos picos gaussianos que foram ajustados na figura 7.1.3 e os resultados são mostrados na figura 7.1.4.
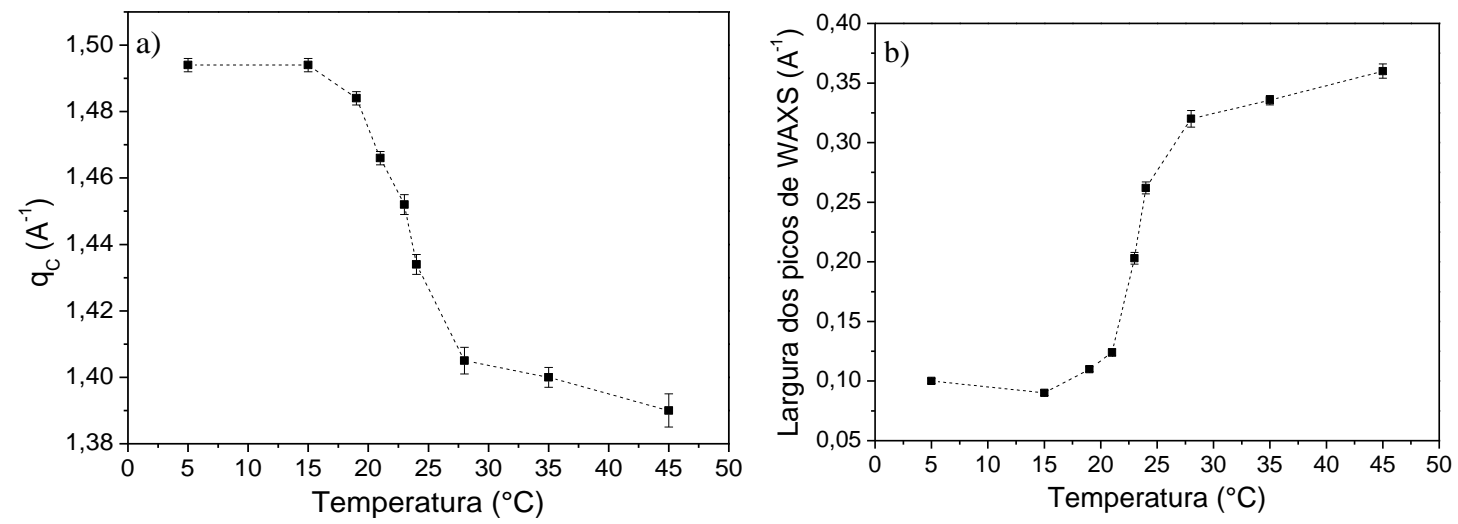

Figura 7.1.4: a) Posição e b) largura dos picos de WAXS para uma dispersão extrusada de 50 mM de DMPG em tampão a baixa força iônica. 
A partir dos resultados da figura 7.1.4 é possível observar com mais clareza uma "região de transição de fase" sendo que as mudanças no empacotamento das cadeias hidrocarbônicas ocorrem gradualmente entre 19 e $28^{\circ} \mathrm{C}$, temperaturas muito próximas às de $T_{m}{ }^{\text {on }}$ e $T_{m}{ }^{\text {off }}$ vistas por DSC (figura 5.8.4).

\subsection{Espalhamento de raios-X a baixo ângulo (SAXS)}

Resultados de SAXS de dispersões não extrusadas de DMPG em tampão HEPES a baixa força iônica foram obtidos anteriormente em alta concentração lipídica (50 mM) (Fernandez et al., 2008, Riske et al., 2001, 2004), uma vez que, na época em que estas medidas foram realizadas, não era possível realizar medidas com concentrações lipídicas menores, por limitações do aparato experimental. Desta forma, realizamos novos experimentos de SAXS, com diferentes concentrações lipídicas de DMPG, antes e depois da extrusão, em tampão HEPES a baixa força iônica e em água.

Nas figuras 7.2.1 e 7.2.2 são mostrados resultados de SAXS obtidos no Laboratório Nacional de Luz Síncroton para dispersões em água de 1, 10 e 50 mM de DMPG, antes da extrusão, e para 10 mM de DMPG depois da extrusão, nas temperaturas de 5, 10, 15, $19,23,28,45$ e $60^{\circ} \mathrm{C}$ (figura 7.2.1) e para dispersões em tampão a baixa força iônica de 1, 10, 20 e 50 mM de DMPG, antes e depois da extrusão nas temperaturas de 5, 10, 15, 19, 23, 28 e $45^{\circ} \mathrm{C}$ (figura 7.2.2).

Um importante resultado de nossas medidas foi a observação do pico de Bragg na região de muito baixo q em todas as temperaturas medidas $\left(\right.$ de 5 a $45^{\circ} \mathrm{C}$ ) para dispersões extrusadas de 50 mM de DMPG em tampão HEPES a baixa força iônica. Em publicações anteriores (Riske et al., 2001, 2004), para dispersões não extrusadas, este pico foi observado apenas nas temperaturas da "região de transição de fase" e foi relacionado à uma distância de correlação mesoscópica de $370 \AA$ A que foi interpretada como a presença de poros correlacionados na bicamada. Portanto, quando temos uma dispersão mais homogênea com relação ao tamanho das vesículas lipídicas, esse pico de correlação de SAXS é observado em todas as temperaturas, e não somente na região de transição de fase. Sendo uma característica da dispersão de DMPG em baixa força iônica, em todas as temperaturas. 
Para as medidas de SAXS de dispersões de DMPG em água, o pico de Bragg também foi observado em todas as temperaturas (de 5 a $60^{\circ} \mathrm{C}$ ) para dispersões não extrusadas de $50 \mathrm{mM}$ de DMPG e a partir de $15^{\circ} \mathrm{C}$ para dispersões extrusadas de $10 \mathrm{mM}$ de DMPG, sendo que os picos são muito mais pronunciados do que os picos observados para as dispersões em tampão a baixa força iônica. Estes resultados serão discutidos a seguir.

Para as discussões dos resultados de SAXS, dividiremos esta seção em duas partes: espalhamento na região de baixo q (entre 0,4 e $5 \mathrm{~nm}^{-1}$ ), de onde obtivemos informações quanto à bicamada lipídica das vesículas de DMPG, e espalhamento na região de muito baixo q (abaixo de $0,4 \mathrm{~nm}^{-1}$ ), onde são observados os picos de Bragg. 

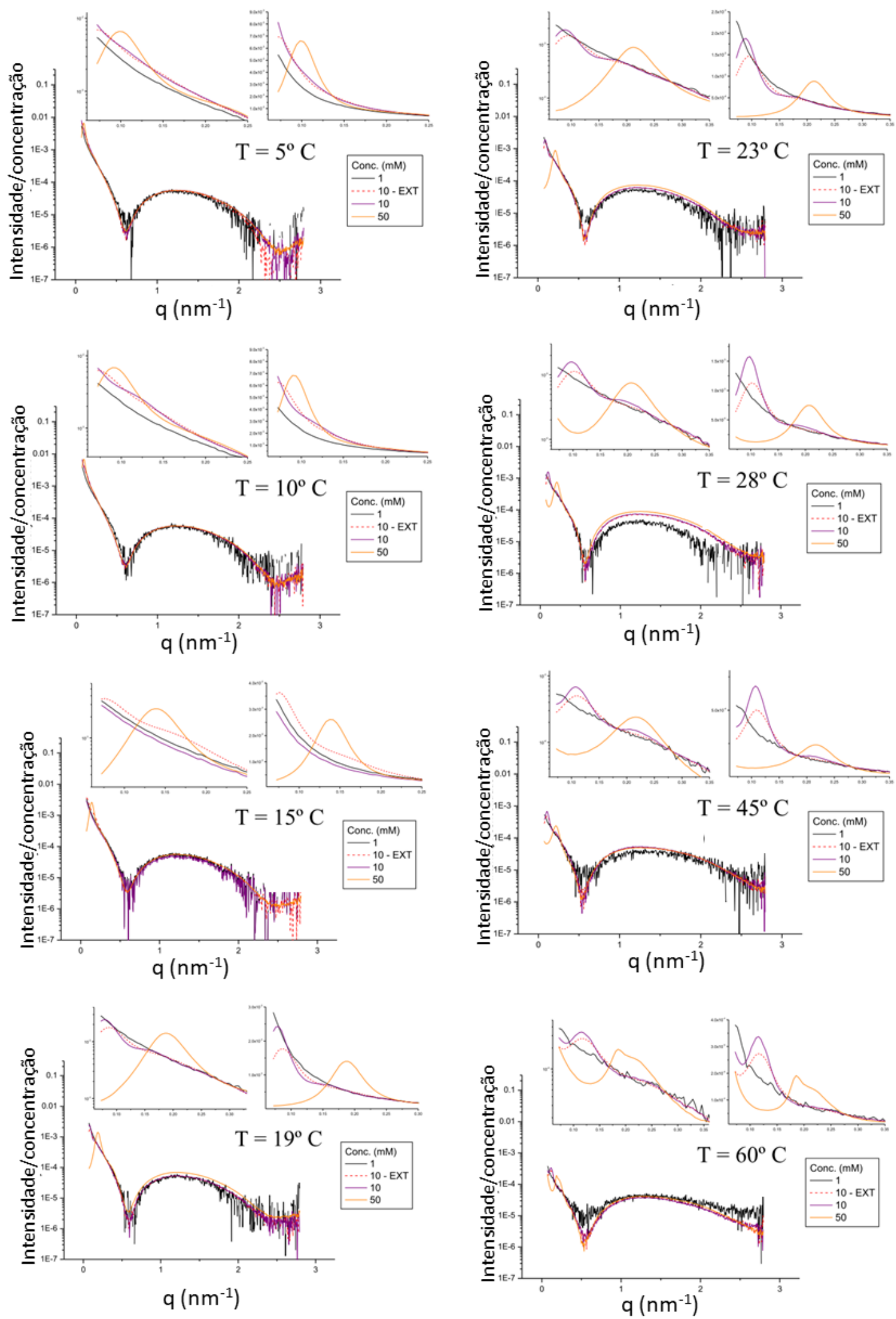

Figura 7.2.1: Curvas de SAXS normalizadas pela concentração lipídica para dispersões de DMPG em água nas concentrações de 1, 10 e 50 mM, antes (curvas continuas) e depois (curvas tracejadas) da extrusão (apenas a dispersão de $10 \mathrm{mM}$ foi extrusada). Os gráficos em destaque representam a região de muito baixo q, em escala linear e logarítmica. 

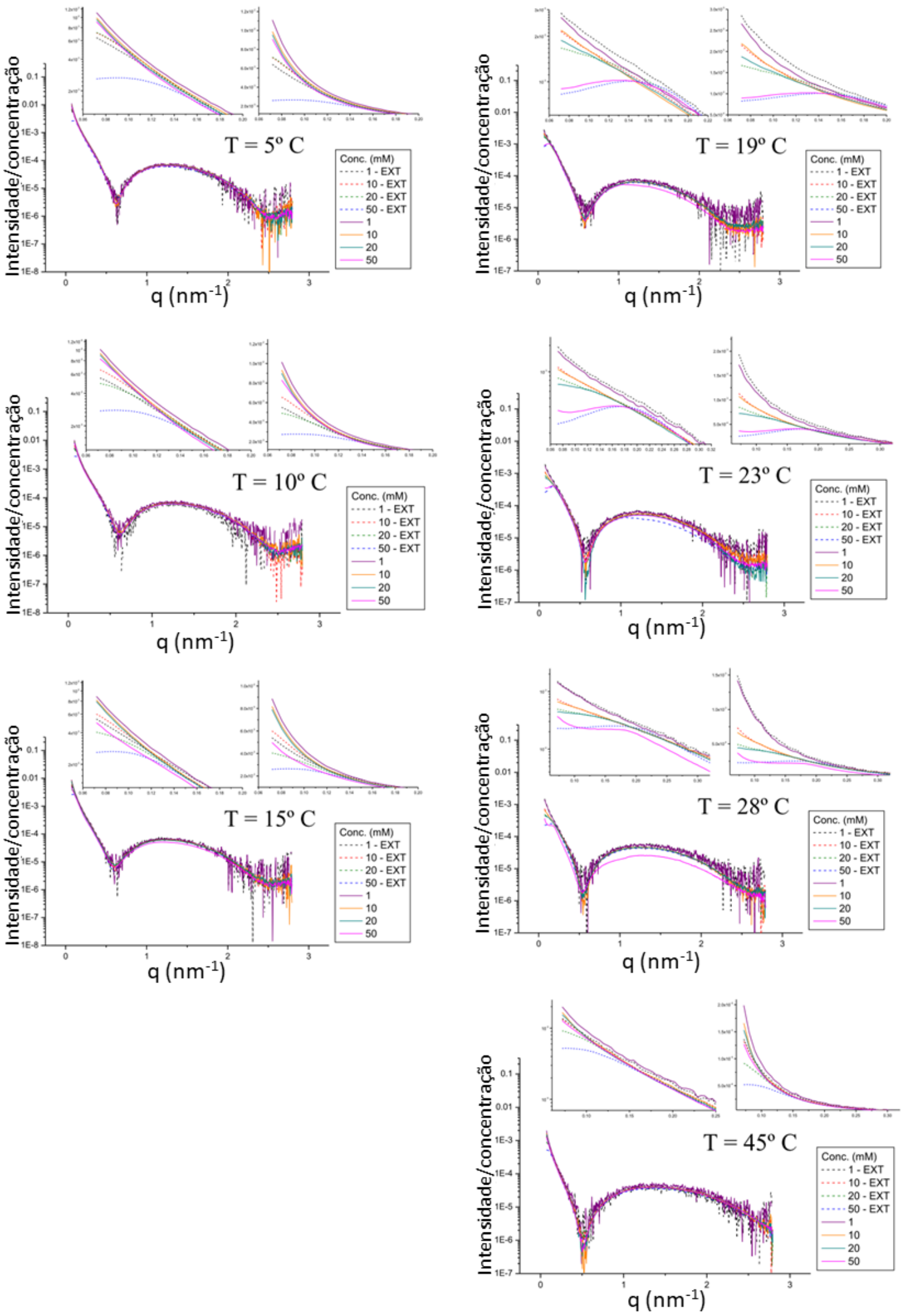

Figura 7.2.2: Curvas de SAXS normalizadas pela concentração lipídica para dispersões de DMPG em tampão HEPES, nas concentrações de 1, 10, 20 e 50 mM, antes (curvas continuas) e depois (curvas tracejadas) da extrusão. Os gráficos em destaque representam a região de muito baixo q, em escala linear e logarítmica. 


\subsubsection{Espalhamento na região de baixo q}

Nesta região de espalhamento é possível obter informações referentes à bicamada lipídica. Os dados foram analisados a partir de ajustes realizados com o software GAP, considerando apenas o fator de forma das partículas espalhadoras, de modo a obter o perfil de densidade eletrônica (equação 2.4.4) e então calcular as espessuras das bicamadas (equação 2.4.5) das vesículas de DMPG em diferentes concentrações lipídicas, temperaturas e força iônica.
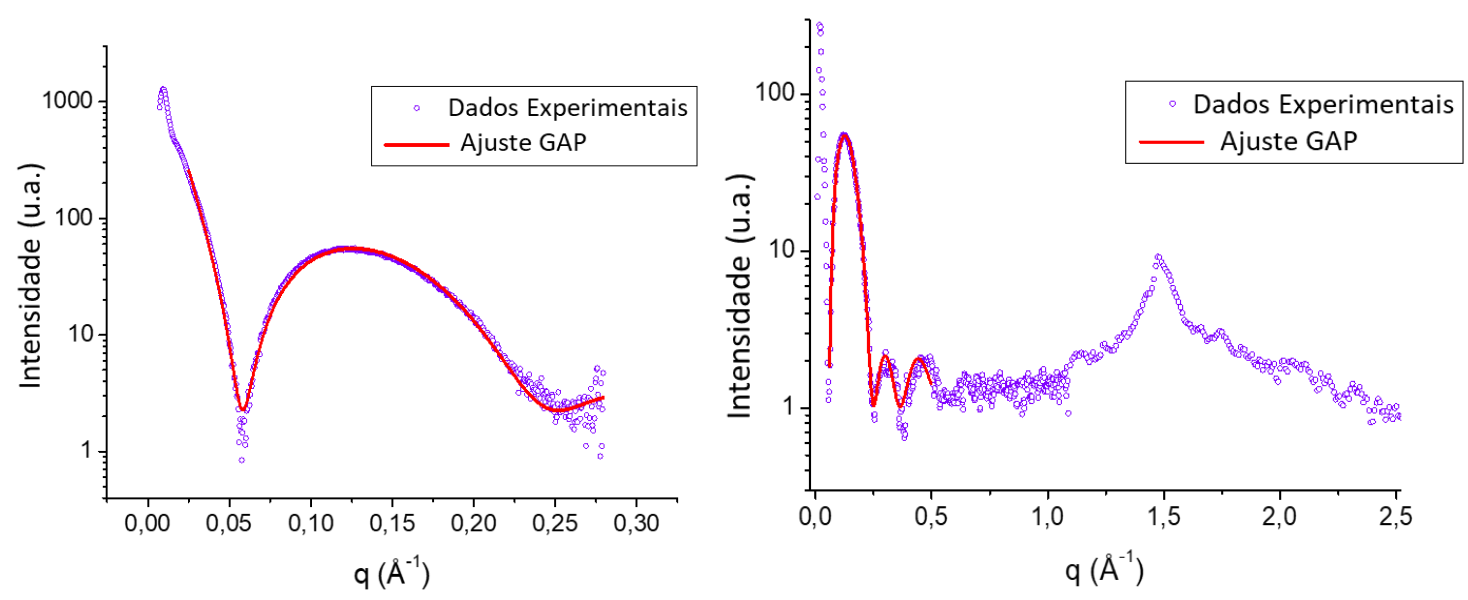

Figura 7.2.3: Exemplos de ajustes obtidos com o programa GAP na região de baixo ângulo de uma curva de SAXS (gráfico da esquerda) de uma dispersão de $10 \mathrm{mM}$ de DMPG em água, medida no LNLS, e de uma curva de SWAXS (gráfico da direita) de uma dispersão de 50 mM de DMPG em tampão a baixa força iônica, medida no aparelho SAXSpace, ambas a $23^{\circ} \mathrm{C}$.

Como mostrado na figura 7.2.3, foi possível obter bons ajustes para a região de q entre 0,04 e $0,5 \AA^{-1}$ considerando-se o fator de forma de bicamadas únicas, sendo que o mesmo foi observado para todas as curvas das figuras 7.2.2 e 7.2.1 e para as medidas realizadas no SAXSpace, em Graz.

Na figura 7.2.4 apresentamos o perfil de densidade eletrônica obtido para dispersão extrusada de $10 \mathrm{mM}$ de DMPG em água, sendo que os perfis obtidos nas diferentes concentrações lipídicas, antes e depois da extrusão foram muito semelhantes. 


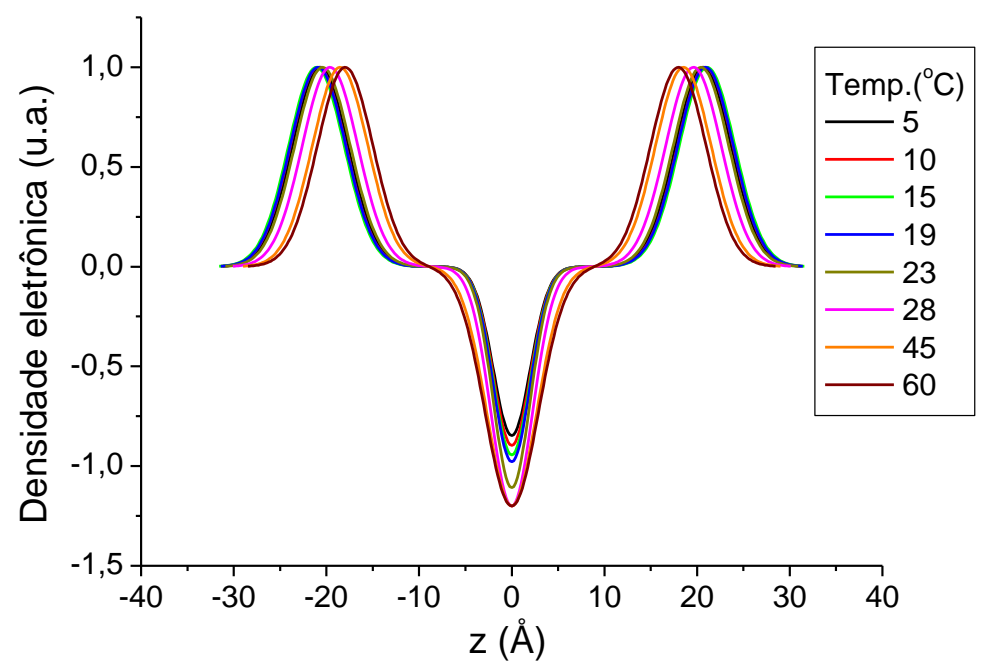

Figura 7.2.4: Perfil de densidade eletrônica de uma dispersão extrusada de $10 \mathrm{mM}$ de DMPG em água em diferentes temperaturas.

Vemos na figura 7.2.4 que, conforme a temperatura aumenta os picos que representam a densidade eletrônica das cabeças polares se aproximam, indicando a diminuição na espessura da bicamada, conforme é esperado após a transição da fase gel para a fase fluida. Na figura 7.2.5 comparamos as espessuras das bicamadas $\left(d_{B}\right)$ obtidas a partir das simulações e usando a equação 2.4.5.

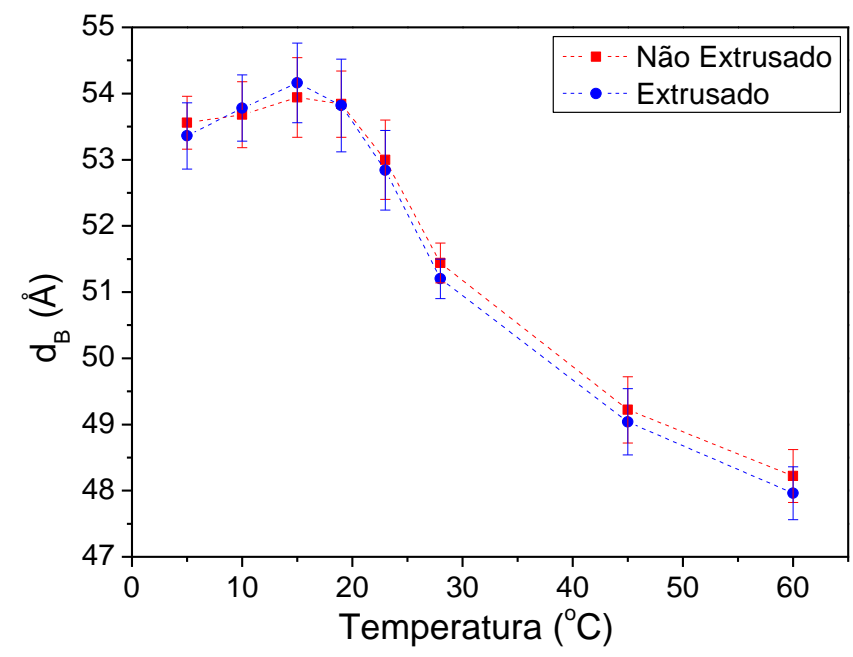

Figura 7.2.5: Variação da espessura das bicamadas $\left(d_{B}\right)$ com a temperatura para dispersões extrusadas e não extrusadas de 10 mM de DMPG em água.

A partir da figura 7.2.5, vemos que as mudanças na espessura da bicamada são semelhantes para as dispersões extrusadas e não extrusadas, sendo observada a diminuição da espessura para temperaturas acima de $19^{\circ} \mathrm{C}$. A espessura calculada é de 
$\sim 54 \AA$ na fase gel e de $\sim 48$ Å na fase fluida. Estes valores são muito próximos aos obtidos em Riske et al., 2001, que foi de $\sim 52 \AA$ na fase gel e de $\sim 45 \AA$.

Na figura 7.2.6 é apresentado o perfil de densidade eletrônica de uma dispersão extrusadas de 10 mM de DMPG em tampão HEPES a baixa força iônica.

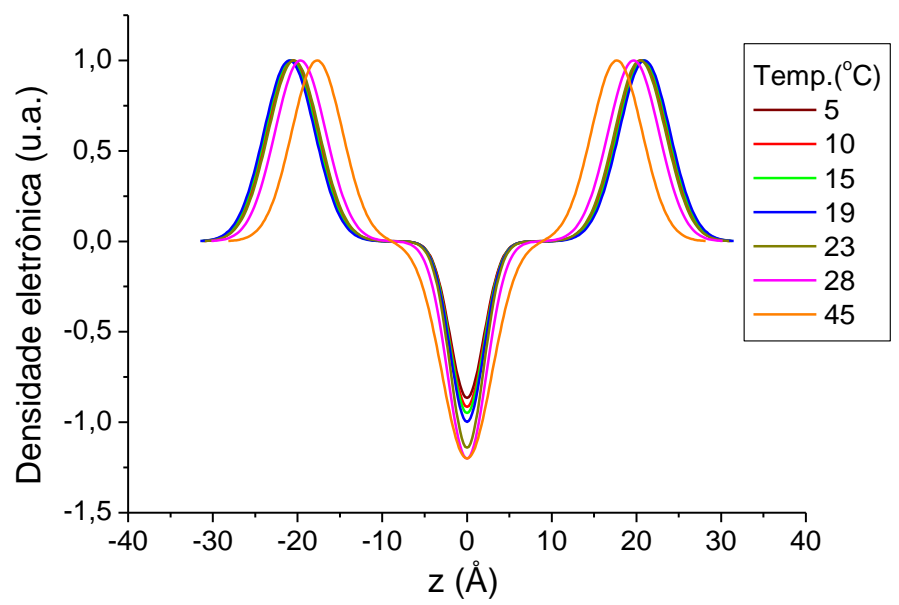

Figura 7.2.6: Perfil de densidade eletrônica de uma dispersão extrusada de $10 \mathrm{mM}$ de DMPG em tampão a baixa força iônica em diferentes temperaturas.

Os perfis da figura 7.2.6 são muito semelhantes aos obtidos para as dispersões em água na figura 7.2.4. Iremos comparar as espessuras das bicamadas em água e em tampão na figura 7.2.7.

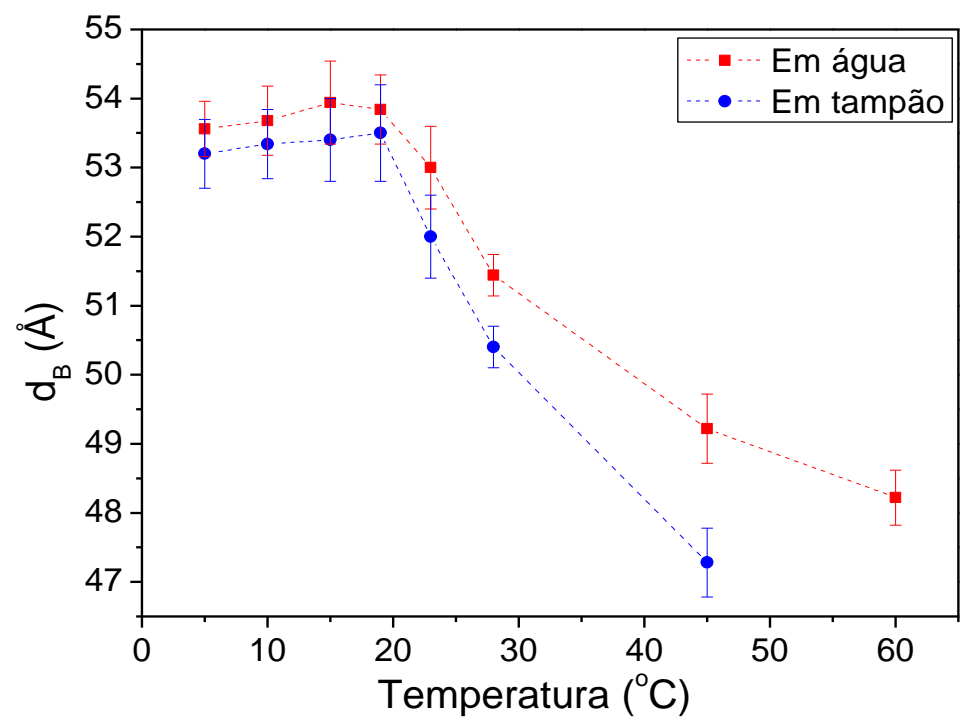

Figura 7.2.7: Espessura das bicamadas $\left(d_{B}\right)$ de dispersões extrusadas de $10 \mathrm{mM}$ de DMPG em água e em tampão a baixa força iônica.

Na figura 7.2.7 vemos que a espessura das bicamadas de vesículas de DMPG após a extrusão em água e em tampão são semelhantes até $19^{\circ} \mathrm{C}$, sendo que a partir desta 
temperatura as espessuras começam a diminuir. Na fase fluida, as bicamadas de DMPG em água são mais espessas do que em tampão, o que pode estar relacionado com os resultados de RPE (figura 6.2.8) que mostraram bicamadas mais empacotadas em água, em altas temperaturas.

$\mathrm{Na}$ figura 7.2.8 apresentamos as espessuras das bicamadas de dispersões extrusadas de 50 mM de DMPG em água e em tampão a baixa força iônica.

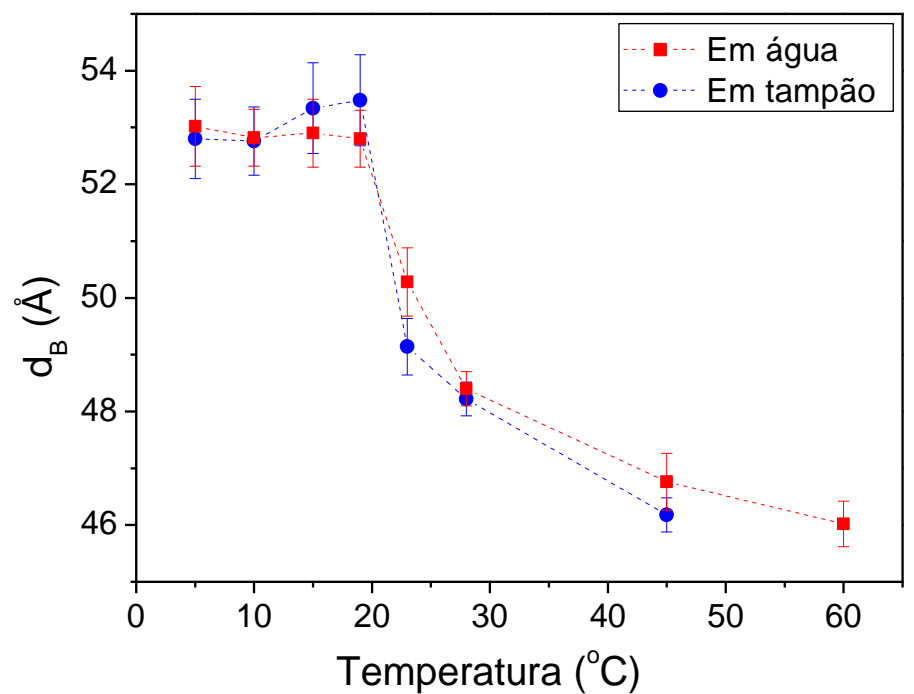

Figura 7.2.8: Espessura das bicamadas $\left(d_{B}\right)$ de dispersões extrusadas de $50 \mathrm{mM}$ de DMPG em água e em tampão a baixa força iônica.

Vemos que a variação das espessuras das bicamadas com a temperatura é semelhante para as dispersões de 10 e $50 \mathrm{mM}$ de DMPG sendo que os valores das espessuras são próximos. Apesar da transição de fase vista por DSC começar em temperaturas diferentes para as dispersões em água e em tempão (figuras 5.1 .3 e 5.8.4), o processo de afinamento das bicamadas é semelhante para os dois sistemas, tendo início a partir de $19^{\circ} \mathrm{C}$.

Estas simulações mostraram que a região de as curvas de SAXS podem ser bem ajustadas considerando-se bicamadas lipídicas que ficam mais finas com o aumento da temperatura, estando de acordo com o que é esperando após a transição da fase gel para a fase fluída da bicamada.

Em tampão, os dados de WAXS e SAXS para 10 e $50 \mathrm{mM}$, mostram um início da transição próximo ao valor de $\mathrm{T}_{\mathrm{m}}{ }^{\text {on }}$ visto por DSC (figura 5.8.4). Entretanto em água, tanto para 10 como para $50 \mathrm{mM}$, a absorção de calor começa em $\sim 10-12^{\circ} \mathrm{C}$, e medidas de WAXS e SAXS não mostram mudanças na bicamada até $19^{\circ} \mathrm{C}$. Pelos resultados de 
$h_{+1} / h_{0}$ em RPE (figura 6.2.8), vemos que o crescimento mais significativo do parâmetro se dá em torno de $\sim 15^{\circ} \mathrm{C}$. Pode ser que no início da transição, está ocorrendo algum processo de absorção de calor, mas que não está relacionado às cadeias carbônicas.

\subsubsection{Espalhamento na região de muito baixo $\mathrm{q}$}

Nesta seção daremos atenção aos resultados de espalhamento de raios-X na região de muito baixo q (abaixo de 0,4 $\mathrm{nm}^{-1}$ ), onde um pico de Bragg é observado para dispersões de DMPG em água e em tampão a baixa força iônica.

Realizamos diversas tentativas de ajustar a região de muito baixo $q$ através de diferentes fatores de estrutura (ver alguns exemplos no apêndice $C$ ), utilizando o programa GAP e também o programa SASFit (escrito por Joachim Kohlbrecher e Ingo Bressler, do Laboratory for Neutron Scattering, Suíça). Dada a impossibilidade de se obter bons ajustes, foi possível calcular uma distância de repetição a partir dos picos de Bragg, assumindo que a posição de máximo de intensidade observada está relacionada apenas com o fator de estrutura, quando estes eram visíveis. 

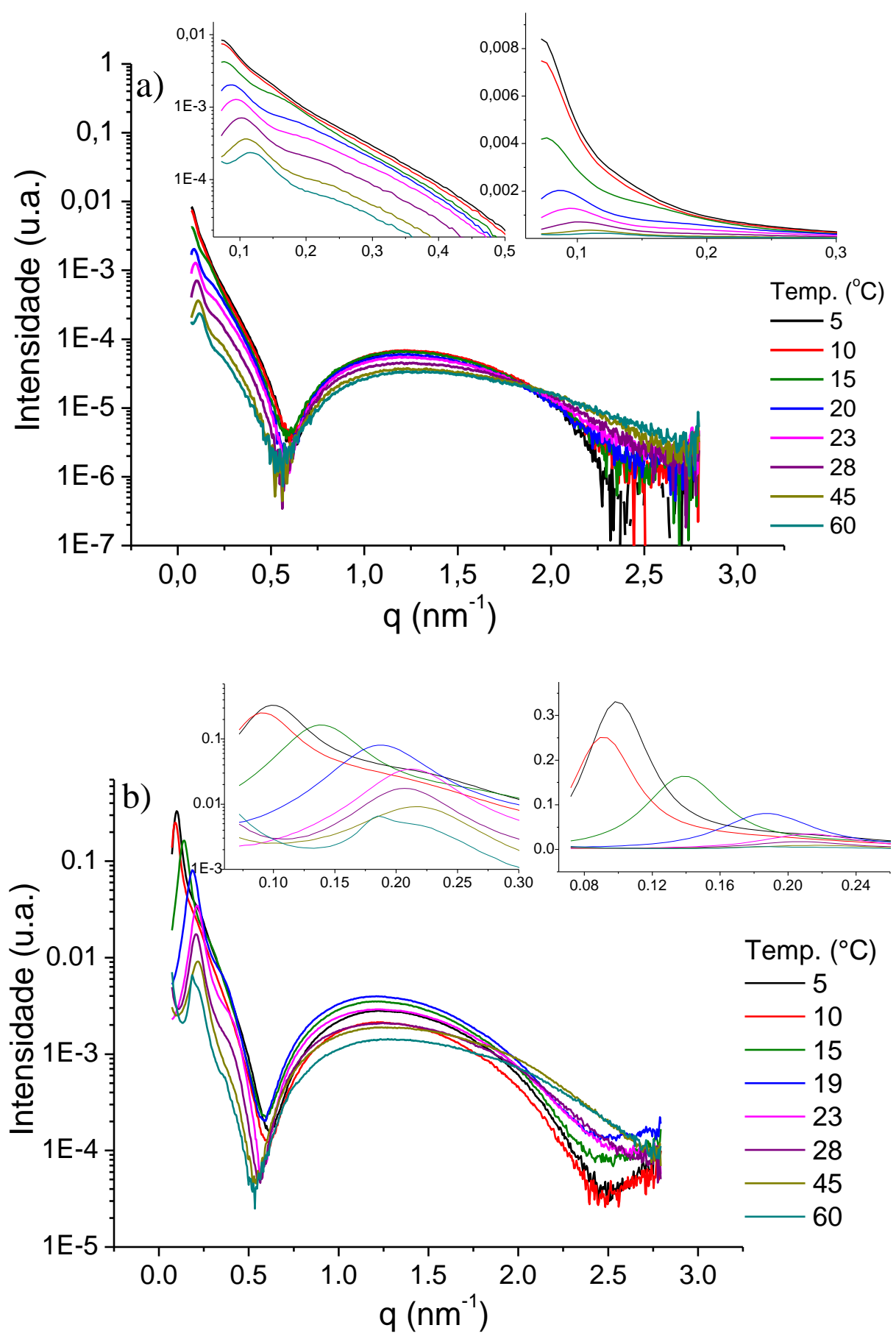

Figura 7.2.9: Curvas de SAXS de dispersões extrusadas de DMPG em água em diferentes concentrações lipídicas: a) $10 \mathrm{mM}$ e b) $50 \mathrm{mM}$. A região de muito baixo q é apresentada em destaque, para a melhor visualização dos picos, em escala linear e logarítmica.

Na figura 7.2.9 vemos que os picos de Bragg das dispersões de DMPG em água são bastante visíveis e estão presentes em todas as temperaturas, de 5 a $60^{\circ} \mathrm{C}$, sendo que para a dispersão de $10 \mathrm{mM}$ (figura 7.2 .9 a), nas temperaturas de 5 e $10^{\circ} \mathrm{C}$ não é possível determinar se o centro dos picos se encontra em valores menores de q do que 
os medidos. A seguir, na figura 7.2.10, mostramos a comparação de resultados obtidos para dispersões extrusadas e não extrusadas de 10 mM de DMPG em água.

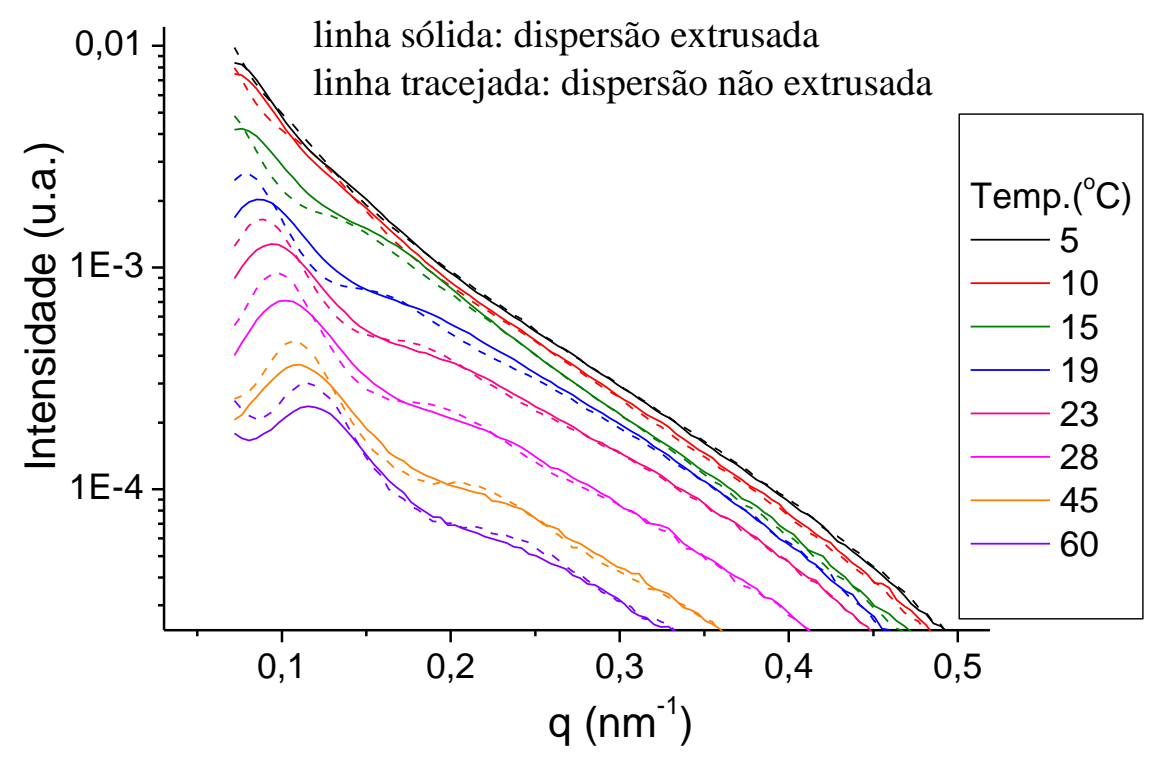

Figura 7.2.10: Picos de Bragg de dispersões extrusadas (linhas sólidas) e não extrusadas (linhas tracejadas) de dispersões de 10 mM de DMPG em água.

Na figura 7.2.10, observamos que não há diferenças notáveis nos picos de Bragg de dispersões de DMPG em água antes e depois da extrusão para temperaturas acima de $19^{\circ} \mathrm{C}$. Nas temperaturas abaixo de $19^{\circ} \mathrm{C}$, as dispersões extrusadas já apresentam uma curvatura no início da curva, enquanto as dispersões não extrusadas não apresentam.

De modo a obter mais informações sobre esta região de muito baixo ângulo, realizamos medidas no LNLS aumentando a distância amostra-detector, possibilitando a observação de ângulos mais baixos. Na figura 7.2.11 mostramos os resultados obtidos nesta nova configuração para uma dispersão extrusada de 30 mM de DMPG em água, sendo que só foi possível realizar medidas de 9 a $28^{\circ} \mathrm{C}$. 


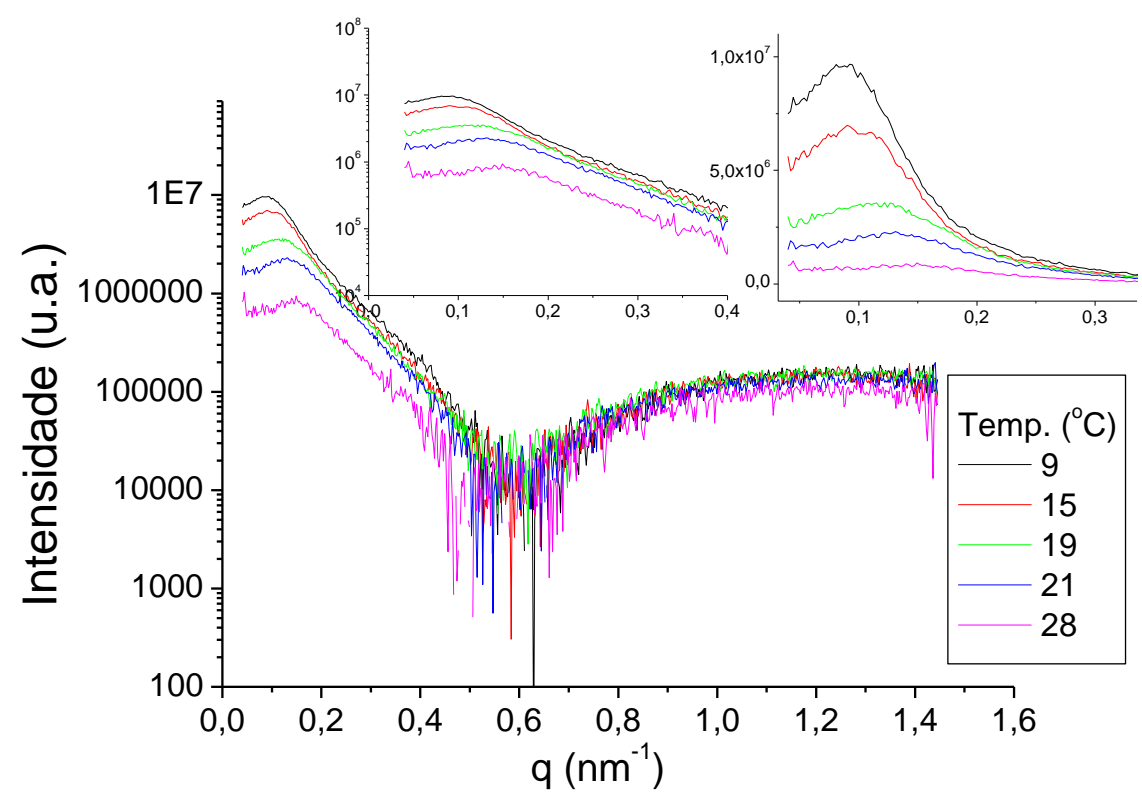

Figura 7.2.11: Medidas de SAXS de dispersões extrusadas de $30 \mathrm{mM}$ de DMPG em água medidas com a máxima distância amostra-detector possível no LNLS. A região de muito baixo q é apresentada em destaque, para a melhor visualização dos picos, em escala linear e logarítmica.

A partir dos resultados das figuras 7.2.9 e 7.2.11 determinamos as posições centrais ( $\mathrm{q}_{\mathrm{p}}$ ) dos picos de Bragg e então calculamos uma distância de repetição (d) a partir da equação 2.4.6:

$$
d=\frac{2 \pi}{q_{p}}
$$
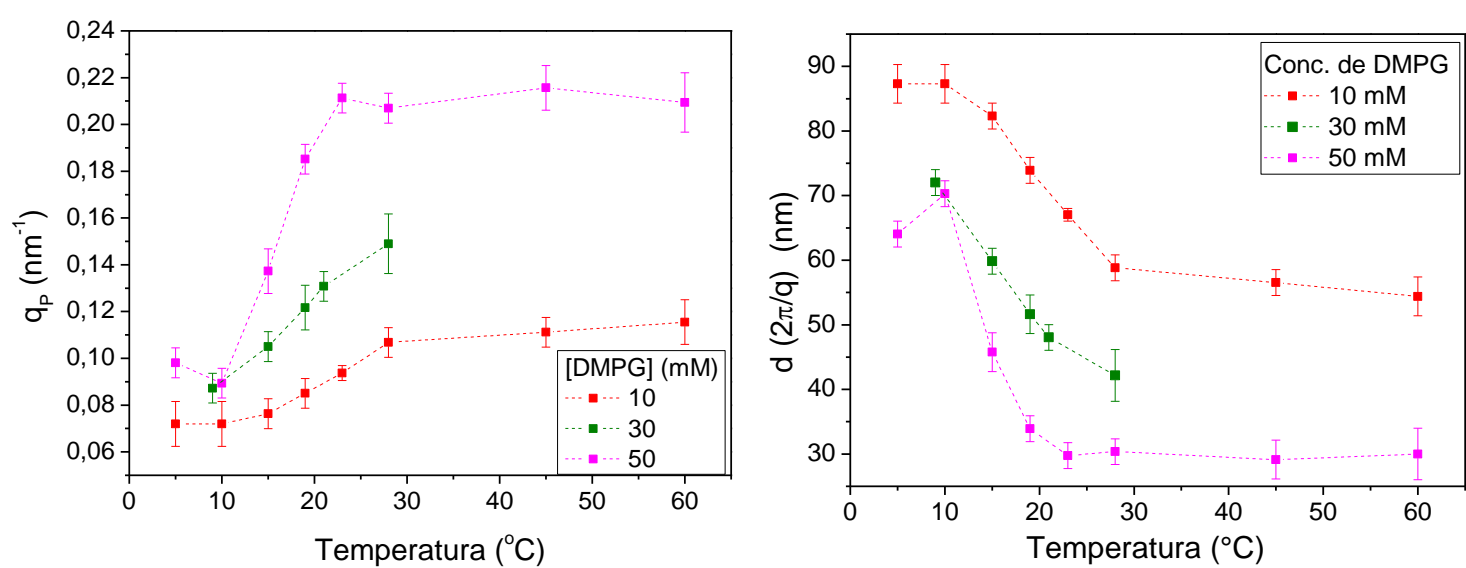

Figura 7.2.12: Posição dos picos de Bragg ( $\mathrm{q}_{\mathrm{p}}$ ) e distâncias de repetição (d) calculadas para dispersões extrusadas de 10, 30 e 50 mM de DMPG em água.

Na figura 7.2.12 vemos que as posições dos picos mudam para valores maiores de q após $10^{\circ} \mathrm{C}$, coincidindo com a temperatura de início da transição de fase 
monitorada por DSC (figura 4.1.1), sendo que este aumento ocorre até $\sim 25^{\circ} \mathrm{C}$, sendo possível observar, para as dispersões de 10 e $50 \mathrm{mM}$, que o pico permanece na mesma posição até $60^{\circ} \mathrm{C}$.

Além da mudança da posição do pico com a termperatura, é notável a mudança de $d$ com a concentração de DMPG, sendo que quanto maior a concentração lipídica, menor é a distância calculada.

A seguir apresentaremos os picos de Bragg observados para dispersões de DMPG em tampão HEPES a baixa força iônica e posteriormente discutiremos possíveis correlações que podem originar estes picos. 

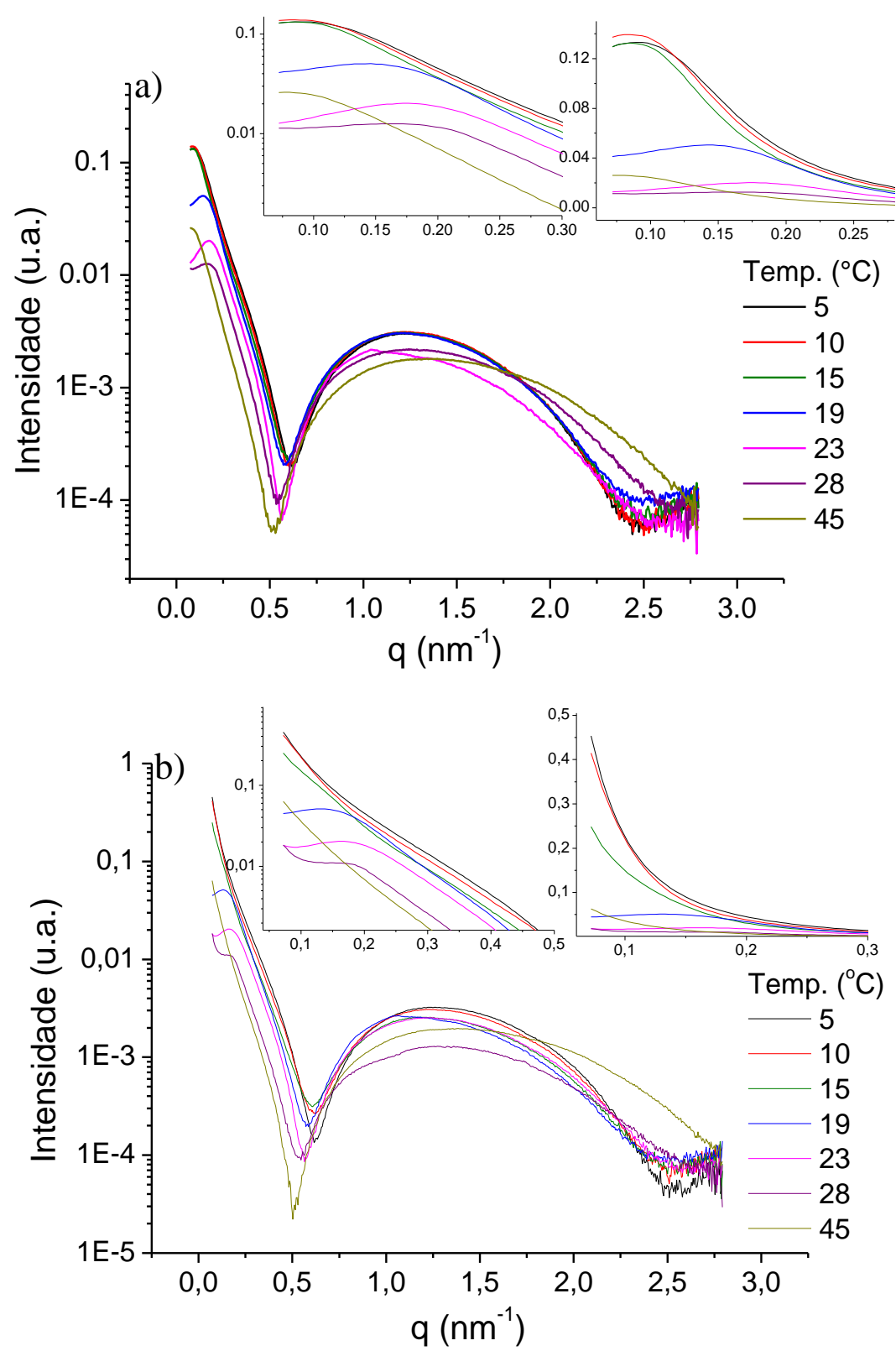

Figura 7.2.13: Curvas de SAXS de dispersões de $50 \mathrm{mM}$ de DMPG em tampão a) depois da extrusão e b) sem extrusar. A região de muito baixo q é apresentada em destaque, para a melhor visualização dos picos, em escala linear e logarítmica.

A partir da figura 7.2.13, vemos que, enquanto para a dispersão não extrusada os picos só aparecem nas temperaturas da "região de transição de fase" (19, 23 e $\left.28^{\circ} \mathrm{C}\right)$, como foi observado em trabalhos anteriores (Riske et al., 2001, 2004), para a dispersão extrusada (figura 7.2.13 a) é possível observar o pico de Bragg em todas as temperaturas, de 5 a $45^{\circ} \mathrm{C}$, sendo que nas fases gel e fluída os picos aparecem bem no início das curvas medidas. 
Assim como nas medidas de SAXS de dispersões em água (7.2.9), observamos a diminuição na intensidade de espalhamento de raios- $X$ na região de transição de fase, sendo que em água a intensidade continua diminuindo até $60^{\circ} \mathrm{C}$. Esta diminuição na intensidade de espalhamento na região de muito baixo ângulo pode estar relacionada com maiores interações repulsivas entre as partículas (Kikhney \& Svergun, 2015), sendo que o comportamento visto por SAXS está de acordo com as medidas de mobilidade eletroforética (figura 5.4.2), que mostrou o aumento das cargas das vesículas na transição de fase.

Da mesma forma que foi feito para as dispersões em água, determinamos as posições dos picos e calculamos a distância de repetição relacionadas aos picos de Bragg.
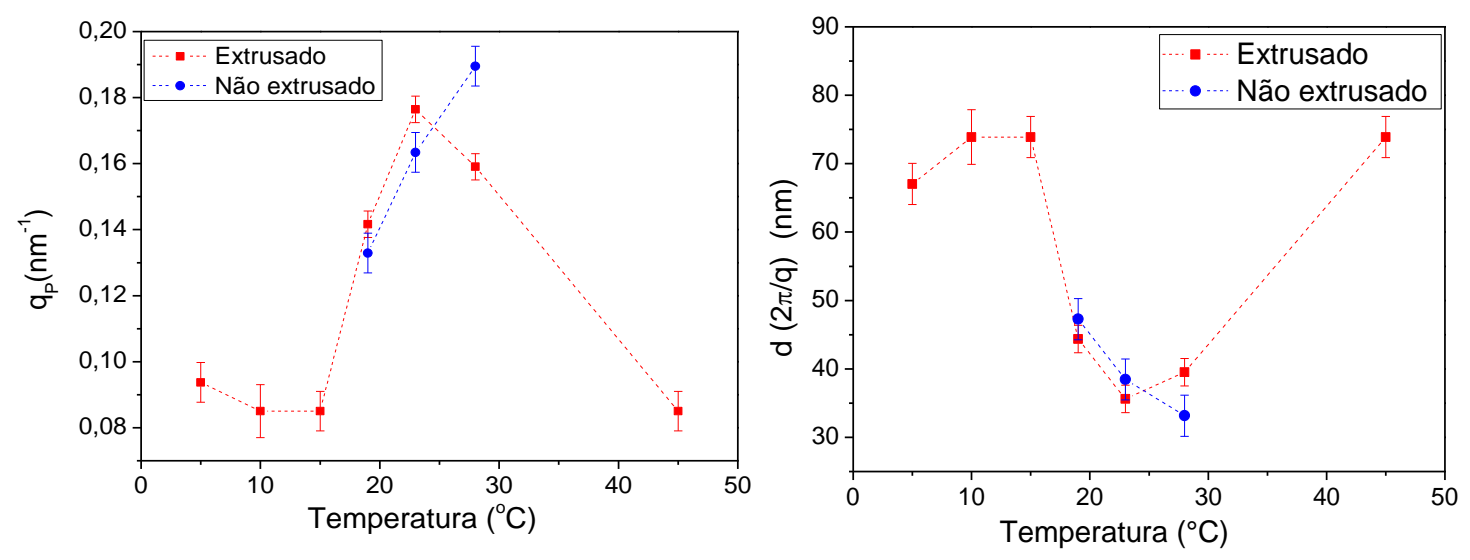

Figura 7.2.14: Posição dos picos de Bragg ( $q_{p}$ ) e distâncias de repetição (d) calculadas para dispersões extrusadas e não extrusadas de 50 mM de DMPG em tampão.

Na figura 7.2.14 vemos que, para a dispersão extrusada, o pico vai para valores maiores de q após $15^{\circ} \mathrm{C}$, retornando para valores menores em $45^{\circ} \mathrm{C}$. Durante a transição de fase $\left(19,23\right.$ e $\left.28^{\circ} \mathrm{C}\right)$ a posição dos picos para as dispersões extrusadas e não extrusadas é parecida e o valor da distância de repetição é muito próxima ao calculado em Riske et al., 2001, que foi de $37 \mathrm{~nm}$.

Durante estágio realizado em Graz, foram realizadas inúmeras tentativas de se observar os picos de Bragg em dispersões de diferentes concentrações lipídicas e em várias temperaturas, entretanto, notamos que após a subtração da curva de espalhamento do tampão, não era possível determinar a posição dos picos com precisão. Pela desconfiança de que se tratava de algum problema com a correção de 
fundo, comparamos várias medidas realizadas com o tampão, que deveriam ser idênticas, uma vez que estavamos usando a mesma porta amostra e as mesmas configurações do aparelho. Entretanto, como mostrado na figura 7.2.15, o perfil mudava de medida para medida, mesmo estando a mesma temperatura, de $23^{\circ} \mathrm{C}$.

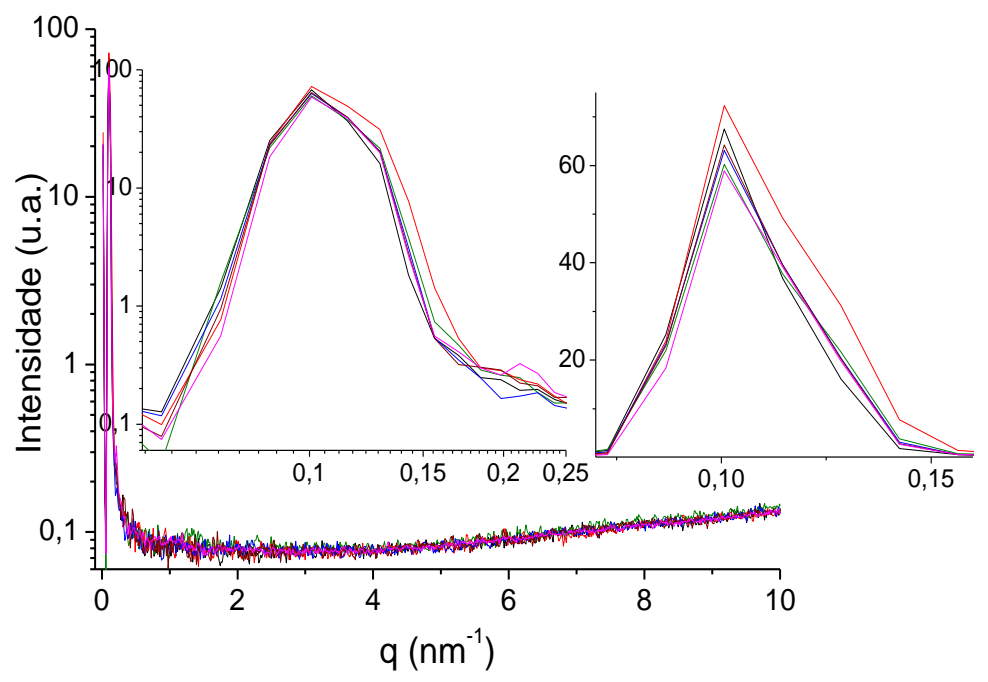

Figura 7.2.15: Diferentes medidas de SAXS do tampão HEPES, usando-se as mesmas configurações e a $23^{\circ} \mathrm{C}$, realizadas no SAXSpace. Em destaque é apresentada a região de muito baixo q em escala linear e logarítmica.

Vemos na figura 7.2.15 que o perfil de espalhamento do tampão muda, principalmente na região de baixo q, com o passar do tempo e quando o aparelho era reiniciado, sendo este um grande problema para o pico que estamos investigando, uma vez que essas mudanças são bem na região que o pico aparece. Então, medimos diferentes concentrações de DMPG (de 10 a 60 mM) em tampão, na temperatura de $23^{\circ} \mathrm{C}$, realizando varreduras rápidas de 30 minutos de duração, sendo que a cada duas medidas realizava-se uma nova medida do tampão, para que a subtração ficasse correta (figura 7.2.16). Também tomou-se o cuidado de que o sistema do aparelho não fosse reiniciado até que todas as amostras fossem medidas. Para este experimento, as disferentes concentrações foram obtidas a partir de diluições da amostra mais concentrada. 


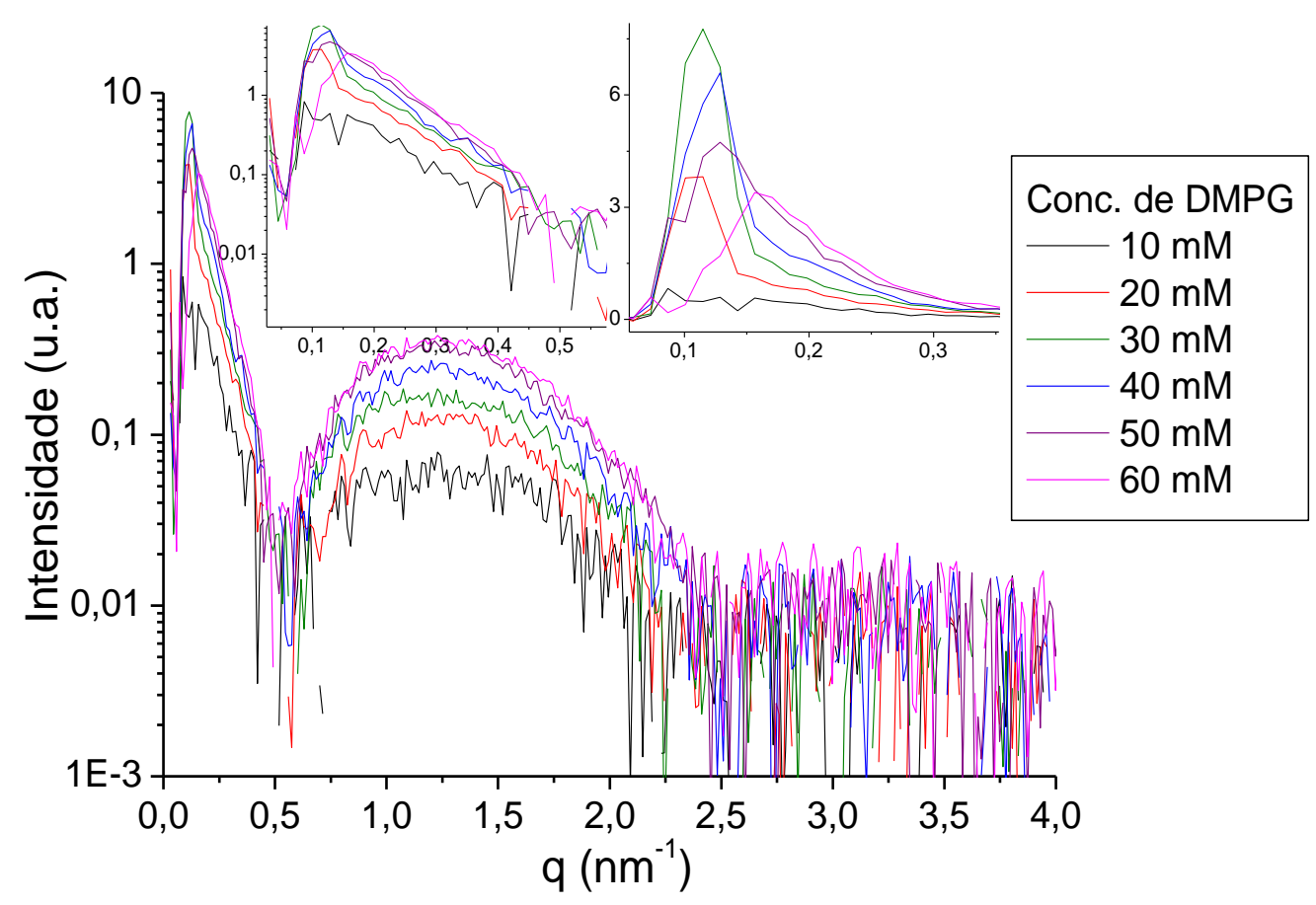

Figura 7.2.16: Medidas de SAXS para dispersões extrusada de 10, 20, 30, 40, 50 e 60 mM de DMPG em tampão a baixa força iônica a $23^{\circ} \mathrm{C}$, com tempo de exposição para cada curva de 30 minutos.

Apesar do ruído das curvas da figura 7.2.16, foi possível observar o pico a baixo q para todas as concentrações lipídicas, exceto $10 \mathrm{mM}$. Ajustamos os picos por Lorentzianas utilizando o software Origin e graficamos os valores das posições dos picos e relacionamos com uma distância de repetição em função da concentração lipídica (figura 7.2.17), assumindo que a posição deste pico está relacionada somente com um fator de estrutura da amostra, como dito acima.
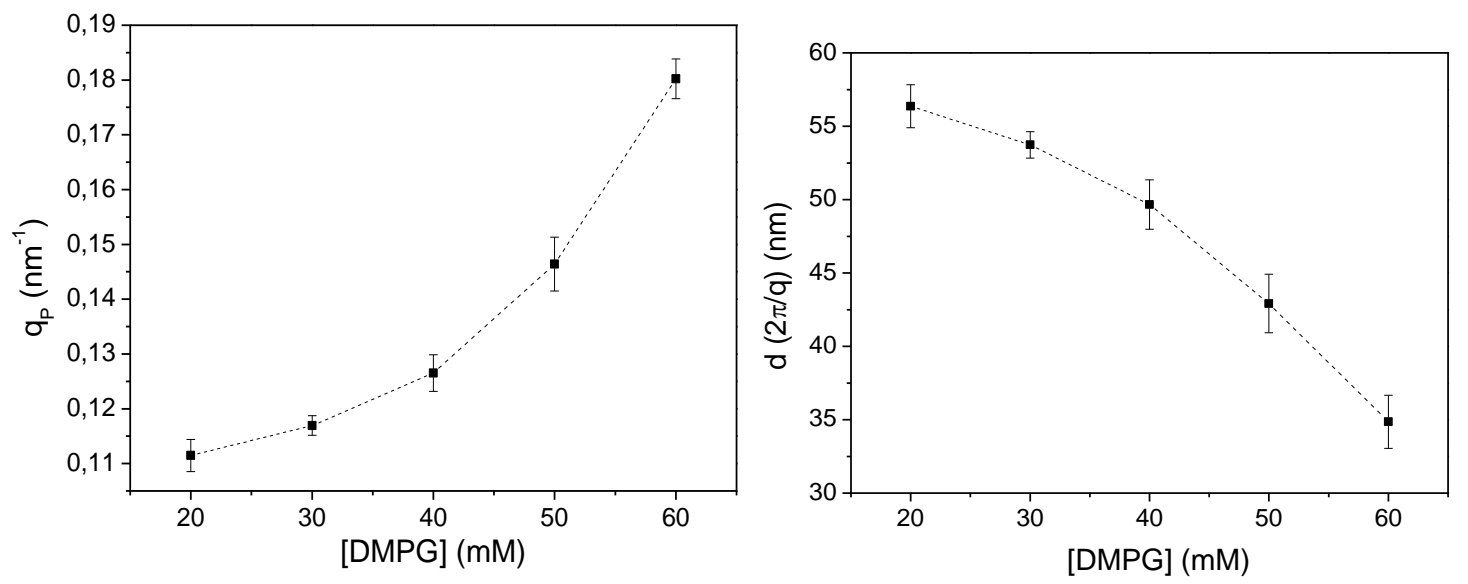

Figura 7.2.17: Posição dos picos e distância de repetição calculadas a partir dos picos a baixo q da figura 7.2.16. 
Assim como observado nas dispersões em água (figura 7.2.12), vemos na figura 7.2.17 que a distância de correlação diminue com o aumento da concentração de DMPG.

Portanto, uma primeira hipótese seria que esta distância estivesse relacionada com uma distância média entre os centros das vesículas, que diminuiria com o aumento da concentração de vesículas. Por outro lado, pelo fato da distância de correlação diminuir nas mesmas temperaturas em que foi observado o aumento no raio das vesículas por DLS (figura 5.6.3), foi proposto pelo prof. Pabst que a distância de repetição poderia estar relacionada à distância entre bicamadas de vesículas vizinhas ( $x$ na figura 7.2.18). Discutiremos as hipóteses abaixo.

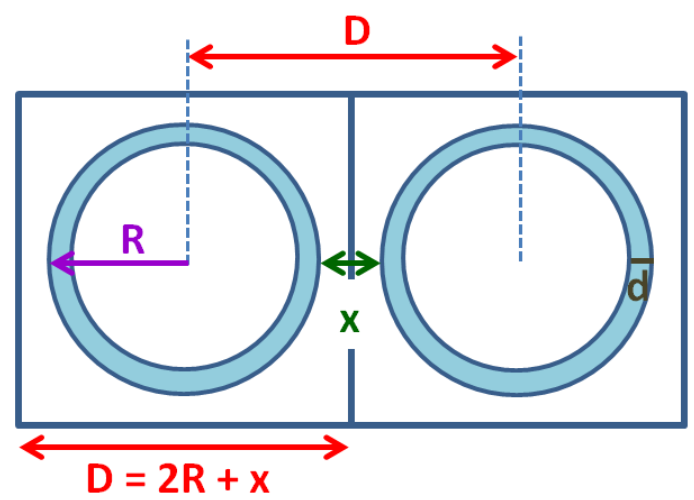

Figura 7.2.18: Esquematização do modelo em que cada vesícula ocupa um mesmo volume $\left(D^{3}\right)$, sendo $D$ a distância entre os centros de vesículas vizinhas e $x$ a distância entre suas bicamadas. $R$ é o raio da vesícula e $d$ é a espessura da bicamada.

Calculamos a distância média entre os centros de vesículas vizinhas (D), a partir da equação 2.7.6:

$$
D=\sqrt[3]{\frac{4 \pi\left[R_{e f}^{2}+\left(R_{e f}-d_{B}\right)^{2}\right]}{a \cdot[D M P G] N_{A}}}
$$

Com o valor de D, calculamos a distância entre as superfícies de vesículas vizinhas $(x)$, a partir da relação:

$$
x=D-2 R_{e f}
$$

Os cálculos foram realizados para diferentes concentrações lipídicas (30, 40, 50 e $60 \mathrm{mM}$ ) e utilizou-se para os valores das espessuras das bicamadas os valores obtidos 
pelas simulações de SAXS (figura 7.2.8) e para a área por cabeça polar os valores de 0,48 $\mathrm{nm}^{2}$ na fase gel e $0,60 \mathrm{~nm}^{2}$ na fase fluida (Marsh \& Phill, 1990).

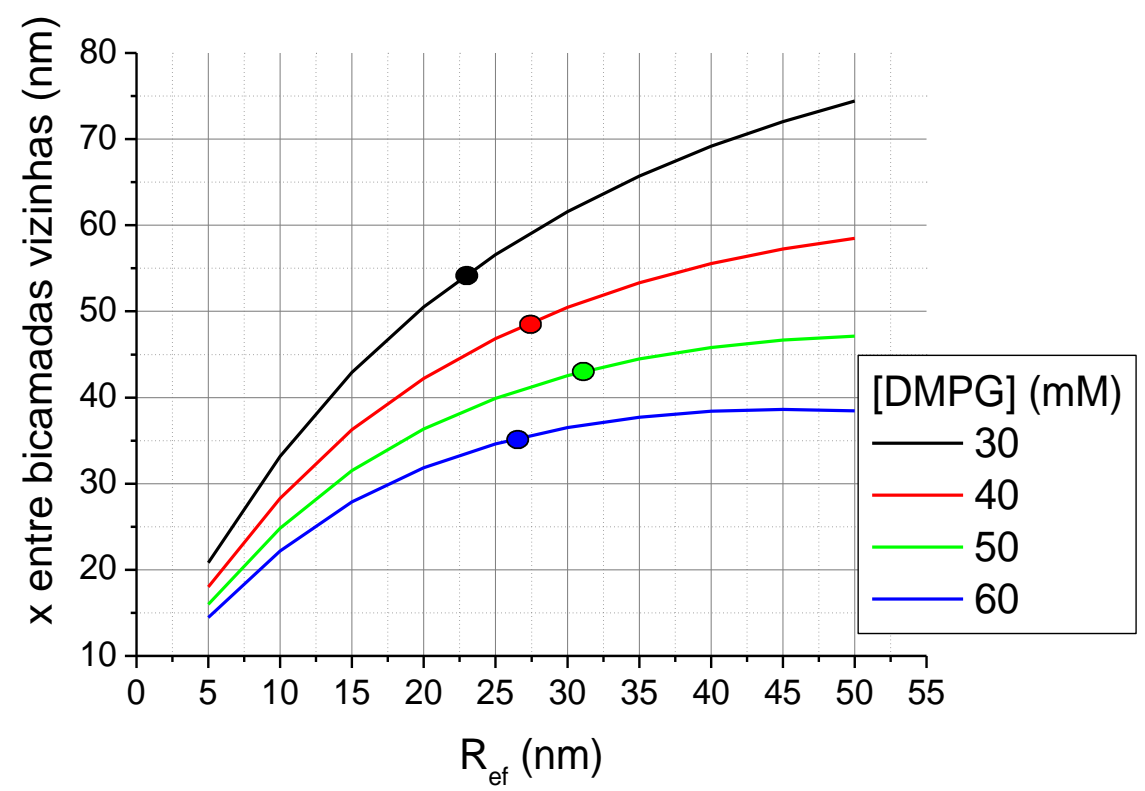

Figura 7.2.19: Cálculos das distâncias entre bicamadas de vesículas vizinhas (distância $x$ da figura 7.2.18) para diferentes concentrações lipídicas. Os pontos coloridos indicam as distâncias de correlação da figura 7.2.17.

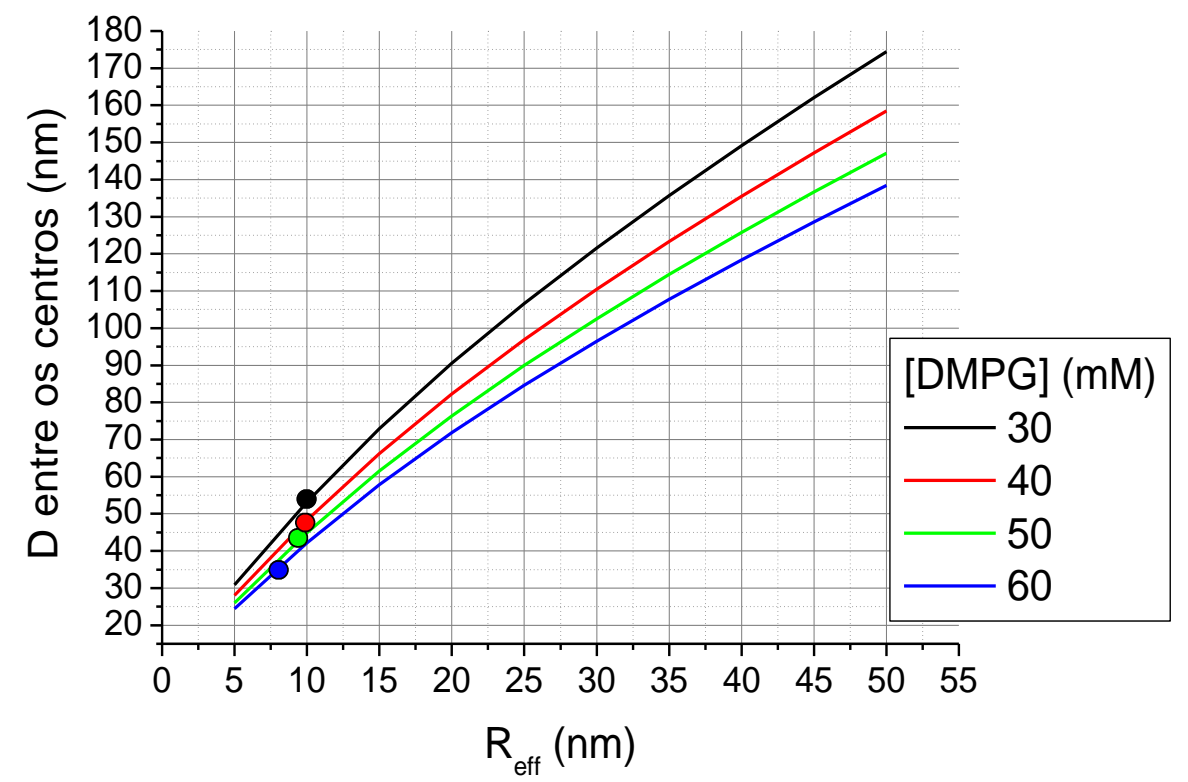

Figura 7.2.20: Cálculos das distâncias entre os centros de vesículas vizinhas (distância D da figura 7.2.18) para diferentes concentrações lipídicas. Os pontos coloridos indicam as distâncias de correlação da figura 7.2.17.

Considerando que as distâncias de correlação da figura 7.2.17 são as distâncias entre bicamadas de vesículas vizinhas ( $\mathrm{x}$ na figura 7.2.18), vemos na figura 7.2.19 que as vesículas teriam raios entre 23 e $31 \mathrm{~nm}$, sendo que, em $20^{\circ} \mathrm{C}$, o raio efetivo calculado 
por DLS foi de $28,6 \pm 1,5 \mathrm{~nm}$ (tabela 5.1), mostrando que esta hipótese é plausível, isto é, os valores são compatíveis. Por outro lado, se considerarmos que as distâncias de repetição são as distâncias entre os centros de vesículas vizinhas, pela figura 7.2.20, teríamos vesículas com raios entre 8 e $10 \mathrm{~nm}$, muito menor do que o raio medido por DLS, e que realmente é um tamanho muito pequeno para vesículas e parece bem pouco provável.

Utilizando os mesmos cálculos da figura 7.2.19, calculamos os raios efetivos a partir das distâncias de repetição dos picos de SAXS para as dispersões em água (figura 7.2.12), considerando-se que as distâncias de repetição equivalem às distâncias entre bicamadas de vesículas vizinhas, Calculou-se o raio efetivo a $15^{\circ} \mathrm{C}$ a partir da equação 7.2 e considerou-se que a distância entre os centros das vesículas não se altera nas outras temperaturas (tabela 7.1).

Tabela 7.1: Raios calculados a partir das distâncias de repetição obtidas pelos resultados de SAXS para dispersões de 10, 30 e 50 mM de DMPG em água. Também é apresentado os resultados que foram obtidos por medidas de DLS para dispersões de $1 \mathrm{mM}$ de DMPG em água.

\begin{tabular}{|c|c|c|c|c|}
\hline \multirow[b]{2}{*}{ Temp. $\left({ }^{\circ} \mathrm{C}\right)$} & \multicolumn{3}{|c|}{ Raios calculados (nm) } & \multirow{2}{*}{$\begin{array}{l}\text { Raio efetivo (DLS) } \\
(\mathrm{nm})\end{array}$} \\
\hline & $10 \mathrm{mM}$ & $30 \mathrm{mM}$ & $50 \mathrm{mM}$ & \\
\hline 15 & 18 & 22 & 24 & $21,6 \pm 1,6$ \\
\hline 19 & 26 & 30 & 36 & $28,5 \pm 1,7\left(20^{\circ} \mathrm{C}\right)$ \\
\hline 23 & 33 & 34 & 40 & \\
\hline 28 & 41 & 40 & 39 & $45,5 \pm 2,6\left(30^{\circ} \mathrm{C}\right)$ \\
\hline 45 & 43 & & 41 & $47,8 \pm 0,8$ \\
\hline 60 & 42 & & 42 & \\
\hline
\end{tabular}

Olhando para os valores da tabela 7.1 e da figura 7.2.19, vemos que a hipótese de que os picos de repetição podem estar relacionados com as distâncias entre as bicamadas de vesículas vizinhas não deve ser descartada. Não foi possível encontrar na literatura nenhum trabalho que relacione o pico de repetição de SAXS à distância entre superfícies de vesículas vizinhas, sendo que para que pudéssemos simular esses picos para verificar sua origem precisaríamos desenvolver um modelo teórico próprio, o que demandaria bastante tempo e conhecimento da técnica, não sendo algo trivial.

Em discussões com o Prof. Otto Glatter, que é um pesquisador extremamente experiente na área de SAXS, acerca destes resultados, ele foi enfático em dizer que não acredita que as distâncias de correlação podem ser as distâncias entre bicamadas de 
vesículas vizinhas, principalmente porque o pico visto nas curvas de SAXS é bastante pronunciado, tratando-se de uma correlação "forte".

Neste capítulo mostramos que os picos de Bragg na região de muito baixo $q$, observados em dispersões de DMPG a baixa força iônica (em HEPES ou água), estão presentes em todas as temperaturas, e não somente na chamada região de transição de fase. Em HEPES, é importante que a amostra seja extrusada, para diminuir a polidispersidade das vesículas. Mostramos, também, que a posição do pico depende da concentração lipídica, e da temperatura da amostra: menores distâncias de repetição são encontradas na região de transição de fase da membrana. Portanto, mostramos que esse pico de Bragg não dá suporte à hipótese de abertura de poros na bicamada lipídica durante a sua transição de fase (Riske et al., 2004 e 2009).

\subsection{Medidas de curvatura espontânea do DMPG}

Durante o estágio realizado em Graz, foi sugerido pelo Prof. Pabst que realizássemos medidas da curvatura espontânea do DMPG em meios de diferente força iônica, sendo que estes experimentos estão sendo bastante utilizados e desenvolvidos pelo Prof. Pabst e seu grupo de pesquisa (ver, por exemplo, Kollmitzer et al., 2013, Eicher et al., 2018).

Para o experimento de determinação da curvatura espontânea $\left(\mathrm{J}_{0}\right)$ de uma monocamada de DMPG seguimos a metodologia descrita em Kollmitzer et al., 2013 e as medidas foram feitas com o auxílio do estudante de doutorado Michael Pachler, do grupo do Prof. Pabst. Neste experimento obteve-se as curvaturas espontâneas do DMPG em meios de diferentes forças iônicas: em água pura, em tampão HEPES $+2 \mathrm{mM}$ de $\mathrm{NaCl}$ e em tampão HEPES $+250 \mathrm{mM}$ de $\mathrm{NaCl}$ em diferentes temperaturas: $20,30,40$ e $50^{\circ} \mathrm{C}$. Para tal, realizou-se medidas de SAXS da fase hexagonal invertida $\left(H_{\| 1}\right)$ da mistura de DOPE ("host lipid"), que é um lipídio conhecido por formar H॥, com DMPG ("guest lipid") em diferentes concentrações $(\chi=7,5 ; 10 ; 15 ; 20 ; 30$ e 40 mol\% em DOPE) nos diferentes solventes e diferentes temperaturas de interesse.

Após misturar bem os lipídios, espera-se que o DMPG modifique a curvatura da mistura de forma linear com o aumento de sua concentração (Kollmitzer et al., 2013):

$$
J_{0}^{\text {mistura }}=\chi J_{0}^{D M P G}+(1-\chi) J_{0}^{D O P E}
$$


de modo que a curvatura espontânea do DMPG é obtida pela extrapolação de $\chi \rightarrow 100 \%$.

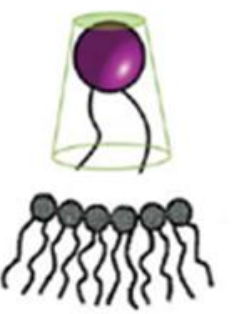

$\mathrm{J}_{0}<0$

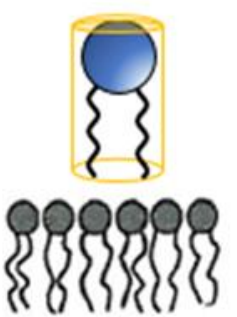

$\mathrm{J}_{0}=0$

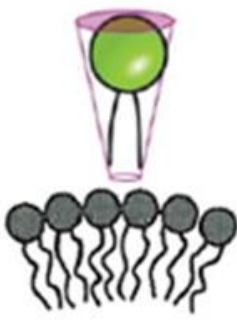

$\mathrm{J}_{0}>0$

Figura 7.3.1: Curvatura espontânea $\left(\mathrm{J}_{0}\right)$ de acordo com a geometria dos lipídios. [figura adaptada de Kollmitzer et al., 2013]

A figura 7.3.1 ilustra os valores de $J_{0}$ de acordo com a geometria dos lipídios, sendo $\mathrm{J}_{0}=0$ para lipídios cilíndricos, $\mathrm{J}_{0}<0$ para lipídios cujas áreas da seção transversal das caudas hidrofóbicas são maiores que área de superfície das cabeças polares e $\mathrm{J}_{0}<0$ quando a área de superfície das cabeças polares é maior do que a área da seção transversal das caudas hidrocarbônicas (Kollmitzer et al., 2013).

Para determinar os parâmetros de rede e o perfil de densidade eletrônica da fase hexagonal reversa, usou-se a rotina de MATLAB desenvolvida no grupo do Prof. Pabst pelos estudantes Benjamin Kollmitzer e Michael Pachler para o ajuste dos picos de Bragg (tipicamente de 5 a 7 picos eram visíveis) usando Lorentzianas e estimativas para a correção da radiação de fundo (figura 7.3.2). 


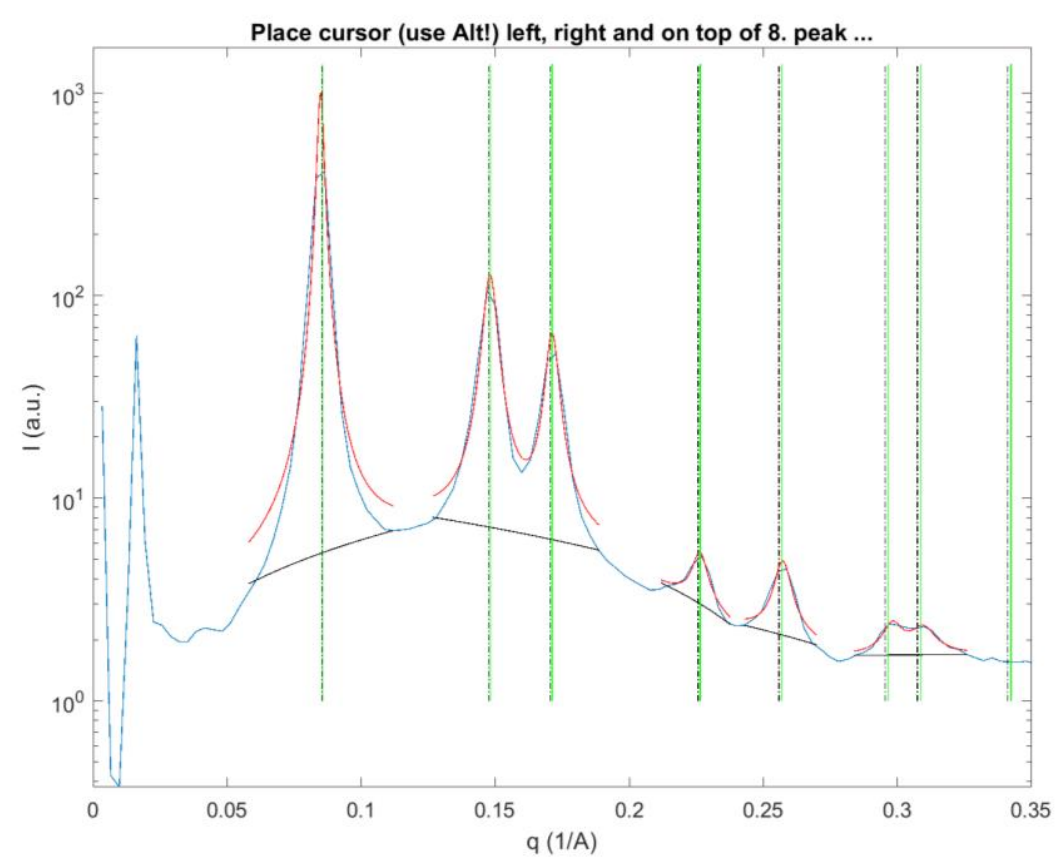

Figure 7.3.2: Padrão de SAXS da amostra de 7,5 mol\% de DMPG em DOPE a $40^{\circ} \mathrm{C}$. As posições dos picos experimentais coincidem com os esperados para uma fase puramente hexagonal, indicados pelas linhas verdes e nenhum pico extra foi observado. As linhas pretas indicam as linhas de base estimadas para a correção do fundo e em vermelho estão os ajustes dos picos por lorentzianas.

As medidas de DMPG:DOPE em meios de diferentes forças iônicas apresentaram a formação da fase hexagonal reversa até diferentes valores de $\chi$. Em alta força iônica (HEPES $10 \mathrm{mM}+250 \mathrm{mM}$ de $\mathrm{NaCl}$ ), foi possível observar $\mathrm{H}_{\|}$em todas as proporções DMPG:DOPE testadas (de 7,5 a 40 mol\% de DMPG em DOPE), em tampão a baixa força iônica (HEPES $10 \mathrm{mM}+2 \mathrm{mM}$ de $\mathrm{NaCl}$ ), a fase hexagonal só foi observada até a proporção de 30 mol\% de DMPG e em água apenas até 20 mol\% de DMPG, sendo que para concentrações maiores de DMPG não foi mais detectada a formação de a partir dos resultados de SAXS. O fato de menos dados serem considerados na extrapolação para $100 \%$ de DMPG é levado em conta no cálculo da incerteza de $J_{0}$. 

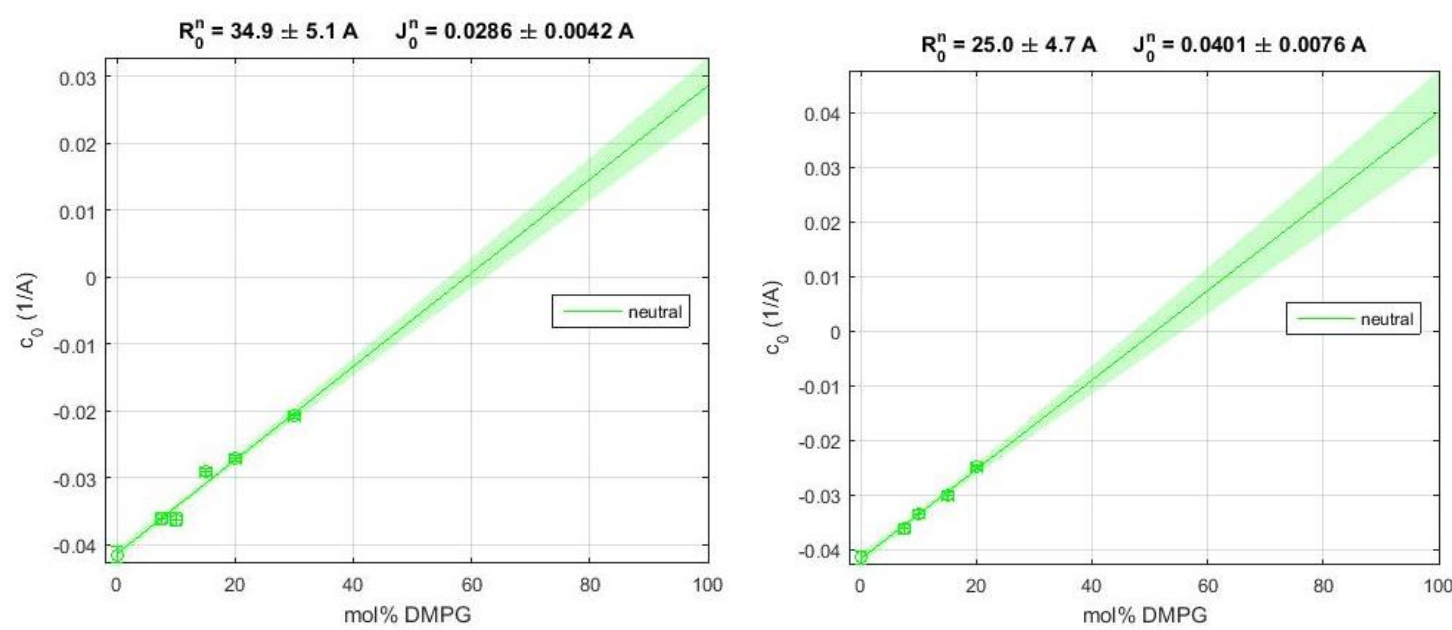

Figura 7.3.3: Exemplos de extrapolaçôes realizadas para os valores de curvatura espontânea da mistura DMPG:DOPE para 100 mol\% de DMPG. O ponto em 0 mol\% de DMPG representa a curvatura do DOPE puro. O gráfico da esquerda é do sistema DMPG:DOPE em tampão a baixa força iônica e o da direita em água pura, ambos a $40^{\circ} \mathrm{C}$. As extrapolações foram feitas para todas as temperaturas $\left(20,30,40\right.$ e $50^{\circ} \mathrm{C}$ ) nos 3 meios de diferente força iônica.

Usando os valores obtidos das extrapolações para 100 mol\% de DMPG em água e em tampão HEPES a baixa e alta força iônica, determinamos os valores da curvatura espontânea do DMPG nesses diferentes meios em função da temperatura (figura 7.3.4 e tabela 7.2).

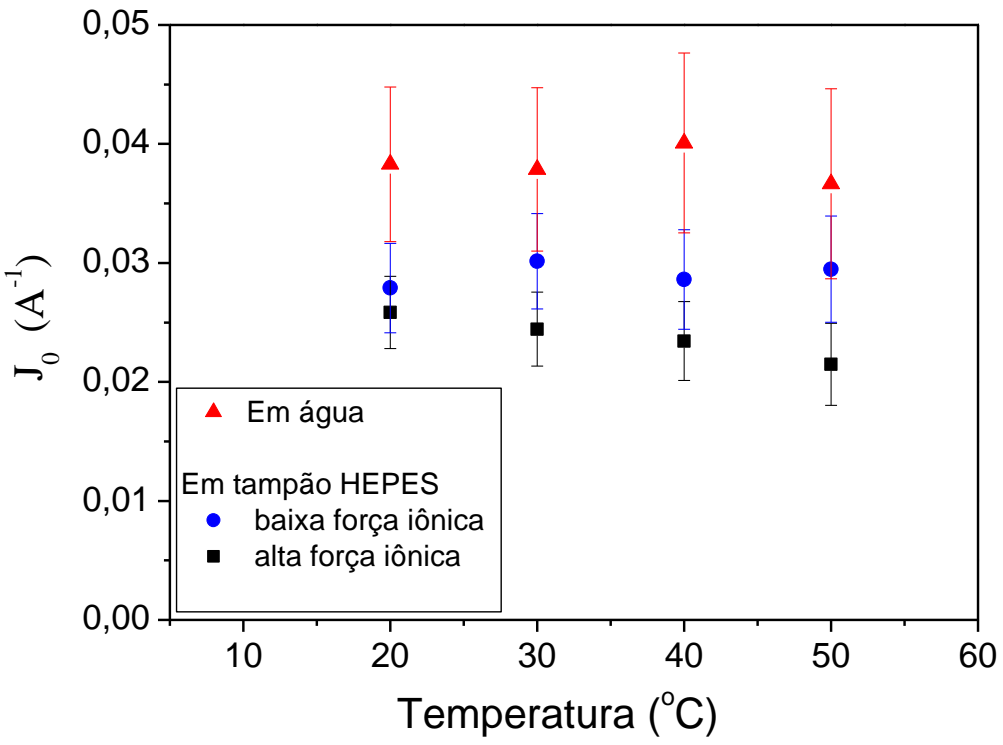

Figura 7.3.4: Curvatura espontânea da monocamada de DMPG em meios de diferente força iônica e em diferentes temperaturas. 
Tabela 7.2: Curvatura espontânea da monocamada de DMPG em tampão HEPES alta força iônica (250 mM de $\mathrm{NaCl}$ ), baixa força iônica (2 mM de $\mathrm{NaCl}$ ) e em água pura.

\begin{tabular}{cccc}
\hline & Alta força iônica & Baixa força iônica & Água \\
\hline Temp. $\left({ }^{\circ} \mathbf{C}\right)$ & $\mathbf{J}_{\mathbf{0}}\left(\mathbf{A}^{-\mathbf{1}}\right)$ & $\mathbf{J}_{\mathbf{0}}\left(\mathbf{A}^{-1}\right)$ & $\mathbf{J}_{\mathbf{0}}\left(\mathbf{A}^{-1}\right)$ \\
\hline $\mathbf{2 0}$ & $0,026 \pm 0,003$ & $0,028 \pm 0,004$ & $0,038 \pm 0,007$ \\
\hline $\mathbf{3 0}$ & $0,024 \pm 0,003$ & $0,030 \pm 0,004$ & $0,038 \pm 0,007$ \\
\hline $\mathbf{4 0}$ & $0,023 \pm 0,003$ & $0,029 \pm 0,004$ & $0,040 \pm 0,008$ \\
\hline $\mathbf{5 0}$ & $0,021 \pm 0,003$ & $0,029 \pm 0,004$ & $0,037 \pm 0,008$ \\
\hline
\end{tabular}

A partir dos dados da figura 7.3.4 e da tabela 7.2, vemos que os valores de $J_{0}$ não mudam com a temperatura e que, apesar da incerteza considerável, a curvatura diminui com o aumento da força iônica do meio. $\mathrm{O}$ fato de $\mathrm{J}_{0}$ em água ser mais positiva que em tampão, indica que, possivelmente, a maior repulsão entre as cabeças polares aumenta a distância entre as mesmas, aumentando a curvatura medida, lembrando que para lipídios de geometria cilíndrica, como o DMPG, é esperada uma curvatura próxima a zero (figura 7.3.1).

Os valores de curvatura obtidos por este método não indicaram mudanças em Jo com a temperatura, diferente do que foi observado em Alakoskela et al., 2010, onde a mudança na curvatura espontânea do DMPG em tampão a baixa força iônica foi interpretada como um indício de formação de poros na "região de transição de fase". 


\section{Capítulo 8 - Discussão}

\section{conclusões}

Neste capítulo é apresentada uma discussão geral dos resultados obtidos com as diferentes técnicas experimentais para dispersões extrusadas e não extrusadas de DMPG em água e em tampão a baixa força iônica. Apresentamos também as conclusões obtidas com esta tese e sua contribuição no estudo deste sistema 
A partir dos resultados obtidos nesta tese, mostramos que, de fato, a força iônica do meio desempenha um papel fundamental na estrutura dos agregados de DMPG, e no comportamento peculiar monitorado por diferentes técnicas experimentais.

Enquanto o comportamento observado em meio de alta força iônica (10 mM de HEPES + $250 \mathrm{mM}$ de $\mathrm{NaCl}$ ) (figura 8.1.1) é muito parecido ao de dispersões do lipídio zwitteriônico DMPC, o mesmo não acontece para dispersões de DMPG em meios de baixa força iônica.

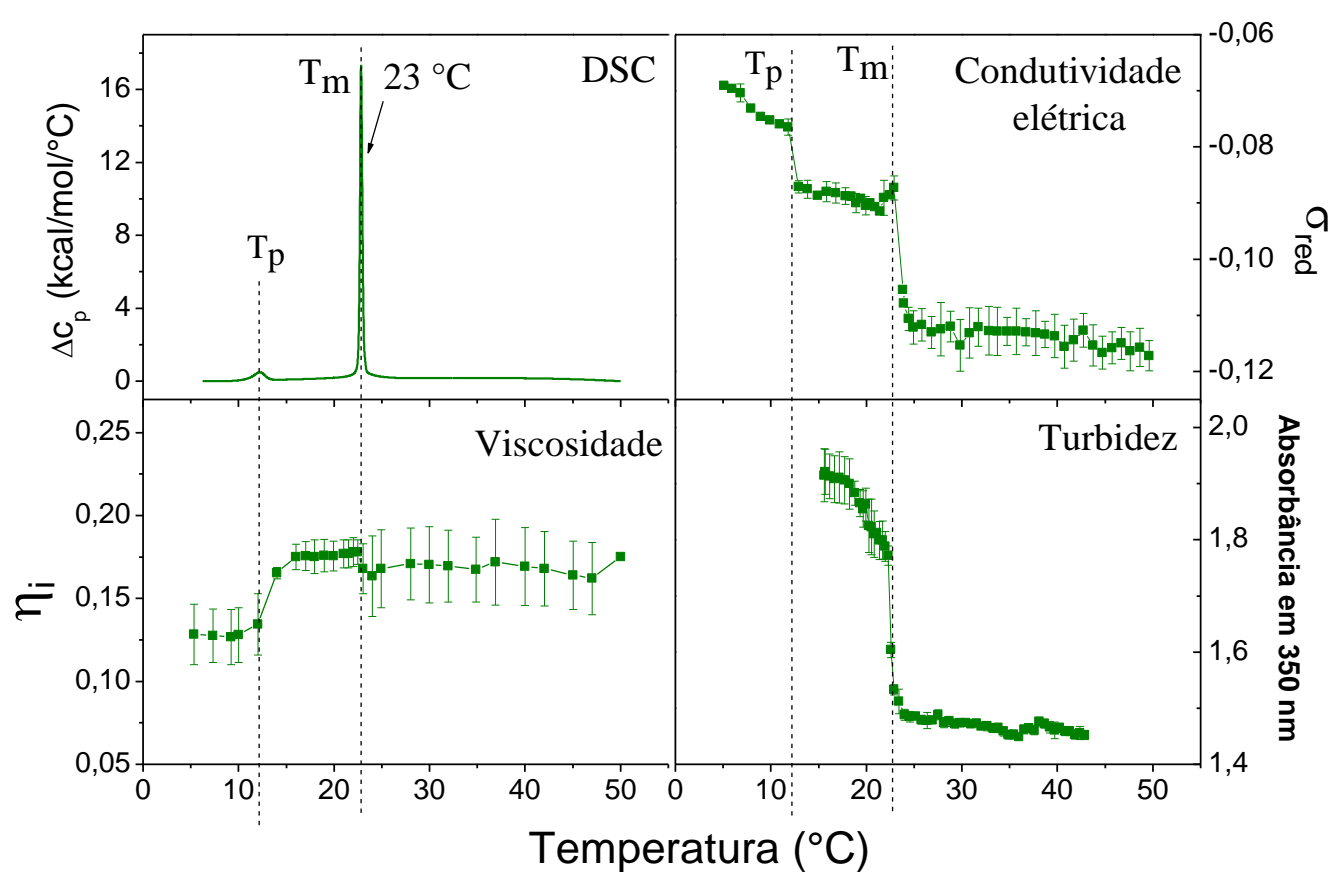

Figura 8.1: Resultados de DSC, incremento da viscosidade relativa $\left(\eta_{i}\right)$, condutividade reduzida $\left(\sigma_{\text {red }}\right.$ ) e turbidez de dispersões não extrusadas de $10 \mathrm{mM}$ de DMPG em tampão HEPES a alta força iônica (250 mM de $\mathrm{NaCl}$ ). (Resultados obtidos em Barroso, 2010).

Em dispersões de DMPG em meio de alta força iônica (figura 8.1), é observada uma transição de fase altamente cooperativa, em $T_{m}=23^{\circ} \mathrm{C}$, sendo que acontecem variações da viscosidade e condutividade a partir da temperatura de pré-transição $\left(T_{p}\right)$ e uma queda brusca da turbidez em $\mathrm{T}_{\mathrm{m}}$. Nas medidas de DLS que realizamos com dispersões extrusadas de $1 \mathrm{mM}$ de DMPG em tampão a alta força iônica (figura 5.6.3) o raio efetivo variou de $(50 \pm 2) \mathrm{nm}$ na fase gel para $(57 \pm 2) \mathrm{nm}$ na fase fluida, que também são valores compatíveis aos obtidos para dispersões de DMPC (Enoki, 2010). O fato da condutividade reduzida ser negativa, isto é, a condutividade da dispersão ser mais baixa do que a condutividade do tampão, foi atribuído ao encapsulamento dos íons do 
solvente pelas vesículas de DMPG e o mesmo comportamento é visto em dispersões de DMPC. A queda na turbidez após a transição de fase é atribuída à diminuição do índice de refração da bicamada lipídica, ao passar da fase gel para a fluida (Disalvo, 1991; Yi and MacDonald, 1973). As variações na condutividade elétrica e na viscosidade após a pré transição e a transição de fase principal ainda são objetos de estudo, mas provavelmente estão relacionadas às variações da ionização da bicamada lipídica após a transição (Barroso, 2010).

Retomando a sobreposição dos resultados obtidos para dispersões extrusadas de 10 mM de DMPG em tampão a baixa força iônica (10 mM de HEPES + 2 mM de $\mathrm{NaCl}$ ) que foi apresentada na figura 5.7.1b, acrescentamos as medidas da espessura da bicamada, da posição do pico de WAXS, da distância de repetição do pico de Bragg na região de muito baixo ângulo e da razão $h+1 / h_{0}$.

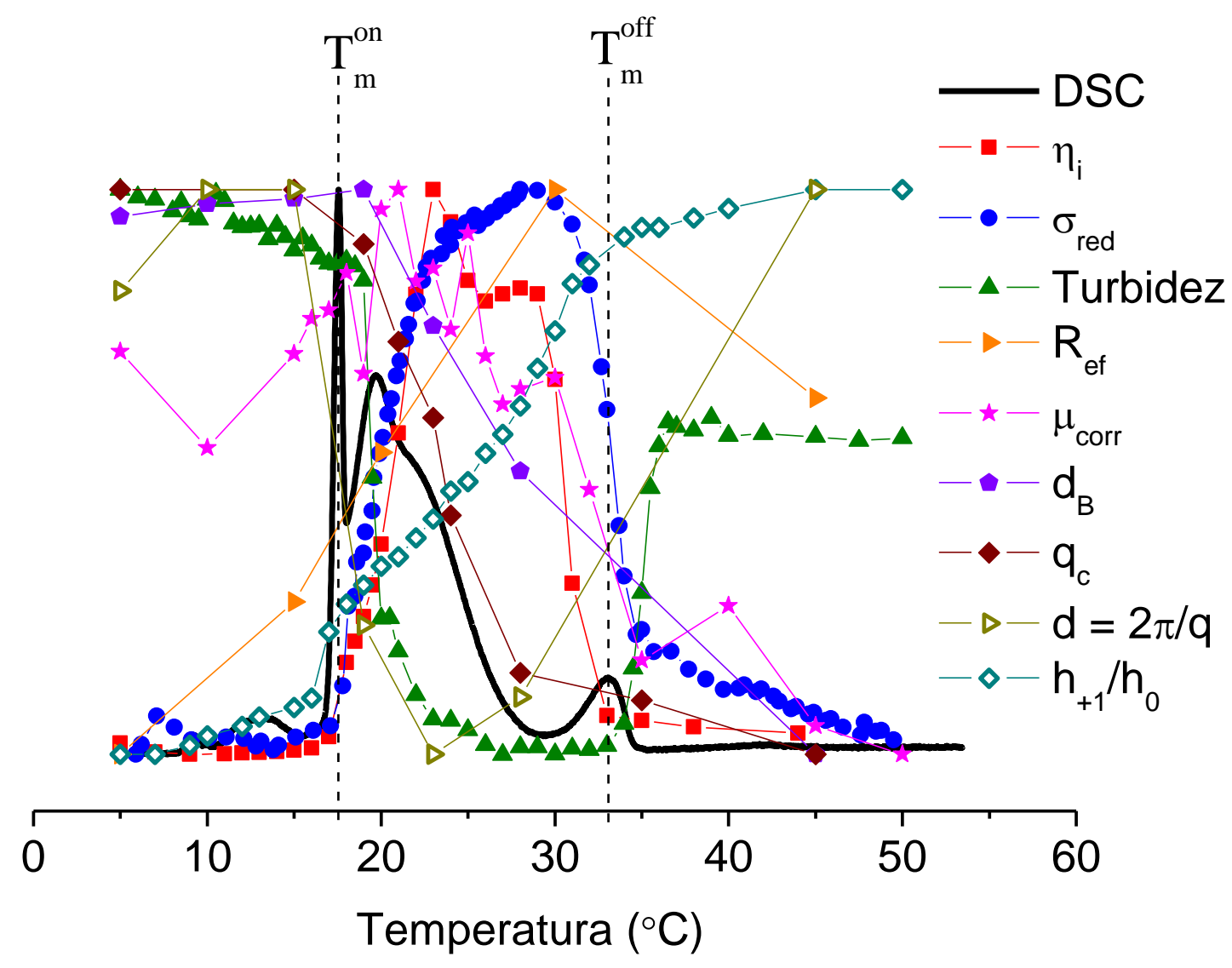

Figura 8.2: Sobreposição dos resultados de DSC, incremento da viscosidade relativa $\left(\eta_{i}\right)$, condutividade reduzida $\left(\sigma_{\text {red }}\right)$, turbidez, mobilidade elefrorética corrigida $\left(\mu_{c o r r}\right)$ e raio efetivo ( $\left.R_{e f}\right)$ calculado por DLS, espessura da bicamada $\left(d_{B}\right)$, posição do pico de WAXS $\left(q_{c}\right)$, distância de repetição dos picos de SAXS na região de muito baixo q ( $d$ ) e $h+1 / h o$ de dispersões extrusadas de $10 \mathrm{mM}$ ( $1 \mathrm{mM}$ para a medida de $R_{e f}$ e $50 \mathrm{mM}$ para $q_{c}$ e $d$ ) de DMPG em tampão a baixa força iônica. 
Com dispersões de DMPG em tampão a baixa força iônica, o comportamento observado pelas diferentes técnicas experimentais é bastante diferente dos resultados em alta força iônica, sendo observada uma "região de transição e fase". As características "anômalas", que já haviam sido descritas para as dispersões não extrusadas de DMPG, foram observadas também para as dispersões extrusadas. Ao longo da "região de transição de fase", são observados picos de absorção de calor por DSC, altos valores de condutividade elétrica, viscosidade, mobilidade eletroforética, raio efetivo e baixa turbidez. Sendo que após o término dos picos de absorção de calor, quando as bicamadas se encontram na fase fluida, os valores de condutividade elétrica e viscosidade voltam a assumir valores próximos ao do tampão, como observado na fase gel, o raio efetivo e a mobilidade eletroforética corrigida diminuem e a turbidez assume valores próximos ao da fase gel.

O uso de dispersões mais homogêneas, extrusadas por filtros de $100 \mathrm{~nm}$, levou à descoberta de que o pico de Bragg observado em valores muito baixos de q não está somente relacionado com a "região de transição de fase", portanto não deve ser modelado como poros na bicamada lipídica que se abririam nesta região. Como consequência, os dois sinais de RPE, observados com o marcador de spin 16-PCSL (Riske et al., 2003), vindos de sítios com estruturas/mobilidades diferentes, e interpretados como marcadores na bicamada e na borda do poro, devem ter uma outra interpretação, uma vez que, mesmo para dispersões extrusadas a dupla população só é vista na "região de transição de fase" (Duarte et al., trabalho em elaboração).

Revisitamos os dados de SLS, e mostramos que a aproximação de Zimm é válida para as medidas de dispersões de DMPC, em todas as temperaturas, e para dispersões de DMPG em tampão a baixa força iônica, mas apenas nas fases gel $\left(16^{\circ} \mathrm{C}\right)$ e fluida $\left(45^{\circ} \mathrm{C}\right)$. Nas temperaturas de 20 e $28^{\circ} \mathrm{C}$ (que se encontram na "região de transição de fase"), a metodologia de Zimm Plot não é válida para a análise dos dados, uma vez que o comportamento de $\Delta R_{\theta} / K c$ não é linear com q ${ }^{2}$ (ver equação 2.3.13). Este fato pode estar relacionado com maiores interações entre as partículas nesta região, como mostrado pelas medidas de condutividade elétrica e mobilidade eletroforética, sendo necessário adotar um modelo que leve em consideração essas interações no fator de estrutura. Possivelmente, este resultado também explica a grande diferença para os 
raios efetivos obtidos pelas técnicas de DLS e SLS neste intervalo de temperaturas em Enoki et al., 2012.

Resultados de SAXS e WAXS mostraram mudanças na espessura e no empacotamento das bicamadas após $19^{\circ} \mathrm{C}$, estando de acordo com a temperatura de $\mathrm{T}_{\mathrm{m}}{ }^{\text {n }}$, que indica o início da transição de fase. Medidas da razão de despolarização da luz espalhada mostraram a presença de agregados isotrópicos (de 5 a $45^{\circ} \mathrm{C}$ ), mesmo após se passar 1 semana da preparação das amostras. Medidas de DSC, viscosidade e condutividade, aumentando e diminuindo a temperatura, foram similares, mostrando a reversibilidade dos eventos observados.

Como medidas de SAXS e WAXS foram realizadas com dispersões extrusadas de 50 mM de DMPG em tampão a baixa força iônica, também caracterizamos esse sistema, sendo observada uma "região de transição de fase" em um intervalo de temperaturas menor (entre 20 e $27^{\circ} \mathrm{C}$, figura 5.8.4) que o de dispersões de $10 \mathrm{mM}$ de DMPG e que o de dispersões de 50 mM não extrusadas. Esta região também apresenta baixa turbidez, alta condutividade e viscosidade, sendo que a viscosidade não permanece alta durante todas as temperaturas da "região de transição", como observado para dispersões não extrusadas (Barroso, 2010). Comparações entre amostras de DMPG a várias concentrações estão discutidas em Barroso et al., 2010 e o efeito observado é similar so observado com a variação da força iônica do solvente.

Após a extrusão, para dispersões de 10 e 50 mM de DMPG, são observados valores de entalpia, condutividade, viscosidade e tubidez (na fase gel) consideravelmente menores que os resultados obtidos para dispersões não extrusadas. Este fato deve estar relacionado com a ausência das vesículas maiores, que são eliminadas após a extrusão, portanto a maior homogeneidade das dispersões.

Para dispersões de $10 \mathrm{mM}$ de DMPG extrusadas por filtros de $30 \mathrm{~nm}$ a "região de transição de fase" ainda é observada por medidas de DSC, e medidas de DLS mostraram agregados de diâmetros próximos a $30 \mathrm{~nm}$, enquanto para dispersões extrusadas por filtros de $100 \mathrm{~nm}$, o diâmetro medido é próximo a $60 \mathrm{~nm}$, mostrando que o processo de agitação do filme lipídico em solução aquosa forma uma maioria de vesículas pequenas e o processo de extrusão por filtros de $100 \mathrm{~nm}$ apenas elimina algumas vesículas maiores. 
Experimentos de microscopia óptica (Riske et al., 2009) mostraram que vesículas gigantes de DMPG desaparecem no plano focal do microscópio apenas nas temperaturas da "região de transição de fase", possivelmente pela perda de contraste óptico das bicamadas, notando-se flutuações de tamanho e forma das vesículas. A baixa turbidez observada a partir do início da transição de fase pode estar relacionada com flutuações da bicamada ou devido à maior passagem de água pela bicamada, estando de acordo com medidas de RPE (Lamy-Freund e Riske, 2003) que sugerem que na região de transição existem bicamadas com lipídios extremamente frouxos. Além disto, medidas de RPE mostraram que não há fusão dos agregados de DMPG ao longo da transição de fase (Lamy-Freund e Riske, 2003), o que descarta a formação de uma fase esponja (Schneider et al., 1999) na "região de transição".

A partir destes resultados, podemos propor a coexistência de vesículas maiores e menores nas dispersões de DMPG em tampão a baixa força iônica, sendo que o processo de extrusão por filtros de $100 \mathrm{~nm}$ apenas eliminaria algumas vesículas maiores. Desta forma, as vesículas de menores tamanho (maior curvatura) iniciariam o processo de transição antes das maiores, dando origem às duas populações distintas vistas por RPE na "região de transição de fase".

Outra proposta seria a de presença de vesículas deformadas na "região de transição", sendo que estas deformações poderiam ser disparadas por algum evento térmico ou pela coexistência de regiões mais e menos carregadas. Regiões mais carregadas, onde a repulsão eletrostática entre as cabeças polares é maior, favoreceriam a fase fluida da bicamada e regiões menos carregadas, a fase gel, sendo que esta coexistência de fases levaria a deformações na bicamada (figura 8.3). Isto explicaria a coexistência das duas populações de mobilidades diferentes, vistas por RPE.

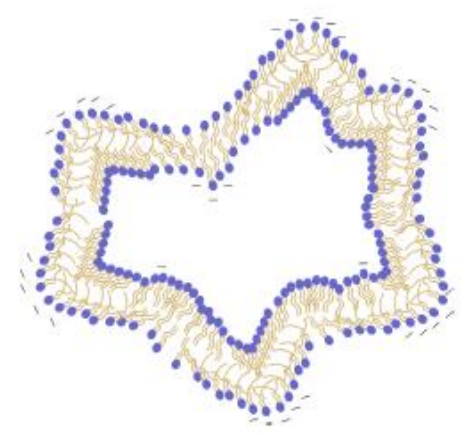

Figura 8.3: Modelo de vesículas com deformações na bicamada. [fonte: Enoki, 2010]. 
Essas deformações, em média, manteriam a forma esférica da vesícula, de acordo com as medidas de razão de despolarização da luz espalhada, que se manteve baixa em todas as temperaturas (de 5 a $45^{\circ} \mathrm{C}$ ). Este modelo está de acordo com os resultados obtidos, uma vez que valores altos de calor específico podem indicar grandes flutuações de energia e densidade da bicamada, sendo que as interações hidrofóbicas das cadeias hidrocarbônicas (atrativas) e interações eletrostáticas entre as cabeças polares (repulsivas) competem causando as flutuações. A alta queda da turbidez e a perda de contraste óptico na microscopia óptica estariam relacionadas com a maior passagem de água das regiões deformadas, fazendo com que o índice de refração da bicamada seja próximo ao do solvente. Explica também o aumento da condutividade e mobilidade eletroforética, sendo que nas regiões deformadas os lipídios estão mais carregados. Junto com o aumento de carga, grandes flutuações e deformações causariam o aumento da viscosidade do meio. Se interpretarmos o pico de SAXS observado na região de muito baixo ângulo como a distância entre bicamadas de vesículas vizinhas, o aumento do raio efetivo diminuiria esta distância, de acordo com o que foi observado experimentalmente.

Para dispersões em força iônica ainda mais baixa, em água pura, os resultados mostraram um comportamento bem diferente do observado para dispersões em tampão a alta e baixa força iônica. Retomamos a sobreposição dos resultados obtidos para dispersões extrusadas de $10 \mathrm{mM}$ de DMPG em água, que foi apresentada na figura 5.7.1a, também acrescentamos os dados de espessura da bicamada, da posição do pico de WAXS, da distância de repetição do pico de Bragg na região de muito baixo ângulo e da razão $h_{+1} / h_{0}$. 


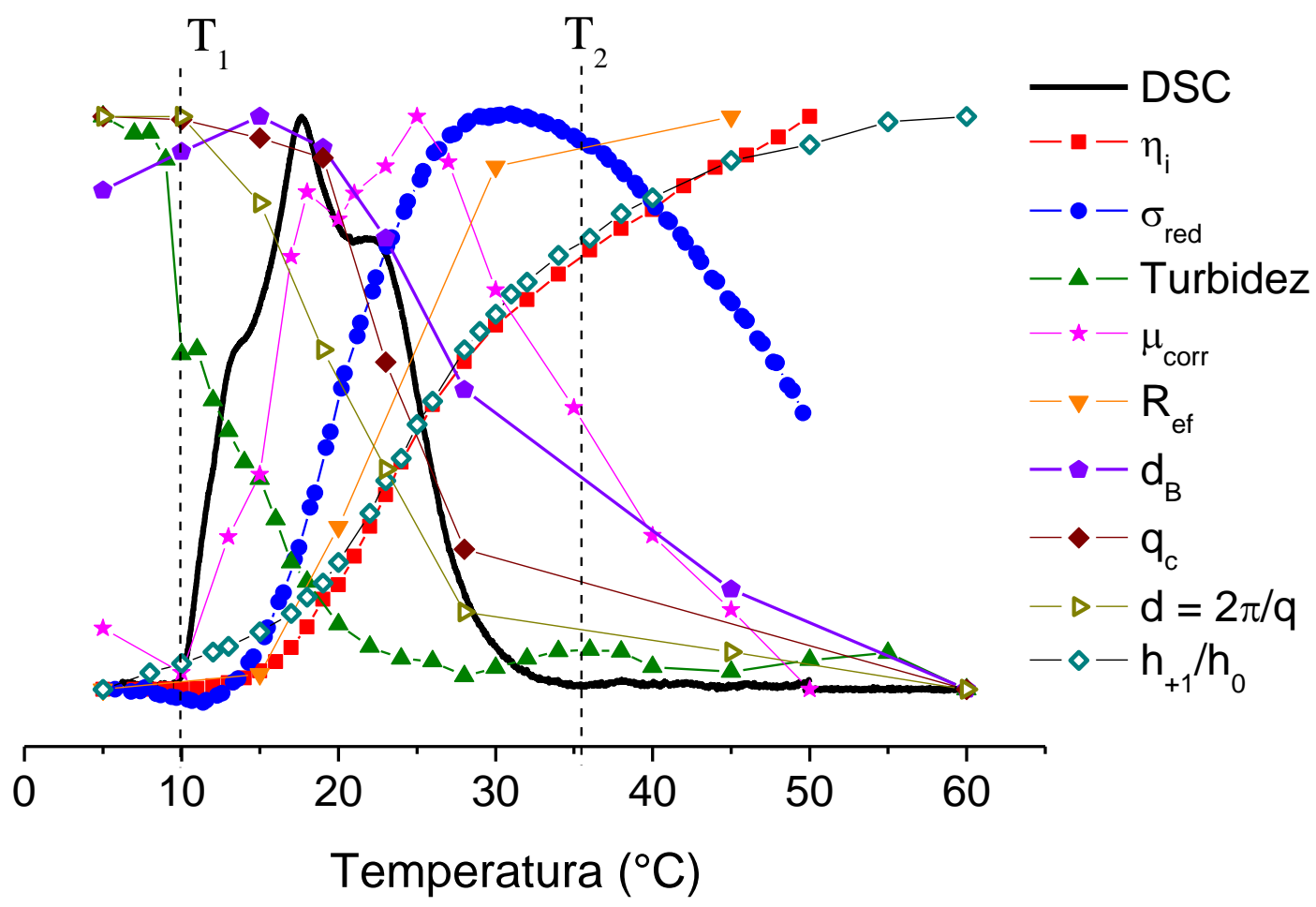

Figura 8.4: Sobreposição dos resultados de DSC, incremento da viscosidade relativa $\left(\eta_{i}\right)$, condutividade reduzida $\left(\sigma_{\text {red }}\right)$, turbidez, mobilidade elefrorética corrigida $\left(\mu_{\text {corr }}\right)$ e raio efetivo ( $\left.R_{e f}\right)$ calculado por DLS, espessura da bicamada $\left(d_{B}\right)$, posição do pico de WAXS $\left(q_{c}\right)$, distância de repetição dos picos de SAXS na região de muito baixo q $(d)$ e $h+1 / h o$ de dispersões extrusadas de $10 \mathrm{mM}$ ( $1 \mathrm{mM}$ para a medida de $R_{e f}$, e $50 \mathrm{mM}$ para $q_{c}$ e $d$ ) de DMPG em água.

Para dispersões em água pura, uma "região de transição de fase" ainda mais extensa é observada, sendo que os picos de absorção de calor (-) têm início em uma temperatura ainda mais baixa, em torno de $10^{\circ} \mathrm{C}$. É notável que um processo se inicia em $\mathrm{T}_{1}$, sendo que a partir de $10^{\circ} \mathrm{C}$ a turbidez $(\Delta)$ tem uma queda brusca e a mobilidade eletroforética da vesícula de DMPG $(\star)$ começa a crescer. Em $\sim 15^{\circ} \mathrm{C}$, observa-se o início do aumento da condutividade elétrica (O) e da viscosidade ( $\square$ ) da dispersão, e a diminuição da distância de repetição relacionada ao pico de baixo q de SAXS $(D)$. Entretanto, grandes mudanças estruturais na bicamada lipídica só serão observadas próximo a $20^{\circ} \mathrm{C}$ : diminuição do valor de q do pico de WAXS $(\nabla)$, concomitante ao seu alargamento (figura ); diminuição da espessura da bicamada lipídica ( ) monitorada por SAXS; e crescimento rápido do parâmetro da RPE $h_{+1} / h_{0}(\diamond)$, que indica a fluidificação da bicamada lipídica. Também $\sim 20^{\circ} \mathrm{C}$ observa-se o aumento do raio hidrodinâmico da vesícula $(\nabla)$, e a turbidez $(\Delta)$ da amostra já é praticamente zero. Portanto, podemos 
especular que alguma mudança na membrana comece a $10^{\circ} \mathrm{C}$, talvez somente em sua superfície, como variação de carga, relacionada com pequenas deformações da superfície, algo como uma "pré-transição" de fase, mas a transição gel-fluido das cadeias hidrocarbônicas só começaria a acontecer em torno de $20^{\circ} \mathrm{C}$. Mudanças de fase não sincrônica entre a região das cabeças polares e as cadeias hidrocarbônicas já foram observadas em Wu et al., 2009, em dispersões aquosas de DODAB.

Diferente do observado para as dispersões em tampão a baixa força iônica (figura 8.2), mesmo após o fim dos picos de absorção de calor, algumas das características anômalas que aparecem apenas na "região de transição de fase" das dispersões em tampão, permanecem até altas temperaturas nas dispersões em água, sendo que após $\mathrm{T}_{2}$ a condutividade elétrica (O) começa a diminuir lentamente, a mobilidade eletroforética $(\star)$ diminui, o raio hidrodinâmico $(\nabla)$ permanece alto, as amostras permanecem transparentes até $60^{\circ} \mathrm{C}$, e o incremento da viscosidade relativa ( $\square$ ) continua aumentando, mas de maneira mais sutil. Esta característica bastante peculiar para a viscosidade de dispersões de DMPG em água, que permanece aumentando com o aumento da temperatura, fez com que a preparação e a extrusão das amostras fossem realizadas em baixas temperaturas (em torno de $5^{\circ} \mathrm{C}$ ), pois a alta viscosidade dificultava a mistura das amostras, criando bolhas de ar difíceis de ser retiradas.

Apesar da entalpia das transições em água e em tampão a baixa força iônica serem iguais ( $\Delta \mathrm{H}=5,0(5) \mathrm{kcal} / \mathrm{mol}$ para as dispersões extrusadas), vemos que os perfis de DSC são bastante diferentes para os dois sistemas, sendo que a transição de fase das dispersões em água é muito menos cooperativa que a transição em tampão, dada a ausência de um pico estreito e intenso na transição. Apesar de pouco cooperativa, medidas de WAXS (figura 7.1.2) e de RPE (figuras 6.1.3 e 6.1.7) mostraram mudanças no empacotamento da bicamada, indicando que de fato está havendo a transição de uma fase gel, onde a bicamada está mais empacotada e ordenada para uma fase fluida mais desordenada.

O fato da transição ser menos cooperativa, a maior facilidade em se realizar a extrusão, a menor turbidez na fase gel e o fato de medidas de dispersões extrusadas e não extrusadas serem muito semelhantes, indicavam que os agregados de DMPG em água seriam menores do que os agregados em tampão a baixa força iônica. Entretanto, 
medidas de DLS mostraram vesículas de tamanhos semelhantes para os dois sistemas. Neste caso, devemos ter em mente que o raio efetivo medido por DLS leva em conta a camada de hidratação que se move junto com as vesículas de DMPG.

Sendo o inverso do comprimento de Debye $\left(\lambda_{D}\right)$ dado pelo inverso do parâmetro de Debye-Hückel (к) (Hiemenz, 1986):

$$
\kappa^{2}=\frac{e^{2} \sum_{i} z_{i}^{2} n_{i}}{\varepsilon k T}
$$

onde e $=1,6.10^{-19} \mathrm{C}$ é a carga fundamental, $\mathrm{k}=1,38.10^{-23} \mathrm{~J} / \mathrm{K}$ é a constante de Boltzmann, T é a temperatura em $K, \varepsilon$ é a permissividade do meio, $z_{i}$ é a carga dos íons e $n_{i}$ referese ao número de íons $/ \mathrm{m}^{3}$.

Podemos relacionar $\mathrm{n}_{\mathrm{i}}$ com a concentração molar, $\mathrm{M}_{\mathrm{i}}$, em mol/l pela relação:

$$
n_{i}=1000 \cdot M_{i} \cdot N_{A}
$$

uma vez que $1 \mathrm{~m}^{3}=1000 \mathrm{I}$.

A força iônica, I, de uma solução é dada por:

$$
I=\frac{\sum_{i} z_{i}^{2} M_{i}}{2}
$$

De modo que a equação 8.1 pode ser escrita por:

$$
\kappa^{2}=\frac{1000 \cdot e^{2} N_{A}(2 I)}{\varepsilon k T}
$$

Podemos calcular $\mathrm{K}$ a $25^{\circ} \mathrm{C}(\mathrm{T}=298 \mathrm{~K})$, usando que $\varepsilon=\varepsilon_{0} \varepsilon_{\mathrm{r}}$, sendo $\varepsilon_{0} \approx 8,85.10^{-12}$ $\mathrm{C}^{2} \mathrm{~J}^{-1} \mathrm{~m}^{-1}$, a permissividade no vácuo, e $\varepsilon_{\mathrm{r}} \approx 78,54$, a constante dielétrica da água nesta temperatura:

$$
\kappa^{2}=\frac{1000 \cdot\left(1,6 \cdot 10^{-19}\right)^{2}\left(6 \cdot 02 \cdot 10^{23}\right)(2 I)}{(78,54) \cdot\left(8,85 \cdot 10^{-12}\right) \cdot\left(1,38 \cdot 10^{-23}\right) \cdot(298)}
$$

Vemos que $\mathrm{k}$ e, consequentemente, $\lambda_{\mathrm{D}}$, dependem apenas da força iônica do meio.

No caso da água pura, os únicos íons em solução a distâncias grandes das vesículas, são provenientes das moléculas de água $\left(\mathrm{H}_{3} \mathrm{O}^{+}\right.$e $\left.\mathrm{OH}^{-}\right)$, ou seja, podemos 
determinar a força iônica da água a partir das medidas do $\mathrm{pH}$, sendo que em $25^{\circ} \mathrm{C}$ o valor que medimos foi de 6,2 para a água Milli-Q utilizada. Para as soluções tampão foi utilizado $\mathrm{pH}=7,4$ e deve-se levar em conta o acréscimo de $\mathrm{NaCl}$.

Tabela 8.1: Cálculo do comprimento de Debye para meios de diferentes forças iônicas.

\begin{tabular}{ccc}
\hline & $\mathbf{2 l}(\mathbf{m M})$ & $\boldsymbol{\lambda}_{\mathrm{D}}(\mathbf{n m})$ \\
\hline Água & $6,3.10^{-4}$ & 543 \\
\hline HEPES + $\mathbf{2} \mathbf{~ m M ~ d e ~ N a C l}$ & 6,0 & 5,6 \\
\hline HEPES + $250 \mathrm{mM}$ de NaCl & 254 & 0,9 \\
\hline
\end{tabular}

A partir da tabela 8.1, vemos que o comprimento de Debye, que serve como uma medida aproximada da espessura da dupla camada elétrica que que se forma ao redor das vesículas de DMPG, é maior quanto menor a força iônica do meio, sendo muito maior para a dispersão em água pura do que em tampão. Desta forma, pode ser que as vesículas de DMPG em água sejam menores que em tampão a baixa força iônica, mas a camada elétrica que se forma ao seu redor, e que entra no cálculo do raio efetivo em experimentos de DLS, é mais espessa do que a camada que se forma ao redor das vesículas em tampão. Como esta camada de íons não deve influenciar o espalhamento de luz visto pelas medidas de turbidez, vesículas menores nas dispersões em água explicariam a menor turbidez na fase gel (figura 5.5.2).

Apesar dos tamanhos medidos por DLS já serem pequenos (tabela 5.1), principalmente se levarmos em conta que as extrusões foram realizadas com filtros de $100 \mathrm{~nm}$, medidas de DSC mostraram que, mesmo após a extrusão por filtros de $30 \mathrm{~nm}$, a "região de transição de fase" ainda é observada, mostrando que é possível a formação de vesículas de DMPG com diâmetros tão pequenos quanto $30 \mathrm{~nm}$.

Comparando os tamanhos dos raios medidos por DLS (tabela 5.1), vemos que o aumento observado para os agregados em tampão a alta força iônica é compatível com o aumento da área por cabeça polar visto na literatura. 0 aumento de 0,48 para 0,60 $\mathrm{nm}^{2}$ (Marsh \& Phill, 1990) após a transição de fase, equivale a um aumento de área de $25 \%$. Como a área de superfície de vesículas esféricas é dada por $4 \pi R^{2}$, o aumento visto por DLS de vesículas em alta força iônica é de $29 \%$ na área. Já para as dispersões em tampão a baixa força iônica, este aumento seria de $40 \%$ após a transição de fase, e para 
a dispersão em água a área superficial seria cerca de 3 vezes maior após a transição de fase! Medidas da curvatura espontânea do DMPG (figura 7.3.4) nos meios de diferentes forças iônicas indicaram uma curvatura maior quanto menor a força iônica, indicando que a área ocupada por cabeça polar diminui com o aumento da força iônica do meio. O grande aumento observado das vesículas em água poderia explicar o aumento da viscosidade. Entretanto, o aumento de 2 vezes na área parece ser muito grande para ser explicado considerando-se apenas um aumento na área ocupada por lipídio na bicamada, e possivelmente este aumento também não deve estar relacionado com um grande aumento da dupla camada elétrica com o aumento da temperatura, pois em primeira aproximação só é dependente da força iônica do meio (equação 8.4). Como mostrado nas medidas de condutividade elétrica e mobilidade eletroforética, as vesículas de DMPG em água ficam mais carregadas após a transição e fase, sendo que possíveis interações entre os agregados podem estar ocorrendo e levando a valores errôneos medidos por DLS.

Outra hipótese para a menor turbidez das vesículas de DMPG em água na fase gel, pode estar relacionada com o resultado visto por RPE (figura 6.2.8) onde mostrouse que as bicamadas de DMPG em água, na fase gel, são menos empacotadas do que em tampão a baixa força iônica. Desta forma, pode ser que mais moléculas de água estejam presentes na bicamada, diminuindo o contraste óptico observado.

Na fase fluida, resultados de RPE (figura 6.2.9) mostraram bicamadas mais empacotadas em água do que em tampão a baixa força iônica, sendo que a polaridade medida é maior para as dispersões em água. Desta forma, pode-se especular que mais moléculas de água penetrariam a bicamada de DMPG em água, causando a maior polaridade, ao mesmo tempo que as moléculas de água diminuiriam a mobilidade das cadeias hidrocarbônicas. Este fato também pode explicar a turbidez que permanece baixa nas dispersões de DMPG em água até altas temperaturas.

Várias são as indicações que temos vesículas e não micelas ou bicelas em dispersões de DMPG em água, como foi proposto anteriormente por Epand e Hui, 1986. Medidas da razão de despolarização da luz espalhada (figura 5.6.7) mostraram a presença de agregados isotrópicos de DMPG em água e em tampão nas temperaturas de 5 a $45^{\circ} \mathrm{C}$. Medidas de RPE com os marcadores 5-PCSL e 16-PCSL mostraram curvas 
típicas de bicamadas lipídicas, sendo que os espectros apresentaram uma ordem maior do que espectros de micelas de $\mathrm{C}_{18} \mathrm{TAB}$ (octadecil trimetil amônio brometo) (Benatti et al, 2001). Simulações de SAXS foram bem ajustadas considerando-se bicamadas únicas e mostraram uma diminuição na espessura da bicamada após a transição de fase, sendo mais um indício da transição de uma fase gel para uma fase fluida. A espessura da bicamada em água é ligeiramente maior do que em tampão a baixa força iônica na fase fluida, estando de acordo com as cadeias menos imóveis vistas por RPE. Os resultados obtidos apontam para a presença de vesículas unilamelares esféricas, tanto em água quanto em tampão a baixa força iônica.

Os picos de SAXS em baixo $q$ foram observados em todas as temperaturas medidas para dispersões de 10, 30 e 50 mM de DMPG em água. Foi observada a dependência da posição deste pico com a temperatura, sendo que ele se desloca para valores maiores de $q$ na transição de fase e com a concentração lipídica, sendo que o pico vai para $q$ maiores (menores distâncias de repetição) com o aumento da concentração lipídica, tanto para dispersões em água quanto em tampão a baixa força iônica. Desta forma, não há nenhum indício de que estes picos estejam relacionados com membranas perfuradas na região da transição de fase, como foi proposto anteriormente. A partir destes resultados, e das medidas de DLS, especulamos que estas distâncias de repetição estariam relacionadas com as distâncias entre bicamadas de vesículas vizinhas, sendo que após a extrusão o sistema ficaria menos polidisperso e mais homogêneo, deixando o pico mais em evidência em todas as temperaturas. Entretanto, esta idéia precisa ser mais bem embasada, sendo necessário o desenvolvimento de um modelo teórico que possibilite a realização de simulações destes dados.

Um resultado bastante interessante é a presença de duas populações distintas nos espectros de RPE de dispersões extrusadas em água desde $5^{\circ} \mathrm{C}$. Como foi visto que mesmo extrusando as amostras por filtros de $100 \mathrm{~nm}$ os agregados de DMPG apresentam um tamanho bem menor, de cerca de $40 \mathrm{~nm}$, é possível que se formem uma maioria de agregados pequenos nas dispersões em água, menores do que em tampão a baixa força iônica, sendo que somente alguns agregados maiores seriam eliminados após a extrusão. Desta forma, essas duas populações vistas por RPE podem estar 
relacionadas com vesículas de tamanhos diferentes, sendo que vesículas menores apresentam uma curvatura maior e sinal mais frouxo e vesículas maiores apresentam menor curvatura e um sinal mais rígido. Outra hipótese, que não exclui a anterior, seria a de presença de vesículas com deformações na bicamada (figura 8.3), que originariam dois sinais distintos, desde a fase gel das bicamadas.

Deformações de vesículas na fase gel já foram observadas anteriormente por microscopia de fluorescência (ver, por exemplo, Hirst et al., 2013). Essas deformações foram relacionadas com a fase ripple de membranas cuja organização na fase gel é inclinada com relação ao eixo perpendicular à membrana ("tilted"). Foi proposto que na fase ripple (entra as temperaturas de pré transição e do início da transição principal) a membrana deixaria de ser plana e passaria a ser periodicamente ondulada (Heimburg, 2000; Riske et al., 2009), devido à coexistência de regiões de diferentes microestruturas.
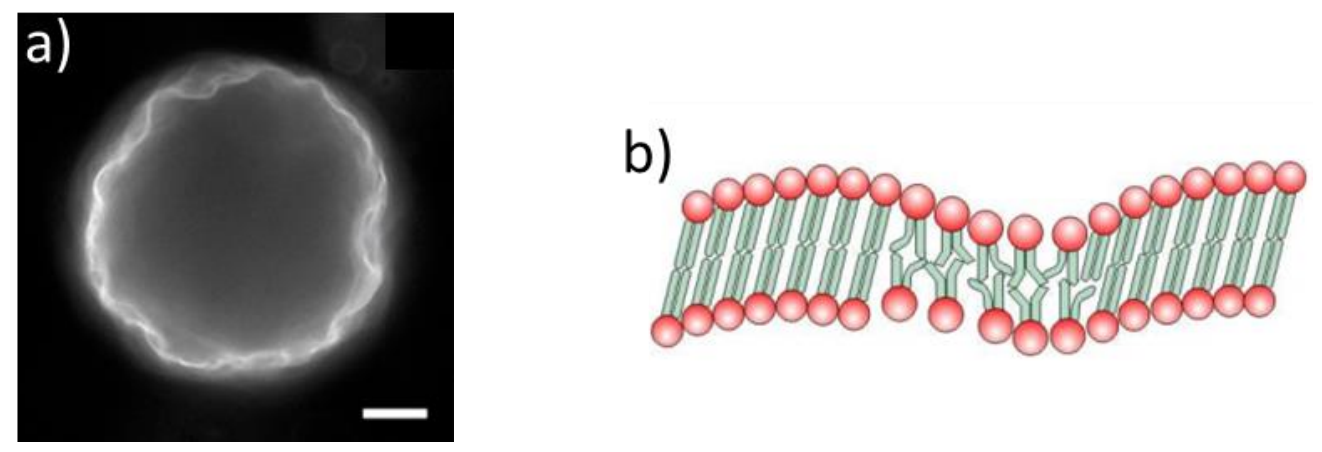

Figura 8.5: a) Deformações observadas por microscopia de fluorescência de vesículas de DPPC em água marcadas com 0,09 mol\% de NBD-PE [Figura 1 de Selinger et al., 2013]. b) Representação de uma bicamada na fase ripple [fonte: Barroso, 2010].

Os resultados obtidos com dispersões de DMPG em água reforçam o comportamento anômalo visto para dispersões de DMPG em tampão a baixa força iônica, e deste modo, propomos os modelos de vesículas que foram discutidos para o sistema de DMPG em tampão, isto é, a coexistência de vesículas pequenas e grandes e/ou a presença de vesículas deformadas, na fase gel. Sendo que as vesículas pequenas na dispersão em água, por serem menores do que em tampão, apresentariam o sinal de RPE de população mais frouxa desde $5^{\circ} \mathrm{C}$, portanto iniciaria a transição de fase em temperaturas mais baixas do que a das vesículas em tampão. 
Apesar de não ser possível propor um modelo final que explique todos os resultados obtidos, acreditamos que este trabalho trouxe importantes contribuições no estudo de dispersões de DMPG em baixa força iônica. Resultados obtidos com dispersões extrusadas de DMPG evidenciaram a relevância de trabalhar-se com dispersões lipídicas mais homogêneas. Os resultados mostraram que em água pura o comportamento anômalo do DMPG também é observado, mas de maneira mais intensa e ao longo de um intervalo maior de temperatura, o que deve se relacionar com os efeitos das cargas das vesículas, que não estão blindadas pela presença de sais no solvente. Sabemos que todos estes efeitos anômalos estão relacionados com as cargas na superfície da membrana de DMPG, e, portanto, com o balanço das interações entre as cabeças polares e as cadeias hidrocarbônicas. Ainda é necessário um modelo termoestatístico, que inclua as interações eletrostáticas e as chamadas "hidrofóbicas", que consiga descrever os fenômenos observados.

Do ponto de vista físico-químico, podemos dizer que dispersões de DMPG em baixa força iônica são sistemas extremamente interessantes e intrigantes e que podem ser utilizados como exemplo de dispersões de vesículas carregadas, altamente ionizadas. 


\section{Apêndice A - Medidas de espalhamento de luz de nanoesferas de poliestireno}

Como houve atualizações no aparelho de espalhamento de luz da Brookhaven (figura 3.2.6) do Laboratório de Biomembranas do IFUSP, sendo que o laser de $\mathrm{He}-\mathrm{Ne}$ foi trocado por um de diodo, o detector foi substituído por um mais moderno, com polarizador acoplado, mudamos o aparato experimental para uma sala mais adequada, e os softwares de aquisição de dados foram atualizados, realizamos medidas de dispersões preparadas com nanoesferas de poliestireno de tamanhos bem definidos $((21,0 \pm 1,5) \mathrm{nm}, \quad(46,0 \pm 2,0) \mathrm{nm}$ e $(92,0 \pm 3,7) \mathrm{nm})$ para verificar o correto funcionamento do equipamento e também verificar possíveis limitações no uso das técnicas de espalhamento de luz dinâmico e estático, neste aparelho, no estudo de sistemas coloidais.

Também realizamos medidas de DLS das dispersões de nanoesferas de poliestireno com o aparelho da Malvern (figura 3.2.7), de modo a comparar os resultados obtidos com os diferentes aparelhos, sendo que no aparelho da Malvern só é possível realizar medidas de espalhamento a $90^{\circ}$.

As amostras com nanoesferas de poliestireno foram preparadas em solução salina de $\mathrm{NaCl}$ com água Mili-Q filtrada por filtros com poros de $0.1 \mu \mathrm{m}$, em tubos de ensaio de vidro, totalmente translúcidos e sem danos. As alíquotas da suspensão polimérica foram coletadas por seringas Hamilton, e os tubos vedados foram mantidos à temperatura ambiente.

Tomou-se extremo cuidado, de modo a evitar contaminações por poeiras. Não se agitou as amostras, apenas tombou-se o tubo de ensaio em um movimento suave, conforme indicado pelo fabricante, para evitar a formação de micro bolhas de ar. 


\section{A.1 DLS de dispersões de nanoesferas de poliestireno}

Preparou-se duas amostras monodispersas suficientemente diluídas para cada tamanho de nanoesfera, e o resultado obtido pelo método dos Cumulantes (Kopel, 1972) diretamente do software da Brookhaven é mostrado a seguir.

Tabela A.1: Medidas de DLS a $90^{\circ}$ para amostras monodispersas.

\begin{tabular}{|c|c|c|c|c|}
\hline \multirow{2}{*}{$\begin{array}{c}\text { Diâmetro } \\
\text { fornecido (nm) }\end{array}$} & \multirow{2}{*}{$\begin{array}{c}\text { Concentração } \\
\text { das dispersões } \\
(\mathbf{m g} / \mathbf{m L})\end{array}$} & \multicolumn{3}{|c|}{ Cumulantes } \\
\cline { 3 - 5 } & & $\begin{array}{c}\text { Linear } \\
\text { Diâm. (nm) }\end{array}$ & $\begin{array}{c}\text { Quadrático } \\
\text { Diâm. (nm) }\end{array}$ & Polidispersão \\
\hline $21,0 \pm 1,5$ & 0,15 & $22,3 \pm 0,4$ & $21,4 \pm 0,2$ & $0,10 \pm 0,01$ \\
\hline $92,0 \pm 3,7$ & 0,09 & $90,7 \pm 0,4$ & $89,6 \pm 0,3$ & $0,03 \pm 0,01$ \\
\hline
\end{tabular}

Vemos que os valores medidos são compatíveis com os valores de diâmetro fornecidos pelo fabricante, quando consideramos as incertezas.

Por outro lado, realizamos medidas de DLS a diferentes ângulos (70, 90, 110 e $130^{\circ}$ ) destas mesmas amostras, e usando os valores médios de $\Gamma$ obtidos pelo método do cumulantes do software, e a equação 2.3.6, obtivemos o coeficiente médio de difusão translacional ( $\left.D_{T}\right)$ dos centros espalhadores, que é o coeficiente angular da reta ajustada de $\Gamma \mathrm{x} \mathrm{q}^{2}$.

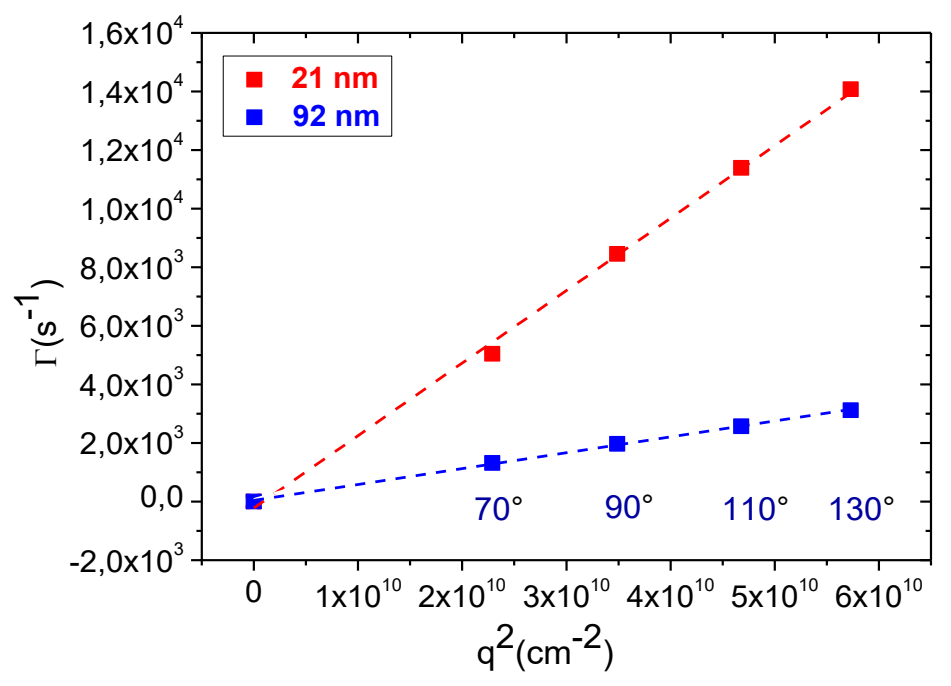

Figura A.1.1: Gráfico de $\Gamma \times q^{2}$ para medidas de DLS feitas a $70^{\circ}, 90^{\circ}, 110^{\circ}$ e $130^{\circ}$, onde os coeficientes de difusão translacional são dados pelos coeficientes angulares das retas. 
A partir dos valores de $D_{T}$ obtidos a partir do gráfico da figura A.1.1, e considerando que estamos em um regime muito diluído, usamos a equação 2.3.7 para obter os diâmetros efetivos dos centros espalhadores e os resultados são mostrados a seguir.

Tabela A.2: Valores dos coeficientes de difusão obtidos pela figura 3.12 e diâmetro efetivo calculado pela equação 2.3.7.

\begin{tabular}{|c|c|c|}
\hline Esferas & $D_{\mathbf{T}}\left(\mathbf{1 0}^{-\mathbf{7}} \mathbf{c m}^{\mathbf{2}} \mathbf{s}\right)$ & $d_{\text {ef }}(\mathbf{n m})$ \\
\hline $21 \mathrm{~nm}$ & $2,50(6)$ & $21,0(5)$ \\
\hline $92 \mathrm{~nm}$ & $0,54(1)$ & $92,9(1)$ \\
\hline
\end{tabular}

Dada a compatibilidade dos diâmetros efetivos calculados pela relação de Stokes-Einstein com os diâmetros fornecidos pelo fabricante, vemos que, de fato, podemos considerar que estamos lidando com sistemas pouco interagentes e que 0 equipamento está bem alinhado.

Preparamos dispersões misturando os dois tamanhos de nanoesferas e devemos lembrar que, nesta técnica, os diâmetros efetivos são calculados de acordo com uma média do tipo Z-average $\left(\overline{D_{z}}\right)$ :

$$
\bar{D}_{z}=\frac{\sum_{i} N_{i} M_{i}^{2} D_{i}}{\sum_{i} N_{i} M_{i}^{2}}
$$

sendo $N_{i}$ o número de agregados $i$ e $M_{i}$ a massa do agregado $i$ (Hiemenz, 1984).

Como $\mathrm{M}$ é proporcional a $\mathrm{R}^{3}$, portanto $\overline{D_{z}}$ é proporcional a $\mathrm{R}^{6}$ ! Por essa razão, as populações de diâmetros maiores influenciam muito mais o diâmetro médio obtido.

Além disso, sabendo a concentração das suspensões que contém as nanoesferas, relacionamos o número de nanoesferas presentes em um mesmo volume. Considerando que a massa está uniformemente distribuída no volume da esfera, isto é, o número de nanoesferas é proporcional a massa/volume obtemos, para relação entre $21 \mathrm{~nm}$ e $92 \mathrm{~nm}$ : 


$$
\frac{n^{21}}{n^{92}}=\frac{m^{21}}{V_{o l} l^{21}} \cdot \frac{V_{o l} l^{92}}{m^{92}}=\frac{20,6}{11,9} \cdot \frac{(46,0)^{3}}{(10,5)^{3}} \cong 140
$$

Isto é, em um mesmo volume de suspensão de esferas de $21 \mathrm{~nm}$ e $92 \mathrm{~nm}$, temos 140 nanoesferas de $21 \mathrm{~nm}$ para cada uma de $92 \mathrm{~nm}$.

Preparamos então duas misturas de nanoesferas de 21 e $92 \mathrm{~nm}$. Na primeira adicionamos volumes iguais das suspensões de 21 e $92 \mathrm{~nm}$ e na segunda adicionamos um volume 10 vezes maior de nanoesferas de $21 \mathrm{~nm}$ do que de $92 \mathrm{~nm}$ e os resultados de DLS a $90^{\circ}$ são apresentados na tabela A.3.

Tabela A.3: DLS a $90^{\circ}$ de misturas com esferas de 21 e $92 \mathrm{~nm}$, sendo as proporções entre elas dadas na coluna " $N^{\circ}$ de esferas".

\begin{tabular}{|c|c|c|c|c|c|c|c|c|}
\hline \multirow{2}{*}{$\begin{array}{c}\text { Diâmetro } \\
\text { fornecido } \\
\text { (nm) }\end{array}$} & \multirow{2}{*}{$\begin{array}{c}\text { Conc. das } \\
\text { soluções } \\
(\mathrm{mg} / \mathrm{mL})\end{array}$} & \multicolumn{2}{|c|}{$\begin{array}{c}\text { Calculados } \\
\text { (eq. A.1) }\end{array}$} & \multicolumn{3}{|c|}{ Cumulantes } & \multicolumn{2}{|c|}{ Dupla Exponencial } \\
\hline & & $\begin{array}{c}\mathbf{N}^{\circ} \text { de } \\
\text { esferas }\end{array}$ & $\begin{array}{l}\bar{D}_{z} \\
\text { (nm) }\end{array}$ & $\begin{array}{c}\text { Linear } \\
\text { Diâm.(nm) }\end{array}$ & $\begin{array}{l}\text { Quadrático } \\
\text { Diâm.(nm) }\end{array}$ & $\begin{array}{l}\text { Indice de } \\
\text { Polid. }\end{array}$ & $\begin{array}{l}\text { Diâm. } \\
\text { (nm) }\end{array}$ & $\begin{array}{l}\text { Diâm. } \\
\text { (nm) }\end{array}$ \\
\hline \multirow{2}{*}{$21: 92$} & 0,24 & $140: 1$ & 90,6 & $89,6 \pm 0,3$ & $88,9 \pm 0,3$ & $0,02 \pm 0,01$ & \multicolumn{2}{|c|}{ Não convergente } \\
\hline & 1,6 & $1400: 1$ & 80,3 & $82,4 \pm 2,0$ & $76,0 \pm 0,8$ & $0,16 \pm 0,02$ & $20,4 \pm 1,1$ & $90,4 \pm 1,6$ \\
\hline
\end{tabular}

Os resultados da tabela A.3 mostram que, os diâmetros obtidos pelo método dos cumulantes é próximo ao valor do diâmetro calculado pela equação 3.7, como era esperado, dando um peso muito maior para as esferas maiores (92 $\mathrm{nm}$ ) mesmo tendo muito mais nanoesferas de $21 \mathrm{~nm}$ na dispersão. Além disso, o método da dupla exponencial, que distingui dois decaimentos na função de correlação, não tem sensibilidade para distinguir as duas populações no primeiro caso em que a proporção entre as nanoesferas de 21 e $92 \mathrm{~nm}$ é de 140 pra 1. Mas quando temos 1400 nanoesferas de $21 \mathrm{~nm}$ para cada uma de $92 \mathrm{~nm}$, esse método distingui corretamente as duas populações.

Abaixo mostramos resultados obtidos no aparelho de DLS da Malvern (Fig. 3.2.7), com o uso de softwares lá disponíveis, para análise da função de autocorrelação. Como dissemos em materiais e métodos (seção 3.2.8), as medidas são obtidas com o detector a $90^{\circ}$ do feixe incidente. 
Na tabela A.4, nas quatro colunas à direita, mostramos os resultados obtidos para amostras monodispersas, amostras mistas com nanoesferas de 21 e $92 \mathrm{~nm}$, e mistas com nonoesferas de 21, 46 e $92 \mathrm{~nm}$ de diâmetro (para simplificar, escrevemos os diâmetros das nanoesferas somente com os dois primeiros algarismos). Estes resultados foram obtidos com a Expansão dos Cumulantes e o método de Multi-exponencias.

Também estão apresentados a proporção de esferas de cada tamanho nas dispersões usadas (coluna "Proporção") e o z-average do diâmetro $\left(\overline{D_{z}}\right)$, calculado através da Eq. A.1 (colunas à esquerda).

Tabela A.4: DLS a $90^{\circ}$ medidas no aparelho da Malvern dispersões monodispersas e polidispersas de nanoesferas de poliestirenos.

\begin{tabular}{|c|c|c|c|c|c|c|}
\hline \multirow{2}{*}{$\begin{array}{c}\text { Amostras } \\
\text { (diâmetro, nm) }\end{array}$} & \multicolumn{2}{|c|}{ Calculados } & \multicolumn{2}{c|}{ Expansão em Cumulantes } & \multicolumn{2}{c|}{ Multi-exponencias } \\
\cline { 2 - 7 } & Proporção & $\begin{array}{c}\overline{D_{z}} \text { (nm) } \\
\text { (Eq. A.1) }\end{array}$ & $\overline{D_{z}}$ (nm) & $\begin{array}{c}\text { Índice de } \\
\text { polidispersidade }\end{array}$ & $\begin{array}{c}\text { População 1 } \\
\text { diâm.(nm) [\%] }\end{array}$ & $\begin{array}{c}\text { População 2 } \\
\text { diâm.(nm) [\%] }\end{array}$ \\
\hline 21 & & & $22,1 \pm 0,1$ & $0,12 \pm 0,02$ & $24,2 \pm 0,2[100]$ & - \\
\hline 92 & & & $90,9 \pm 0,9$ & $0,03 \pm 0,02$ & $95,5 \pm 1,4[100]$ & - \\
\hline \multirow{3}{*}{$21: 92$} & $140: 1$ & 90,6 & $89,1 \pm 0,4$ & $0,02 \pm 0,01$ & $93,7 \pm 1,4[100]$ & - \\
\cline { 2 - 7 } & $700: 1$ & 85,6 & $81,2 \pm 0,5$ & $0,15 \pm 0,01$ & $95,5 \pm 0,8[100]$ & - \\
\cline { 2 - 7 } & $1400: 1$ & 80,3 & $74,7 \pm 1,5$ & $0,20 \pm 0,02$ & $94,6 \pm 2,3[92,9]$ & $20,3 \pm 2,0[7,1]$ \\
\cline { 2 - 7 } & $2100: 1$ & 75,7 & $69,9 \pm 0,8$ & $0,24 \pm 0,01$ & $94,8 \pm 1,0[93,3]$ & $17,0 \pm 0,5[6,7]$ \\
\hline \multirow{2}{*}{$21: 46: 92$} & $140: 9: 1$ & 84,7 & $82,3 \pm 0,3$ & $0,07 \pm 0,01$ & $89,3 \pm 0,5[100]$ & - \\
\cline { 2 - 7 } & $2100: 90: 1$ & 59,6 & $56,9 \pm 0,4$ & $0,15 \pm 0,01$ & $67,9 \pm 1,0[100]$ & - \\
\hline
\end{tabular}

A partir da tabela A.4, vemos que, para as amostras monodispersas, obtemos resultados próximos ao esperado para o tamanho das partículas em solução, da mesma forma que foi obtido com o aparelho da Brookhaven (tabelas A.1 e A.2).

No caso das dispersões mistas, os valores dos diâmetros calculados (z-average, $\overline{D_{z}}$ ) pelo equipamento, com o uso da Expansão em Cumulantes até $2 \underline{a}$ ordem, são semelhantes aos valores calculados teoricamente (Eq. A.1), mas ligeiramente menores. É importante notarmos a enorme influência das partículas grandes no cálculo de $\overline{D_{z}}$ !

O índice de polidispersidade não é confiável como indicativo da polidispersidade da amostra, já que soluções monodispersas e multidispersas apresentaram índices similares, tanto nas medidas realizadas no aparelho da Malvern, quanto nas realizadas no Brookhaven. 
Para amostras multidispersas, a análise por multi-exponenciais mostrou-se muito falha. Por exemplo, para as misturas de esferas de $21 \mathrm{~nm}$ e $92 \mathrm{~nm}$, o software só começa a distinguir as duas populações na proporção de 1400 esferas de $21 \mathrm{~nm}$ para cada esfera de $92 \mathrm{~nm}$, sendo esta a mesma proporção necessária para a separação das populações no aparelho da Brookhaven (tabela A.3). Além disso, a porcentagem fornecida de cada população é totalmente errada, e apenas mostra que a população de tamanho maior contribui muito mais para a intensidade de luz espalhada, mesmo estando em muito menor proporção na dispersão. Na presença de três populações, de 21, 46 e 92 nm, o software não foi capaz de distinguir as diferentes populações.

Os resultados de DLS obtidos com os dois equipamentos diferentes foram muito semelhantes, sendo que as medidas e análises obtidas para dispersões mistas mostram que devemos ter muito cuidado ao interpretar esses dados, uma vez que os métodos são muito mais sensíveis à presença de partículas maiores! Podemos confiar nas medidas de $\overline{D_{z}}$. Porém, não podemos confiar no indicativo de presença ou não de mais de uma população, nas frações dessas populações, e no índice de polidispersidade. 


\section{A.2 SLS de dispersões de nanoesferas de poliestireno}

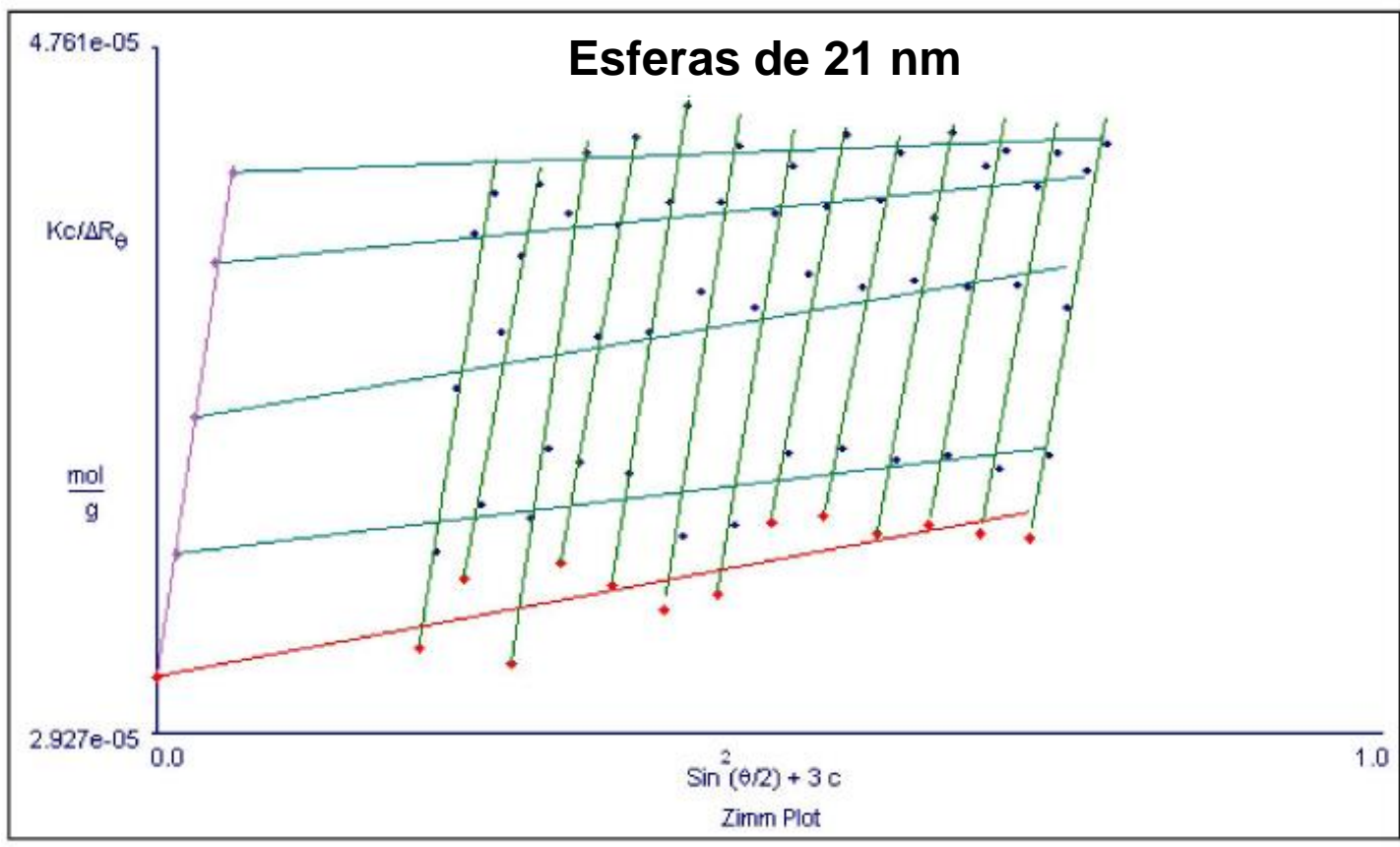

Figura A.2.1: Gráfico de Zimm para amostras com esferas de $21 \mathrm{~nm}$ e concentrações: 0,$52 ; 1,03 ; 1,55$ e $2,06 \mathrm{mg} / \mathrm{mL}$ )

Os resultados obtidos a partir da figura 3.15, calculados pela aproximação de Zimm Plot (equação 2.27) estão listados abaixo:

Tabela A.5: Resultados do gráfico de Zimm para microesferas de $21 \mathrm{~nm}$.

\begin{tabular}{cccc}
\hline \multicolumn{2}{c}{ Extrapolação a ângulo zero } & \multicolumn{2}{c}{ Extrapolação a concentração zero } \\
$\mathbf{M}_{\mathbf{w}}(\mathbf{g} / \mathbf{m o l})$ & $(3,25 \pm 0,08) 10^{4}$ & $\mathbf{M}_{\mathbf{w}}(\mathbf{g} / \mathbf{m o l})$ & $(3,25 \pm 0,07) 10^{4}$ \\
$\mathbf{R}_{\mathbf{g}}(\mathbf{n m})$ & $29,4 \pm 4,0$ & $\mathbf{A}_{\mathbf{2}}\left(\mathbf{c m}^{3} \cdot \mathbf{m o l} / \mathbf{g}^{2}\right)$ & $(3,3 \pm 0,2) 10^{-4}$ \\
Diâmetro $(\mathbf{n m})$ & $75,8 \pm 11$ & & \\
\hline
\end{tabular}

Pelos valores da tabela A.5, notamos que medidas de SLS pelo método de Zimm Plot não é capaz de caracterizar amostras com partículas de $21 \mathrm{~nm}$ sendo mais limitada que o DLS na caracterização de partículas pequenas. 


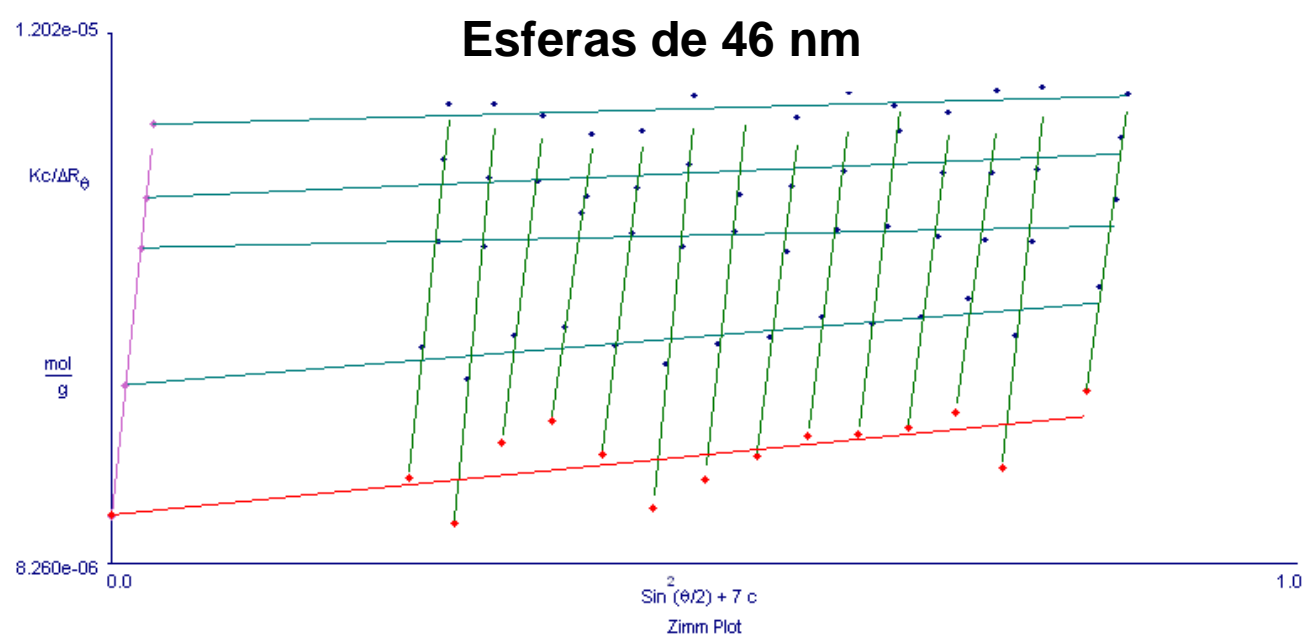

Figura A.2.2: Gráfico de Zimm para amostras com esferas de $46 \mathrm{~nm}$ e concentrações: 0,$50 ; 0,83 ; 1,16$ e $1,50 \mathrm{mg} / \mathrm{mL}$ )

Os resultados obtidos a partir da figura 3.16, calculados pela aproximação de Zimm Plot (equação 2.27) estão listados abaixo:

Tabela A.6: Resultados do gráfico de Zimm para microesferas de $46 \mathrm{~nm}$

Extrapolação a ângulo zero

$M_{w}(g / m o l)$

$R_{g}(n m)$

Diâmetro (nm)
$(1,13 \pm 0,02) 10^{5}$

$18,7 \pm 4,4$

$48 \pm 11$
Extrapolação a concentração zero

$$
\text { Mw (g/mol) }
$$

$(1,13 \pm 0,05) 10^{5}$

$A_{2}\left(\mathrm{~cm}^{3} \cdot \mathrm{mol} / \mathrm{g}^{2}\right)$

$(2,5 \pm 0,5) 10^{-4}$ 


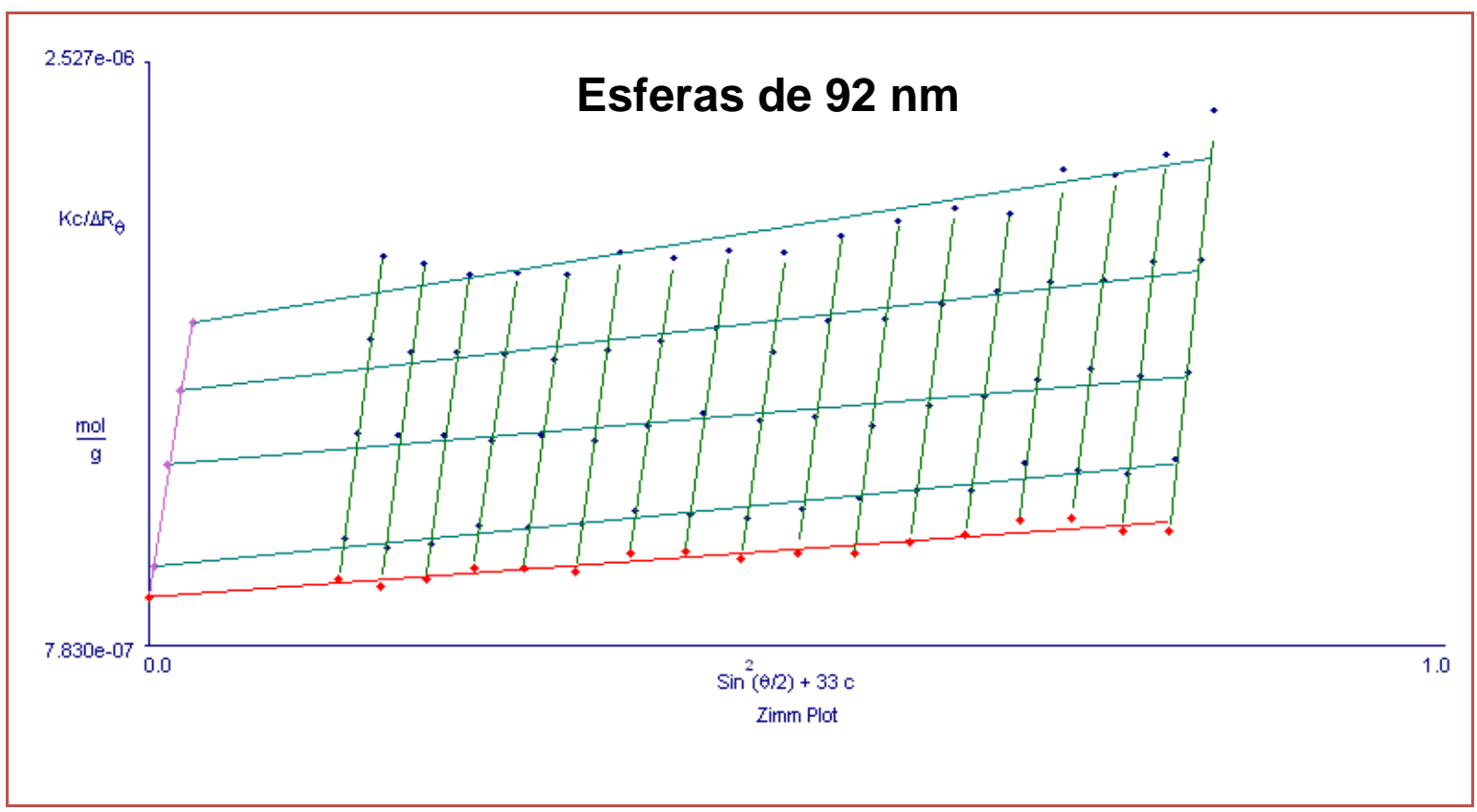

Figura A.2.3: Gráfico de Zimm para amostras com esferas de $92 \mathrm{~nm}$ e concentrações: 0,$30 ; 0,60 ; 0,90$ e $1,19 \mathrm{mg} / \mathrm{mL}$ )

Tabela A.7: Resultados do gráfico de Zimm para microesferas de $92 \mathrm{~nm}$.

\begin{tabular}{cccc}
\hline \multicolumn{2}{c}{ Extrapolação a ângulo zero } & \multicolumn{2}{c}{ Extrapolação a concentração zero } \\
$\mathbf{M}_{\mathbf{w}}(\mathrm{g} / \mathrm{mol})$ & $(1,5 \pm 0,04) 10^{6}$ & $\mathbf{M}_{\mathbf{w}}(\mathbf{g} / \mathbf{m o l})$ & $(1,5 \pm 0,04) 10^{6}$ \\
$\mathbf{R}_{\mathbf{g}}(\mathbf{n m})$ & $36,0 \pm 2$ & $\mathbf{A}_{\mathbf{2}}\left(\mathbf{c m}^{3} \cdot \mathbf{m o l} / \mathbf{g}^{2}\right)$ & $(4,2 \pm 0,2) 10^{-4}$ \\
Diâmetro $(\mathbf{n m})$ & $92,9 \pm 5,2$ & & \\
\hline
\end{tabular}

A partir dos diâmetros das tabelas A.6 e A.7 vemos que o SLS é adequado na caracterização de partículas de diâmetros 46 e $92 \mathrm{~nm}$ aqui medidos. O fato de $A_{2}$ ser positivo nas medidas apresentadas indica interações repulsivas entre as partículas em solução.

Como visto na tabela A.5, o SLS não tem sensibilidade para enxergar partículas de $21 \mathrm{~nm}$, e portanto fizemos uma medida usando misturas de esferas de $46 \mathrm{~nm}$ e $92 \mathrm{~nm}$ na proporção de $90: 1$, como exemplo de uma dispersão polidispersa. 


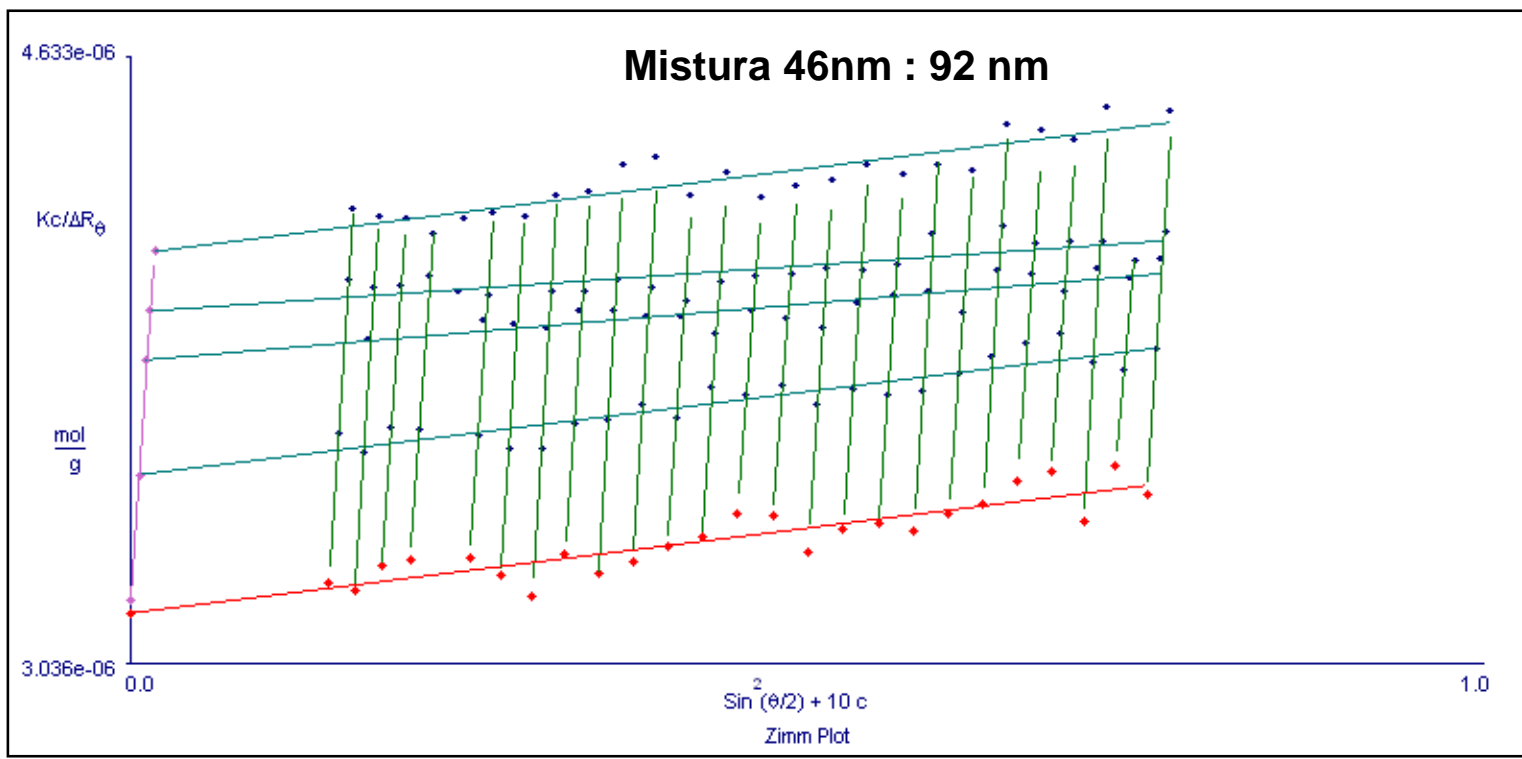

Figura A.2.4: Gráfico de Zimm para misturas com esferas de $46 \mathrm{~nm}$ e $92 \mathrm{~nm}$ com 90 esferas de $46 \mathrm{~nm}$ para cada uma de $92 \mathrm{~nm}$, nas concentrações totais de: 0,73; 1,09; 1,45 e $1,81 \mathrm{mg} / \mathrm{mL}$ )

Tabela A.8: Resultados do gráfico de Zimm para a mistura de $46 \mathrm{~nm}$ e $92 \mathrm{~nm}$.

\begin{tabular}{cccc}
\hline \multicolumn{2}{c}{ Extrapolação a ângulo zero } & \multicolumn{2}{c}{ Extrapolação a concentração zero } \\
$\mathbf{M}_{\mathbf{w}}(\mathbf{g} / \mathbf{m o l})$ & $(3,26 \pm 0,02) 10^{5}$ & $\mathbf{M}_{\mathbf{w}}(\mathrm{g} / \mathbf{m o l})$ & $(3,26 \pm 0,07) 10^{5}$ \\
$\mathbf{R}_{\mathbf{g}}(\mathbf{n m})$ & $24,6 \pm 1,4$ & $\mathbf{A}_{\mathbf{2}}\left(\mathbf{c m}^{3} \cdot \mathbf{m o l} / \mathbf{g}^{2}\right)$ & $(3,16 \pm 0,07) 10^{-4}$ \\
Diâmetro $(\mathbf{n m})$ & $63,5 \pm 3,6$ & & \\
\hline
\end{tabular}

Olhando para a tabela A.8, e como a relação de 90 esferas de $46 \mathrm{~nm}$ para cada uma de 90nm foi respeitada nas diferentes concentrações, para a qual $\overline{D_{z}}=65,2 \mathrm{~nm}$ (calculado pela equação A.1), vemos que o diâmetro obtido é muito próximo a esse valor. Além disso, não se distingui os diferentes tamanhos. Os demais parâmetros ainda devem ser melhores estudados para futuras interpretações.

As medidas de DLS (seção A.1) e SLS com as nanoesferas de tamanhos definidos nos mostraram que o transporte, remontagem e alinhamento do equipamento da Brookhaven foram bem-sucedidos, sendo que os valores obtidos são compatíveis com o esperado. Desta forma, pudemos utilizar o equipamento para o estudo das dispersões de DMPG com a certeza de que o equipamento está funcionando corretamente e de que os softwares utilizados são apropriados. 


\section{Apêndice B - Medidas de DLS com diferentes concentrações lipídicas}

Sabendo-se da importância de medidas de DLS com dispersões onde a interação entre partículas seja desprezível, no Laboratório de Biomembranas da USP, realizou-se um estudo com diferentes concentrações lipídicas de DMPG $(0,05 ; 0,5 ; 1,0$ e 1,5 mM) em água. Para tal, realizamos medidas no aparelho da Brookhaven, medindo o espalhamento dinâmico em diferentes ângulos para a confecção do gráfico de $\Gamma \times q^{2} a$ $20^{\circ} \mathrm{C}$ e realizamos medidas de DLS no zetasizer, da Malvern, que só realiza medidas de espalhamento a $90^{\circ}$, em diferentes temperaturas.

No aparelho da Malvern só foi possível medir a dispersão de 0,5 mM de DMPG em água, pois a amostra de 0,05 mM, por ser muito diluída, não espalhava intensidade suficiente para ser medida neste aparelho e as dispersões de 1,0 e 1,5 mM se mostraram inadequadas em temperaturas acima de $20^{\circ} \mathrm{C}$ (onde as vesículas ficam mais carregadas, de acordo com a figura 4.4.2) e o programa mostrava uma mensagem de erro indicando agregados muito grandes e polidispersos para o uso da técnica, além de um ajuste ruim para a função de correlação, conforme resumido na figura B.1. 
Cumulants Fit

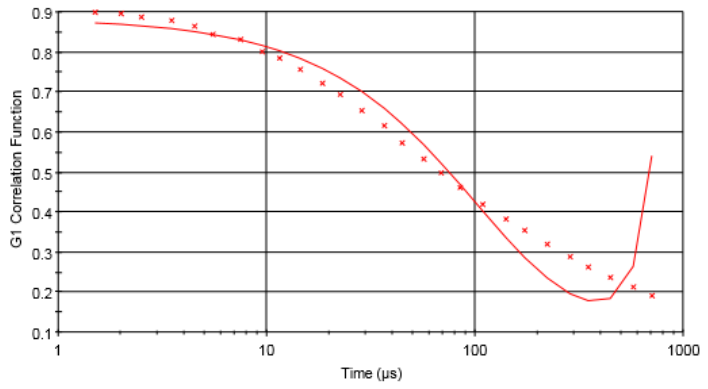

Size Distribution by Intensity

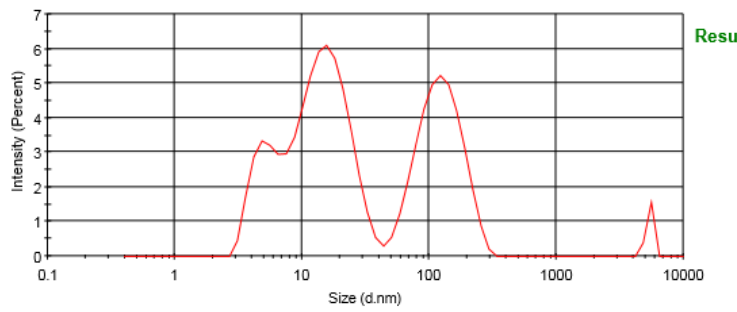

Data Fit

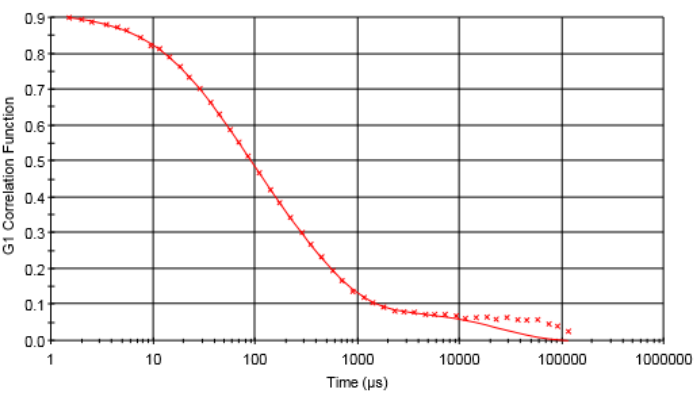

Results

Figura B.1: Resumo dos resultados obtidos no zetasizer para a dispersão de $1,5 \mathrm{mM}$ de DMPG em água a $45^{\circ} \mathrm{C}$.

A figura B.1 exemplifica os resultados obtidos para as dispersões de 1,0 e 1,5 mM nas temperaturas de 30 e $45^{\circ} \mathrm{C}$. O primeiro gráfico de cima mostra o ajuste que $\mathrm{O}$ programa fez para o método dos cumulantes (equação 2.3.9), onde fica claro que o ajuste não acompanha os pontos experimentais e, portanto, os valores de Z-average e da polidispersidade não são confiáveis. O segundo gráfico de cima mostra o ajuste da distribuição de tamanhos (transformada inversa de Laplace - CONTIN), sendo a distribuição apresentada no gráfico abaixo. Novamente o ajuste não é bom e a distribuição é muito dispersa, impossibilitando a obtenção de bons resultados, semelhante ao que foi observado na figura 4.6.2 para a dispersão de $10 \mathrm{mM}$ de DMPG. Apesar de aparecer a mensagem "Refer to quality Report" em "Result quality" o programa apresenta como resultado agregados com tamanho médio de $32,57 \mathrm{~nm}$, o que, como discutido, não está correto. Por isso é muito importante certificar-se que os ajustes estão corretos e adequados para o sistema de interesse e não apenas confiar no resultado final obtido pelo programa. 
Cumulants Fit

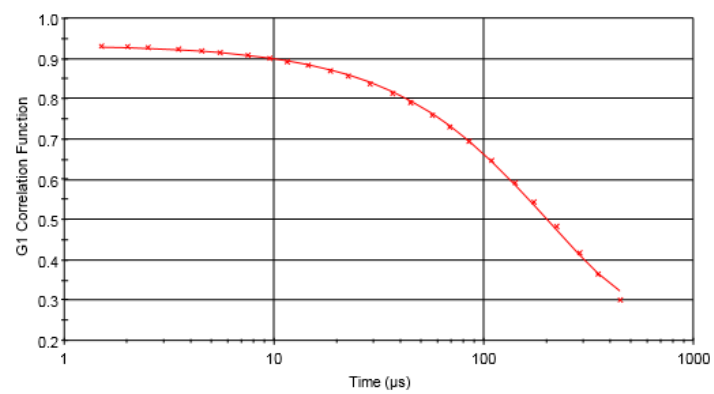

Size Distribution by Intensity

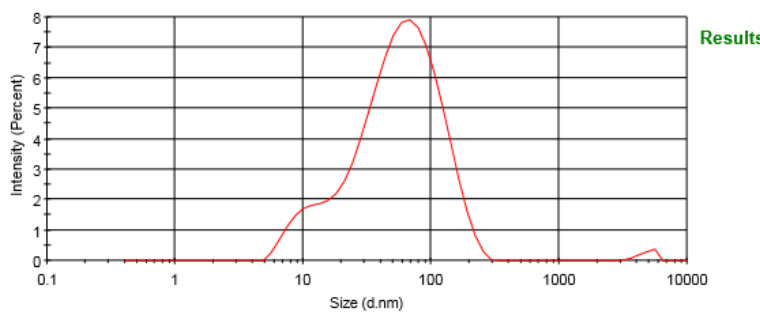

Data Fit

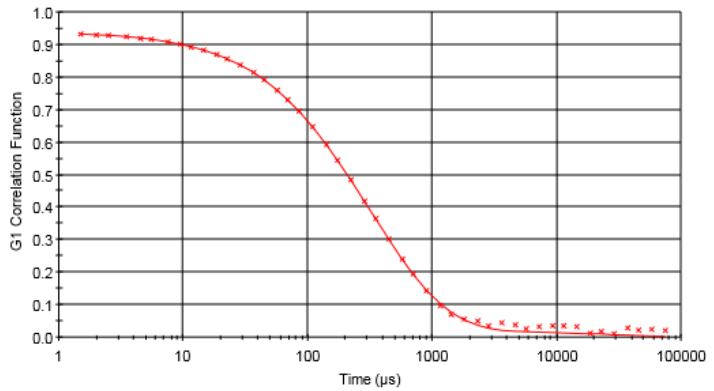

Z-Average (d.nm): 40,06

Pdl: 0,437

Intercept: 0,938

Result quality : Good

Figura B.2: Resumo dos resultados obtidos no zetasizer para a dispersão de $1,5 \mathrm{mM}$ de DMPG em água a $20^{\circ} \mathrm{C}$.

No caso apresentado na figura B.2, da mesma amostra utilizada na figura B.1, mas desta vez a $20^{\circ} \mathrm{C}$, os ajustes estão mais adequados e o resultado parece confiável. Desta vez em "Result quality" aparece a mensagem "good", diferente do observado anteriormente. Não é muito claro o porquê de o programa considerar apenas uma parte da função de correlação no ajuste pelo método dos cumulantes, não sendo observável a queda "completa" da função, assim como no ajuste da distribuição de tamanhos. Uma dificuldade em trabalhar com esse equipamento é o fato de se ter quase nenhum acesso aos parâmetros utilizados pelo software, não sendo possível realizar alterações de acordo com a necessidade. Apresentamos na tabela B.1 os resultados com "bons" ajustes obtidos no aparelho Zetasizer da Malvern.

Tabela B.1: Resultados de DLS obtidos no aparelho da Malvern para diferentes temperaturas e concentrações lipídicas.

\begin{tabular}{|c|c|c|c|c|c|c|}
\cline { 2 - 8 } \multicolumn{1}{c|}{} & \multicolumn{3}{c|}{ Cumulantes - Diametro (nm) } & \multicolumn{3}{c|}{ Contin - Diam (nm) Pico 1} \\
\cline { 2 - 8 } & \multicolumn{3}{c|}{ [DMPG] (mM) } & \multicolumn{3}{c|}{ [DMPG] (mM) } \\
\hline Temp $\left({ }^{\circ} \mathbf{C}\right)$ & $\mathbf{0 , 5}$ & $\mathbf{1 , 0}$ & $\mathbf{1 , 5}$ & $\mathbf{0 , 5}$ & $\mathbf{1 , 0}$ & $\mathbf{1 , 5}$ \\
\hline $\mathbf{5}$ & $46,6 \pm 3,0$ & $39,78 \pm 1,6$ & $34,1 \pm 1,8$ & $52 \pm 3$ & $50 \pm 4$ & $49 \pm 3$ \\
\hline $\mathbf{2 0}$ & $63,5 \pm 1,6$ & $53,2 \pm 1,3$ & $40,4 \pm 0,8$ & $81 \pm 3$ & $84 \pm 5$ & $66 \pm 4$ \\
\hline $\mathbf{3 0}$ & $70,6 \pm 2,0$ & - & - & $125 \pm 7$ & - & - \\
\hline $\mathbf{4 5}$ & $69,1 \pm 2,0$ & - & - & $115 \pm 5$ & - & - \\
\hline
\end{tabular}




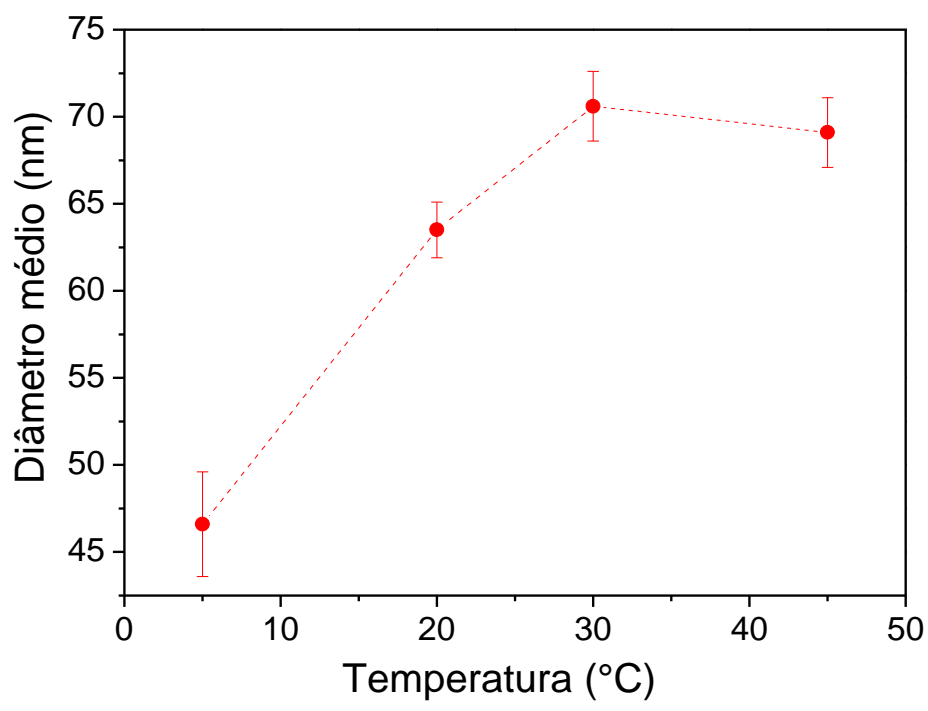

Figura B.3: Diâmetros médios dos centros espalhadores calculados pelo método dos cumulantes no aparelho da Malvern para dispersão de 0,5 mM de DMPG em água.

Vemos na tabela B.1, nas temperaturas de 5 e $20^{\circ} \mathrm{C}$ que puderam ser medidas nas 3 concentrações diferentes, que os diâmetros obtidos pelo método dos cumulantes vai diminuindo com o aumento da concentração lipídica, mostrando que nestas concentrações precisaríamos calcular o coeficiente de difusão em diluição infinita, no limite de $c \rightarrow 0$. Vemos que quanto maior a concentração, menor é o diâmetro efetivo calculado por Stokes-Einstein (equação 2.3.7), como visto anteriormente em Enoki, 2010. Parece que com o aumento das interações, aumenta-se o coeficiente de difusão, que é interpretado como uma diminuição no diâmetro das partículas espalhadoras.

Como visto nas medidas de DLS realizadas em Graz (tabela 4.1), para a dispersão de $1 \mathrm{mM}$ de DMPG, o tamanho das vesículas aumenta com a temperatura, permanecendo grandes na fase fluida, sendo que os valores dos diâmetros para a dispersão de 0,5 mM de DMPG, obtidos pelo método dos cumulantes, nas diferentes temperaturas, são compatíveis, dentro das incertezas das medidas, com os diâmetros obtidos para a dispersão de 1 mM de DMPG.

Pela tabela B.1, vemos que resultados obtidos pelos métodos dos cumulantes e do CONTIN são diferentes entre si, sendo que os valores do CONTIN são sempre maiores que do método dos cumulantes. Apesar de, teoricamente, o método do CONTIN da Malvern também ser uma transformada inversa de Laplace, como calculada pelo programa ORTLight, vemos que os valores pelo método dos cumulantes estão mais 
próximos aos mostrados na tabela 4.1. A partir do estudo realizado com esferas de poliestireno de tamanhos conhecidos, foi mostrado que o método do CONTIN utilizado por este aparelho não fornece resultados tão precisos e confiáveis como o método dos cumulantes.

Com as mesmas dispersões utilizadas no aparelho da Malvern (tabela B.1) de DMPG em água realizamos medidas no aparelho da Brookhaven, sendo que as medidas foram realizadas no mesmo dia. As medidas foram realizadas a $20^{\circ} \mathrm{C}$ e nos ângulos 30 , $50,70,90,110$ e $130^{\circ}$ (figura B.4)

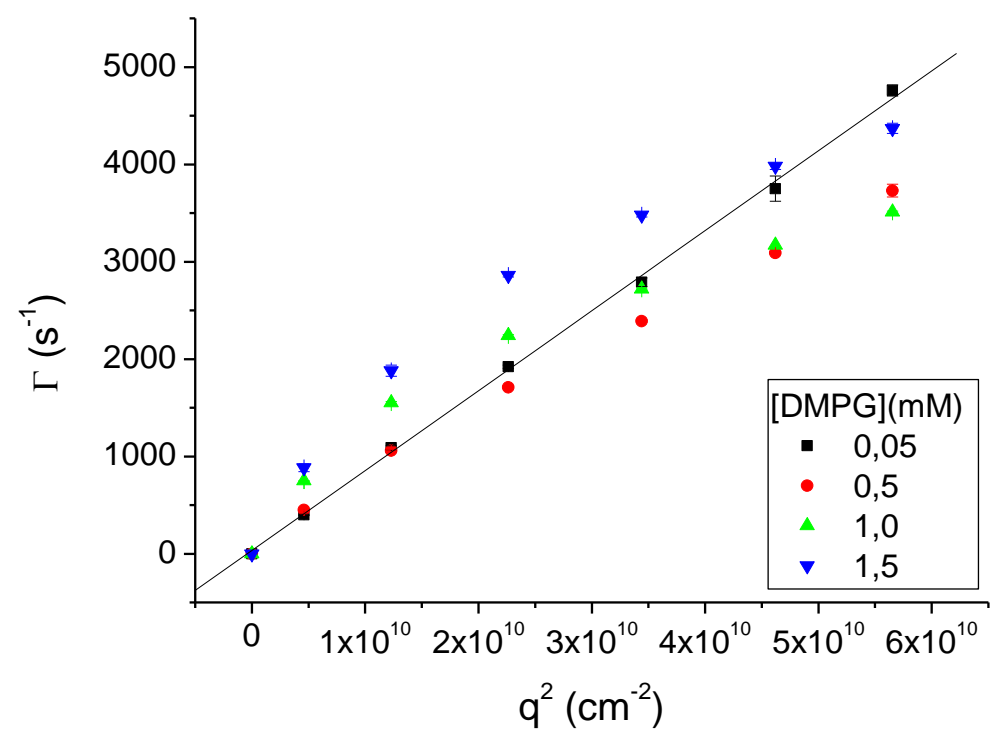

Figura B.4: Gráfico de $\Gamma x q^{2}$ para medidas de $D L S$ de dispersões extrusadas de 0,$05 ; 0,5$; 1,0 e $1,5 \mathrm{mM}$ de DMPG em água, feitas a diferentes ângulos: $30^{\circ}, 50^{\circ}, 70^{\circ}, 90^{\circ}, 110^{\circ} \mathrm{e}$ $130^{\circ}$ a $20^{\circ} \mathrm{C}$.

No gráfico da figura B.4, os únicos dados que puderam ser ajustados por uma reta que passa pelo ponto $(0,0)$ foram os medidos para a concentração $0,05 \mathrm{mM}$ de DMPG em água (pontos pretos e reta preta traçada no gráfico). Tomando o coeficiente angular da reta como sendo o coeficiente de difusão translacional dos centros espalhadores ( $D_{T}$ - equação 2.3.6), podemos calcular o $d_{\text {ef }}$ usando a equação 2.3.7 e obtivemos $d_{\mathrm{ef}}=(59 \pm 2) \mathrm{nm}$ para a dispersão de 0,05 $\mathrm{mM}$ de DMPG em água. É interessante observar que para os dados medidos em Graz (tabela 4.1), para uma dispersão de 1,0 mM de DMPG em água, obtivemos $d_{\mathrm{ef}}=(57 \pm 3) \mathrm{nm}$ e no aparelho da Malvern (tabela B.1) obteve-se $d_{\mathrm{ef}}=(64 \pm 2) \mathrm{nm}$ para a dispersão de 0,5 mM, ou seja, valores muito próximos. 
O fato de as outras concentrações lipídicas da figura B.4 não serem bem ajustadas por retas são um indicativo de que o sistema está fora das aproximações e da teoria de DLS, detalhada na seção 2.3.1 desta tese, por exemplo, o sistema pode não ser suficientemente diluído e as interações não podem ser desprezadas. É interessante observar que a concentração de 0,5 mM de DMPG pode ser medida e analisada no aparelho da Malvern, mas parece ser muito concentrada para as análises do aparelho da Brookhaven, da mesma forma, no aparato de Graz foi possível medir e analisar a dispersão de 1,0 mM de DMPG em água enquanto os aparelhos da Brookhaven e da Malvern não se mostraram confiáveis para esta medida.
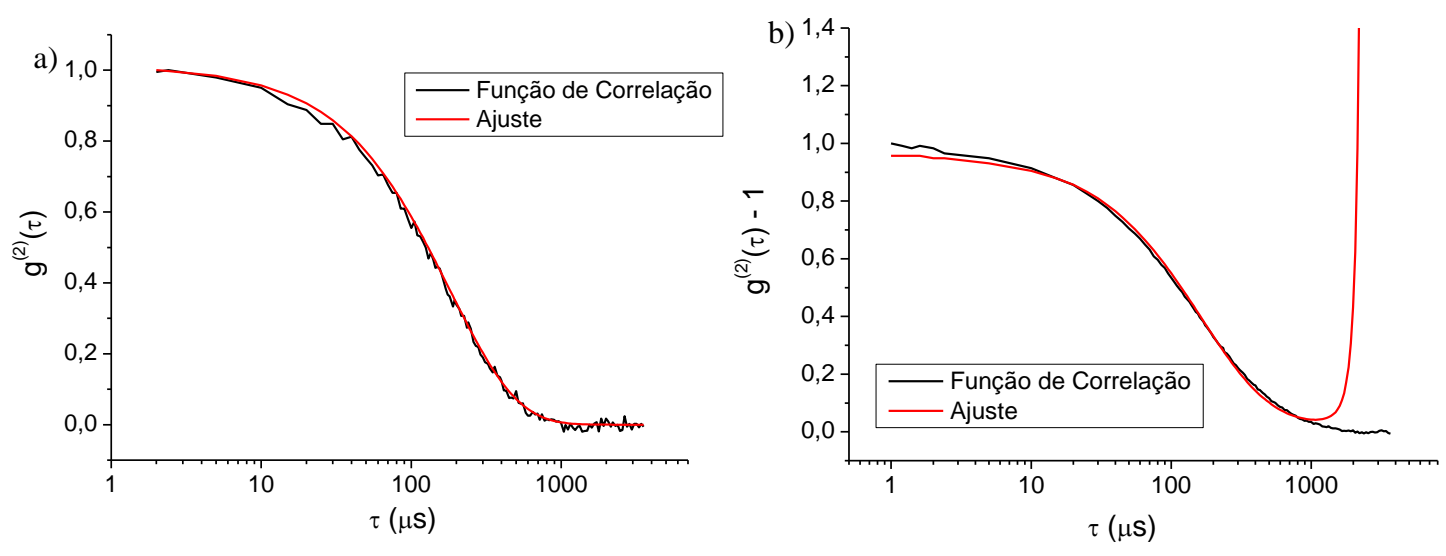

Figura B.5: Funções de correlação a $90^{\circ}$ medidas no aparelho da Brookhaven para a dispersão de 0,05 mM de DMPG (a) e 1,5 mM de DMPG (b), com os ajustes (em vermelho) realizado pelo software para o método dos cumulantes.

Além do fato de o gráfico de de $\Gamma x q^{2}$ não ser uma reta para as amostras mais concentradas, quando analisamos as funções de correlação medidas pelo software, juntamente com o ajuste de cumulantes que o mesmo realiza, vemos que para as amostras concentradas o ajuste não é razoável e é interessante notar que o problema no ajuste da função de 1,5 mM da figura B.5 é muito parecido com o da figura B.1! O motivo para o ajuste sair totalmente da função de correlação no final da curva, indo para valores altos, não é claro, mas pode ser um indicio de que, quando isso ocorre, o sistema não está de acordo com a teoria de DLS usada. Podemos também comparar as distribuições de tamanho obtidas pelo software da Brookhaven. 


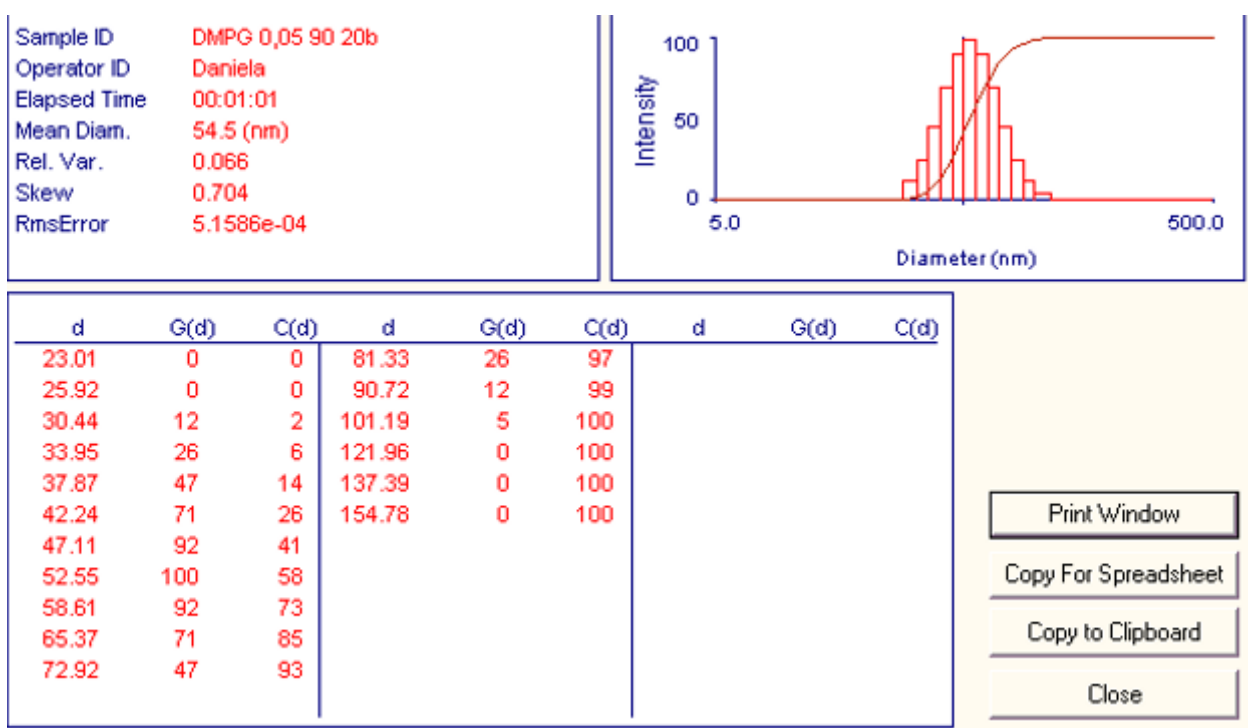

Figura B.6: Distribuição de tamanhos da dispersão de 0,05 mM de DMPG medida pelo software da Brookhaven.

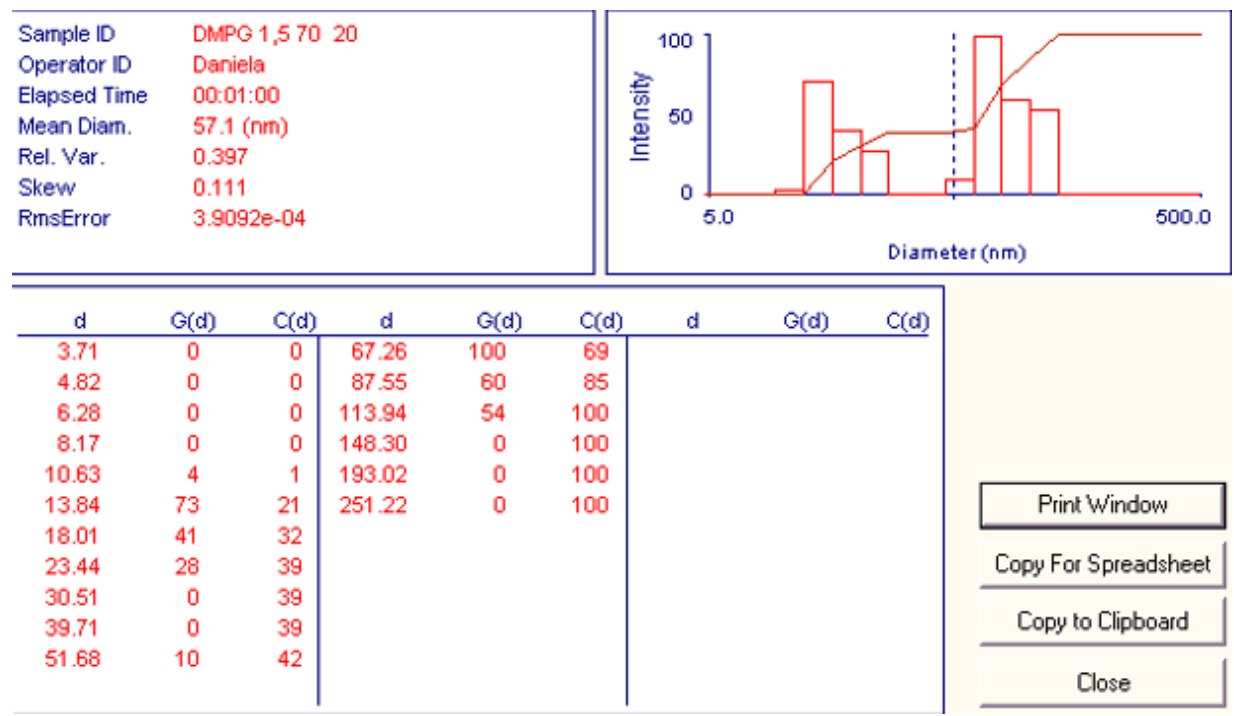

Figura B.7: Distribuição de tamanhos da dispersão de 1,5 mM de DMPG medida pelo software da Brookhaven.

Vemos que para a dispersão mais concentrada, similarmente ao visto nas figuras B.1 e 4.6.2, para $10 \mathrm{mM}$, a distribuição de tamanhos é bem mais larga e dividida em diferentes picos.

Com esses resultados vemos que sempre devemos ter muito cuidado ao realizar medidas de DLS, de modo a garantir que o sistema esteja dentro das aproximações da técnica e que as medidas sejam confiáveis, sendo muito importante observar e avaliar o ajuste da função de correlação. Além disto, aparentemente, cada equipamento e montagem experimental tem limitações diferentes, ao menos em relação à máxima 
concentração lipídica que podemos utilizar. Como as medidas realizadas em Graz foram feitas com um laser bem mais potente e com um sistema de detector com pseudo correlação cruzada, além das análises terem sido realizadas através do software desenvolvidos pelo próprio Prof. Otto Glatter, tendo-se controle quanto ao $\tau$ inicial e final e sobre o ajuste utilizado, foi possível obter bons resultados para a dispersão de 1 mM de DMPG em água, que foram compatíveis com os resultados obtidos para a dispersão de 0,5 mM de DMPG (tabela B.1 e figura B.3), medida no aparelho da Malvern. Como as medidas em Graz foram realizadas em uma temperatura a mais que as medidas no aparelho da Malvern $\left(15^{\circ} \mathrm{C}\right)$, consideramos como medidas de dimensões das vesículas de DMPG em água, os resultados mostrados na tabela 4.1 e figura 4.6 .3 para dispersão de $1 \mathrm{mM}$ de DMPG. 


\section{Apêndice C - Simulações de SAXS na região de muito baixo q}

Começamos as tentativas de simular a região de baixo q das curvas de SAXS utilizando o programa GAP (Global Analysis Program), que foi desenvolvido pelo Prof. Georg Pabst durante seu doutorado e que foi o programa que utilizamos no cálculo do fator de forma das curvas de SAXS. Entretanto, os fatores de estrutura disponíveis neste programa são para sistemas multilamelares, e o fator de estrutura considera flutuações térmicas (pequenas flutuações nas posições das bicamadas em torno de posições de equilíbrio bem definidas e igualmente espaçadas), teoria paracristalina (desordem de bicamadas perfeitamente planas que se deslocam de suas posições principais) e teoria de Caillé modificada (leva em conta flutuações de ondulação da membrana) (Pabst et al., 2003). No caso das dispersões de DMPG temos vesículas unilamelares, mas tentamos realizar diversas simulações, com as diferentes dispersões de DMPG e em diferentes temperaturas e alguns dos ajustes obtidos são apresentados na figura C.1. 

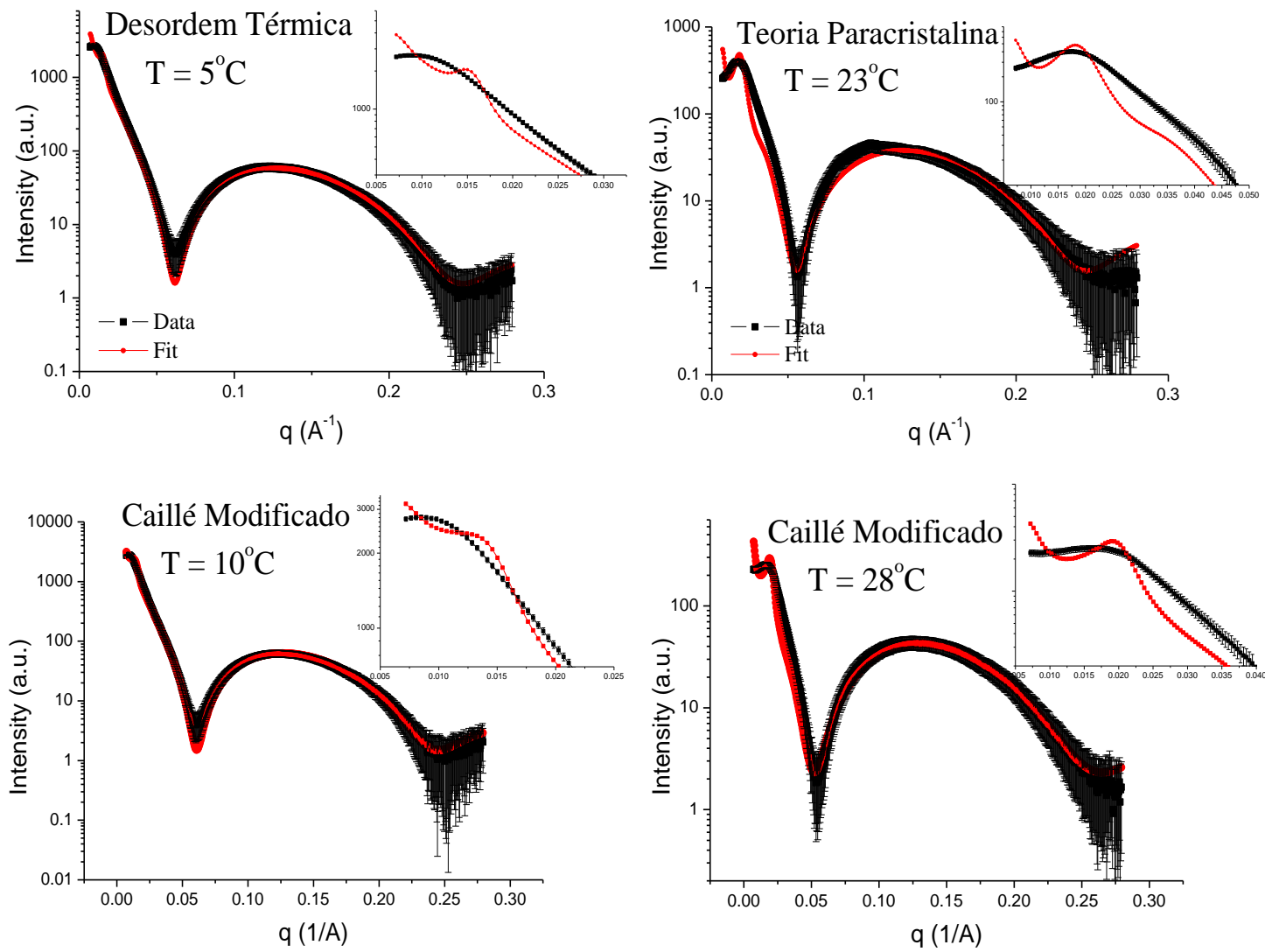

Figura C.1: Exemplos de ajustes obtidos com o programa GAP para diferentes fatores de estrutura de dispersões de 50 mM de DMPG em tampão a baixa força iônica.

Nas simulações (pontos vermelhos) da figura C.1, consideramos que a correlação era apenas entre duas membranas, entretanto, os ajustes para os picos não foram razoáveis em nenhuma das tentativas. Como mencionado anteriormente, esses fatores de estruturas levam em conta sistemas multilamelares, onde as membranas estão empilhadas, e que apresentam uma correlação muito maior do que no caso de correlação entre membranas de vesículas vizinhas. Desta forma, é compreensível que nenhum destes modelos teóricos foi capaz de ajustar nossos dados. Conversando com o prof. Georg Pabst, que tem bastante experiência em SAXS de membranas biológicas, e procurando na literatura, não existe um modelo teórico ou resultados publicados que relacionem o pico de repetição com a distância entre bicamadas de vesículas vizinhas. Para que escrevêssemos tal modelo teórico, seria necessário alguém com bastante experiência e tempo disponível, o que não foi possível no momento.

Por sugestão do prof. Pabst, utilizei também o programa SASFIT (escrito por Joachim Kohlbrecher e Ingo Bressler, do Laboratory for Neutron Scattering, Suiça). Este 
programa é bastante utilizado para simulações de curvas de espalhamento de raios $\mathrm{X} e$ nêutrons a baixos ângulos, e apresenta diversas opções de fatores de forma e estrutura.

Neste programa consideramos que o fator de estrutura mais adequado para o nosso sistema é a aproximação RMSA (rescaled mean spherical approximation) (Hayter and Penfold, 1981; Hasen and Hayter, 1982) para esferas carregadas, que leva em conta as interações eletrostáticas entre partículas carregadas. E para o fator de forma utilizamos a aproximação para vesículas lipídicas.

Dentre as muitas simulações que foram tentadas, mostramos abaixo as que se ajustaram melhores às curvas experimentais de uma dispersão de $50 \mathrm{mM}$ de DMPG em tampão, após a extrusão. As simulações foram realizadas considerando uma distribuição de tamanhos de Maxwell, o fator de forma de bicamada (parâmetros: espessura da cabeça polar: $1 \AA$; espessura interna da bicamada: $3 \AA$; $\eta_{\text {cabeça }}=0,05 ; \eta_{\text {solução }}=0,034$ e $\eta_{\text {cadeia }}=0,03$ ) os valores de $\eta$ (scattering length density) foram calculados pelo programa SASFIT, a partir da composição química de cada componente. Os parâmetros mantidos fixos para o fator de estrutura RMSA foram a fração volume $(\eta=0,12)$; a força iônica do solvente (salt $=0,004 \mathrm{M})$ e a constante dielétrica da água $(\varepsilon=78,3)$, enquanto o raio das vesículas $(R)$, a carga efetiva $(Z)$ e a temperatura $(T)$ variaram para as diferentes temperaturas.

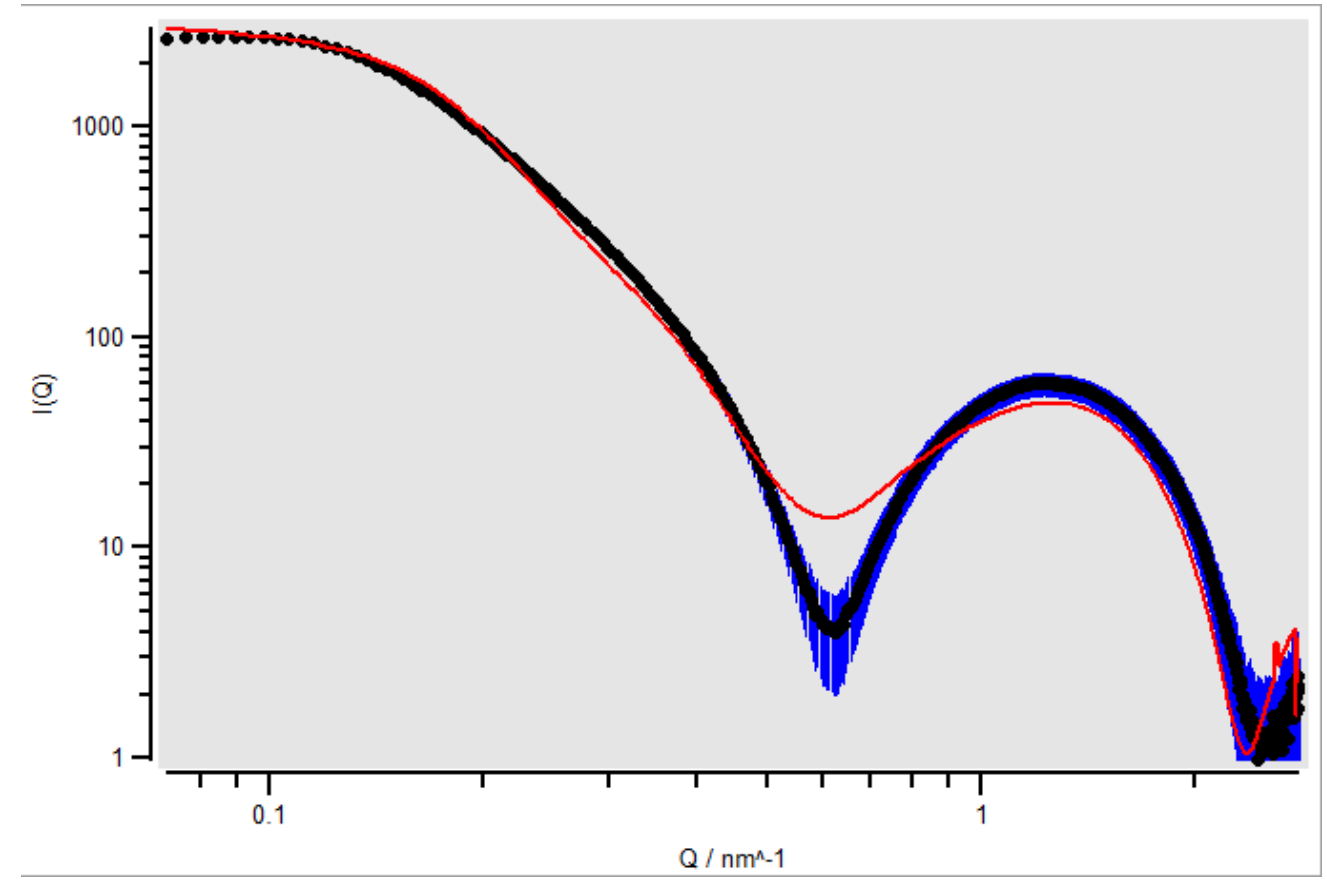

Figura C.2: Simulação no SASFIT (curva vermelha) para os dados de DMPG $50 \mathrm{mM}$ em tampão após extrusão a $5^{\circ} \mathrm{C}$. Parâmetros: $\mathrm{T}=278 \mathrm{~K} ; \mathrm{R}=16 \mathrm{~nm}$ e Z = 0,5. 


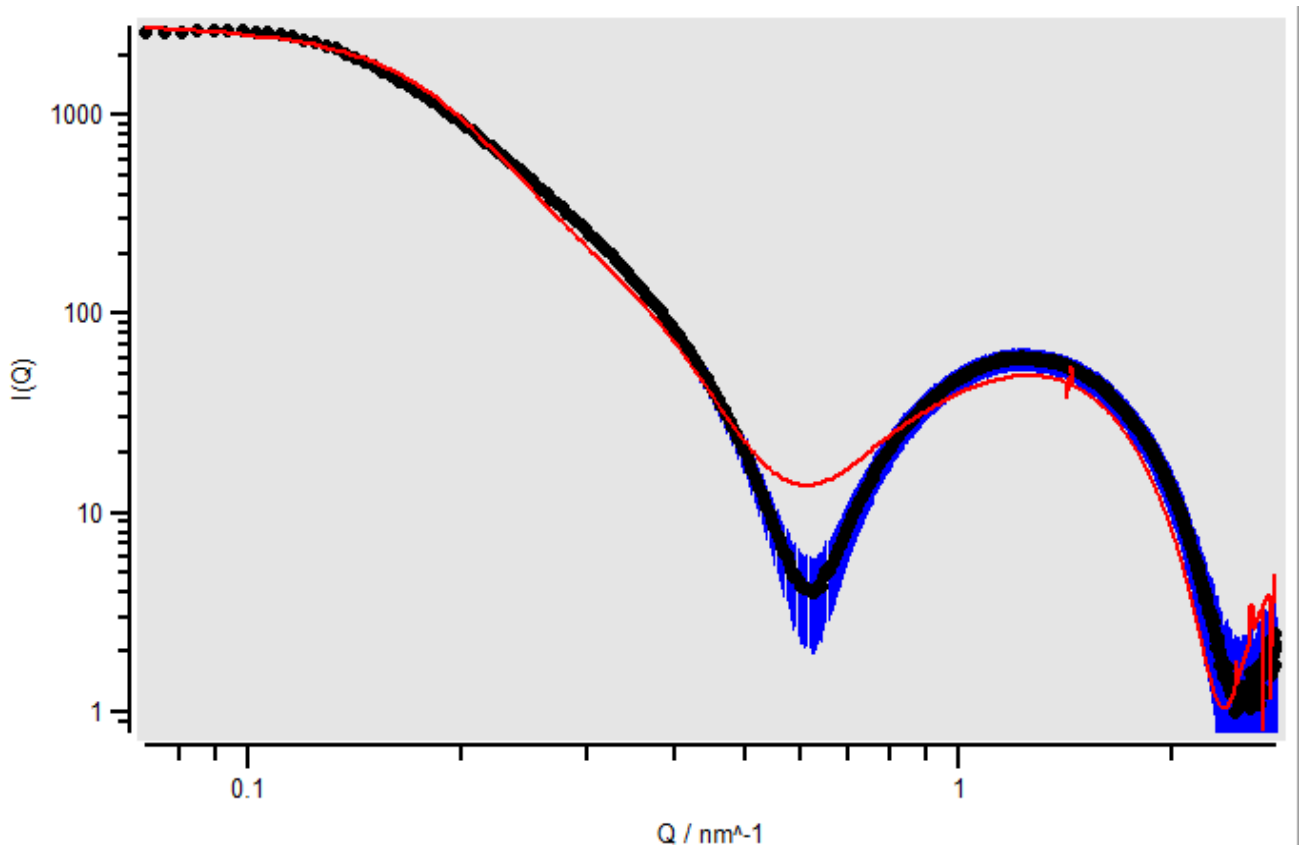

Figura C.3: Simulação no SASFIT (curva vermelha) para os dados de DMPG $50 \mathrm{mM}$ em tampão após extrusão a $15^{\circ} \mathrm{C}$. Parâmetros: $\mathrm{T}=288 \mathrm{~K} ; \mathrm{R}=16 \mathrm{~nm}$ e Z $=16$.

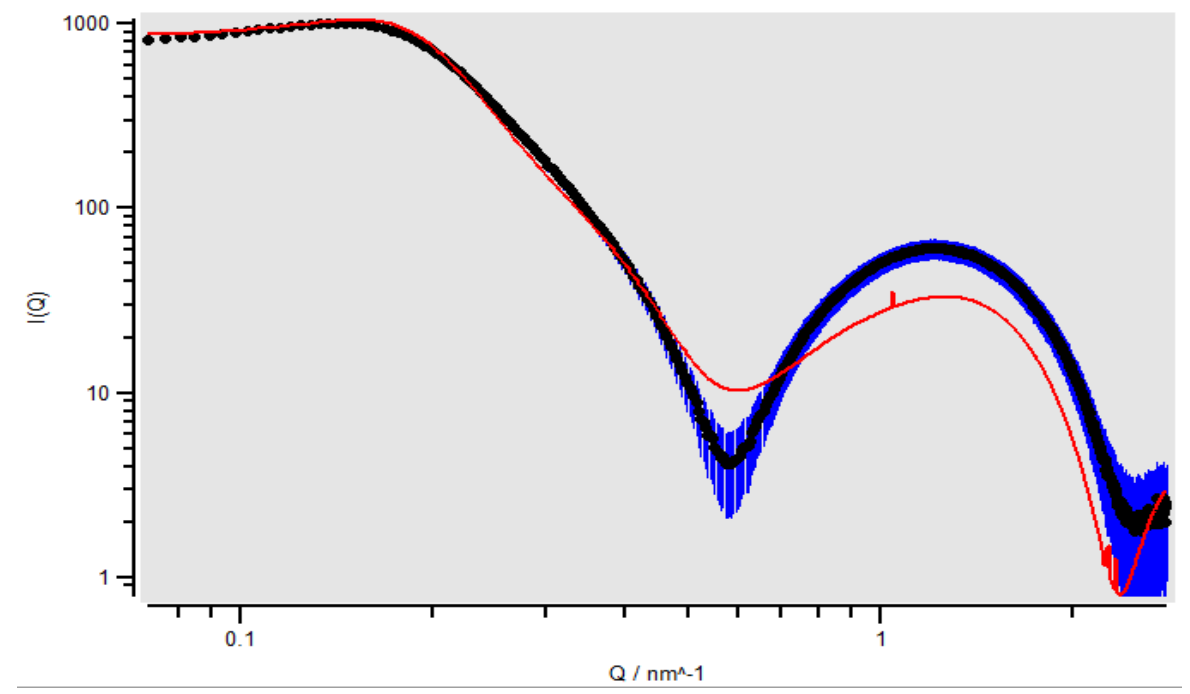

Figura C.4: Simulação no SASFIT (curva vermelha) para os dados de DMPG $50 \mathrm{mM}$ em tampão após extrusão a $19^{\circ} \mathrm{C}$. Parâmetros: $\mathrm{T}=292 \mathrm{~K} ; \mathrm{R}=12 \mathrm{~nm}$ e Z $=43$.

Nas figuras C.2, C.3 e C.4 vemos que, após inúmeras tentativas, conseguimos ajustes bastante razoáveis para os picos a baixo q. E ao aumentar a temperatura, nas simulações, a carga efetiva aumentou, estando de acordo com as medias de mobilidade eletroforética (Figura 5.4.1). Entretanto, o fato dos raios efetivos das simulações serem 
em torno de $15 \mathrm{~nm}$, isto é, muito pequenos, fez com que o Prof. Pabst nos encorajasse a abandonar essas simulações. Entretanto, agora que mostramos que podemos ter vesículas de DMPG tão pequenas quanto com $30 \mathrm{~nm}$ de diâmetro, existe a possibilidade de retornarmos a estas simulações de modo a verificar se a origem do pico a baixo q seria das interações repulsivas entre as partículas.

Fizemos então um estudo de como alguns parâmetros influenciam a posição do pico de SAXS a baixo q.
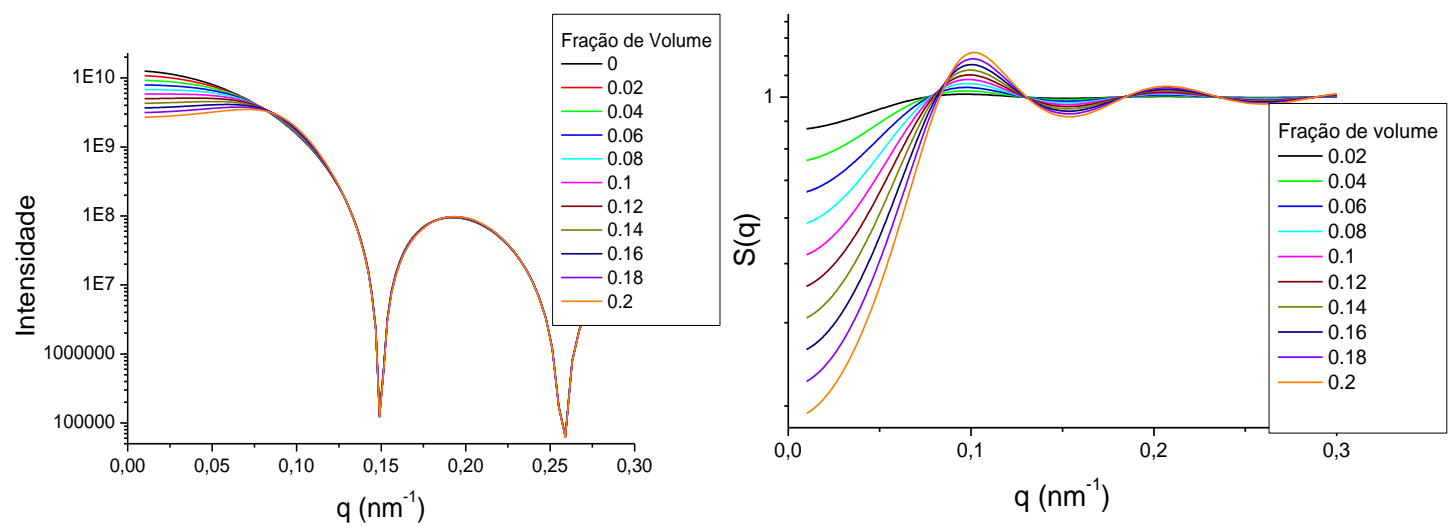

Figura C.5: Alterando a fração de volume entre 0 e 0,2 para esferas de $30 \mathrm{~nm}$ de diâmetro e fator de estrutura de esfera dura. S(q) (à direita) foi obtido dividindo-se I(q) por $F(q)$.

Na figura C.5, é possível observar uma mudança sutil na posição do pico de correlação para valores maiores de q com o aumento da fração de volume, sendo que para a concentração de $50 \mathrm{mM}$ de DMPG a fração de volume é 0,05. Para tornar essa mudança mais visível, fizemos novas simulações, desta vez variando a fração de volume entre 0,1 e 0,8 .
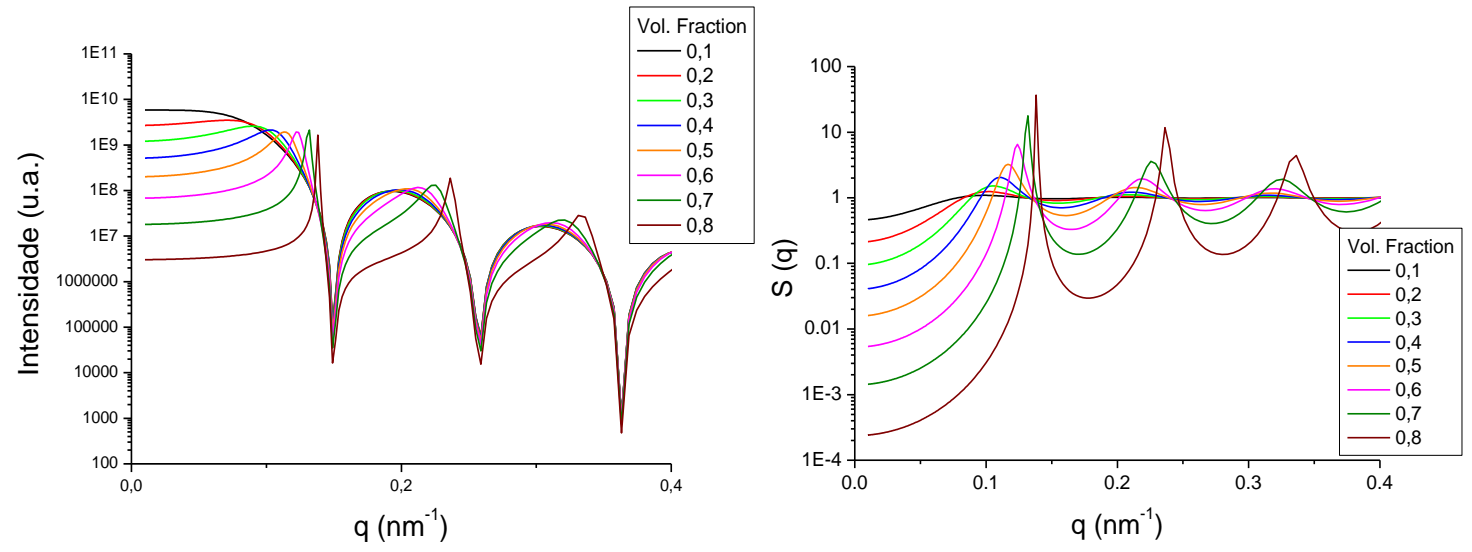

Figura C.6: Alterando a fração de volume entre 0,1 e 0,8 para esferas de $30 \mathrm{~nm}$ de diâmetro e fator de estrutura de esfera dura. S(q) (à direita) foi obtido dividindo-se I(q) por $F(q)$. 
Na figura C.6 vemos mais claramente a mudança na posição e formato do pico de repetição. Com o aumento da fração de volume, o pico se desloca para q maiores (menores distâncias) e fico mais estreito. Neste caso, a fração de volume aumenta com o aumento da concentração lipidica e este deslocamento está de acordo com o mostrado na figura 7.2.17,

As próximas simulações foram realizadas fixando um fator de forma de bicamada e varianda a carga efetiva (Z) e depois o raio efetivo (R) da aproximação RMSA.

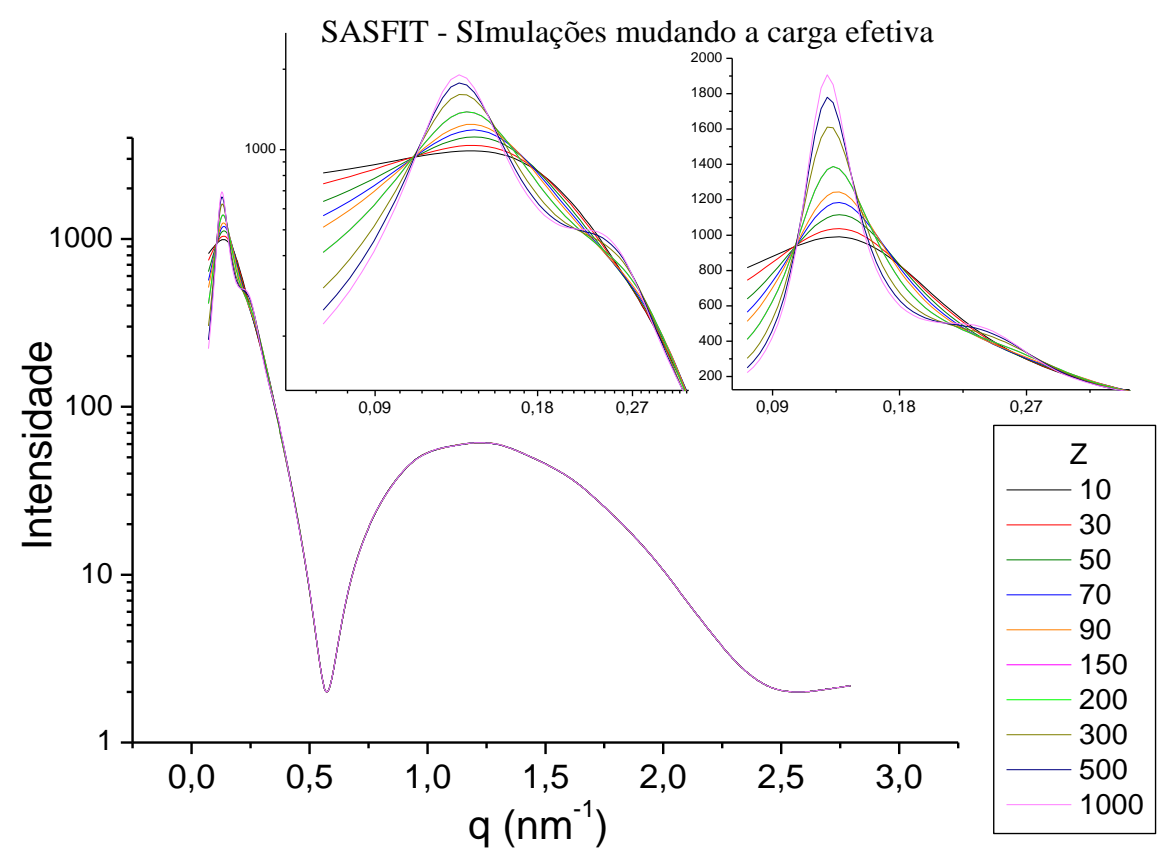

Figura C.7: Simulações variando a carga efetiva (Z) de 10 a 1000, fixando-se um raio de $20 \mathrm{~nm}$. 


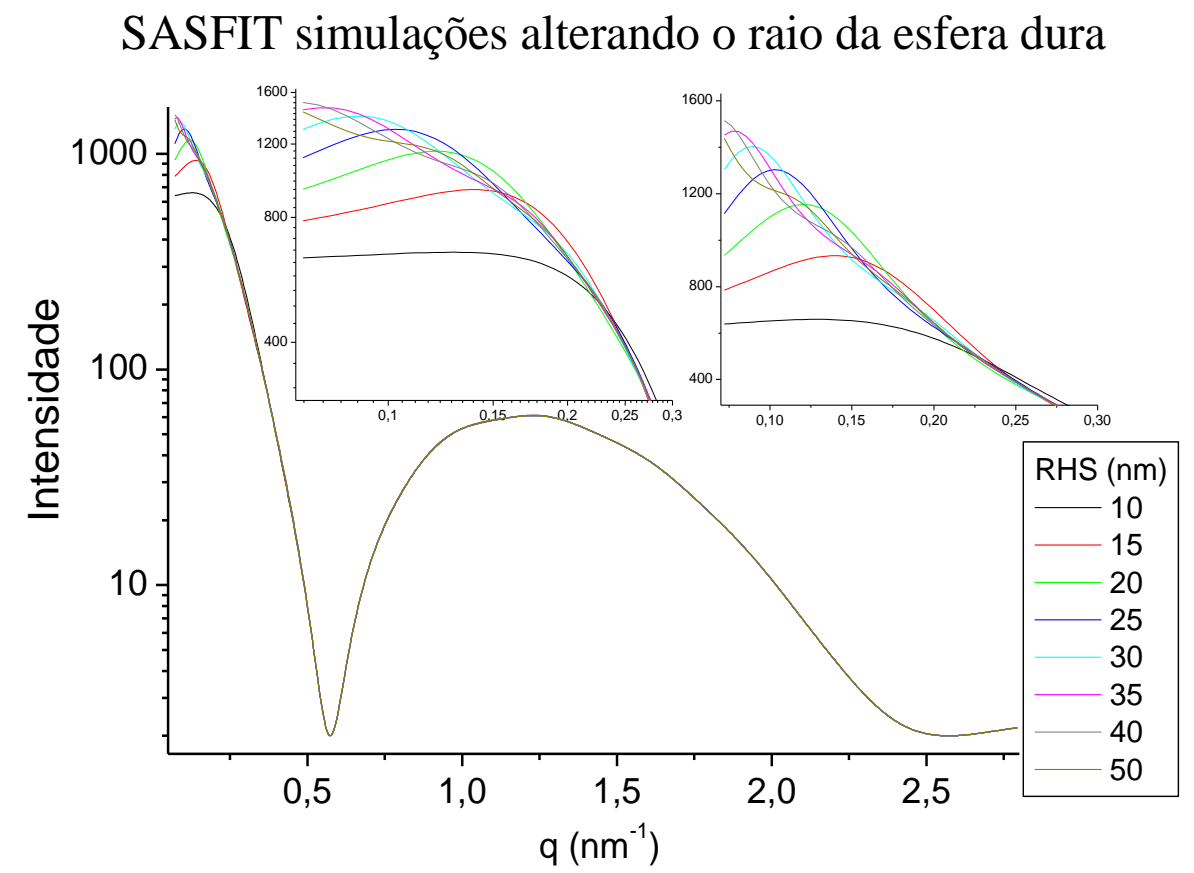

Figura C.8: Simulações variando o raio de 10 a $50 \mathrm{~nm}$, fixando-se $Z=50$.

Na figura C.7 vemos que o aumento da carga efetiva altera sutilmente a posição do pico para q menores (com a maior repulsão entre as partículas, a distância entre elas seria maior), mas a mudança maior é no formato do pico, que fica mais estreito com o aumento da carga efetiva.

Na figura C.8 vemos que o aumento do raio efetivo das partículas faz com que o pico se desloque para q menores.

Desta forma, ainda não é clara a origem do pico de repetição visto nas curvas experimentais, sendo que pelas simulações das figuras C.7 e C.8 o fato do pico se deslocar para q maiores na transição de fase estaria relacionado a uma diminuição no raio efetivo ou diminuição da carga efetiva, que são resultados opostos ao que obtivemos por medidas de DLS e de mobilidade eletroforética. Desta forma, mais estudos são necessários para determinar-se a origem e entender o comportamento dos picos observados nas curvas experimentais. 


\section{Referências}

Alakoskela, J. M. I. e Kinnunen, P. K. J; "Thermal Phase Behavior of DMPG: The Exclusion of Continuous Network and Dense Aggregates." Langmuir, 23, 4203-4213, 2007.

Alakoskela, J. M.; Parry, M. J.; Kinnunen, P. K. J.; "The intermediate state of DMPG is stabilized by enhanced positive spontaneous curvature." Langmuir 26, 4892-4900. 2010

Althenbach, C. Programa escrito em LabVIEW (National Instruments) e disponível em: http://www.chemistry.ucla.edu/directory/hubbell-wayne-I. 2017

Bales, B.L.. em "Biological Magnetic Resonance". Berliner LJ, Reuben J, editors. Plenum Press, Nova York, pp 77-130, 1989.

Barroso, R. P., "Dispersões Lipídicas de dimiristoil fosfatidil glicerol: um estudo termoestrutural". Tese de Doutorado, Instituto de Física da Universidade de São Paulo, 2010.

Barroso, R.P., Riske, K.A., Henriques, V.B. e Lamy, M.T. "Ionization and structural changes of the DMPG vesicle along its anomalous gel-fluid phase transition: a study with different lipid concentrations." Langmuir 26, 13805-13814, 2010.

Barroso, R. P. ; Perez, K. R. ; Cuccovia, I. M. ; Lamy, M. T.; "Aqueous dispersions of DMPG in low salt contain leaky vesicles." Chemistry and Physics of Lipids, v. 165, p. 169177, 2012.

Benatti, C. R., Feitosa, E., Fernandez, R. M. e Lamy-Freund. M.T., "Structural and thermal characterization of dioctadecyldimethyllammammonium bromide dispersions by spin label." Chem. Phys. Lipids, 111, 93-104, 2001

Bergntröm, M.; Pedersen, J.; "Structure of pure SDS and DTAB micelles in brine determined by small-angle neutron scattering (SANS)". Physical Chemistry Chemical Physics 1, 4437-4446. 1999

Berne, B.J. e Pecora, R. "Dynamic Light Scattering with applications to Chemistry, Biology and Physics", John Wile and Sons. 2000

Brown, W; "Dynamic Light Scattering, the methods and some applications". Carendon Press. 1993

Carlson, C.W., Flory, P.J., "Separation of collision-induced from intrinsic molecular depolarized Rayleigh scattering." Journal of the Chemical Society, Faraday Transactions 2(73), $1505-1520.1977$

Disalvo, E. A., "Optical properties of lipid dispersions induced by permeate molecules." Chem. Phys. Lipids, 59, 199-206. 1991 
Duarte, E.L., Oliveira, T.R., Alves, D.S., Micol, V. e Lamy, M.T. "On the interaction of the anthraquinone barbaloin with negatively charged DMPG bilayer." Langmuir 24, 4041-4049, 2008.

Engelman, D. M. "Membranes are more mosaic than fluid" Nature 438, 578-580. 2005

Enoki, T.A. "Caracterização por espalhamento de luz de dispersões aquosas de agregados lipídicos aniônicos". Dissertação de Mestrado, Instituto de Física da Universidade de São Paulo. 2010

Enoki, T.A., Henrique, V. B., Lamy, M.T. "Light scattering on the structural characterization of DMPG vesicles along the bilayer anomalous phase transition", Chem. Phys. Lipids, 165(8), pp 826-837, 2012.

Epand, R. M.; Hui, W.; "Effect of electrostatic repulsion on the morphology and thermotropic transitions of anionic phospholipids" Febs Lett. 209, 257-260. 1986

Fernandez, R.M. e M.T. Lamy-Freund. "Correlation between the effects of a cationic peptide on the hydration and fluidity of anionic lipid bilayers: a comparative study with sodium ions and cholesterol." Biophysical Chemistry 87(2-3), 87-102, 2000.

Fernandez, R.M., Riske, K.A., Amaral, L.Q., Itri, R., Lamy, M.T. "Influence of salt on the structure of DMPG studied by SAXS and optical microscopy" Biochim. Biophys. Acta, 1778, 907-916. 2008.

Freed, J.H.. In Spin Labeling, Theory and Applications. Berliner L, editor. Academic Press. 53-132, 1976.

Gershfeld, N. L.; Stevens, W. F., Jr.; Nossal, R. J.; " Equilibrium studies of phospholipid bilayer assembly. Coexistence of surface bilayers and unilamellar vesicles"Faraday Discuss Chem Soc, 19-28. 1986

Glatter, O.; e Kratky, O.; "Small Angle X-ray Scattering" Academic Press New York, 1982.

Goldman, C.; "Modified surface fluctuations by impurity binding in amphiphilic dispersions." Journal of Chemical Physics, v.114, 6242-6248, 2001.

Goldman, C., Riske, K. A. e Lamy-Freund, M. T.; "The role of soft and hard aggregates in the thermodinamic of lipid dispersions." Physical Review E, 60, 7349-7353, 1999.

Grell, E.; “Membrane Spectroscopy”, Springer-Verlag, New York. 1981

Hansen, J. P., and Hayter, J. B.; "A Rescaled MSA Structure Factor for Dilute Charged Colloidal Systems"; Molecular Physics 46(3):651-656. 1982

Hayter, J. B., and Penfold, J.; "An Analytic Structure Factor for Macroion Solutions.", Molecular Physics, 42, 109-118. 1981 
Heimburg, T. e Biltonen, R. L.; "Thermotropic behavior of dimyristoyl phosphatidyl glycerol and its interaction with cytochrome - C" Biochemistry, 33, 9477-9488, 1994.

Heimburg, T. "A model for the lipid pretransition: coupling of ripple formation with the chain-melting transition." Biophys J. 78(3):1154-65. 2000

Heimburg, T. "Thermal Biophysics of membranes". Wiley - VHC. 2007

Hiemenz, P.; "Polymer chemistry". Marcel Dekker, Inc. 1985

Hiemenz, P.; "Principles of colloid and surface chemistry", 2a edição, Marcel Dekker, Inc. 1986

Hirai, M.; Sato, S.; Kimura, R.; Hagiwara, Y.; Kawai-Hirai, R.; Ohta, N.; Igarashi, N.; Shimizu, N. "Effect of Protein-Encapsulation on Thermal Structural Stability of Liposome Composed of Glycosphingolipid/Cholesterol/Phospholipid", J. Phys Chem B.,119(8): 3398-3406, 2015.

Hirst, L.S.; Ossowski, A.; Fraser, M.; Geng J.; Selinger, J.V.; Selinger, R.L.;"Morphology transition in lipid vesicles due to in-plane order and topological defects". PNAS, 110 (9) pp 3242-3247. 2013

Hubbell, W.L.; McConnell , H.M.; "Molecular motion in spin-labeled phospholipids and membranes." J. Am. Chem. Soc., 93 (2), pp 314-326. 1971

Jähnig, F.; "Electrostatic free energy and shift of the phase transition for charged lipid membranes" Biophys. J., 4, pp. 309-318. 1976

Kikhney, A. G., Svergun, D.I.; "A practical guide to small angle X-ray scattering (SAXS) of flexible and intrinsically disordered proteins." FEBS Lett.; 589(19 Pt A):2570-7. 2015

Kinoshita, M.; Kato, S.; Takahashi, H.; "Effect of bilayer morphology on the subgel phase formation" Chemistry and Physics of Lipids, 151, pp. 30-40. 2008

Knowles, P. F.; Marsh, D.; Rattle, H. W. E. "Magnetic resonance of biomolecules: an introduction to the theory and practice of NMR and ESR in biological systems." John Wiley, New York, 1976.

Kodama, M; Miyata, T. "Effect of Na+ concentrations on both size and multiplicity of multilamellar vesicles composed of negatively charged phospholipid as revealed by differential scanning calorimetry and electron microscopy" Thermoch. Acta 267, pp 365-372. 1995

Kollmitzer, B., Heftberger, P., Rappolt, M; Pabst, G.; "Monolayer spontaneous curvature of raft-forming membrane lipids" Soft Matter 9 (45), 10877-10884, 2013.

Koppel, D.; "Analysis of Macromolecular Polydispersity in Intensity Correlation Spectroscopy: The Method of Cumulants", J. Chem. Phys., 57, 4814. 1972 
Koshinuma, M.; Tajima, K.; Nakamura, A.; Gershfeld, N. L.; "Influence of Surface Charge and Hydrocarbon Chain Length on the Sponge-Vesicle Transformation of an Ionized Phospholipid" Langmuir 15, 3430- 3436. 1999

Lamy, M.T. e Riske, K. A. "The peculiar thermo-structural behavior of the anionic lipid DMPG", Chemistry and Physics of Lipids, 122, 19-32, 2003.

Luzzati, V., In: Biological Membranes. Vol. 1, D. Chapman, editor. Academic Press, New York. 71-123, 1968.

Marsh, D.; em "Membrane spectroscopy", Ed. Ernst Grell, Springer Verlag, 1981

Marsh, D., and Phil, M. A., Handbook of Lipid Bilayers. CRC Press. 1990.

Nunes, R. G., Barbetta, C. R., Lamy, M. T., Tamashiro, M. N. e Henriques, V. B.; " Phase Transitions In Charged-lipid Membranes: A Statistical Model" Biophysical Journal, 96, 458a-459a , 2009.

Oliveira, T.R., Benatti, C.R., Lamy, M.T. "Structural characterization of the interaction of the polyene antibiotic amphotericin B with DODAB bicelles and vesicles." Biochim. Biophys. Acta 1808, 2629-2637. 2011

Pabst, G., M. Rappolt, H. Amenitsch, and P. Laggner. "Structural information from multilamellar liposomes at full hydration: Full q-range fitting with high quality $x$ ray data" Phys. Rev. E 62:4000-4009, 2000.

Pabst, G.; Koschuch, R.; Pozo-Navas, B.; Rappolt, M.; Lohner, K.; Laggner, P. "Structural analysis of weakly ordered membrane stacks" J. Appl. Cryst. 36, 1378-1388, 2003.

Pabst, G.; "Global properties of biomimetic membranes: Perspectives on molecular features." Biophys. Rev. Lett. 1: 57 - 84. 2006

Plotnikov, V.V.; Brandts, J.M.; Lin, L.; Brandts, J.F.; "A New Ultrasensitive Scanning Calorimeter." Anal Biochem. 250, pp 237-244. 1997

Reed, W.F., "A conformational interpretation for the peak of reduced viscosity for polyelectrolytes at low ionic strength." J. Chem. Phys. 100, pp 7825-7827. 1994

Riske, K. A., Politi, M. J., Reed, W. F. e Lamy-Freund, M. T. "Temperature and ionic strength dependent light scattering of DMPG dispersions." Chem. Phys. Lipids, 89, 31-44, 1997.

Riske, K. A., Nascimento, O. R., Peric, M., Bales, B. L. e Lamy-Freund, M. T. "Probing DMPG vesicle surface with a cationic aqueous soluble spin label." Biochimica Et Biophysica Acta-Biomembranes, 1418,133-146, 1999.

Riske, K.A. "Comportamento Térmico Peculiar de Dispersões Aquosas do Fosfolipídio aniônico DMPG". Tese de Doutorado apresentada no Instituto de Física da Universidade de São Paulo, 2001. 
Riske, K. A., Amaral, L. Q. e Lamy-Freund, M. T.; "Thermal transitions of DMPG bilayers in aqueous solution: SAXS structural studies." Biochimica Et Biophysica ActaBiomembranes, 1511, 297-308, 2001.

Riske, K. A., Fernandez, R. M., Nascimento, O. R., Bales, B. L. e Lamy-Freund, M. T.; "DMPG gel-fluid thermal transition monitored by a phospholipid spin labeled at the acyl chain end." Chem. Phys. Lipids,, 124, 69-80, 2003.

Riske, K. A., Amaral, L.Q., Dobereiner, H.-G., Lamy, M.T.; "Mesoscopic Structure in the chain melting regime of anionic phospholipid vesicles" Biophysical Journal, 86, 3722-3733, 2004.

Riske, K. A., Amaral, L. Q. ; Lamy, M. T.; "Extensive bilayer perforation coupled with the phase transition region of an anionic phospholipid." Langmuir. 2009a.

Riske, K. A., Barroso, R. P., Vequi-Suplicy, C. C., Germano, R., Henriques, V. B. e Lamy, M. T.; "Lipid bilayer pre-transition as the beginning of the melting process." Biochim Biophys Acta, 1788, 954-63, 2009b.

Salonen, I. S., Eklund, K. K., Virtanen, J. A. e Kinnunen, P. K. J.; "Comparison of the effects of $\mathrm{NaCl}$ on the thermotropic behaviour of $\mathrm{sn}-\mathrm{I}$ ' and ' $n-3$ ' stereoisomers of 1,2dimyristoyl-sn-glycero-3-phosphatidylglycerol." Biochimica Et Biophysica Acta, 982, 205-215, 1989.

Schnablegger, H.; Glatter, O.; "Sizing of colloidal particles with light scattering: corrections for beginning multiple scattering"Appl. Opt. 34(18) 3489-3501 (1995).

Schneider, M. F., Marsh, D., Jahn, W., Kloesgen, B. e Heimburg, T. "Reversible network formation of lipid membranes - triggering structural transitions by chain melting." Proc.Natl.Acad.Sci.USA 96: 14312-14317, 1999.

Shahine, A., Van Rhijn, I., Cheng, T.Y., Iwany, S., Gras, S., Moody, D.B., Rossjohn, J.; "A molecular basis of human $\mathrm{T}$ cell receptor autoreactivity toward selfphospholipids." Sci Immunol. 2(16),1384. 2017

Skoog, D. A.; West, D. M.; Holler, F. J.; Crouch, S. R.; Fundamentos de química analítica. São Paulo: Thomson Learning, 2006.

Smith, I.C.P.; em "Biological Applications of Electron Spin Resonance". Editors, Swartz, H. M.; Bolton, J.R.; Borg., D.C.; Wiley-Interscience, pp 483-539. 1972.

Spinozzi, F., Paccamiccio, L., Mariani, P., Amaral, L. Q.; "Melting Regime of the Anionic Phospholipid DMPG: New Lamellar Phase and Porous Bilayer Model." Langmuir, 26 (9), pp 6484-6493, 2010

Spinozzi, F. e Amaral, L. Q. "Pore Model in the Melting Regime of a Lyotropic Biomembrane with an Anionic Phospholipid". Langmuir, 32 (50), pp 13556-13565. 2016 
Tamashiro, M.N., V.B. Henriques, and M.T. Lamy; "Aqueous suspensions of charged spherical colloids: Dependence of the surface charge on ionic strength, acidity, and colloid concentration." Langmuir, 21(24): pp. 11005-11016. 2005

Träuble, H.; Teubner, M.; P. Woolley; Eibl, h.; "Electrostatic interactions at charged lipid membranes: I. Effects of ph and univalent cations on membrane structureElectrostatic interactions at charged lipid membranes." Biophys. Chem., 4, pp. 319-342. 1976

Tresset, G. "The multiple faces of self-assembled lipidic systems" PMC Biophys; 2: 3. 2009

Valeur, B. " Molecular Fluorescence: Principles and Applications" Wiley-VCH Verlag, 2001

Voet, D.; Voet, J.G. "Fundamentos de Bioquímica - A Vida em Nível Molecular", 2a. Edição, Editora Artmed. 2008

Voet, D.; Voet, J.; Pratt, C. W. "Fundamentos de bioquímica: a vida em nível molecular." 4a ed. Porto Alegre: Artmed. 2014

Wertz, J. E.; Weil, J. A.; Bolton, J. R.; "Electron paramagnetic resonance: Elementary theory and applications". Wiley-interscience, New York, 1994.

Williams. C., "Methods of experimental physics, vol. 3 - molecular physics." Academic Press. 1962

Wu, F., Wang, N., Yu, Z., "Nonsynchronous Change in the Head and Tail of Dioctadecyldimethylammonium Bromide Molecules during the Liquid Crystalline to Coagel Phase Transformation Process", Langmuir, 25 (23), pp 13394-13401, 2009.

Yi, P.N., MacDonald, R.C., "Temperature dependence of optical properties of aqueous dispersions of phosphatidylcholine." Chem. Phys. Lipids, 11, 114-134. 1973. 